\author{
UNIVERSIDADE DE SÃO PAULO \\ ESCOLA DE ARTES, CIÊNCIAS E HUMANIDADES \\ PROGRAMA DE PÓS-GRADUAÇÃO EM SUSTENTABILIDADE
}

NATALIA ALMEIDA SANTOS MATTOS

Alternativas locacionais em Estudos de Impacto Ambiental no Estado de São Paulo

São Paulo 


\section{Alternativas locacionais em Estudos de Impacto Ambiental no Estado de}

\section{São Paulo}

Versão corrigida

Dissertação apresentada a Escola de Artes, Ciências e Humanidades da Universidade de São Paulo para obtenção do título de Mestre em Ciências pelo Programa de Pós-graduação em Sustentabilidade.

Versão corrigida contendo as alterações solicitadas pela comissão julgadora em 18 de março de 2019. A versão original encontra-se em acervo reservado na Biblioteca da EACHUSP e na Biblioteca Digital de Teses e Dissertações da USP (BDTD), de acordo com a Resolução CoPGr 6018, de outubro de 2011.

Área de concentração:

Gestão Ambiental

Orientador:

Prof. Dr. Marcelo Marini Pereira de Souza

São Paulo 
Autorizo a reprodução e divulgação total ou parcial deste trabalho, por qualquer meio convencional ou eletrônico, para fins de estudo e pesquisa, desde que citada a fonte.

CATALOGAÇÃO-NA-PUBLICAÇÃO

(Universidade de São Paulo. Escola de Artes, Ciências e Humanidades. Biblioteca) CRB $8-4936$

Mattos, Natalia Almeida Santos

Alternativas locacionais em Estudos de Impacto Ambiental no Estado de São Paulo / Natalia Almeida Santos Mattos ; orientador, Marcelo Marini Pereira de Souza - 2019.

$128 \mathrm{f}$. : il.

Dissertação (Mestrado em Ciências) - Programa de Pós-

Graduação em Sustentabilidade, Escola de Artes, Ciências e Humanidades, Universidade de São Paulo

Versão corrigida

1. Gestão ambiental - São Paulo. 2. Impactos ambientais Avaliação - São Paulo. 3. Impactos ambientais - Estudo - São Paulo. I. Souza, Marcelo Marini Pereira de, orient. II. Título.

CDD 22.ed. -577.068098161 
Nome: MATTOS, Natalia Almeida Santos

Título: Alternativas locacionais em Estudos de Impacto Ambiental no Estado de São Paulo

Dissertação apresentada a Escola de Artes, Ciências e Humanidades da Universidade de São Paulo para obtenção do título de Mestre em Ciências pelo Programa de Pós-graduação em Sustentabilidade.

Área de concentração:

Gestão Ambiental

Aprovado em: 18 / 03 / 2019

\section{Banca Examinadora}

Profa. Dra. Anne Caroline Malvestio

Universidade Federal de Uberlândia

Prof. Dr. Evandro Mateus Moretto

Universidade de São Paulo. Escola de Artes, Ciências e Humanidades

Profa. Dra. Maria Rita Raimundo e Almeida

Universidade Federal de Itajubá. Instituto de Recursos Naturais 


\section{Agradecimentos}

Gostaria de começar agradecendo ao professor Marcelo, pela oportunidade em desenvolver esse projeto e pela confiança depositada, mesmo eu estando longe e dividindo meu tempo entre outras tarefas. Agradeço pelas prosas por Skype, pelos emails, pelas reflexões e por sempre me receber com bom humor e grande disposição em me ajudar.

Esse trabalho certamente não seria possível sem a incrível base de pessoas que me apoiaram e me incentivaram ao longo desses anos. Agradeço a minha família, mãe, pai, Juju e Thiago por sempre me incentivar, por me aguentar falando sobre diversos casos de EIAs, pelo apoio incondicional, total confiança e por sempre estarem presentes.

Agradeço aos queridos da Bio, Carol, Isa, Gabriel, Bunni e Murillo, por terem participado da minha formação desde o início e continuarem sempre me apoiando com a incrível amizade que construímos ao longo desses anos.

Ao pessoal da editora, em especial à minha gestora Isabel e minha coordenadora Fabíola, pelo total apoio e confiança em conciliar trabalho e pesquisa, sempre se dispondo a ajudar e possibilitar melhores formas para eu conseguir realizar esse grande desafio.

Aos colegas de mestrado, por terem me acompanhado nas disciplinas, pelas longas discussões sobre sustentabilidade e por terem proporcionado uma ótima vivência durante esse período.

A todos os funcionários da biblioteca da CETESB que sempre me receberam tão bem e possibilitaram o acesso aos documentos. À Sandra da biblioteca da EACH pela ajuda com a organização das referências e a conferência dos padrões. Às professoras Maria Rita e Aline, por toda a gentileza e comentários construtivos no exame de qualificação.

Por fim, agradeço ao Programa de Pós-Graduação em Sustentabilidade da $\mathrm{EACH} / \mathrm{USP}$, por todo o aprendizado durante as disciplinas e por proporcionar um ambiente e um programa que une pessoas com formações tão diferentes, porém tão igualmente dispostas a entender os desafios de nossa sociedade e buscar soluções. 


\title{
RESUMO
}

\author{
MATTOS, Natalia Almeida Santos. Alternativas locacionais em Estudos de \\ Impacto Ambiental no Estado de São Paulo. 2019. 128p. Dissertação (Mestrado \\ em Ciências) - Programa de Pós-Graduação em Sustentabilidade, Escola de Artes, \\ Ciências e Humanidades, Universidade de São Paulo, São Paulo, 2019. Versão \\ corrigida.
}

A Avaliação de Impacto Ambiental (AIA) é um processo de caráter prévio que visa fundamentar e auxiliar no processo de tomada de decisão sobre a viabilidade ambiental de um empreendimento ou atividade. No Brasil, uma das principais etapas deste processo é a elaboração do Estudo de Impacto Ambiental (EIA). Objetivando o embasamento para a tomada de decisão, um ponto fundamental de um EIA é a apresentação e comparação de alternativas locacionais. Apesar de ter um papel primordial na análise dos possíveis cenários de impactos ambientais, na prática atual, tanto no contexto nacional como internacional, a análise de alternativas de localização dentro da AIA exibe diversas deficiências e falhas indicadas por inúmeros autores, como a não apresentação de alternativas de localização, a presença de alternativas impraticáveis, a ausência de comparação entre as alternativas, a baixa qualidade dos estudos e a fraca justificativa da seleção locacional. Dessa maneira, o presente estudo objetivou descrever e analisar a qualidade dos estudos de alternativa locacional apresentadas nos EIAs do estado de São Paulo no período de 2005 a 2016. Para isso, elaborou-se uma lista de verificação que foi então aplicada para a amostra de 52 EIAs e 33 Termos de Referência (TR). Verificou-se que, do total de estudos analisados, $46 \%$ não apresentaram alternativas de localização para o empreendimento proposto. Além disso, $75 \%$ dos critérios estabelecidos na lista de verificação obtiveram conceitos insatisfatórios. Mesmo entre os estudos que continham alternativas de localização, 58\% dos critérios foram também avaliados como insatisfatórios, indicando uma baixa qualidade geral dos estudos e diversas fragilidades, principalmente referentes aos processos de seleção de alternativas a serem analisadas, de comparação entre as alternativas e de justificativa de seleção do local determinado com base na análise locacional apresentada. Os critérios que obtiveram os melhores conceitos foram os referentes a apresentação e descrição de alternativas, indicando um caráter muito mais descritivo do estudo de localização do que comparativo. Os TRs avaliados também obtiveram conceitos insatisfatórios, o que indicou que não apenas a qualidade dos estudos locacionais é inadequada, como também a qualidade das diretrizes que os guiam. Os resultados observados reforçaram as deficiências encontradas na literatura e evidenciaram a necessidade de aprimoramento desta etapa da AIA no estado de São Paulo, principalmente por meio da inclusão de diretrizes mais detalhadas nos TRs, do desenvolvimento de instrumentos de planejamento territorial que auxiliem e direcionem os estudos locacionais e da melhora nos processos de seleção de alternativas para análise, comparação entre as alternativas e justificativa do local selecionado dentro dos estudos locacionais nos EIAs.

Palavras-chave: Avaliação de impacto ambiental. Estudo de impacto ambiental. Alternativa locacional. 


\begin{abstract}
MATTOS, Natalia Almeida Santos. Locational alternatives in Environmental Impact Studies in the State of São Paulo. 2019. 128p. Dissertation (Master of Science) - Postgraduate program in Sustainability - School of Arts, Sciences and Humanities, University of São Paulo, São Paulo, 2019. Corrected version.
\end{abstract}

The Environmental Impact Assessment (EIA) is a tool that aims to support and assist the decision-making process about the environmental viability of a project or activity. In Brazil, one of the main steps in this process involves the elaboration of the Environmental Impact Study (EIS). To properly support the decision-making process, an EIS key point is the study of locational alternatives, including the presentation, analysis and comparison of alternatives. In spite of having a primary role in analysing possible scenarios of environmental impacts, in current practice, both in the national and international context, the locational alternatives analysis in the EIA process shows several deficiencies indicated by many authors, such as the lack of alternatives consideration, the presence of unreasonable alternatives, the lack of comparison between alternatives, the poor quality of the studies and the poor justification of the site selection. Thus, this study aimed to describe and evaluate the quality of the alternative locational studies presented in the EISs of the state of São Paulo from 2005 to 2016. For this purpose, a checklist was elaborated, which was then applied to a sample of 52 EISs and 33 Terms of Reference (TR). The results show that $46 \%$ of the studies did not consider any locational alternatives. Additionally, $75 \%$ of the criteria set out in the checklist were assessed as unsatisfactory. Even among the studies that considered locational alternatives, $58 \%$ of the criteria were also assessed as inadequate, indicating a low general quality of the studies and several weaknesses, mainly referring to the processes of selecting alternatives to be analysed, of comparing alternatives and of justifying the site selection based on the presented locational analysis. The criteria that obtained the best results were those referring to the alternatives presentation and description, indicating that the locational analysis tend to approach a much more descriptive aspect rather than a comparative approach. The TRs criteria were also evaluated as inadequate, indicating that not only the quality of the locational studies is insufficient, but the quality of its guidelines is also inappropriate. The results in this study support the deficiencies found in the literature review and point out the need to improve the locational analysis in the EISs of São Paulo state, mainly through the input of more detailed guidelines in the TRs, the development of territorial planning tools that can help to guide the studies in the selection of reasonable alternatives to be assessed and the improvement of alternatives analysis, comparison and justification.

Keywords: Environmental impact assessment. Environmental impact study. Locational Alternative. 


\section{LISTA DE FIGURAS}

Figura 1 - Fluxo de etapas do processo de Licenciamento Ambiental do Estado de São Paulo.

Figura 2 - Conceitos (A-D) atribuídos aos critérios da categoria Apresentação e descrição para todos os EIAs analisados.

Figura 3 - Conceitos (A-D) atribuídos aos critérios da categoria Apresentação e descrição para os EIAs que apresentaram alternativas locacionais .68

Figura 4 - Conceitos (A-D) atribuídos aos itens da categoria Critérios considerados para todos os EIAs analisados

Figura 5 - Conceitos (A-D) atribuídos aos itens da categoria Critérios considerados para os EIAs que apresentaram alternativas locacionais.

Figura 6 - Atribuição total de conceitos (A-D) da categoria Critérios considerados por setor.

Figura 7 - Conceitos (A-D) atribuídos aos critérios da categoria Comparação e análise em todos os EIAs analisados.

Figura 8 - Conceitos (A-D) atribuídos aos critérios da categoria Comparação e análise para os EIAs que apresentaram alternativas locacionais

Figura 9 - Conceitos (A-D) atribuídos aos critérios da categoria Consistência para todos os EIAs analisados

Figura 10 - Conceitos (A-D) atribuídos aos critérios da categoria Consistência para os EIAs que apresentaram alternativas locacionais. .80

Figura 11 - Conceitos (A-D) atribuídos aos critérios da categoria Análise do TR para todos os TRs analisados.

Figura 12 - Conceitos (A-D) atribuídos aos critérios da categoria Análise do TR para os TRs de EIAs que apresentaram alternativas locacionais. .85

Figura 13 - Distribuição total de conceitos atribuídos para todos os EIAs analisados.

Figura 14 - Distribuição total de conceitos atribuídos para ElAs com alternativas 
Figura 15 - Comparação entre distribuição de conceitos para EIAs de empreendimentos novos e EIAs de ampliações...

Figura 16 - Comparação da distribuição de conceitos entre as categorias de análise para todos os EIAS.

Figura 17 - Comparação da distribuição de conceitos entre as categorias de análise para EIAs que apresentaram alternativas locacionais. .89 


\section{LISTA DE QUADROS}

Quadro 1 - Resumo das principais características da aplicação da AIA no Brasil......23

Quadro 2 - Deficiências da prática do processo de consideração e análise de

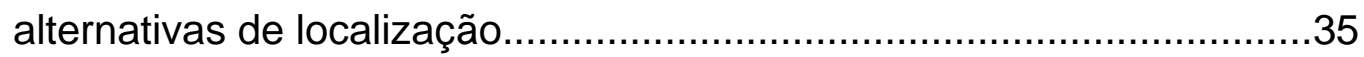

Quadro 3 - Amostra final de 52 EIAs/RIMAs e 33 TRs.........................................49

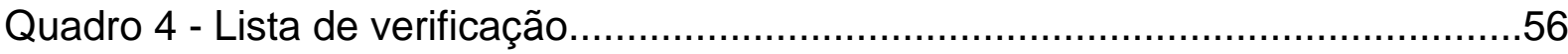

Quadro 5 - Identificação e explicação dos conceitos de análise................................58

Quadro 6 - Categoria Apresentação e Descrição da lista de verificação......................66

Quadro 7 - Categoria Critérios considerados da lista de verificação...........................69

Quadro 8 - Categoria Comparação e análise da lista de verificação............................74

Quadro 9 - Categoria Consistência da lista de verificação.........................................79

Quadro 10 - Categoria Análise do TR da lista de verificação......................................84 


\section{LISTA DE TABELAS}

Tabela 1 - Número de EIAs total e na amostra considerando a porcentagem por setor.

Tabela 2 - Porcentagem de ampliações por setor e número amostral final................48

Tabela 3 - Número de alternativas por setor de empreendimento............................60

Tabela 4 - Critérios considerados na análise e na seleção de alternativas...................63

Tabela 5 - Número de critérios diferentes considerados por cada setor.....................64 


\section{LISTA DE ABREVIATURAS E SIGLAS}
AIA Avaliação de Impacto Ambiental
AAE Avaliação Ambiental Estratégica
CETESB Companhia de Tecnologia de Saneamento Ambiental
CONAMA Conselho Nacional do Meio Ambiente
CONSEMA Conselho Estadual do Meio Ambiente
DNPM Departamento Nacional de Produção Mineral
EIA Estudo de Impacto Ambiental
EAS Estudo Ambiental Simplificado
Ibama Instituto Brasileiro do Meio Ambiente e dos Recursos Naturais Renováveis
IAIA International Association for Impact Assessment
ITAP Setor de Triagem e Acompanhamento de Processos da CETESB
LI Licença de Instalação
LO Licença de Operação
LP Licença Prévia
NEPA National Environmental Policy Act
PNMA Política Nacional do Meio Ambiente
RAP Relatório Ambiental Preliminar
RIMA Relatório de Impacto Ambiental
SISNAMA Sistema Nacional do Meio Ambiente
SMA Secretaria do Meio Ambiente
TR Termo de Referência 


\section{SUMÁRIO}

1 INTRODUÇÃO

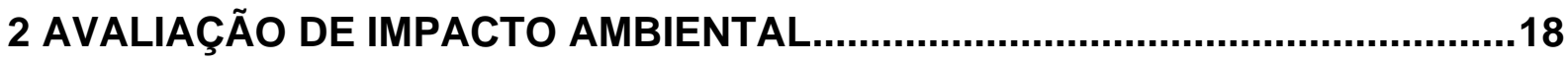

2.1 AVALIAÇÃO DE IMPACTO AMBIENTAL NO BRASIL ................................20

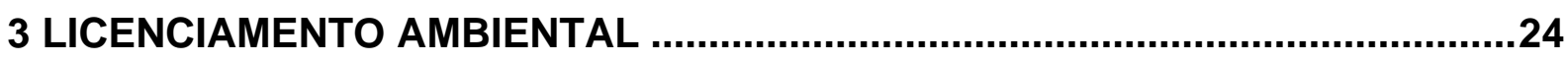

3.1 LICENCIAMENTO AMBIENTAL NO ESTADO DE SÃO PAULO ....................27

3.2 ESTUDO DE IMPACTO AMBIENTAL E RELATÓRIO DE IMPACTO

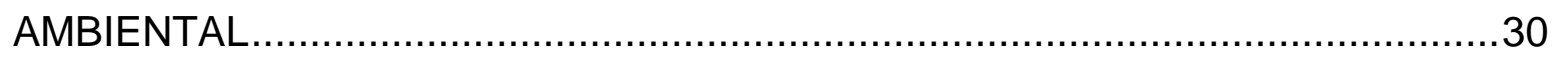

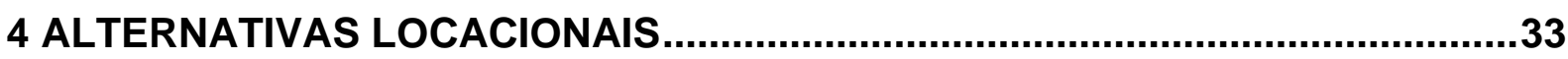

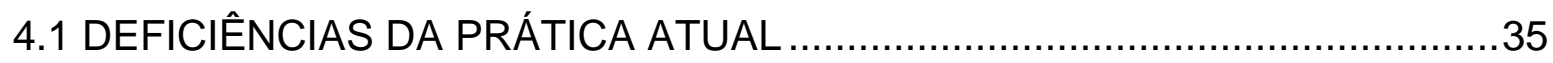

4.2 DEFINIÇÃO DE ALTERNATIVAS E INSERÇÃO NO ESCOPO ......................37

5 EFETIVIDADE DA AIA E A QUALIDADE DOS ESTUDOS DE IMPACTO

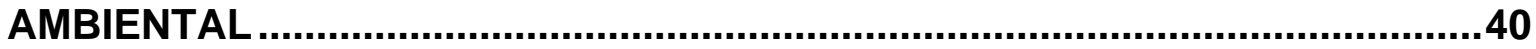

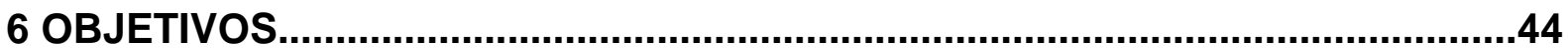

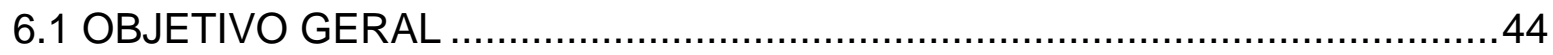

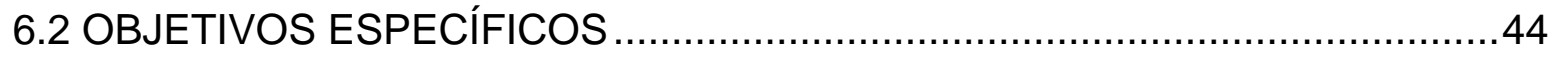

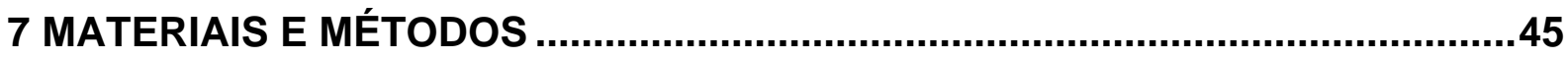

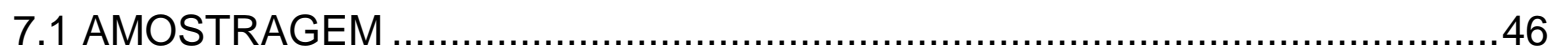

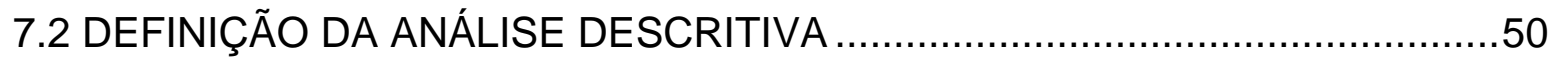

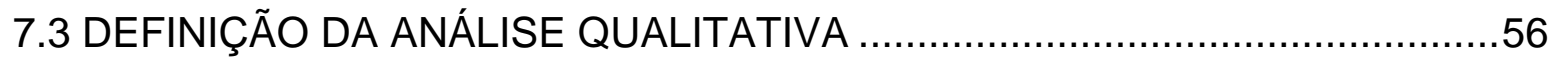

8 RESULTADOS E DISCUSSÃO

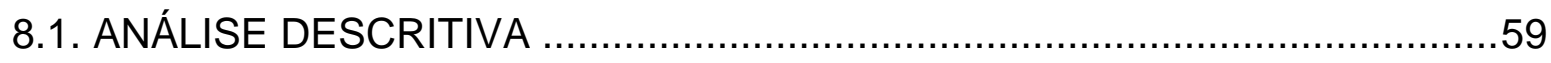

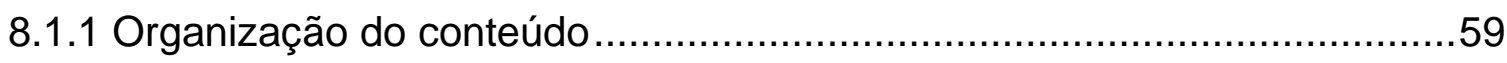

8.1.2 Número de alternativas e alternativas locacionais de estruturas e layout..60

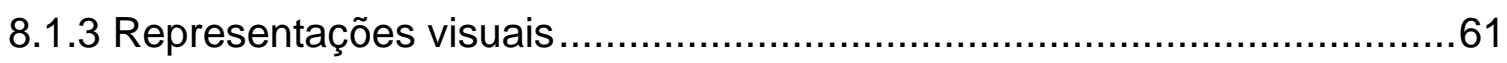

8.1.4 Critérios considerados e sistemas de ponderação e classificação .............62

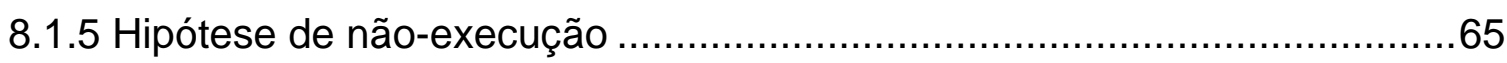

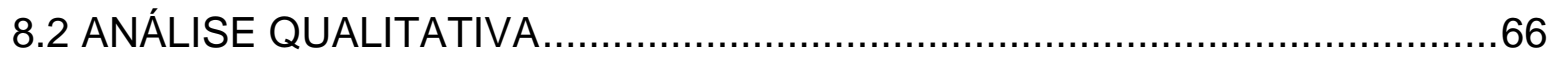

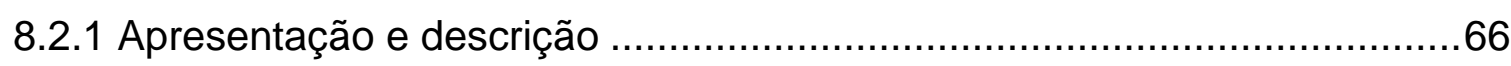

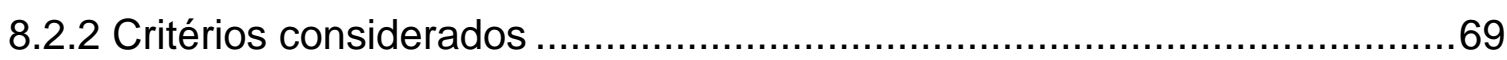

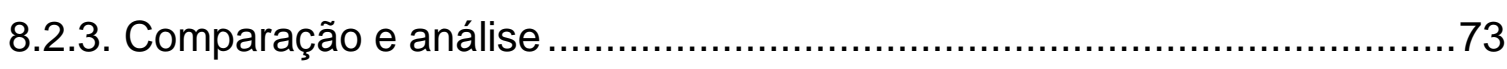

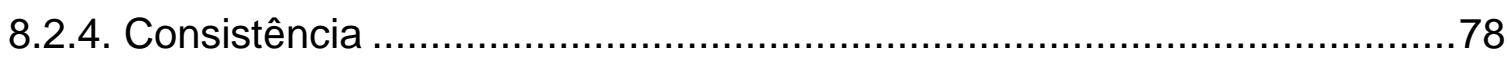

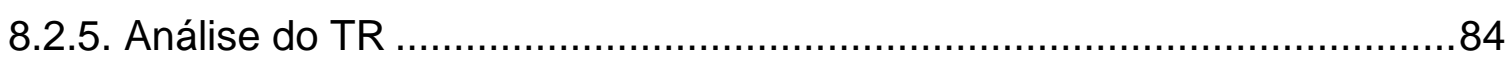


8.2.6. Análises gerais .86

9 CONCLUSÃO .90

REFERÊNCIAS .95

APÊNDICE A - LISTA DE ESTUDOS DE IMPACTO AMBIENTAL DE 2005 A 2016

A

APÊNDICE B - QUADRO DE INDICADORES DE CLASSIFICAÇÃO DOS CONCEITOS PARA CADA CRITÉRIO 116

APÊNDICE C - FICHA DE ANÁLISE. 120

APÊNDICE D - DADOS GERAIS DA ANÁLISE DESCRITIVA 123 APÊNDICE E - DADOS GERAIS DA ANÁLISE QUALITATIVA 127 


\section{INTRODUÇÃO}

A escolha do local de um empreendimento ou atividade sempre foi considerada um ponto chave do processo decisório da implantação de uma nova atividade, tanto para o empreendedor, quanto para o planejamento do uso da área e para comunidade do local como um todo; o procedimento usual para tal escolha pode ser resumido em quatro grandes etapas: a decisão sobre quais critérios serão utilizados para considerar alternativas, a identificação de quais critérios são relevantes à decisão, o desenvolvimento das alternativas de localização e, por fim, a avaliação de tais alternativas chegando a uma conclusão (STEVENSON, 1993). Esses procedimentos, contudo, se restringiram por muito tempo a uma esfera prática e econômica exclusiva do empreendedor, de tal forma que os critérios relevantes ao estudo locacional e à formulação de alternativas de localização eram usualmente focados em questões de proximidade ao mercado consumidor, mão de obra disponível, proximidade com os fornecedores e, por fim, considerações locais, nas quais até poderiam ser abordadas, de maneira pouco restritiva, questões do âmbito ambiental (KRAJEWSKI; RITZMAN,1993).

O reconhecimento das implicações das mudanças no ambiente causadas por ações antrópicas foi um ponto primordial para o início das primeiras preocupações com políticas públicas ambientais (MORGAN, 2012) e, portanto, para a valorização da dimensão ambiental como relevante às tomadas de decisão relacionadas com a criação de políticas públicas e com a implantação de novos empreendimentos e atividades. A formalização de uma ferramenta voltada especificamente para essa análise ocorreu inicialmente nos Estado Unidos, com a criação do National Environmental Policy Act (NEPA), por meio do qual se consolidou a definição de Avaliação de Impacto Ambiental (AIA) em 1969 (SÁNCHEZ, 2013).

A AIA consiste em uma avaliação de propostas quanto às suas implicações em todos os aspectos do ambiente, físicos, biológicos e sociais, antes que sejam tomadas decisões sobre essas ações, formulando, ainda, respostas apropriadas às questões levantadas na avaliação (MORGAN, 2012). Esse processo de avaliação de impactos de uma proposta de empreendimento ou atividade pode ainda ser sistematizado, de acordo com Sánchez e Mitchell (2017), nas seguintes atividades: identificar impactos e riscos diretos, indiretos e cumulativos; fazer previsões sobre o estado futuro do ambiente, com e sem o projeto proposto; avaliar a significância dos 
impactos considerando as perspectivas das comunidades afetadas, das organizações da sociedade civil, das agências governamentais e de outras partes interessadas; fazer recomendações sobre meios eficazes para mitigar, evitar, reduzir, restaurar ou compensar os impactos prejudiciais.

Toda e qualquer análise de uma proposta e de suas implicações perpassa uma questão fundamental anterior a qualquer discussão mais aprofundada, a localização do empreendimento ou atividade a ser implantada, já que a previsão de impactos e a proposição de medidas de mitigação estão intrinsicamente ligadas à questão locacional. Desta forma, a formulação, apresentação e comparação de alternativas de localização nos estudos para a implementação de empreendimentos ou atividades são consideradas etapas básicas do processo de avaliação de impactos ambientais e da tomada de decisão, uma vez que evidencia a preferência fundamental por evitar e reduzir os impactos ambientais (VALVE, 1999; SOUZA, 2000; TICKENER; GEISER, 2004; SÁNCHEZ, 2013).

Para Steinemann (2001), apesar da proposição de alternativas ser considerada o "coração" da AIA, o exercício do desenvolvimento dessas alternativas é pouco praticado, não havendo foco no que é realmente necessário para a formulação e comparação de boas alternativas. De fato, ao analisar historicamente o estudo de alternativas locacionais dentro dos processos de Avaliação de Impacto Ambiental, identifica-se que as etapas de desenvolvimento, análise e comparação das alternativas de localização vem sendo continuamente identificadas como pontos fracos da AIA, tendência que não apresentou grandes modificações com o passar dos anos (LANDIM; SÁNCHEZ, 2012; JHA-THAKUR; FISCHER, 2016).

A qualidade do desenvolvimento e da proposição dessas alternativas de localização se torna significativa na medida em que se relaciona diretamente a qualidade da AIA como processo de análise da viabilidade ambiental, o que, essencialmente, pode influenciar a efetividade desse instrumento como ferramenta de análise e base para a tomada de decisão (GLASSON, THERIVEL; CHADWICK, 2005).

Com o intuito de afastar-se de uma etapa burocrática e se aproximar de seu objetivo proposto, o processo de Avaliação de Impacto Ambiental necessita estar em constate aprimoramento (MORGAN, 2012; SÁNCHEZ, 2012). A definição, apresentação, comparação e seleção da alternativa de localização dentro da AIA são 
etapas fundamentais para a real análise da viabilidade ambiental de um empreendimento (AGRA-FILHO et al., 2012; SÁNCHEZ, 2013; IAIA, 2015), apesar disso, essa etapa é constantemente indicada como falha no processe de AIA (MORGAN, 2012; POPE et al. 2013), de modo que investigar a prática e avaliar o estudo de alternativas dentro desse processo se torna indispensável para o melhor entendimento e aprimoramento da AIA como um instrumento de política ambiental.

Considerando o exposto, o presente estudo se propõem a investigar descritiva e qualitativamente a presença de alternativas de localização em estudos de AIA do estado de São Paulo, por meio da análise de Estudos de Impacto Ambiental (EIA) e de seus respectivos Termos de Referência (TR) deste estado, apresentados ao órgão ambiental no período entre 2005 e 2016.

Com tais considerações, essa pesquisa se justifica por apresentar um cenário histórico-atual de tal etapa para o estado de São Paulo, identificando e avaliando a presença das alternativas de localização nos estudos de AIA, seus critérios e métodos. Gerando assim, uma importante base de dados para discussão e aprimoramento das ideias referentes a esse componente da AIA, sua estruturação e formalização por meio de instrumentos como o EIA e sua inserção no processo de licenciamento ambiental brasileiro de maneira geral.

Para isso, esse estudo apresentará inicialmente, no capítulo 2, uma descrição do processo de Avaliação de Impacto Ambiental no cenário internacional, aprofundando-se em suas etapas e procedimentos básicos que serão, em seguida, especificados para o cenário brasileiro.

No capítulo 3, o processo de licenciamento ambiental, no qual a AIA está inserida no país, será descrito, explicitando as diferenças entre esses dois processos, discutindo como eles se relacionam e apresentando o histórico das principais legislações e resoluções relativas a esses procedimentos no contexto nacional e, em seguida, especificamente no estado de São Paulo. Nesse capítulo, também são apresentados com mais detalhes os documentos que foram utilizados nessa pesquisa, o Estudo de Impacto Ambiental (EIA), o Relatório de Impacto Ambiental (RIMA) e o Termo de Referência (TR).

O capítulo 4 traz um panorama geral sobre a questão das alternativas de localização dentro do processo da AIA, em que se descreve a relevância da questão locacional dentro dos objetivos propostos pela Avaliação de Impacto Ambiental, as 
principais características necessárias aos estudos locacionais, as principais práticas atuais e as deficiências identificadas nesta etapa da AIA, tanto no contexto internacional, como nacional.

No capítulo 5 , será discutida a efetividade da AIA, considerando as diferentes dimensões de efetividade desse processo, ressaltando a atual necessidade de revisão, abordando o processo de aprendizado por meio da análise do uso desse instrumento, focando especificamente na qualidade dos estudos de impacto ambiental e nos principais métodos atualmente empregados nesse tipo de análise.

Com esses 5 capítulos, apresenta-se um panorama geral da produção acadêmica sobre o processo da AIA e os estudos locacionais, identificando, em seguida, os objetivos desta pesquisa no capítulo 6 .

O capítulo 7 apresentará os materiais e métodos empregados nesse estudo, desde a obtenção dos documentos analisados, a definição da amostra e as metodologias empregadas na obtenção e análise de dados.

Dando sequência, no capítulo 8 serão expostos os resultados obtidos para as análises propostas, os quais são avaliados e discutidos considerando o cenário e as referências abordadas na revisão da literatura.

Por fim, no capítulo 9, tendo em vista os objetivos iniciais propostos, sintetizase os achados e as discussões dessa pesquisa em uma conclusão, resumindo o cenário encontrado para a análise de alternativas locacionais no cenário de São Paulo e apresentado os principais pontos com o intuito de contribuir para a reflexão desta etapa da AIA tanto no contexto da prática estadual, como na discussão dos objetivos e procedimentos da Avaliação de Impacto Ambiental como um todo. 


\section{AVALIAÇÃO DE IMPACTO AMBIENTAL}

Desde a formalização da Avaliação de Impacto Ambiental pelo NEPA, nos EUA, em 1969, diversos países passaram a adotar modelos semelhantes, tornando a AIA um instrumento reconhecido e adotado por inúmeros governos, organizações internacionais e entidades privadas (LEE; GEORGE, 2000; SÁNCHEZ, 2013).

A institucionalização da AIA no cenário internacional progrediu continuamente, principalmente impulsionada pelo crescente reconhecimento político dos problemas associados às mudanças climáticas, à perda de biodiversidade, às ameaças às fontes de água doce e à qualidade da água, aos danos às áreas marinhas e a outras formas de mudança ambiental global (MORGAN, 2012). Desta forma, até 2012, 191 dos 193 países integrantes das Nações Unidas apresentavam algum tipo de legislação nacional ou haviam assinado alguma forma de instrumento legal internacional que se refere ao uso da AIA no país (MORGAN, 2012).

De acordo com a International Association for Impact Assessment (IAIA, 1999), os principais objetivos da Avaliação de Impacto Ambiental são:

- Assegurar que as considerações ambientais sejam explicitamente abordadas e incorporadas ao processo de tomada de decisões de desenvolvimento;

- Antecipar, evitar, minimizar ou compensar os impactos biofísicos e sociais significativos e outros relevantes das propostas de desenvolvimento;

- Proteger a produtividade e a capacidade dos sistemas naturais e os processos ecológicos que mantêm suas funções;

- Promover o desenvolvimento que seja sustentável e otimize as oportunidades de uso e gestão de recursos.

Desde seu surgimento, algumas etapas foram se consolidando, com pequenas variações na literatura, como fundamentais ao processo de Avaliação de Impacto Ambiental (IAIA, 1999; GLASSON, THERIVEL; CHADWICK, 2005; SÁNCHEZ, 2013), sendo estas:

- Triagem: etapa na qual são analisados ou selecionados os empreendimentos, atividades ou ações que devem se submeter a uma Avaliação de Impacto Ambiental; 
- Escopo: uma vez determinada a necessidade de AIA, esta etapa tem como objetivo especificar a abrangência e o detalhamento do estudo, servindo-se de impactos esperados e conhecimentos sobre a prática para estabelecer conteúdos mínimos que devem ser abordados nesse estudo;

- Elaboração do estudo de impacto ambiental: nesta etapa central do processo, o estudo deve ser realizado de maneira clara e imparcial, buscando determinar os impactos ambientais previstos, a significância dos efeitos, as propostas de mitigação e as considerações do público e das comunidades interessadas e afetadas pelo processo. Ressalta-se que a elaboração do estudo deve ser realizada por profissionais habilitados e de diferentes áreas, para que se possa contemplar o caráter multidisciplinar próprio da Avaliação de Impacto Ambiental;

- Participação pública: etapa na qual os grupos de interesse devem ser consultados sobre o empreendimento ou atividade, dialogando com 0 proponente e com o órgão ambiental e expondo suas ponderações, dúvidas e propostas que deverão ser consideradas durante todo o processo, tanto pelo proponente quanto pelo órgão ambiental.

- Análise técnica do estudo: a etapa de análise visa determinar se o estudo apresentado cumpre os termos de referência estabelecidos na etapa do escopo, proporcionando uma avaliação clara da proposta, que contenha as informações necessárias para embasar a tomada de decisão;

- Decisão: etapa na qual, com base na análise do estudo, é aprovado ou rejeitada a implantação do projeto, podendo ainda serem estabelecidas condições para sua aprovação;

- Acompanhamento: esta etapa objetiva garantir que as condições de aprovação sejam cumpridas, monitorar os impactos reais do empreendimento, averiguar a eficácia das medidas de mitigação, avaliar o processo de avaliação ambiental e fortalecer futuras aplicações desse processo pelo aprendizado.

De maneira geral, pode-se entender a AIA, portanto, como uma ferramenta de gestão ambiental participativa e antecipatória (JAY et al., 2007). Apesar do conceito e método variarem entre os diversos países que a empregam, em geral o processo 
guarda características comuns que estão fundamentadas exatamente no caráter prévio e no vínculo com o processo decisório (SÁNCHEZ, 2013).

Ainda que a AIA esteja bastante consolidada no contexto internacional, 0 cenário atual é certamente diferente do contexto de seu surgimento no final da década de 1960 e início dos anos 1970. Questões atuais globais como as mudanças climáticas, a pressão sobre os ecossistemas, a escassez de recursos, a crescente urbanização, a valorização do empreendedorismo e a interconexão econômica mundial levam ao questionamento sobre quanto essa ferramenta, no formato da prática atual, é capaz de lidar com tais pontos de maneira efetiva (RETIEF et al., 2016). Desta forma, a visão de que uma revisão de certos pontos da AIA é fundamentalmente necessária para que esse instrumento possa responder aos desafios do século XXI perpassa a esfera acadêmica, sendo igualmente reconhecida pelos profissionais que a utilizam (BANHALMI-ZAKAR et al., 2018)

\subsection{AVALIAÇÃO DE IMPACTO AMBIENTAL NO BRASIL}

No Brasil, o processo de institucionalização da AIA em âmbito nacional iniciou com a implantação de um novo instrumento de política ambiental proposto pela Lei Federal nำ6.938 de 1981, a Política Nacional do Meio Ambiente (PNMA). A PNMA estabelece um conjunto amplo de ações baseadas em seu objetivo principal de promover a preservação, a melhoria e a recuperação da qualidade ambiental propícia à vida, visando assegurar condições ao desenvolvimento socioeconômico, aos interesses da segurança nacional e à proteção da dignidade da vida humana. Cabe destacar que a PNMA apresenta como um dos objetivos (art. 4ํ․) à compatibilização do desenvolvimento econômico-social com a preservação da qualidade do meio ambiente e do equilíbrio ecológico (BRASIL, 1981). Portanto, associado ao local onde será desenvolvido um determinado empreendimento ou atividade.

Assim, a AIA foi estabelecida como um dos 13 instrumentos propostos pela PNMA, os quais ainda incluíam outros associados ao processo de avaliação de impactos e ao estudo de alternativas locacionais, como o licenciamento e a revisão de atividades efetiva ou potencialmente poluidoras, o sistema nacional de informações sobre o meio ambiente e o zoneamento ambiental (BRASIL, 1981).

Para a organização de um novo sistema que buscasse a incorporação desses objetivos e novos instrumentos, a PNMA inovou ao criar o Sistema Nacional do Meio 
Ambiente (SISNAMA) e um conselho constituído por representantes da sociedade civil, órgãos federais e estaduais, o Conselho Nacional do Meio Ambiente (CONAMA), o qual seria responsável por estabelecer as diretrizes gerais da política ambiental nacional (SÁNCHEZ, 2013).

Após sua criação, o CONAMA apresentou a Resolução ํo 001 de 1986, estabelecendo os critérios básicos e as diretrizes gerais para a regulamentação da Avaliação de Impacto Ambiental como um dos instrumentos da Política Nacional do Meio Ambiente. A resolução estabelece a formulação de dois documentos, o Estudo de Impacto Ambiental (EIA) e o Relatório de Impacto Ambiental (RIMA), como procedimento básico da AIA no país para processos de licenciamento ambiental de empreendimentos e atividades modificadoras do meio ambiente. Determina também a lista positiva inicial de empreendimentos condicionados a elaboração deste tipo de estudo para o processo de licenciamento (BRASIL, 1986).

Posteriormente, em 1988, a exigência da AIA é ainda reforçada pelo artigo 225 da Constituição Federal, explicitando a obrigação do Poder Público em exigir, na forma da lei, estudo prévio de impacto ambiental, ao qual se deve dar publicidade, para instalação de obra ou atividade potencialmente causadora de significativa degradação do meio ambiente (BRASIL, 1988).

Desta forma, a aplicação da AIA no Brasil passou a ser principalmente vinculada ao processo de licenciamento ambiental de empreendimentos potencialmente causadores de significativo impacto ambiental, o que, para Assunção, Bursztyn e Abreu (2010), teria restringido sua abrangência a determinados empreendimentos e atividades, desconsiderando a potencialidade da Avaliação de Impacto Ambiental sobre planos, programas e políticas.

Onze anos depois, a Resolução CONAMA no 237 de 1997 apresentou diretrizes complementares para o sistema de licenciamento ambiental no país, definindo conceitos, determinando procedimentos e detalhando os empreendimentos e atividades sujeitos ao processo de licenciamento ambiental com elaboração de EIA. A nova resolução também assegurou a responsabilidade aos respectivos órgãos ambientais em estabelecer outros estudos ambientais pertinentes ao licenciamento de atividades ou empreendimentos nos quais não fosse verificado um potencial causador de significativa degradação do meio ambiente (BRASIL, 1997). Outro ponto inicialmente estabelecido por essa resolução, o qual seria posteriormente detalhado 
por nova legislação, são os órgãos ambientais competentes ao processo de licenciamento; o Instituto Brasileiro do Meio Ambiente e dos Recursos Naturais Renováveis (Ibama) como responsável pelos processos de licenciamento em nível federal e os respectivos órgãos ambientais estaduais, no nível estadual, e os órgãos ambientais municipais, no nível local.

Em termos de competência, porém, somente com a Lei Complementar № 140 de 2011, definiu-se com mais clareza a regulamentação das ações administrativas sob a responsabilidade da União, dos Estados e dos Munícipios em relação à proteção das paisagens naturais notáveis, à proteção do meio ambiente, ao combate à poluição em qualquer de suas formas e à preservação das florestas, da fauna e da flora (BRASIL, 2011), incluindo, assim, as competências de cada esfera do Poder Público relacionadas ao processo de licenciamento ambiental.

Sendo assim, uma vez que o processo de AIA pode estar sob a responsabilidade de diferentes esferas do Poder Pública, há certas variações de procedimentos. No entanto, de maneira geral, as principais etapas da prática atual da AIA no contexto brasileiro podem ser resumidas de acordo com o Quadro 1, adaptado de Duarte et al. (2017). As etapas e licenças do licenciamento ambiental aqui mencionadas serão detalhadas na próxima seção. 
Quadro 1 - Resumo das principais características da aplicação da AIA no Brasil

\begin{tabular}{|c|c|}
\hline TRIAGEM & $\begin{array}{l}\text { Uma lista de atividades que devem ser submetidas a elaboração de EIA } \\
\text { faz parte da Resolução CONAMA n001 de 1986; outros projetos podem } \\
\text { ser adicionados a critério de cada órgão ambiental competente. Outros } \\
\text { tipos de estudos ambientais (mais simples do que um EIA) podem ser } \\
\text { necessários para outros tipos de projetos submetidos ao licenciamento } \\
\text { ambiental. }\end{array}$ \\
\hline ESCOPO & $\begin{array}{l}\text { O escopo não é obrigatório, mas a emissão de um Termo de Referência } \\
\text { (TR) para a elaboração do EIA é um procedimento adotado pelo órgão } \\
\text { federal e pelos órgãos ambientais de alguns estados. Geralmente não há } \\
\text { participação pública nesta etapa. }\end{array}$ \\
\hline $\begin{array}{c}\text { PREPARAÇÃO DO } \\
\text { EIA }\end{array}$ & $\begin{array}{l}\text { Geralmente, uma empresa de consultoria é contratada pelo proponente } \\
\text { para preparar o EIA e auxiliar em audiências públicas, reuniões com } \\
\text { agências governamentais, apresentação de estudos técnicos e outras } \\
\text { tarefas. Não há exigência de envolvimento público durante a preparação } \\
\text { do EIA. }\end{array}$ \\
\hline ANÁLISE DO EIA & $\begin{array}{l}\text { A análise é realizada pela equipe do órgão ambiental competente. Para } \\
\text { parte dos EIAs pode ser exigido o fornecimento de informações } \\
\text { complementares e/ou modificações no projeto. }\end{array}$ \\
\hline CONSULTA PÚBLICA & $\begin{array}{l}\text { Uma audiência pode ser realizada durante a etapa de revisão. A audiência } \\
\text { é convocada e conduzida pelo órgão ambiental competente. O proponente } \\
\text { e os consultores que elaboraram o EIA são obrigados a fazer } \\
\text { apresentações e responder a perguntas levantadas pelo público. }\end{array}$ \\
\hline DECISÃO & $\begin{array}{l}\text { Em caso de aprovação, o órgão ambiental emite a Licença Prévia. Outras } \\
\text { autorizações, que devem ser requeridas separadamente, são } \\
\text { frequentemente necessárias, como a autorização para uso e captação de } \\
\text { água e para supressão da vegetação. Dependendo da jurisdição, um plano } \\
\text { de gerenciamento ambiental é apresentado com o pedido de uma Licença } \\
\text { de Instalação, a qual também é emitida pelo órgão ambiental. Ambas as } \\
\text { licenças geralmente contêm uma série de condições para a aprovação. }\end{array}$ \\
\hline ACOMPANHAMENTO & $\begin{array}{l}\text { Os relatórios de monitoramento são apresentados em períodos } \\
\text { determinados. O proponente deve informar sobre a implementação de } \\
\text { todos os programas de gestão ambiental e fornecer os dados de } \\
\text { monitoramento ambiental. }\end{array}$ \\
\hline
\end{tabular}

Fonte: Adaptado de Duarte et al. (2017). 


\section{LICENCIAMENTO AMBIENTAL}

Como explicitado na seção anterior, o processo de Avaliação de Impacto Ambiental no Brasil é principalmente vinculado a certos processos de licenciamento ambiental e, no caso de elaboração do EIA/RIMA, a atividades e empreendimentos potencialmente causadores de significativo impacto ambiental. Sendo assim, ressaltase que todos os projetos sujeitos a elaboração de EIA/RIMA estão associados ao processo de licenciamento ambiental, porém nem todos os processos de licenciamento ambiental estão sujeitos a elaboração de EIA/RIMA, já que estes são determinados apenas aos projetos potencialmente causadores de significativa degradação do meio ambiente (MIRRA, 2006).

$O$ processo de licenciamento ambiental se organiza em três fases a serem expedidas ao empreendimento pelo órgão ambiental responsável (BRASIL, 1997; MIRRA, 2006):

- Licença Prévia (LP): concedida na fase preliminar do planejamento do empreendimento ou atividade e que aprova sua localização e concepção, atestando sua viabilidade ambiental;

- Licença de Instalação (LI): autoriza o início da implantação de acordo com o Projeto Executivo aprovado;

- Licença de Operação (LO): autoriza o início ou continuação das atividades uma vez que verificada o cumprimento das condicionantes propostas nas licenças anteriores pelo órgão ambiental.

De acordo com Sánchez (2013), há uma lógica na sequência de licenças que deve ser respeitada; a Licença Prévia é solicitada concomitantemente ao desenvolvimento do projeto técnico pelo proponente, de modo que tanto as alternativas de localização, como as alternativas tecnológicas, ainda podem ser consideradas. Já o pedido de Licença de Instalação fica condicionado a emissão anterior da Licença Prévia e a realização das adequações do projeto determinadas na licença anterior. Por fim, a Licença de Operação é apenas requisitada após a construção ou instalação do empreendimento, verificando-se que as condições de operação estejam adequadas e de acordo com as determinações fixadas na Licença de Instalação. 
Averiguando a necessidade da elaboração de um EIA para o processo de licenciamento ambiental, este estudo deverá ser realizado, como exige a Resolução CONAMA no 001 de 1986, por profissionais especializados, manifestando um caráter técnico e multidisciplinar.

Muito se discutiu sobre a necessidade de execução desse estudo por terceiros, ou seja, por empresas de consultoria além do próprio proponente e do órgão ambiental. Essa norma, originalmente exigida, acabou por criar um mercado de atividade de consultoria contratadas pelos proponentes cujos objetivos nem sempre eram compatíveis com a produção de um documento que atendesse a proposição real de um EIA (MIRRA, 2006). Com a Resolução CONAMA oo 237 de 1997, a obrigatoriedade de execução por terceiros deixa de existir, embora seja ainda muito praticada, de modo que a relação contratual consultoria ambiental/proponente esteja presente na grande maioria dos EIAs desta pesquisa.

Uma vez que o estudo seja elaborado e apresentado ao órgão ambiental, devese considerar a necessidade ou a solicitação de realizar audiências públicas durante o período de análise do EIA e antes da elaboração do Parecer Técnico sobre a viabilidade ambiental do empreendimento para emissão de licenças. Apesar da audiência pública ser determinada na Resolução CONAMA № 001 de 1986, a realização desta etapa foi melhor definida pela Resolução CONAMA no 009 de 1987, que afirma que o principal objetivo dessas audiências é garantir o princípio da publicidade do processo, visando expor aos grupos de interesse o conteúdo do produto em análise e do referente RIMA, dirimindo dúvidas e recolhendo dos presentes críticas e sugestões a respeito do estudo e do empreendimento de modo geral (BRASIL, 1987).

Segundo Sánchez (2013), os objetivos das audiências públicas, as quais se caracterizam apenas como processos consultivos, podem ser sintetizados nos seguintes tópicos:

- Fornecer aos cidadãos informações sobre o projeto;

- Dar aos cidadãos a oportunidade de se expressarem, de serem ouvidos e de influenciarem nos resultados;

- Identificar as preocupações e os valores do público; 
- Avaliar a aceitação pública de um projeto com vistas a aprimorá-lo;

- Identificar a necessidade de medidas mitigadoras ou compensatórias;

- Legitimar o processo de decisão;

- Aprimorar as decisões;

- Atender requisitos legais de participação pública.

É importante ressaltar que o fornecimento de informações à sociedade se apresenta como base para qualquer processo de participação pública, já que, sem tal etapa inicial, todo o desenvolvimento dessa participação fica comprometido, principalmente em relação a sua qualidade. Nesse caso do licenciamento ambiental brasileiro com elaboração de EIA, a principal forma de divulgação da informação ao público deve estar organizada no RIMA, o qual deve estar acessível ao público anteriormente a etapa de audiência pública. Em muitos casos, no entanto, esses processos são bastantes deficientes, tanto na qualidade do RIMA apresentado, quanto na acessibilidade à informação com antecedência (SÁNCHEZ, 2013).

Além do próprio acesso à informação, outro ponto a ser considerado é a sua forma de apresentação no que se refere a linguagem e organização. Smith (2003), em sua discussão sobre a democracia deliberativa, destaca a importância da comunicação como forma de inclusão, para isso, a discussão sobre a legitimidade das formas de comunicação é imprescindível se o que se busca é a participação social efetiva de diferentes grupos. Sendo assim, a dificuldade de parte do público em decodificar e compreender as informações de caráter técnico e científico da forma como são apresentadas no RIMA e discutidas nas audiências públicas pode ser identificada como uma das deficiências do processo de participação pública na AIA (SÁNCHEZ, 2013).

Por outro lado, a forma de organização e discurso nessas audiências muitas vezes a descaracterizam como espaço de discussão e negociação, gerando um clima de confronto que raramente consegue convergir a um ponto em comum (SÁNCHEZ, 2013).

Assim, analisando esse contexto, diversos autores (COLETTI, 2012; SÁNCHEZ, 2013; OLIVEIRA; NEVES; SOUZA, 2015) afirmam que a participação 
social não tem sido efetiva no processo decisório por meio da audiência pública; esse instrumento é realizado tardiamente no processo e, na maioria dos casos, pode ser considerado como um cumprimento de uma etapa burocrática, apenas legitimando decisões prévias, o que descaracteriza, portanto, sua função como um espaço efetivo de discussão e de influência na tomada de decisão. Contudo, apesar das pesquisas acadêmicas apontarem essas fragilidades na participação da sociedade civil no processo da AIA e reforçar a importância da criação de mecanismos de consulta, ainda há pouca ênfase na proposição de soluções para o aperfeiçoamento da prática no país (DUARTE; DIBO; SÁNCHEZ, 2017).

Com esses procedimentos realizados, é importante destacar que a emissão de qualquer licença pelo órgão ambiental competente estabelece condicionantes na forma de restrições, ações e medidas de controle que deverão ser executadas pelo proponente do projeto. Essas condicionantes estão associadas não só com a emissão das licenças, como também com sua manutenção, já que a não realização de tais medidas pode resultar na não renovação ou suspenção de licenças (BRASIL,1997).

Destaca-se, também, outra exigência fundamental do processo de licenciamento ambiental, a atividade de monitoramento e acompanhamento (MIRRA, 2006). A elaboração de programas de acompanhamento e monitoramento pelo proponente do empreendimento é determinada pela Resolução CONAMA nำ001 de 1986. Esses programas são essenciais para a avaliação da evolução dos impactos, para a aferição da eficiência das medidas mitigadoras implementadas e para verificação de execução das condicionantes determinadas durante o processo de licenciamento ambiental (BRASIL, 2004). Essas ações de monitoramento e acompanhamento não devem se restringir ao registro e análise de dados, e sim utilizálos como base para a proposição de ações corretivas quando necessárias, assim como para proposição de medidas mitigadoras à impactos não-previstos nas etapas anteriores (BRASIL, 2004).

\subsection{LICENCIAMENTO AMBIENTAL NO ESTADO DE SÃO PAULO}

No estado de São Paulo, o processo de licenciamento ambiental é regulado pela Secretaria do Meio Ambiente, sendo competência da Companhia de Tecnologia de Saneamento Ambiental (CETESB) ou dos municípios, para empreendimentos de impacto ambiental local (CETESB, 2014). A CETESB determina que o licenciamento 
ambiental prévio de empreendimentos potencial ou efetivamente causadores de degradação ambiental deve ser realizado com base em estudos ambientais, definidos pelas Resoluções CONAMA no 001 de 1986, Resoluções CONAMA no 237 de 1997, Resolução SMA no 49 de 2014 e Decisão de Diretoria nํ 153 de 2014. Estes estudos consistem em:

- Estudo Ambiental Simplificado - EAS: Para empreendimentos, obras e atividades considerados de baixo potencial de degradação ambiental;

- Relatório Ambiental Preliminar - RAP: Para empreendimentos, obras e atividades considerados potencialmente causadores de degradação do meio ambiente;

- Estudo de Impacto Ambiental e Relatório de Impacto Ambiental - EIA e RIMA: Para empreendimentos, obras e atividades considerados como potencialmente causadores de significativa degradação do meio ambiente.

Não havendo clareza acerca da magnitude e da significância dos impactos ambientais decorrentes da implantação do empreendimento ou atividade, o empreendedor poderá protocolizar consulta ao Departamento de Avaliação Ambiental de Empreendimentos da CETESB, o qual será responsável pela análise desses estudos e pela elaboração dos pareceres técnicos que subsidiam o licenciamento com Avaliação de Impacto Ambiental (CETESB, 2014). Essa consulta é, portanto, uma etapa anterior ao próprio processo de elaboração de qualquer estudo, estando relacionada a decisão acerca de qual tipo de estudo é necessário, correspondendo, assim, a etapa de triagem.

Em relação a etapa de escopo, além das diretrizes gerais de conteúdo mínimo para o EIA apresentada pela Resolução CONAMA no 001 de 1986, a legislação brasileira não indica determinações específicas para a elaboração de escopo, mencionando apenas, na mesma resolução, o fornecimento de instruções adicionais pelo órgão competente, quando necessárias. Essa ausência de diretrizes específicas acarreta em diferenças significativas entre a etapa de escopo nos processos realizados por distintas esferas do Poder Público (BORIONI; GALLARDO; SÁNCHEZ, 2017).

Especificamente no estado de São Paulo, a etapa de determinação do escopo é atualmente regulamentada pela Resolução SMA № 49 de 2014, a qual define que a 
elaboração Termo de Referência (TR) deve ser realizada pelo empreendedor considerando o manual de práticas da CETESB. Em seguida, esse documento será submetido a análise do órgão que, por sua vez, consolidará um Termo de Referência final ao qual se dará publicidade (SÃO PAULO, 2014). De acordo com resoluções anteriores, o processo ocorria de maneira semelhante, porém 0 documento incialmente apresentado pelo proponente era denominado Plano de Trabalho, o qual também era submetido a um processo de análise com a emissão de parecer técnico e consolidação de um Termo de Referência pela CETESB (SÁNCHEZ, 2013).

De acordo com a literatura, a elaboração de um bom escopo pode trazer inúmeros benefícios para a Avaliação de Impacto Ambiental, como maior transparência do processo, melhor custo-eficácia, melhor fornecimento de informações relevantes, melhor estudo de alternativas e impactos cumulativos e melhor governança (BORIONI; GALLARDO; SÁNCHEZ, 2017). Contudo, Borioni, Gallardo e Sánchez (2017) ressaltam que efeitos contrários também são observados no caso de escopos deficientes, como o aumento do tempo de análise do estudo de impacto ambiental e, portanto, a redução do custo-eficácia, maior questionamento público na etapa de consulta pública e o aumento do risco de negligenciar questões importantes que deveriam ser abordadas.

Apesar da determinação de um documento de escopo apresentar um papel importante para a elaboração de um EIA, esta etapa poderia ser melhor explorada, já que, na prática atual brasileira, os aspectos particulares dos projetos não têm sido abordados e analisados de maneira satisfatória nos TRs, sendo inclusive constatado que muitas falhas identificadas nos EIAs estão relacionadas com falhas na elaboração do escopo (BRASIL, 2004; ALMEIDA, 2010).

Considerando todos as etapas descritas anteriormente, o processo de licenciamento ambiental no estado de São Paulo, segue um fluxo de etapas como indicado na Figura 1. 
Figura 1 - Fluxo de etapas do processo de Licenciamento Ambiental do Estado de São Paulo.

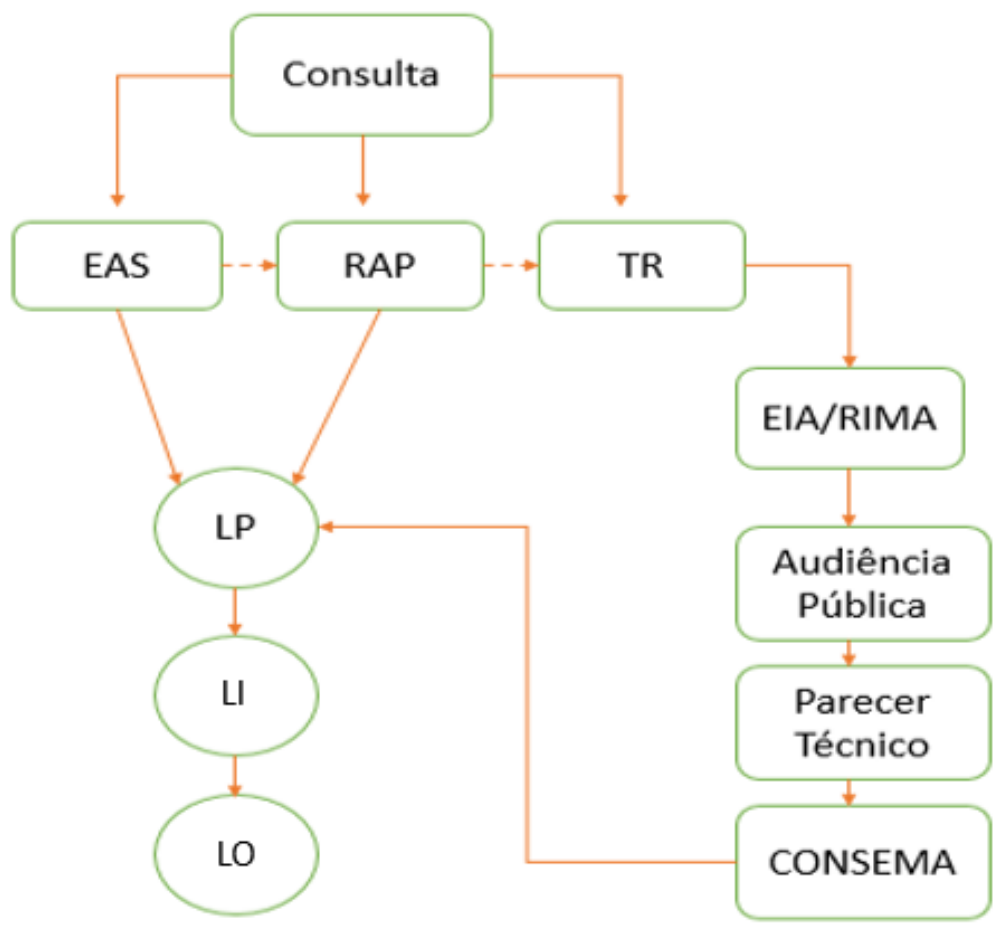

Fonte: Adaptado de CETESB (2014).

\subsection{ESTUDO DE IMPACTO AMBIENTAL E RELATÓRIO DE IMPACTO AMBIENTAL}

Como visto na seção anterior, determinada a necessidade de Avaliação de Impacto Ambiental por meio de elaboração do EIA/RIMA, é necessário estabelecer o escopo de estudo, ou seja, o conjunto de temas e questões que serão tratados e a qual profundidade (SÁNCHEZ, 2013). No caso específico brasileiro, além do Termo de Referência ou de outro documento de escopo que pode ser requerido pelo órgão ambiental competente, esses estudos devem ser formulados considerando as diretrizes gerais de conteúdo da Resolução CONAMA № 001 de 1986, tratadas nos Artigos $5^{\circ}, 6^{\circ}, 7^{\circ}, 8^{\circ}$ e $9^{\circ}$ dessa resolução.

Segundo o Manual para elaboração de estudos para licenciamento com Avaliação de Impacto Ambiental no estado de São Paulo (CETESB, 2014), os EIAs devem obrigatoriamente conter:

- Informações gerais (objeto do licenciamento, empreendedor, empresa responsável pelo estudo ambiental); 
- Justificativa do empreendimento;

- Estudos de alternativas (alternativas locacionais, alternativas tecnológicas e alternativa zero);

- Aspectos legais e institucionais;

- Compatibilidade com planos, programas e projetos colocalizados;

- Caracterização do empreendimento;

- Áreas de influência;

- Diagnóstico ambiental (meios físico, biótico e socioeconômico);

- Identificação e avaliação dos impactos;

- Programas de mitigação monitoramento e compensação;

- Prognóstico ambiental;

- Conclusões gerais;

- Referências;

- Equipe técnica.

Existem críticas, entretanto, ao modelo disciplinar tradicionalmente adotado na elaboração dos EIAs, o qual aborda com certo isolamento as questões do meio físico, biótico e socioeconômico. Essas críticas evidenciam que a abordagem disciplinar parece não ser a maneira mais adequada em relação ao custo, ao tempo, a consideração de impactos cumulativos e sinérgicos e a incorporação de questão mais amplas e interdisciplinares como, por exemplo, considerações de discussões sobre mudanças climáticas (CARMO, 2016).

Como posto pela Constituição Federal de 1988, a publicidade do processo de AIA é garantida. Portanto, como exposto anteriormente, apesar das deficiências desse processo, a realização da audiência pública propõe não só a publicidade do processo como uma oportunidade de diálogo entre proponentes, grupos de interesse e órgãos avaliadores. Considerando esse momento de participação, o RIMA é o documento central que deve ser produzido objetivando a difusão dos principais pontos do EIA. 
Para isso se faz relevante o uso de linguagem objetiva, adequada e ilustrada, por meio de mapas, quadros e outras técnicas de comunicação visual que facilitem a compreensão. Apesar de ser um documento mais conciso, algumas informações devem ser imprescindivelmente apresentadas, sendo exigido como conteúdo mínimo do RIMA pela Resolução CONAMA nº 001 de 1986 os seguintes pontos primordiais: os objetivos e justificativas do projeto, a descrição do projeto e de suas alternativas tecnológicas e locacionais, a síntese dos diagnósticos do EIA bem como dos impactos esperados, a síntese das medidas mitigadoras previstas e dos programas de acompanhamento (BRASIL, 1986).

Para Sánchez (2013), o Estudo de Impacto Ambiental é o ponto central do processo de Avaliação de Impacto Ambiental, já que é com base nesse documento, e de seu respectivo RIMA, que ocorre o processo decisório quanto a viabilidade ambiental da proposta, as medidas mitigadoras e compensatórias. Além disso, considerando o caráter público do processo de AIA, são esses documentos que embasam a troca de informações necessárias para o diálogo e as negociações entre Poder Público, empreendedor e grupos de interesse. 


\section{ALTERNATIVAS LOCACIONAIS}

A apresentação de alternativas é, sem dúvida, um dos pilares da AIA (VALVE, 1999; SOUZA, 2000; TICKENER; GEISER, 2004; AGRA-FILHO et al., 2012 SÁNCHEZ, 2013, IAIA, 2015), sendo considerada um dos princípios operacionais do processo (IAIA, 1999). A análise de alternativas locacionais é indispensável, uma vez que a questão da localização se caracteriza como um pré-requisito a análise de impactos (BRASIL, 2004). Sem a apresentação e comparação de alternativas, a análise se resume a um julgamento da aceitabilidade de impactos inevitáveis de uma única opção (AGRA-FILHO et al., 2012), assim posto, a proposição de alterativas surge como uma forma de incitar a prioridade por soluções e possibilidades menos impactantes em diferentes esferas (SÁNCHEZ, 1993), ou seja, de estabelecer a opção mais ambientalmente viável para alcançar os objetivos do projeto (IAIA, 1999).

De acordo com o artigo 5ํㅡ, inciso I da Resolução CONAMA ํo 001 de 1986, o estudo de impacto ambiental deve contemplar todas as alternativas tecnológicas e de localização de projeto, confrontando-as com a hipótese de sua não execução; ou seja, a apresentação de alternativas locacionais é, de acordo com a resolução, uma diretriz a ser obrigatoriamente seguida para apresentação de um estudo em conformidade com a resolução vigente, sugere-se ainda a análise dessas alternativas tendo em vista a viabilidade da execução do projeto. Apesar de destacar a necessidade de apresentação das alternativas locacionais, a resolução em questão, assim como para os demais temas, não detalha os procedimentos ou os conteúdos que devem ser abordados nessa etapa

Diretrizes definidas pela CETESB estabelecem que as alternativas locacionais correspondem às diferentes possibilidades de traçado, sítio e/ou layout para que o projeto seja ambiental, técnico e economicamente viável e possa atender ao objetivo do empreendimento (CETESB, 2014). De fato, para algumas tipologias de empreendimento, o estudo de alternativas está ainda mais diretamente associado ao projeto, como é o caso dos empreendimentos lineares, que incluem rodovias, ferrovias, linhas de transmissão entre outros, nos quais o estudo de alternativas é frequentemente utilizado para a seleção do traçado (FERNANDES et al., 2017).

Para determinar quais alternativas são mais propensas a resultados menos impactantes em diferentes escalas, é necessário pensar sobre a lógica da tomada de decisão e os critérios sobre os quais as decisões são tomadas (DESMOND, 2009). 
Assim sendo, a CETESB (2014) determina ainda ser necessário a comparação das alternativas por meio de indicadores, valoração e ponderação, apresentando tal análise e indicando e justificando a alternativa locacional selecionada (CETESB, 2014).

Entretanto, é importante ressaltar que grupos de diferentes interesses podem atribuir valores e ponderações distintas a um mesmo atributo de uma alternativa, sendo assim, é conveniente que a atribuição de pesos e valores que resultou na decisão por certa alternativa seja clara e explicitamente apresentada no EIA (SÁNCHEZ, 2013). As possibilidades de análise de tais atributos são vastas, incluindo a análise por multicritérios, atribuição por meio de Sistema de Informações Geográficas (SIG) ou análises por comparação qualitativa; independentemente do método, esse é um processo complexo que envolve a agregação, análise e comparação de informações de diversas naturezas sobre uma mesma questão e deve ser devidamente embasado e explicitado no EIA (SÁNCHEZ, 2013).

Como forma de minimizar a subjetividade do processo, Souza (2000) determina pontos essenciais à formulação e comparação de alternativas:

- Importância de dados e informações com o necessário detalhamento e precisão;

- Possibilidade de ponderação de vários fatores ambientais intervenientes no processo decisório;

- Manifestação da sociedade no estabelecimento de valores e hierarquia relacionado à ponderação dos fatores ambientais;

- Metodologia de acordo com a tipologia;

- Atenção as escalas temporais e espaciais relevantes;

- Atenção aos critérios de análise.

De acordo com a IAIA (2015), o processo e as metodologias utilizadas na seleção e avaliação de alternativas devem ser claros e participativos, de modo que todos os grupos de interesse possam contribuir nessa avaliação, o que, no contexto brasileiro, não ocorre de maneira direta, uma vez que a avaliação de alternativas é 
apresentada no EIA, sendo esse documento elaborado em momento anterior a participação pública.

\subsection{DEFICIÊNCIAS DA PRÁTICA ATUAL}

Apesar de constituir um elemento base da Avaliação de Impacto Ambiental, em termos práticos, diversos autores apontam falhas e inconsistências na prática atual do processo de apresentação e comparação de alternativas de localização, tanto no cenário nacional como internacional (Quadro 2).

Quadro 2 - Deficiências da prática do processo de consideração e análise de alternativas de localização

\begin{tabular}{|c|c|}
\hline Deficiências & Referências \\
\hline $\begin{array}{l}\text { Não consideração do cenário de } \\
\text { não execução }\end{array}$ & $\begin{array}{l}\text { Caldas, 2006; Smith, 2007; Fernandes et. al., } \\
\text { 2017; Schoen et al., } 2016 .\end{array}$ \\
\hline $\begin{array}{l}\text { Ausência ou número insuficiente } \\
\text { de alternativas }\end{array}$ & $\begin{array}{l}\text { BRASIL, 2004; Smith, 2007; Pinho, Maia e } \\
\text { Monterroso, 2007; Momtaz e Kabir, 2013; } \\
\text { Almeida e Montaño, } 2017\end{array}$ \\
\hline $\begin{array}{l}\text { Alternativas impraticáveis, } \\
\text { inconsistentes ou } \\
\text { reconhecidamente inferiores a } \\
\text { selecionada }\end{array}$ & $\begin{array}{l}\text { Clark e Canter, 1997; Zubair, 2001; BRASIL, } \\
\text { 2004; Smith, 2007; Machado, 2015; Fernandes } \\
\text { et. al., 2017; Enríquez-de-Salamanca, } 2018 .\end{array}$ \\
\hline $\begin{array}{l}\text { Baixa qualidade dos estudos de } \\
\text { alternativas }\end{array}$ & $\begin{array}{c}\text { Glasson et al., 1997; Gray e Edwards-Jones, } \\
\text { 2003; Canelas et al., 2005; Pinho, Maia e } \\
\text { Monterroso, 2007; Caldas, 2006; Momtaz e } \\
\text { Kabir, } 2013\end{array}$ \\
\hline $\begin{array}{c}\text { Análise ou comparação } \\
\text { incompletas das alternativas }\end{array}$ & $\begin{array}{l}\text { Lee e Colley, 1992; Lee et al. 1999; Clark e } \\
\text { Canter, 1997; Gray e Edwards-Jones, 2003; } \\
\text { BRASIL, 2004; Smith, 2007; Meireles, 2011; } \\
\text { Almeida et al., 2012; Landim e Sánchez, 2012; } \\
\text { Pinho, Maia e Monterroso, 2007; Momtaz e } \\
\text { Kabir, 2013; Hapuarachchi, Hughey, Rennie, } \\
\text { 2016; Almeida e Montaño, } 2017\end{array}$ \\
\hline $\begin{array}{c}\text { Momento de decisão da } \\
\text { localização anterior a realização } \\
\text { da AIA }\end{array}$ & $\begin{array}{c}\text { Steinemann, 2001; Benson, 2003; Momtaz e } \\
\text { Kabir, 2013; Sánchez, 2013; Naser, 2015; } \\
\text { Okubo, 2016, Khosravi, Jha-Thakur, Fischer, } \\
2019 .\end{array}$ \\
\hline $\begin{array}{c}\text { Ausência ou fraca justificativa da } \\
\text { escolha locacional }\end{array}$ & $\begin{array}{l}\text { BRASIL, 2004; Gray e Edwards-Jones, 2003; } \\
\text { Pinho, Maia e Monterroso, 2007; Almeida e } \\
\text { Montaño, 2017; Fernandes et al., } 2017 .\end{array}$ \\
\hline
\end{tabular}

Fonte: Natalia Almeida Santos Mattos, 2018. 
Frequentemente, as alternativas refletem objetivos limitados do próprio empreendimento, definidos pelos proponentes antes mesmo do início da elaboração do EIA. Sendo assim, as alternativas que são tipicamente expostas muitas vezes estão já vinculadas a uma decisão prévia por um projeto em particular definido pelo empreendedor (STEINEMANN, 2001). Isso ocorre uma vez que o processo de decisão sobre quais alternativas serão consideradas é anterior ao processo de licenciamento, cabendo, assim, somente ao proponente tais considerações (STEINEMANN, 2001, BENSON, 2003; SÁNCHEZ, 2013).

Outro ponto identificado é a apresentação de alternativas reconhecidamente inferiores à selecionada (CLARK; CANTER, 1997; ZUBAIR, 2001 BRASIL, 2004; SMITH, 2007; FERNANDES et al., 2017; ENRÍQUEZ-DE-SALAMANCA, 2018.), o que, segundo Machado (2015), seria uma forma de falsear o espírito da lei na intenção de forçar a escolha de um projeto por meio da apresentação de alternativas manifestamente impraticáveis. Enríquez-de-Salamanca (2018) reforça que a prática de apresentar alternativas reconhecidamente inferiores ou impraticáveis é uma forma de manipulação realizada pelo proponente na tentativa de justificar uma alternativa pré-selecionada.

Outros autores indicam ainda a frequente presença de estudos de alternativas locacionais de baixa qualidade (GLASSON et al., 1997; GRAY; EDWARDS-JONES, 2003; CANELAS et al., 2005; PINHO; MAIA; MONTERROSO, 2007; CALDAS, 2006; MOMTAZ; KABIR, 2013), com descrições pouco detalhadas, informações ausentes, sem a identificação de impactos e sem a descrição adequada dos processos e metodologias utilizados.

A análise e comparação ausente ou incompleta das alternativas também é um ponto comumente identificado na literatura (LEE; COLLEY, 1992; LEE et al. 1999; CLARK; CANTER, 1997; GRAY; EDWARDS-JONES, 2003; BRASIL, 2004; SMITH, 2007; MEIRELES, 2011; ALMEIDA et al., 2012; PINHO; MAIA; MONTERROSO, 2007; MOMTAZ; KABIR, 2013; HAPUARACHCHI; HUGHEY; RENNIE, 2016; ALMEIDA; MONTAÑO, 2017); nesses casos, os estudos se limitam a apresentar e descrever as alternativas sem, contudo, compará-las de maneira adequada, muitas vezes se restringindo a descrição de pontos positivos e negativos, apresentado apenas os critérios de seleção sem comparação ou não fornecendo as informações necessárias para a comparação adequada entre as alternativas. 
Além das falhas indicadas no processo de análise de alternativas, outra fragilidade frequentemente relatada na literatura é a ausência ou fraca justificativa de escolha do local considerado o mais adequado (BRASIL, 2004; GRAY; EDWARDSJONES, 2003; PINHO; MAIA; MONTERROSO, 2007; ALMEIDA; MONTAÑO, 2017; FERNANDES et al., 2017), não sendo totalmente claro por meio do estudo de alternativas descrito como se chegou a tal conclusão.

Todas essas deficiências e inconsistências determinam um cenário preocupante que pode ser interpretado como um reducionismo dos objetivos da AIA e um comprometimento da efetividade desse instrumento, já que o estudo passa a se restringir à identificação de impactos ambientais e medidas mitigadores de uma única proposta (AGRA-FILHO et al., 2012; SÁNCHEZ, 2013).

\subsection{DEFINIÇÃO DE ALTERNATIVAS E INSERÇÃO NO ESCOPO}

$\mathrm{Na}$ definição de alternativas para um projeto, algumas questões devem ser previamente consideradas; como as alternativas deveriam ser identificadas? Qual a faixa razoável de alternativas que deveriam ser consideradas? Em que nível de detalhe cada alternativa deve ser explorada? (FUGGLE, 1992).

Os pontos levantados por Fuggle (1992) recaem inicialmente no escopo. Segundo Sánchez (2013), incluir nos termos de referência alguma orientação quanto às alternativas a serem tratadas é uma estratégia que pode ser adotada ao invés de apenas esperar a apresentação das mesmas pelo proponente. Muitos autores afirmam que a qualidade do estudo de alternativas depende exatamente de quais alternativas são consideradas para análise e como elas são elaboradas, cabendo a etapa de escopo definir e apresentar as diretrizes que devem guiar o proponente na consideração das alternativas a serem estudadas (GLASSON; THERIVEL; CHADWICK, 2005; AGRA-FILHO et al., 2012; IAIA, 2015, FERNANDES et al., 2017, IAIA, 2018).

Além disso, Souza (2006) ressalta a existência de um processo anterior a elaboração e análise das alternativas dentro do EIA; o estudo para identificação da aptidão das áreas territoriais à instalação de atividades. Essas diferentes aptidões do espaço territorial devem ser analisadas considerando critérios científicos, a participação social e o maior número possível de fatores ambientais relevantes para 
cada tipo de ocupação. Considerando essas atribuições do processo de estudo, a questão da definição locacional pode ser analisada sob a perspectiva da relação entre a tipologia do empreendimento e sua localização (SOUZA, 2000; MONTAÑO et al., 2012).

Ainda considerando a questão da aptidão territorial, outros instrumentos de base, como o zoneamento ambiental e bases de referência ambiental, podem ser fundamentais na facilitação dessas orientações, o que resultaria em uma maior base de critérios e dados para o estudo de alternativas locacionais e para a área de influência do empreendimento (SOUZA, 2000; SOUZA, 2006; MONTAÑO et al., 2007; MEIRELES, 2011; FERNANDES et al., 2017).

Segundo Sánchez (2017), mesmo bons EIAs podem ter dificuldades em analisar alternativas com profundidade, isso porque as avaliações individuais de empreendimentos estão normalmente associadas a decisões anteriores e políticas já estabelecidas. Sendo assim, a inserção da questão locacional na Avaliação Ambiental Estratégica (AAE) e a consolidação dessa ferramenta no país se apresenta como um caminho para embasar um desenvolvimento mais adequado dos estudos de localização. Diferentemente da AIA, que é focada em projetos individuais, a Avaliação Ambiental Estratégica é o nome dado aos instrumentos de avaliação de impacto de ações mais amplas, como a inserção das variáveis ambientais no processo de tomada de decisão de políticas, planos e programas (MONTAÑO; OLIVEIRA; SOUZA, 2009; SÁNCHEZ, 2017). O estudo de alternativas, não só referentes a localização, mas com certeza considerando esse aspecto, devem fazer parte do processo de desenvolvimento das políticas, planos e programas e não de análises complementares apenas realizadas posteriormente, sendo assim, um dos principais objetivos da AAE deve ser auxiliar na identificação prévia de alternativas robustas e viáveis (IAIA, 2014).

O uso desses instrumentos de planejamento permitiria, assim, a inserção da variável ambiental em diferentes momentos do processo de tomada de decisão, tanto na formulação de estratégias de desenvolvimento setoriais até a decisão sobre a ocupação de um sítio específico para a implantação de uma determinada atividade (MONTAÑO et al., 2007). Essas considerações direcionam, de certa forma, a uma mesma conclusão: a necessidade de inclusão de considerações sobre aspectos mais 
amplos do planejamento ambiental em etapas anteriores ao desenvolvimento e análise de projetos individuais (CARMO, 2016). 


\section{EFETIVIDADE DA AIA E A QUALIDADE DOS ESTUDOS DE IMPACTO AMBIENTAL}

Desde o surgimento da Avaliação de Impacto Ambiental, no âmbito nacional e internacional, diversas deficiências e inconstâncias foram apontadas não somente na etapa de avaliação de alternativas, mas no processo de avaliação de impacto como um todo (JAY et al., 2007; OLIVEIRA; NEVES; SOUZA, 2015). É inegável que o processo esteja de fato auxiliando na tomada de decisão, mas a forma como é realizado esse auxilio é muitas vezes aquém ao que se propunha em seu desenvolvimento (JAY et al., 2007). De tal forma, há uma imprescindibilidade de atualização constante e aprimoramento da AIA no sentido de aproximá-la do embasamento no processo decisório (JAY et al., 2007; BANCO MUNDIAL, 2008; SÁNCHEZ, 2013).

A efetividade de qualquer processo é passível de análise em diferentes âmbitos e resulta em distintas conclusões. Buscando sistematizar a noção de efetividade, Chanchitpricha e Bond (2013) indicam a consolidação de 4 categorias na literatura: a efetividade processual - relacionado a aderência da análise desenvolvida ao procedimento estabelecido; a efetividade substantiva - referente a capacidade de cumprimento dos objetivos proposto e seu alcance na prática; a efetividade de transação - relacionada a eficácia do uso de recursos humanos e econômicos para o desenvolvimento do processo, bem como do tempo gasto em cada etapa; e a eficácia normativa - relacionada ao senso de princípios que a sociedade concorda e ao próprio conhecimento e desenvolvimento do processo.

$\mathrm{Na}$ revisão da literatura realizada por Loomis e Dziedzic (2018) sobre o processo de avalição da AIA, os autores observaram que existe uma clara preferência em examinar a efetividade processual e que, mesmo nos estudos que examinam mais de uma dimensão da efetividade, é comum relacioná-las com os aspectos procedimentais, já que isso resulta em recomendações políticas imediatas.

Lee e George (2000) afirmam ainda que além das questões metodológicas, outras questões são pertinentes a análise de efetividade da AIA, por exemplo o estágio do processo em que a AIA é realizada; as qualificações, experiência e grau de independência dos revisores dos estudos; a disponibilidade da documentação relevante para análise; os recursos e o tempo fornecido para revisão; a transparência 
e o grau de participação na revisão do processo e a utilização dos resultados da análise em etapas subsequentes do processo de AIA.

Isto posto, é evidente que a efetividade de qualquer processo de AIA, assim como do instrumento ou política no qual está inserida, vai muito além da própria qualidade do estudo de impacto realizado. Contudo, sendo o estudo de impacto ambiental o atual ponto central do processo de AIA (SÁNCHEZ, 2013), a qualidade desse documento é relevante para a análise da efetividade do instrumento. Apesar disso, Loomis e Dziedzic (2018) alertam que extrapolação das descobertas sobre a qualidade dos conteúdos do EIAs para todo o sistema de AIA deve ser feita com cautela.

Sánchez (2013) enuncia dois principais objetivos que devem ser avaliados nos Estudos de Impacto Ambiental: atender aos requisitos mínimos estabelecidos pela regulamentação aplicável e ter qualidade técnica suficiente para subsidiar a tomada de decisão sobre o empreendimento.

Independente da perspectiva de quem analisa um EIA, há a necessidade de critérios de leitura e análise. Posto isto, a existência de um conjunto de critérios preestabelecidos pode ser um facilitador exatamente por ajudar a reduzir a subjetividade da análise (SÁNCHEZ, 2013), uma vez que a qualidade de um EIA depende de múltiplos fatores (LEE; BROWN, 1992, LOOMIS; DZIEDZIC, 2018). Esses conjuntos de critérios e atribuição de conceitos foram estabelecidos em diversas metodologias de análises na literatura (ESTADOS UNIDOS, 1984; LEE; COLLEY, 1992; BOJÓRQUEZ-TAPIA; GARCÍA, 1998; EUROPEAN COMMISSION, 2001; SANDHAM; PRETORIUS, 2008; LANDIM; SÁNCHEZ, 2012), sendo comumente empregado os review packages, pacotes de revisão que constituem um método qualitativo organizado e de fácil aplicabilidade (LOOMIS; DZIEDZIC, 2018).

No contexto brasileiro, há poucos estudos sistemáticos sobre a qualidade de EIAs e o processo da AIA no país (SÁNCHEZ, 2013). Em uma revisão sobre a produção acadêmica relacionada a AIA no Brasil (DUARTE; DIBO; SÁNCHEZ, 2017), 131 estudos foram identificados entre 1985 e 2015, estando grande parte da produção concentrada após 2004. Por meio do mapeamento e análise das pesquisas produzidas nesse período, Duarte, Dibo e Sánchez (2017) estabeleceram os seguintes pontos como conclusão: 
- A maioria da produção acadêmica sobre a AIA no Brasil explora casos de alta complexidade, com concentração em hidrelétricas;

- A produção acadêmica indica fragilidades no sistema de AIA nacional, porém reconhece certos resultados positivos e avanços;

- Pesquisas sobre métodos são apresentadas em menor número, abordando as fragilidades de diferentes etapas do processe da AIA;

- Estudos acadêmicos que avaliam a qualidade dos EIAs mostram deficiências recorrentes, além de uma evolução temporal.

Anteriormente, em outra revisão encomenda pelo Ministério Público Federal (BRASIL, 2004) foram identificadas as principais deficiências dos EIA/RIMA nacionais de diferentes estados, detalhando as falhas recorrentes em cada uma das seções, incluindo no estudo de alternativas.

Outro ponto a ser considerado no âmbito da qualidade é o apresentado por Lamonica (2016), a qual afirma a possibilidade de que a qualidade dos estudos seja insatisfatória, tendo em vista seu objetivo de análise, mesmo que tenha cumprido as demandas e recomendações dos Termos de Referência e as diretrizes da legislação, ou seja, ressalta a necessidade de avaliação da qualidade do processo anterior a própria elaboração do estudo: a definição do escopo e a sistematização das informações relevantes.

A situação econômica vigente no contexto brasileiro tem refletido diretamente no processo de tomada de decisão forçando aprovações independentemente dos impactos ambientais e sociais (MONTAÑO; SOUZA, 2015). A atual situação indica que a visão da AIA como uma barreira ao desenvolvimento é ainda bastante politicamente enraizada (SÁNCHEZ, 2013). A constante necessidade de aprimoramento do processo é muitas vezes empregada em pressões políticas e econômicas sob a justificativa de que a AIA no Brasil é um processo burocrático, demorado, caro e pouco efetivo, representando um entrave ao desenvolvimento. As propostas de reformas do sistema que vem sendo apresentadas no contexto político dos últimos anos, contudo, não apresentam soluções para os problemas identificados no processo de AIA e tendem, inclusive, a enfraquecer pontos fundamentais do processo, como a participação pública (BRAGAGNOLO et al., 2017; FONSECA; SÁNCHEZ; RIBEIRO, 2017). 
Sánchez (2013) sugere que demonstrar os benefícios da AIA à sociedade de maneira tangível é um ponto chave para desvinculação da imagem do processo como um atraso de gastos desnecessários ao desenvolvimento do país.

Lee e George (2000) já apontavam evidências de fraca integração dos resultados do processo de AIA às decisões tomadas, particularmente em países menos desenvolvidos. Jay et al. (2007) reforçam essa noção ao afirmar que, apesar das significativas contribuições da AIA, há um gradual aumento da insatisfação sobre o fato de sua influência ser limitada em relação a tomada de decisão. Isso torna ainda mais complexa a análise de efetividade da AIA dentro do processo de decisão, já que a aderência entre os dois processos se distancia. De maneira geral, embora o entendimento sobre as contribuições da AIA no processo tenha melhorado ao longo do tempo, ainda não existem estudos que medem empiricamente a influência direta da AIA na tomada de decisão (LOOMIS; DZIEDZIC, 2018). 


\section{OBJETIVOS}

Tendo em vista o exposto, esse estudo tem como objetivo analisar os estudos de alterativas locacionais apresentadas nos EIAs do Estado de São Paulo recebidos pela CETESB a partir do ano de 2005; examinando os critérios e metodologias utilizados, o cenário histórico-atual desta etapa do EIA e contribuindo para a discussão do processo de avaliação de impacto.

\subsection{OBJETIVO GERAL}

Analisar os estudos de alternativas locacionais dos EIAs do Estado de São Paulo entre 2005 e 2016.

\subsection{OBJETIVOS ESPECÍFICOS}

- Descrever os estudos de alternativas de localização presentes nos EIAs quanto a apresentação, número de alternativas, critérios considerados e seus sistemas de classificação, representações visuais e hipótese de não-execução.

- Analisar qualitativamente os estudos de alternativas locacionais presentes nos EIAs considerando a apresentação e descrição, os critérios considerados, o processo de comparação, análise e seleção e a consistência do estudo.

- Analisar qualitativamente os TRs dos estudos quanto a delimitação de diretrizes específicas para o estudo de alternativas de localização.

- Fornecer subsídios e discutir a contribuição da atual prática de análise locacional dentro do processo de Avaliação de Impacto Ambiental. 


\section{MATERIAIS E MÉTODOS}

Inicialmente, foi realizada a identificação e o levantamento dos EIAs do estado de São Paulo junto à CETESB a partir de 2005 até 2016. O recorte temporal da análise e a metodologia de amostragem serão detalhados adiante.

Como método de investigação, foi realizada a análise de conteúdo tendo como objeto as alternativas de localização apresentadas nos EIAs levantados. Para identificar esse conteúdo dentro de cada EIA, primeiramente foi realizada uma consulta no sumário, verificando a presença de capítulos destinados a discussão desse conteúdo. Em seguida, para todos os EIAs, foi realizada a análise dos capítulos referentes a identificação, descrição e justificativa do empreendimento. Após essa etapa, o capítulo referente a alternativas foi analisado, caso existisse. Em seguida, foi feita uma busca de palavras para os seguintes termos: alternativa, localização, locacional, local. Todos os termos encontrados foram avaliados com objetivo de verificar a presença de conteúdos sobre alternativas de localização em outros capítulos do EIA ou dispersas pelo texto.

Dois pontos de análise foram definidos, um de caráter descritivo e outro qualitativo. No primeiro, o objetivo central foi identificar as características básicas de forma e conteúdo das alternativas de localização nos EIAs por meio da categorização sistemática das informações apresentadas. No segundo ponto, a qualidade das informações documentais foi analisada por meio de lista de verificação e por escalas de conceitos.

Segundo Miles e Huberman (1984), a análise de conteúdo pode ser dividida em três conjuntos de tarefas:

a) Redução dos dados

b) Apresentação dos dados

c) Conclusões

Desta forma, tanto na análise qualitativa quanto na descritiva, a redução de dados foi realizada pela análise documental seguida de categorização de acordo com o objetivo de cada análise; a apresentação dos dados foi realizada por meio de tabelas e gráficos comparativos explanatórios que possibilitaram a análise, discussão e conclusões das tendências encontradas. 
Sendo assim, o método utilizado nesta pesquisa se apresenta em três grandes etapas: a definição da amostragem, a análise descritiva e a análise qualitativa dos estudos de alternativas de localização.

\subsection{AMOSTRAGEM}

Para análise dos estudos de alternativas locacionais, inicialmente foi realizado um levantamento junto a CETESB de todos os EIAs apresentados entre 2005 e 2016. O recorte temporal a partir de 2005 foi selecionado tendo em vista a Resolução SMA no 54 de 30 de novembro de 2004, a qual apresentou novos procedimentos para o licenciamento ambiental no âmbito da Secretaria do Meio Ambiente e reestruturou os estudos necessários aos diferentes empreendimentos dentro do processo de licenciamento (SÃO PAULO, 2004). Assim, optou-se pela amostragem após a data dessa resolução objetivando uma maior homogeneidade da amostra. O ano de 2016 foi determinado em razão da disponibilidade e coleta de dados e do acesso às informações junto à CETESB.

O levantamento foi realizado por duas vias dentro do órgão ambiental. Por uma primeira via no Setor de Triagem e Acompanhamento de Processos (ITAP), para o qual se encaminhou um pedido de acesso à lista de todos os EIAs protocolados no período de 2005 a 2016, utilizando-se de um formulário oficial encaminhado pessoalmente no setor e, devido à falta de resposta, encaminhado novamente via email. Por uma segunda via por meio do acervo da biblioteca, no qual foi possível acessar a lista do acervo geral de documentos e fazer um levantamento manual ano a ano. A lista final considerada foi a obtida pela consulta no sistema da biblioteca da CETESB. No total foram identificados 314 Estudos de Impacto Ambiental e seus respectivos RIMAs nesse período, os quais estão listados no Apêndice A.

Destes 314 estudos, a amostra considerada para análise foi inicialmente de 50 estudos. Considerando os objetivos propostos, não houve intenção de obter representatividade estatística por meio do número de documentos analisados, de maneira que esse número amostral foi definido considerando o tempo de análise e a dimensão amostral usualmente praticada para esse tipo de pesquisa na literatura. Essa amostra foi determinada de maneira estratifica considerando as proporções dos setores dos empreendimentos. Sendo assim, inicialmente, cada estudo levantado foi classificado de acordo com sua tipologia e posteriormente agregado em setores baseados na Resolução CONAMA nํ 001 de 1986. Outros dois fatores considerados 
na amostragem foram a necessidade de representatividade dos tipos em menor número e a manutenção das proporções entre empreendimentos novos e ampliações. A porcentagem de cada setor foi calculada (Tabela 1) e mantida na amostra determinada, assim como a porcentagem de ampliações dentro de cada setor (Tabela 2). Para os setores que inicialmente deveriam ter apenas 1 estudo na amostra, mas que continham ampliações e novos empreendimentos, considerou-se 2 estudos na amostragem, sendo um novo e uma ampliação.

Tabela 1 - Número de EIAs total e na amostra considerando a porcentagem por setor.

\begin{tabular}{|l|c|c|c|}
\hline \multicolumn{1}{|c|}{ Setores } & $\mathbf{n}^{\circ}$ total & $\%$ & $\begin{array}{c}\text { N amostral } \\
\text { pretendido } \\
\mathbf{5 0}\end{array}$ \\
\hline Aeroportos (A) & 4 & 1 & 1 \\
\hline Portos e terminais (P) & 7 & 2 & 1 \\
\hline Dutos (D) & 9 & 3 & 1 \\
\hline Transportes lineares (TL) & 27 & 9 & 4 \\
\hline Energia (E) & 9 & 3 & 1 \\
\hline Linhas de transmissão (LT) & 5 & 2 & 1 \\
\hline Urbanização (U) & 65 & 21 & 10 \\
\hline Mineração (M) & 35 & 11 & 6 \\
\hline Obra hidráulica (H) & 6 & 2 & 1 \\
\hline Tratamento de resíduos (R) & 48 & 15 & 8 \\
\hline Indústria (I) & 13 & 4 & 2 \\
\hline Agroindústria (Al) & 86 & 27 & 14 \\
\hline TOTAL & 314 & 100 & 50 \\
\hline
\end{tabular}

Fonte: Natalia Almeida Santos Mattos, 2018. 
Tabela 2 - Porcentagem de ampliações por setor e número amostral final.

\begin{tabular}{|c|c|c|c|c|c|c|}
\hline Setores & $\begin{array}{c}\mathrm{n}^{\circ} \\
\text { total }\end{array}$ & $\begin{array}{c}\mathrm{n}^{\circ} \\
\text { ampliações }\end{array}$ & $\begin{array}{c}\% \\
\text { ampliações }\end{array}$ & $\begin{array}{c}\mathrm{N} \text { amostral } \\
\text { pretendido }=50\end{array}$ & $\begin{array}{c}\mathbf{N} \\
\text { amostral } \\
\text { novos }\end{array}$ & $\begin{array}{l}\mathrm{N} \text { amostral } \\
\text { ampliações }\end{array}$ \\
\hline Aeroportos (A) & 4 & 2 & 50 & 1 & 1 & 1 \\
\hline Portos e terminais $(P)$ & 7 & 2 & 29 & 1 & 1 & 1 \\
\hline Dutos (D) & 9 & 0 & 0 & 1 & 1 & 0 \\
\hline Transportes lineares (TL) & 27 & 4 & 15 & 4 & 3 & 1 \\
\hline Energia $(E)$ & 9 & 0 & 0 & 1 & 1 & 0 \\
\hline $\begin{array}{l}\text { Linhas de transmissão } \\
\text { (LT) }\end{array}$ & 5 & 0 & 0 & 1 & 1 & 0 \\
\hline Urbanização (U) & 65 & 0 & 0 & 10 & 10 & 0 \\
\hline Mineração (M) & 35 & 16 & 46 & 6 & 3 & 3 \\
\hline Obra hidráulica $(\mathrm{H})$ & 6 & 0 & 0 & 1 & 1 & 0 \\
\hline $\begin{array}{l}\text { Tratamento de resíduos } \\
\text { (R) }\end{array}$ & 48 & 12 & 25 & 8 & 6 & 2 \\
\hline Indústria (I) & 13 & 2 & 15 & 2 & 1 & 1 \\
\hline Agroindústria $(\mathrm{Al})$ & 86 & 69 & 80 & 14 & 3 & 11 \\
\hline & & & & Total & 32 & 20 \\
\hline & & & & $\begin{array}{l}\mathbf{N} \text { total da } \\
\text { amostra }\end{array}$ & \multicolumn{2}{|c|}{52} \\
\hline
\end{tabular}

Fonte: Natalia Almeida Santos Mattos, 2018.

Dessa forma, a lista resultante (Quadro 3) foi de 52 estudos amostrados de maneira aleatória, por sorteio, considerando as proporções de setor e de ampliações. Os documentos digitais dos EIAs, RIMAs e TRs foram obtidos de duas maneiras: pela página eletrônica da CETESB, que disponibiliza para download alguns processos e, para os que não estavam disponíveis no site, pela equipe da biblioteca da CETESB. Ressalta-se que a obtenção dos TRs não foi possível para todos os EIAs, já que nem todos os arquivos digitais continham anexos os TRs, sendo possível o acesso a 33 TRs da amostra. Todos os respectivos RIMAs estavam disponíveis.

Dois apontamentos são necessários para Quadro 3, a existência de dois anos para cada processo refere-se ao ano em que o processo foi protocolado no órgão ambiental e, em seguida, ao ano em que o estudo foi entregue. Assim como o ano, dois códigos de processo também estão presentes, o primeiro faz referência ao número do processo junto ao órgão ambiental e o segundo ao número de registro do documento no acervo da biblioteca da CETESB. 
Quadro 3 - Amostra final de 52 EIAs/RIMAs e 33 TRs.

\begin{tabular}{|c|c|c|c|c|c|}
\hline EIA & Título & $\begin{array}{l}\text { Ano processo/ } \\
\text { Ano EIA }\end{array}$ & $\begin{array}{l}\text { Processo/ } \\
\text { Registro }\end{array}$ & Setor & TR \\
\hline 1 & $\begin{array}{l}\text { Catarina - Aeroporto Executivo Fashion Outlet e } \\
\text { Corporate Center: São Roque - SP }\end{array}$ & $2012 / 2013$ & $00069 / 0812$ & A & Sim \\
\hline 2 & Ampliação do aeroporto Internacional de Viracopos & $2000 / 2008$ & $13784 / 0669$ & $A^{*}$ & Sim \\
\hline 3 & $\begin{array}{l}\text { Ampliação do terminal marítimo da ULTRAFÉRTIL } \\
\text { S.A. }\end{array}$ & $2010 / 2011$ & $00268 / 0773$ & $P^{*}$ & Não \\
\hline 4 & Novo Píer do TEBAR & $2011 / 2013$ & 00191/0233 & $\mathrm{P}$ & Sim \\
\hline 5 & $\begin{array}{l}\text { Sistema de escoamento dutoviário de álcool e } \\
\text { derivados - SEDA }\end{array}$ & $2009 / 2009$ & $08767 / 0698$ & $\mathrm{D}$ & Sim \\
\hline 6 & Prolongamento da Rodovia SP-083 fase 2 & $2016 / 2016$ & $00025 / 0861$ & TL & Não \\
\hline 7 & $\begin{array}{l}\text { Implantação do sistema integrado Metropolitano - } \\
\text { SIM e do veículo leve sobre trilhos - VLT da Região } \\
\text { Metropolitana da Baixada Santista - RMBS. }\end{array}$ & $2007 / 2008$ & $13845 / 0679$ & TL & Não \\
\hline 8 & $\begin{array}{l}\text { Duplicação da Rodovia dos Tamoios (SP-99) } \\
\text { subtrecho Planalto Km 11+500 ao KM 60+480 }\end{array}$ & $2007 / 2011$ & $13523 / 0772$ & $T L^{*}$ & Sim \\
\hline 9 & Contorno norte de Caraguatatuba & $2011 / 2011$ & $00097 / 0783$ & TL & Sim \\
\hline 10 & $\begin{array}{l}\text { Pequena central hidrelétrica São Francisco - Rio } \\
\text { Pardo }\end{array}$ & $2006 / 2009$ & $13520 / 0723$ & $\mathrm{E}$ & Sim \\
\hline 11 & $\begin{array}{l}\text { Linha de transmissão } 345 \mathrm{Kv} \text { CD - Domênico Rangoni } \\
\text { - Seccionamento Tijuco Preto - Baixada Santista e } \\
\text { Subestação Domênico Rangoni }\end{array}$ & $2013 / 2015$ & 0229/0853 & LT & Sim \\
\hline 12 & City Fazenda Acaraú & $2008 / 2012$ & 01632/0795 & $\mathrm{U}$ & Não \\
\hline 13 & $\begin{array}{l}\text { Loteamento residencial e comercia } \\
\text { Cantagalo }\end{array}$ & $2013 / 2015$ & $00081 / 0846$ & $U$ & Sim \\
\hline 14 & Plano Urbanístico City São Paulo & 2016/2016 & $00047 / 0867$ & $U$ & Sim \\
\hline 15 & Loteamento residencial Lago Azul - Paulínia & $2009 / 2010$ & $03661 / 0750$ & $U$ & Não \\
\hline 16 & $\begin{array}{l}\text { Parcelamento } \\
\text { predominante } \\
\text { estância baln€ }\end{array}$ & $2009 / 2011$ & 08625/0769 & $U$ & Sim \\
\hline 17 & Villa Trump & $2005 / 2005$ & $13723 / 0561$ & $U$ & Não \\
\hline 18 & Projeto Vila Florestal - Reserva de Cotia & $2007 / 2007$ & $13536 / 0638$ & $U$ & Sim \\
\hline 19 & Loteamento residencial Kaloré & $2011 / 2013$ & $00187 / 0820$ & $U$ & Não \\
\hline 20 & Loteamento Residencial Sete Lagos & $2008 / 2010$ & $02140 / 0746$ & $U$ & Não \\
\hline 21 & $\begin{array}{l}\text { Loteamento residencial Fazenda Santo Ângelo: } \\
\text { Americana - SP }\end{array}$ & $2010 / 2013$ & $00278 / 0652$ & $U$ & Sim \\
\hline 22 & Fazenda Santa Esperança & 2013/2013 & $00426 / 0856$ & $\mathrm{M}$ & Não \\
\hline 23 & Mineração de areia a céu aberto & $2006 / 2013$ & $13709 / 0705$ & $M^{*}$ & Não \\
\hline 24 & Ampliação das atividades da Mina Serrinha & $2013 / 2013$ & 00299/0857 & $\mathrm{M}^{*}$ & Não \\
\hline 25 & $\begin{array}{l}\text { Lavra de areia quartzosa Analândia e Corumbataí - } \\
\text { SP }\end{array}$ & 2005/2009 & $13717 / 0685$ & M & Sim \\
\hline 26 & Lavra de calcário - Área Serrinha & $2005 / 2008$ & $13500 / 0677$ & $\mathrm{M}$ & Sim \\
\hline 27 & $\begin{array}{l}\text { Ampliação das atuais áreas de lavra de rocha } \\
\text { fosfática da BUNGE Fertilizantes } S / A\end{array}$ & $2003 / 2009$ & $13623 / 0716$ & $M^{*}$ & Sim \\
\hline 28 & $\begin{array}{l}\text { Obras de Aproveitamento da Bacia do Rio Itapanhaú } \\
\text { para Abastecimento da RMSP }\end{array}$ & $2015 / 2015$ & 00166/0855 & $\mathrm{H}$ & Não \\
\hline 29 & $\begin{array}{l}\text { Aterro sanitário para disposição final de resíduos } \\
\text { sólidos domiciliares do município de São Carlos/SP }\end{array}$ & $2008 / 2010$ & $02219 / 0718$ & $\mathrm{R}$ & Não \\
\hline 30 & Aterro Sanitário Delta B & $2006 / 2009$ & $13777 / 0725$ & $\mathrm{R}$ & Sim \\
\hline 31 & $\begin{array}{l}\text { Centro de Tratamento e Disposição de Resíduos de } \\
\text { Caraguatatuba - CTR Caraguatatuba }\end{array}$ & $2010 / 2010$ & 00042/0754 & $\mathrm{R}$ & Sim \\
\hline
\end{tabular}




\begin{tabular}{|c|c|c|c|c|c|}
\hline 32 & entral de tratamento de resíduos - CTR Itu & $2011 / 2011$ & 00046/0836 & $\mathrm{R}$ & Sim \\
\hline 33 & $\begin{array}{l}\text { ENTRES: Centro de tratamento de resíduos : aterro } \\
\text { anitário com codisposição para resíduo industrial } \\
\text { lasse II A }\end{array}$ & $2003 / 2005$ & $13568 / 0553$ & $\mathrm{R}$ & Não \\
\hline 34 & $\begin{array}{l}\text { mpliação do aterro classe I : RESICONTROL } \\
\text { nidade Tremembé }\end{array}$ & 2010/2011 & 00067/0767 & $\mathrm{R}^{*}$ & Sim \\
\hline 35 & $\begin{array}{l}\text { Central de tratamento e destinação de resíduos } \\
\text { sólidos domiciliares em regime de codisposição com } \\
\text { resíduos industriais classes IIA e IIB, resíduos } \\
\text { perigosos - classe I, central de triagem, britador e } \\
\text { autoclave. CTDR CASA BRANCA }\end{array}$ & $2014 / 2016$ & 00205/0863 & $\mathrm{R}$ & Sim \\
\hline 36 & $\begin{array}{l}\text { npliação do aterro sanitário do centro de } \\
\text { renciamento de resíduos }\end{array}$ & $2012 / 2012$ & 00107/0794 & $\mathrm{R}^{\star}$ & Sim \\
\hline 37 & $\begin{array}{l}\text { Ampliação industrial - produção d } \\
\text { solventes }\end{array}$ & $2007 / 2007$ & $13545 / 0597$ & $I^{*}$ & Sim \\
\hline 38 & abricação de aminoácido lisina & $2005 / 2005$ & $13600 / 0563$ & 1 & Não \\
\hline 39 & Dirceu Luis Bovi: usina de açúcar, etanol e energia & $2007 / 2012$ & $13631 / 0790$ & $\mathrm{Al}$ & Não \\
\hline 40 & $\begin{array}{l}\text { Implantação de unidade industrial, produção e áreas } \\
\text { de plantio da Companhia Energética Cravinhos S/A }\end{array}$ & $2008 / 2010$ & $01145 / 0730$ & Al & Sim \\
\hline 41 & Ipiranga Agroindustrial SA Filial Mococa & $2014 / 2014$ & 00238/0858 & $\mathrm{Al}^{*}$ & Sim \\
\hline 42 & Implantação industrial e agrícola & $2010 / 2012$ & 00252/0784 & Al & Sim \\
\hline 43 & Ampliação da Usina Bela Vista S.A. Pontal/SP & $2006 / 2006$ & $13535 / 0738$ & $\mathrm{Al}^{*}$ & Não \\
\hline 44 & $\begin{array}{l}\text { Ampliação da área agrícola (cana) e produção } \\
\text { industrial: açúcar, álcool e energia }\end{array}$ & $2009 / 2010$ & 00084/0758 & $\mathrm{Al}^{*}$ & Sim \\
\hline 45 & $\begin{array}{l}\text { estilaria São Jorge: ampliação de unidade } \\
\text { groindustrial }\end{array}$ & $2010 / 2012$ & 00043/0789 & $\mathrm{Al}^{*}$ & Sim \\
\hline 46 & agrícola e industrial de $u$ & 2009/2009 & 07023/0720 & $\mathrm{Al}^{*}$ & Sim \\
\hline 47 & $\begin{array}{l}\text { Ampliação da produção e das áreas de plantio: Usina } \\
\text { Santa Fé }\end{array}$ & $2008 / 2009$ & 01687/0709 & $\mathrm{Al}^{*}$ & Sim \\
\hline 48 & Ampliação da TONON Bioenergia S.A. Santa Cândida & $2009 / 2010$ & 00085/0760 & $\mathrm{Al}^{*}$ & Sim \\
\hline 49 & $\begin{array}{l}\text { Baldin Bioenergia S/A - aumento de processamento } \\
\text { de cana e produção de álcool e açúcar }\end{array}$ & $2008 / 2009$ & 02240/0717 & $A l^{*}$ & Sim \\
\hline 50 & Açúcar Guarani: unidade Severina & $2009 / 2009$ & 00013/0722 & $\mathrm{Al}^{*}$ & Sim \\
\hline 51 & $\begin{array}{l}\text { Ampliação industrial e agrícola de unidade de açúcar } \\
\text { e álcool }\end{array}$ & $2008 / 2009$ & 02138/0711 & $\mathrm{Al}^{*}$ & Não \\
\hline 52 & Usina Açucareira Furlan S/A: Unidade Avaré & 2010/2011 & 00069/0778 & $\mathrm{Al}^{*}$ & Não \\
\hline
\end{tabular}

Nota: * identifica EIAs de ampliação de um empreendimento já instalado. (A) Aeroportos, (P) Portos e

Terminais, (D) Dutos, (TL) Transportes lineares, (E) Energia, (LT) Linhas de transmissão, (U)

Urbanização, (M) Mineração, (H) Obra hidráulica, (R) Tratamento de resíduos, (I) Indústria, (Al)

Agroindústria.

Fonte: Natalia Almeida Santos Mattos, 2018.

\subsection{DEFINIÇÃO DA ANÁLISE DESCRITIVA}

De acordo com Gil (2008), as pesquisas de caráter descritivo têm como objetivo primordial a descrição das características de determinada população ou fenômeno ou o estabelecimento de relações entre variáveis. Nesse contexto, considerando a variedade da forma e conteúdo dos estudos de alternativas locacionais dentro dos EIAs, esta etapa da pesquisa objetivou a descrição de alguns aspectos desses estudos por meio da categorização das características observadas. 
Para isso, dois níveis de categorias foram definidos; o primeiro nível foi definido a priori orientado pelos objetivos de descrição desejados e embasados nos principais aspectos apontados como deficiências dos estudos locacionais na literatura, compondo-se, assim, as categorias de análise detalhadas adiante.

Após a análise, cada categoria foi dividida em subitens definidos a posteriori, elaborados a partir das características encontradas na análise documental. Para a definição das categorias dos subitens, considerou-se três pontos principais estabelecidos por Selltiz et al. (1967, apud GIL, 2008): o conjunto de categorias deve ser derivado de um único princípio de classificação; o conjunto de categorias deve ser exaustivo; as categorias do conjunto devem ser mutuamente exclusivas.

O primeiro ponto foi estabelecido pelo objetivo de descrição proposto pela categoria inicial de análise. Para o segundo ponto, Gil (2008) afirma que o estabelecimento das categorias deve ser exaustivo na medida que deve permitir a inclusão de todas as características ou respostas observadas, porém de modo que ainda possibilite o agrupamento e a intepretação dos dados. Já no terceiro princípio, as categorias devem ser organizadas de modo a impossibilitar a classificação de um fator em mais de uma categoria do conjunto. Desse modo, com esses três pontos, as subcategorias foram definidas com base em agrupamentos do universo total de características observadas dentro de cada categoria de análise.

As categorias de análise e as subcategorias definidas estão detalhadas a seguir.

- Organização do estudo de alternativas locacionais dentro do EIA

Com essa categoria pretende-se descrever como o estudo de alternativas locacionais está organizado dentro do EIA, considerando a estruturação em capítulos e tópicos dos conteúdos apresentados no documento e tendo em vista a grande variedade encontrada na amostra. É importante destacar, porém, que não há uma exigência em relação a forma de organização e apresentação do estudo locacional, embora a CETESB (2014) recomende tratar o estudo de alternativas (locacionais + tecnológicas + alternativa zero) como item individual do EIA, evitando abordá-lo de forma conjunto com outros itens, como justificativa do empreendimento ou introdução. Para essa categoria foram identificadas as seguintes subcategorias:

- Em capítulo próprio de estudo de alternativas; 
- Em capítulo próprio de estudo de alternativas mais conteúdo adicional em anexo;

- Dentro do capítulo de justificativa do empreendimento;

- Dentro do capítulo identificado como justificativa do empreendimento e análise de alternativas;

- Dentro do capítulo de características/descrição do empreendimento;

- Dentro do capítulo de informações gerais do empreendimento;

- Dentro do capítulo de introdução;

- Conteúdo não identificado.

- Número de alternativas e alternativas de localização de estruturas e layout

Um dos problemas encontrados na literatura relacionado o estudo locacional é a ausência ou número insuficiente de alternativas de localização (BRASIL, 2004; SMITH, 2007; PINHO; MAIA; MONTERROSO, 2007; MOMTAZ; KABIR, 2013; ALMEIDA; MONTAÑO, 2017). Considerando a ocorrência dessa deficiência, essa categoria tem como objetivo retratar o número de alternativas locacionais consideradas nos diferentes EIAs analisados nesse estudo. A partir dos dados obtidos, foram definidas as seguintes subcategorias:

- Até 5 alternativas;

- Entre 6 e 10 alternativas;

- Mais que 10 alternativas;

- Nenhuma alternativa.

Além disso, verificou-se se a análise de alternativas locacionais era referente a localização e variações de estruturas ou layout dentro de um mesmo local, ou seja, se os EIAs assumiram o estudo da localização do empreendimento como um todo ou se avaliaram a localização de estruturas do empreendimento dentro de uma mesma localidade pré-estabelecida.

- Presença de representações visuais

A partir da variedade de representações visuais presentes nos estudos e considerando as diretrizes apresentadas pela CETESB (2014), as quais indicam a necessidade de representações gráficas ou cartográficas do estudo de alternativas com sobreposição, essa categoria pretende descrever como as alternativas são visualmente representadas, focando nos elementos gráficos e cartográficos dos 
estudos de alternativas locacionais. Considerou-se como representação visual nessa análise as representações cartográficas, fotografias, imagens de satélites e plantas técnicas, resultando nas seguintes subcategorias:

- Imagens com sobreposição das alternativas;

- Imagens sem sobreposição das alternativas;

- Imagem apenas do local selecionado;

- Imagem do local selecionado com sobreposição do Zoneamento Agroambiental;

- Nenhuma representação visual.

- Critérios considerados na avaliação de alternativas

Embora existam trabalhos acadêmicos que proponham o uso de determinados critérios para o estudo locacional de acordo com a tipologia do empreendimento (SOUZA, 2000; MEIRELES, 2011; MONTAÑO et al., 2012), não existem diretrizes ambientais específicas sobre quais critérios devem ser considerados na avaliação de alternativas. Apesar disso, a CETESB (2014) afirma que há a necessidade do uso de indicadores comparativos para o estudo de alternativas locacionais e, embora exemplifique alguns critérios (estimativa de vegetação nativa em estágio médio ou avançado a ser suprimida; intervenção em Unidades de Conservação e outras áreas de proteção ambiental, como áreas indígenas e quilombolas, sítios arqueológicos, Reserva Legal e Área de Proteção dos Mananciais; volumes de solo e rocha movimentados; estimativa do número de famílias a serem desapropriadas e/ou reassentadas), não exige que esses ou outros critérios sejam considerados, cabendo a fase de escopo ou ao proponente a determinação desses indicadores. Sendo assim, com essa categoria pretende-se explicitar e descrever os critérios considerados na análise e seleção de alternativas locacionais dos EIAs analisados. $\mathrm{Na}$ identificação dos critérios, foram considerados todos os mencionados direta ou indiretamente na análise e seleção da alternativa locacional. Em seguida, os critérios foram agrupados em subcategorias mais abrangentes de acordo com o conteúdo que analisavam, com o intuito de garantir melhor compreensão acerca dos temas ao qual se referiam, definindo-se as seguintes subcategorias:

○ Posição do vento;

- Cobertura vegetal; 
- Cobertura vegetal considerando diferentes estágios da vegetação;

- Áreas protegidas (UCs, APPs, etc.);

- Declividade e topografia;

- Extensão do empreendimento/estruturas;

- Acessos e proximidade dos sistemas viários;

- Distância dos centros geradores/produtores/destinos;

- Custo de implantação/operação;

- Curso d'água e hidrografia;

- Interferência no tráfego local;

- Proximidade e interferência nos centros urbanos/ocupações;

- Desapropriações;

- Solo e geologia;

- Interferência na paisagem;

- Impactos ambientais (de maneira geral);

- Aspectos construtivos e operacionais;

- Disponibilidade de áreas;

- Zoneamento e legislações restritivas;

- Fauna;

- Apoio dos governos locais;

- Uso e ocupação da área;

- Demandas futuras e vida útil;

- Densidade populacional do local/região;

- Disponibilidade e interferência de infraestruturas;

- Melhor aproveitamento da área;

- Interferência no patrimônio arqueológico;

- Drenagem;

- Conectividade da paisagem;

- Relação e interferência com outros empreendimentos;

- Proximidade com aeroportos;

- Geração de emprego e renda;

- Clima;

- Entorno e vizinhança;

- Potencial hidrelétrico. 
- Ponderação ou classificação de critérios e/ou indicadores

A CETESB (2014) recomenda que a comparação de alternativas incorpore escalas de valoração e ponderação, com o objetivo de tornar a metodologia de comparação clara e que resulte em um processo sistemático de seleção locacional. Dessa forma, essa categoria objetiva descrever a presença e o tipo dos sistemas de classificação ou ponderação dos critérios e/ou indicadores apresentados no estudo de alternativas locacionais, determinados nas seguintes subcategorias:

- Atribuição de pontos;

- Escala de adequabilidade;

- Escala de impacto;

- Atribuição de pontos com escala de importância dos critérios;

- Escala de aptidão e avaliação positiva/negativa;

- Nenhum sistema de classificação ou ponderação.

- Organização da hipótese de não-execução dentro do EIA

Considerando a exigência de apresentação da hipótese de não-execução pela

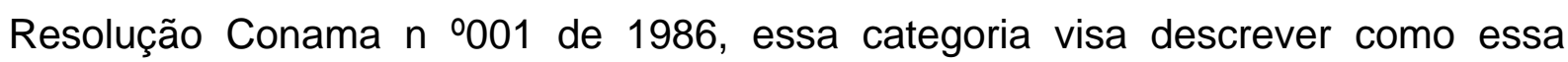
hipótese de não-execução do empreendimento está organizado dentro do EIA, considerando, assim como na primeira categoria, a estruturação em capítulos e tópicos dos conteúdos apresentados no documento, o que se resumiu nas seguintes subcategorias:

- Dentro do capítulo de estudo de alternativas;

- Dentro do capítulo de justificativa do empreendimento;

- Dentro do capítulo identificado como justificativa do empreendimento e; análise de alternativas;

- Dentro do capítulo de descrição do projeto;

- Dentro do capítulo de informações do empreendimento;

- Dentro do capítulo de prognóstico ambiental;

- Dentro do capítulo de impactos ambientais;

- Conteúdo não identificado. 


\subsection{DEFINIÇÃO DA ANÁLISE QUALITATIVA}

Neste estudo, foi elaborada uma lista de verificação própria baseada na legislação federal e estadual, em referências de análise de EIA como um todo e em referências específicas de seleção e análise de alternativas locacionais de diversas tipologias de empreendimento. A estrutura desta lista de verificação foi baseada nas diretrizes de Comissão Europeia (EUROPEAN COMMISSION, 2001) e Lamonica (2016), estando apresentada por meio de perguntas definidas a partir de cada critério a ser avaliado (Quadro 4). As perguntas de análise foram elaboradas tendo em vista um único ponto de análise do EIA, as alternativas de localização.

Quadro 4 - Lista de verificação.

\begin{tabular}{|c|c|c|c|}
\hline Categoria & & Critério & Referência \\
\hline \multirow{3}{*}{$\begin{array}{l}\text { Apresentação } \\
\text { e descrição }\end{array}$} & 1.1 & $\begin{array}{l}\text { Define metodologia para seleção das } \\
\text { alternativas a serem consideradas? }\end{array}$ & Fuggle, 1992 \\
\hline & 1.2 & $\begin{array}{l}\text { Descreve as alternativas de localização de } \\
\text { modo a caracterizar cada uma? }\end{array}$ & $\begin{array}{l}\text { Lee et al., 1999; European } \\
\text { Commission, 2001; } \\
\text { BRASIL, 2004; Caldas, } \\
\text { 2006; CETESB, } 2014\end{array}$ \\
\hline & 1.3 & $\begin{array}{l}\text { Apresenta as alternativas em representação } \\
\text { gráfica e/ou cartográfica? }\end{array}$ & $\begin{array}{c}\text { Caldas, 2006; CETESB, } \\
2014\end{array}$ \\
\hline \multirow{6}{*}{$\begin{array}{l}\text { Critérios } \\
\text { considerados }\end{array}$} & 2.1 & Avalia a distância das infraestruturas? & $\begin{array}{c}\text { Briassoulis, 1995; Souza, } \\
\text { 2000; Montaño et al., } \\
2012 . \\
\end{array}$ \\
\hline & 2.2 & Avalia o uso e ocupação da área? & $\begin{array}{l}\text { Briassoulis, 1995; Souza } \\
\text { 2000; Santos, 2004; } \\
\text { Montaño et al., 2012, } \\
\text { Furlanetto, 2012. }\end{array}$ \\
\hline & 2.3 & $\begin{array}{l}\text { Analisa diretrizes de uso e ocupação da área } \\
\text { de acordo com os planos locais e regionais? }\end{array}$ & $\begin{array}{l}\text { Desmond, 2009; Montaño } \\
\text { et al., } 2012\end{array}$ \\
\hline & 2.4 & $\begin{array}{l}\text { Considera outros empreendimentos e avalia } \\
\text { de maneira geral os impactos cumulativos e as } \\
\text { sinergias para cada localidade? }\end{array}$ & $\begin{array}{l}\text { European Commission, } \\
\text { 2001; BRASIL, } 2004\end{array}$ \\
\hline & 2.5 & $\begin{array}{l}\text { Determina critérios específicos de acordo com } \\
\text { a tipologia do empreendimento? }\end{array}$ & $\begin{array}{c}\text { Briassoulis, 1995; Souza } \\
\text { 2000; Santos, 2004; } \\
\text { Desmond, 2009; Montaño } \\
\text { et al., 2012; Furlanetto, } \\
\text { 2012. } \\
\end{array}$ \\
\hline & 2.6 & $\begin{array}{l}\text { Explicita e justifica os critérios de análise } \\
\text { considerados? }\end{array}$ & $\begin{array}{l}\text { CETESB, 2014; Sánchez, } \\
\text { 2013; IAIA, 2015. }\end{array}$ \\
\hline \multirow{2}{*}{$\begin{array}{l}\text { Comparação } \\
\text { e análise }\end{array}$} & 3.1 & $\begin{array}{l}\text { Apresenta critérios comparáveis entre as } \\
\text { alternativas? }\end{array}$ & $\begin{array}{c}\text { European Commission, } \\
\text { 2001; BRASIL, 2004; } \\
\text { CETESB, 2014; Machado, } \\
\text { 2015; IAIA, 2015. }\end{array}$ \\
\hline & 3.2 & $\begin{array}{l}\text { Compara os indicadores dos critérios entre as } \\
\text { alternativas explicitando e descrevendo a } \\
\text { metodologia de comparação? }\end{array}$ & $\begin{array}{l}\text { Sánchez, 2013; CETESB, } \\
2014\end{array}$ \\
\hline
\end{tabular}




\begin{tabular}{|c|c|c|c|}
\hline \multirow{4}{*}{$\begin{array}{l}\text { Comparação } \\
\text { e análise }\end{array}$} & 3.3 & $\begin{array}{l}\text { Apresenta e justifica a ponderação relativa à } \\
\text { importância de cada critério considerado? }\end{array}$ & $\begin{array}{l}\text { Souza, 2000; Sánchez, } \\
\text { 2013; CETESB, } 2014\end{array}$ \\
\hline & 3.4 & $\begin{array}{l}\text { Apresenta uma justificativa de escolha da } \\
\text { alternativa priorizada baseada na análise } \\
\text { comparativa dos critérios? }\end{array}$ & $\begin{array}{c}\text { Brasil, 1986; Lee et al., } \\
\text { 1999; Steinemann, 2001; } \\
\text { European Commission, } \\
\text { 2001; Brasil, 2004; } \\
\text { Caldas, 2006; Pinho, Maia } \\
\text { e Monterroso, 2007; } \\
\text { CETESB, 2014, Sánchez, } \\
2013 \\
\end{array}$ \\
\hline & 3.5 & $\begin{array}{l}\text { Justifica as escolhas de escalas temporais de } \\
\text { acordo com a tipologia e localidade? }\end{array}$ & Souza, 2000 \\
\hline & 3.6 & $\begin{array}{l}\text { Justifica as escolhas de escalas espaciais de } \\
\text { acordo com a tipologia e localidade? }\end{array}$ & Souza, 2000; João, 2002 \\
\hline \multirow{6}{*}{ Consistência } & 4.1 & $\begin{array}{l}\text { Reconhece e explicita as limitações dos } \\
\text { métodos e justificativas? }\end{array}$ & $\begin{array}{l}\text { Lee et al., 1999; Glasson, } \\
\text { Therivel e Chadwick, } 2005\end{array}$ \\
\hline & 4.2 & $\begin{array}{l}\text { Identifica as fontes de dados sobre as } \\
\text { informações relevantes de cada alternativa? }\end{array}$ & $\begin{array}{l}\text { Souza, 2000; European } \\
\text { Commission, 2001; } \\
\text { Sánchez, 2013; CETESB, } \\
\text { 2014; IAIA, } 2015 \\
\end{array}$ \\
\hline & 4.3 & $\begin{array}{l}\text { Identifica e descreve os profissionais } \\
\text { responsáveis pelos estudos e dados } \\
\text { apresentados na análise locacional? }\end{array}$ & $\begin{array}{l}\text { Brasil, } 1997 \text {; Sánchez, } \\
\text { 2013; CETESB, } 2014\end{array}$ \\
\hline & 4.4 & $\begin{array}{l}\text { Os estudos de alternativa locacional estão em } \\
\text { conformidade com o requisitado no TR? }\end{array}$ & $\begin{array}{c}\text { São Paulo, 2014; } \\
\text { Sánchez, 2013; CETESB, } \\
2014\end{array}$ \\
\hline & 4.5 & $\begin{array}{l}\text { Apresenta RIMA compatível com as principais } \\
\text { informações sobre a análise de alternativas } \\
\text { locacionais bem como justificativa clara sobre } \\
\text { a escolha? }\end{array}$ & $\begin{array}{l}\text { Sánchez, 2013; CETESB, } \\
2014\end{array}$ \\
\hline & 4.6 & Considera o cenário de não execução? & $\begin{array}{c}\text { Brasil, 1986; European } \\
\text { Commission, 2001; Pinho, } \\
\text { Maia e Monterroso, 2007; } \\
\text { IAIA, 2015 } \\
\end{array}$ \\
\hline \multirow{3}{*}{$\begin{array}{l}\text { Análise do } \\
\text { TR }\end{array}$} & 5.1 & $\begin{array}{l}\text { O TR apresenta diretrizes específicas para a } \\
\text { seleção de alternativas a serem estudadas? }\end{array}$ & $\begin{array}{l}\text { Glasson; Therivel; } \\
\text { Chadwick, 2005; Sánchez, } \\
\text { 2013, IAIA, } 2018\end{array}$ \\
\hline & 5.2 & $\begin{array}{l}\text { O TR indica a necessidade de descrição, } \\
\text { comparação e justificativa de escolha com } \\
\text { base na comparação de alternativas? }\end{array}$ & $\begin{array}{l}\text { Agra-Filho et al., 2012; } \\
\text { Sánchez, 2013; CETESB, } \\
\text { 2014, Fernandes et al., } \\
\text { 2017; IAIA, } 2018\end{array}$ \\
\hline & 5.3 & $\begin{array}{l}\text { O TR especifica detalhes técnicos sobre a } \\
\text { profundidade e nível de detalhamento } \\
\text { esperado no estudo de alternativas? }\end{array}$ & $\begin{array}{l}\text { Agra-Filho et al., 2012; } \\
\text { Sánchez, 2013; CETESB, } \\
\text { 2014, Fernandes et al., } \\
\text { 2017; IAIA, } 2018\end{array}$ \\
\hline
\end{tabular}

Fonte: Natalia Almeida Santos Mattos, 2018.

Para a avaliação acerca da qualidade do conteúdo do documento relacionado a cada pergunta, optou-se pelo sistema de atribuição de conceitos múltiplos, o qual, 
segundo Sánchez (2013), permite uma avaliação mais completa, uma vez que amplia a análise além do "sim" ou "não", possibilitando a identificação de parcialidades.

O sistema de conceitos utilizados foi adaptado do modelo elaborado por Lee e Colley (1992) e do adotado pela Comissão Europeia (European Commission, 2001) (Quadro 5). A adaptação desse sistema deve-se ao fato de apresentar conceitos suficientes a uma análise mais completa, porém sem apresentar uma escala muito extensa, o que, considerando a especificidade do objeto analisado e a menor extensão da informação usualmente apresentada para esse objeto, dificultaria uma atribuição conceitual precisa com escalas mais extensas. Sendo assim, optou-se pela adaptação e redução do número de categorias consideradas, assumindo-se 4 categoriais de conceito.

Como forma de definir um processo sistemático de análise e classificação dos conceitos, para cada questão foram elaborados indicadores de classificação à atribuição dos respectivos conceitos de $A$ a $D$ (Apêndice $B$ ).

Para análise de cada documento de EIA e seu respectivo RIMA e TR, utilizouse uma ficha de análise (Apêndice C), adaptada de Lamonica (2016), de forma a sistematizar a coleta de dados para posterior organização e análise.

Quadro 5 - Identificação e explicação dos conceitos de análise.

\begin{tabular}{|c|l|}
\hline Conceito & \multicolumn{1}{c|}{ Explicação } \\
\hline A & $\begin{array}{l}\text { Fornecimento completo de informações sem lacunas nem pontos } \\
\text { fracos. }\end{array}$ \\
\hline B & $\begin{array}{l}\text { Fornecimento adequado de informações, com lacunas ou deficiências } \\
\text { na informação que não são vitais para o processo de decisão. }\end{array}$ \\
\hline C & $\begin{array}{l}\text { Fraco fornecimento de informações com lacunas e fraquezas que } \\
\text { dificultam o processo de decisão e requerem complementações }\end{array}$ \\
\hline D & $\begin{array}{l}\text { Fornecimento de informações inadequado ou inexistente com grandes } \\
\text { lacunas ou pontos fracos que impediriam o processo de decisão e } \\
\text { exigiriam grande reestruturação. }\end{array}$ \\
\hline
\end{tabular}

Elaborado com base em: Lee e Colley (1992) e European Commission (2001). 


\section{RESULTADOS E DISCUSSÃO}

Neste capítulo serão apresentados os resultados obtidos nas análises descritivas e qualitativas e as discussões pertinentes.

\subsection{ANÁLISE DESCRITIVA}

A grande variedade de formas e características dos estudos de alternativas locacionais apresentados dentro dos EIAs torna a análise descritiva uma estratégia interessante para a obtenção de um cenário dessas variedades que permite, ainda, a correlação com os dados qualitativos, possibilitando, assim, uma maior compreensão tanto relacionada com a qualidade do conteúdo abordado, como com a forma com que este é trabalhado.

Os dados descritivos coletados neste estudo foram organizados de acordo com as categorias de análise a seguir, os dados brutos tabulados estão disponíveis no Apêndice D.

\subsubsection{Organização do conteúdo}

Em relação a organização do conteúdo referente ao estudo de alternativas locacionais nos EIAs, duas formas de organização foram predominantemente observadas; aproximadamente $46 \%$ dos estudos apresentaram esse conteúdo em um capítulo próprio de estudo de alternativas (normalmente contendo também o estudo de alternativas tecnológicas). Desses $46 \%$ houve ainda um caso em que, além do capítulo próprio, o EIA apresentava também um estudo mais detalhado das alternativas locacionais em anexo. Já 33\% dos estudos apresentaram o conteúdo equivalente dentro do capítulo de justificativa do empreendimento. Outras formas ainda foram identificadas, $8 \%$ dos estudos apresentaram no capítulo voltado às informações gerais, $4 \%$ no capítulo referente às características do empreendimento, $4 \%$ em um capítulo com título referente à justificativa e análise de alternativas no mesmo capítulo, $2 \%$ no capítulo denominado de introdução e, em $4 \%$ dos EIAs nenhum tipo de menção ao estudo ou processo de escolha locacional foi identificado em todo o texto. Ressalta-se que por estudo de alternativas locacionais entende-se o conteúdo referente ao processo de escolha locacional, de modo que nem todos os EIAs que apresentaram esse conteúdo em algum momento do EIA, continham, de fato, a análise de diferentes alternativas locacionais, como será discutido adiante. 


\subsubsection{Número de alternativas e alternativas locacionais de estruturas e layout}

Quando se analisa o número de alternativas apresentadas pelos estudos, verifica-se que cerca de $46 \%$ dos EIAs não apresentaram nenhuma alternativa locacional, enquanto aproximadamente $37 \%$ dos EIAs continham até 5 alternativas locacionais, em torno de $10 \%$ apresentavam entre 6 e 10 alternativas e $8 \%$ continham mais de 10 alternativas locacionais. A grande proporção de EIAs que não apresentaram alternativas reforça a deficiência apontada em diversos trabalhos (BRASIL, 2004; SMITH, 2007; PINHO; MAIA; MONTERROSO, 2007; MOMTAZ; KABIR, 2013; ALMEIDA; MONTAÑO, 2017) sobre a ausência ou número insuficiente de alternativas.

Ao focar esses resultados por setor, de acordo com as diferentes tipologias de empreendimento, entre os setores com pelo menos mais de um EIA analisado, apenas nos setores de tratamento de resíduos e de portos e terminais todos os EIAs continham alternativas locacionais (Tabela 3), sendo também no setor de tratamento de resíduos as maiores proporções de EIAs com mais de 5 alternativas locacionais consideradas.

Tabela 3 - Número de alternativas por setor de empreendimento.

\begin{tabular}{|c|c|c|c|c|}
\hline \multirow{2}{*}{ Setores } & \multicolumn{4}{|c|}{ Porcentagem de EIAs (número de EIAs) por setor } \\
\cline { 2 - 5 } & $\begin{array}{c}\text { Nenhuma } \\
\text { alternativa }\end{array}$ & Até 5 alternativas & $\begin{array}{c}\text { Entre 6 e 10 } \\
\text { alternativas }\end{array}$ & $\begin{array}{c}\text { Mais que 10 } \\
\text { alternativas }\end{array}$ \\
\hline Aeroportos (A) & $50 \%(1)$ & $0 \%$ & $0 \%$ & $50 \%(1)$ \\
\hline Agroindústria (AI) & $100 \%(14)$ & $0 \%$ & $0 \%$ & $0 \%$ \\
\hline Indústria (I) & $50 \%(1)$ & $50 \%(1)$ & $0 \%$ & $0 \%$ \\
\hline Dutos (D) & $0 \%$ & $100 \%(1)$ & $0 \%$ & $0 \%$ \\
\hline Energia (E) & $0 \%$ & $100 \%(1)$ & $0 \%$ & $0 \%$ \\
\hline Obra hidráulica (H) & $0 \%$ & $100 \%(1)$ & $0 \%$ & $0 \%$ \\
\hline $\begin{array}{c}\text { Linhas de } \\
\text { transmissão (LT) }\end{array}$ & $0 \%$ & $100 \%(1)$ & $0 \%$ & $0 \%$ \\
\hline Mineração (M) & $33 \%(2)$ & $17 \%(1)$ & $33 \%(2)$ & $25 \%(2)$ \\
\hline $\begin{array}{c}\text { Portos e terminais } \\
\text { (P) }\end{array}$ & $0 \%$ & $100 \%(2)$ & $0 \%$ & $0 \%$ \\
\hline $\begin{array}{c}\text { Tratamento de } \\
\text { resíduos (R) }\end{array}$ & $0 \%$ & $25 \%(2)$ & $50 \%(4)$ & $0 \%$ \\
\hline $\begin{array}{c}\text { Transportes lineares } \\
\text { (TL) }\end{array}$ & $25 \%(1)$ & $75 \%(3)$ & $0 \%$ & $0 \%$ \\
\hline Urbanização (U) & $50 \%(5)$ & $50 \%(5)$ & & $0 \%$ \\
\hline
\end{tabular}

Fonte: Natalia Almeida Santos Mattos, 2018. 
Já comparando os empreendimentos novos com as ampliações, cerca de 70\% das ampliações não apresentaram alternativas locacionais. Cerca de $20 \%$ dos estudos apresentaram alternativas de localização apenas referente a estruturas e layout, enquanto somente $10 \%$ dos estudos consideraram alternativas de localização do empreendimento como todo.

Entre EIAs de novos empreendimentos, a situação é praticamente oposta, aproximadamente $69 \%$ dos EIAs apresentam ao menos duas alternativas e cerca de $31 \%$ não apresentaram nenhuma alternativa. Dentre os que continham alternativas locacionais, nove EIAs tratavam da localização de estruturas e/ou layout, o que corresponde a aproximadamente $28 \%$ dos empreendimentos novos.

Essa significativa discrepância descritiva entre o número de alternativas em EIAs de empreendimentos novos e de ampliações parece ser um indicativo de que o estudo de alternativas de localização em casos de ampliação não é frequente na prática atual, de maneira que, mesmo nas poucas vezes em que é considerado, ele se resume na análise da localização de estruturas do empreendimento dentro de uma área pré-definida, geralmente correspondente a do empreendimento já operante.

Essa prática, no entanto, não se resume às ampliações, como visto anteriormente, cerca de $28 \%$ dos empreendimentos novos também apresentaram o estudo de alternativas de localização restrito a análise locacional de estruturas ou variações de layout dentro de uma área já previamente delimitada.

É relevante ressaltar, porém, que todos os estudos de mineração que apresentaram alternativas relacionadas às estruturas, cerca de $33 \%$ dos EIAs com alternativas locacionais, justificaram a ausência de discussão de alternativas do empreendimento como um todo pautados na rigidez locacional associada a presença de jazidas, apresentando no estudo de alternativas os respectivos processos referentes a essas jazidas junto ao Departamento Nacional de Produção Mineral (DNPM).

\subsubsection{Representações visuais}

Sobre as representações visuais, aproximadamente $35 \%$ dos EIAs não apresentaram qualquer representação visual dentro do estudo de alternativas. Importante reforçar nesse momento que esta análise descritiva considerou apenas as 
representações visuais inseridas na discussão de alternativas locacionais, já que todos os ElAs continham imagens em outras seções do estudo.

Cerca de $31 \%$ dos EIAs apresentaram imagens com sobreposição das alternativas analisadas, enquanto $17 \%$ continham representações individuais, aproximadamente $8 \%$ apresentaram apenas a representação do local selecionado, enquanto cerca de $10 \%$ continham a imagem do local selecionado associada a sobreposição cartográfica do Zoneamento Agroambiental, sendo esta última exclusivamente presente em estudos do setor agroindustrial sucroenergético, tratando-se do Zoneamento Agroambiental para o setor sucroalcooleiro no Estado de São Paulo.

Esse instrumento, Zoneamento Agroambiental, foi estabelecido por meio da Resolução Conjunta SMA-SAA N.4 de dezembro de 2008, com o principal objetivo de disciplinar e organizar a expansão, a ocupação e o uso do solo pelo setor sucroenergético, além fornecer elementos para a elaboração de políticas públicas voltadas para as questões relacionadas a esse setor. Ele consiste basicamente na definição de um mapa único elaborado com base em dados sobre condições climáticas, qualidade do ar, relevo, solo, disponibilidade e qualidade de águas superficiais e subterrâneas, unidades de conservação, áreas de proteção ambiental e fragmentos florestais para incremento da conectividade, cujo objetivo é indicar áreas adequadas e inadequadas para o cultivo de cana-de-açúcar, regulando, assim, a ocupação das terras e a instalação e a ampliação de unidades agroindustriais (SÃO PAULO, 2008). Com a definição desse instrumento, definiu-se também sua inserção no processo de licenciamento ambiental de empreendimentos desse setor no estado de São Paulo por meio da Resolução SMA № 088 de dezembro de 2008, a qual determina conjuntos de procedimentos e normas a serem realizados e seguidos de acordo com a localização do empreendimento dentro da respectiva área do zoneamento.

\subsubsection{Critérios considerados e sistemas de ponderação e classificação}

Entre os EIAs analisados, cerca de $71 \%$ apresentaram algum critério de análise e seleção no estudo locacional, sendo que aproximadamente $38 \%$ continham até 5 critérios, $25 \%$ entre 6 e 10 critérios e cerca de $8 \%$ dos estudos continham mais que 
10 critérios. Os outros 29\% dos EIAs não apresentaram nenhum critério, direta ou indiretamente descritos no estudo da análise locacional.

No total foram identificados 35 grupos de critérios. O critério mais presente nos EIAs foi Cobertura vegetal, com 17 EIAs o utilizando, considerando dentro desse número aqueles que ainda distinguiram diferentes estágios da vegetação. Em seguida o critério mais presente foi Zoneamento e legislações restritivas, seguido de Acessos e proximidade dos sistemas viários e Proximidade e interferência nos centros urbanos/ocupações (Tabela 4). Ao analisarmos a presença dos critérios por setor, nota-se que os empreendimentos relacionados ao setor de tratamento de resíduos foram os que apresentaram maior variedade de critérios considerados no estudo de alternativas, seguido dos setores de urbanismo e de mineração (Tabela 5).

Tabela 4 - Critérios considerados na análise e na seleção de alternativas.

\begin{tabular}{|c|c|c|c|c|c|c|c|c|c|c|c|c|c|}
\hline \multirow{2}{*}{$\begin{array}{c}\text { Grupos de critérios considerados na análise e } \\
\text { seleção de alternativas }\end{array}$} & \multirow{2}{*}{$\begin{array}{l}\text { № } \\
\text { EIAs }\end{array}$} & \multicolumn{12}{|c|}{ № de ElAs por setor } \\
\hline & & A & $\mathbf{P}$ & D & TL & $\mathbf{E}$ & LT & $\mathbf{U}$ & $\mathbf{M}$ & H & $\mathbf{R}$ & I & Al \\
\hline Posição do vento & 2 & 1 & 0 & 0 & 0 & 0 & 0 & 0 & 0 & 0 & 1 & 0 & 0 \\
\hline Cobertura vegetal & 15 & 0 & 0 & 0 & 2 & 0 & 1 & 4 & 2 & 1 & 5 & 0 & 0 \\
\hline $\begin{array}{l}\text { Cobertura vegetal com diferentes estágios da } \\
\text { vegetação }\end{array}$ & 2 & 0 & 0 & 0 & 0 & 0 & 0 & 1 & 1 & 0 & 0 & 0 & 0 \\
\hline Áreas protegidas (UCs,APPs, etc.) & 9 & 1 & 1 & 0 & 2 & 0 & 1 & 1 & 1 & 1 & 1 & 0 & 0 \\
\hline Declividade e topografia & 9 & 0 & 0 & 1 & 1 & 0 & 0 & 2 & 0 & 0 & 4 & 0 & 1 \\
\hline Extensão do empreendimento/estruturas & 9 & 0 & 1 & 1 & 0 & 0 & 0 & 1 & 1 & 1 & 3 & 0 & 1 \\
\hline Acessos e proximidade dos sistemas viários & 13 & 0 & 0 & 0 & 0 & 0 & 1 & 3 & 1 & 0 & 6 & 0 & 2 \\
\hline $\begin{array}{l}\text { Distância dos centros } \\
\text { geradores/produtores/destinos }\end{array}$ & 11 & 1 & 0 & 0 & 0 & 0 & 0 & 1 & 4 & 0 & 5 & 0 & 0 \\
\hline Custo de implantação/operação & 7 & 0 & 1 & 0 & 0 & 1 & 0 & 1 & 0 & 1 & 3 & 0 & 0 \\
\hline Curso d'água e hidrografia & 12 & 1 & 0 & 0 & 3 & 0 & 1 & 0 & 1 & 1 & 5 & & 0 \\
\hline Interferência no tráfego local & 4 & 0 & 1 & 0 & 0 & 0 & 0 & 0 & 1 & 0 & 2 & 0 & 0 \\
\hline $\begin{array}{l}\text { Proximidade e interferência nos centros } \\
\text { urbanos/ocupações }\end{array}$ & 13 & 1 & 1 & 1 & 3 & 0 & 1 & 0 & 2 & 1 & 3 & 0 & 0 \\
\hline Desapropriações & 2 & 0 & 0 & 0 & 1 & 0 & 0 & 0 & 0 & 0 & 1 & 0 & 0 \\
\hline Solo e geologia & 5 & 0 & 0 & 0 & 0 & 0 & 0 & 0 & 0 & 0 & 4 & 0 & 1 \\
\hline Interferência na paisagem & 4 & 0 & 1 & 0 & 0 & 0 & 0 & 1 & 0 & 0 & 2 & 0 & 0 \\
\hline Impactos ambientais (de maneira geral) & 6 & 0 & 1 & 0 & 0 & 1 & 0 & 2 & 1 & 0 & 1 & 0 & 0 \\
\hline Aspectos construtivos e operacionais & 7 & 0 & 1 & 0 & 1 & 1 & 1 & 2 & 0 & 0 & 1 & 0 & 0 \\
\hline Disponibilidade de áreas & 5 & 0 & 0 & 0 & 0 & 0 & 0 & 0 & 0 & 0 & 0 & 0 & 5 \\
\hline Zoneamento e legislações restritivas & 14 & 1 & 0 & 0 & 0 & 0 & 0 & 3 & 1 & 0 & 5 & 0 & 4 \\
\hline Fauna & 3 & 0 & 0 & 0 & 0 & 0 & 0 & 0 & 1 & 0 & 2 & 0 & 0 \\
\hline Apoio dos governos locais & 4 & 0 & 0 & 0 & 0 & 0 & 0 & 0 & 0 & 0 & 0 & 0 & 4 \\
\hline Uso e ocupação da área & 8 & 0 & 0 & 1 & 1 & 0 & 0 & 1 & 1 & 0 & 3 & 0 & 1 \\
\hline Demandas futuras e vida útil & 4 & 0 & 1 & 0 & 0 & 0 & 0 & 0 & 1 & 0 & 2 & 0 & 0 \\
\hline Densidade populacional do local/região & 2 & 0 & 0 & 0 & 0 & 0 & 0 & 0 & 0 & 0 & 2 & 0 & 0 \\
\hline
\end{tabular}




\begin{tabular}{|l|c|l|l|l|l|l|l|l|l|l|l|l|l|}
\hline Disponibilidade e interferência de infraestruturas & 10 & 0 & 0 & 1 & 1 & 0 & 0 & 3 & 0 & 0 & 5 & 0 & 0 \\
\hline Melhor aproveitamento da área & 4 & 0 & 1 & 0 & 0 & 0 & 0 & 2 & 1 & 0 & 0 & 0 & 0 \\
\hline Interferência no patrimônio arqueológico & 1 & 0 & 0 & 0 & 0 & 0 & 1 & 0 & 0 & 0 & 0 & 0 & 0 \\
\hline Drenagem & 3 & 0 & 0 & 0 & 0 & 0 & 0 & 1 & 1 & 0 & 1 & 0 & 0 \\
\hline Conectividade da paisagem & 2 & 0 & 0 & 0 & 0 & 0 & 0 & 2 & 0 & 0 & 0 & 0 & 0 \\
\hline $\begin{array}{l}\text { Relação e interferência com outros } \\
\text { empreendimentos }\end{array}$ & 3 & 0 & 0 & 0 & 0 & 0 & 0 & 1 & 0 & 0 & 2 & 0 & 0 \\
\hline Proximidade com aeroportos & 2 & 0 & 0 & 0 & 0 & 0 & 0 & 0 & 0 & 0 & 2 & 0 & 0 \\
\hline Geração de emprego e renda & 2 & 0 & 0 & 0 & 0 & 0 & 0 & 0 & 0 & 0 & 2 & 0 & 1 \\
\hline Clima & 1 & 0 & 0 & 0 & 0 & 0 & 0 & 0 & 0 & 0 & 0 & 0 & 1 \\
\hline Entorno e vizinhança & 2 & 0 & 0 & 0 & 0 & 0 & 0 & 0 & 1 & 0 & 1 & 0 & 0 \\
\hline Potencial hidrelétrico & 1 & 0 & 0 & 0 & 0 & 1 & 0 & 0 & 0 & 0 & 0 & 0 & 0 \\
\hline
\end{tabular}

Fonte: Natalia Almeida Santos Mattos, 2018.

Tabela 5 - Número de critérios diferentes considerados por cada setor.

\begin{tabular}{|c|c|}
\hline Setor & $\begin{array}{c}\text { No de } \\
\text { grupos } \\
\text { de } \\
\text { critérios }\end{array}$ \\
\hline Aeroportos (A) & 6 \\
\hline Portos e terminais (P) & 10 \\
\hline Dutos (D) & 5 \\
\hline Transportes lineares (TL) & 9 \\
\hline Energia (E) & 4 \\
\hline Linhas de transmissão (LT) & 7 \\
\hline Urbanização (U) & 18 \\
\hline Mineração (M) & 17 \\
\hline Obra hidráulica (H) & 6 \\
\hline Tratamento de resíduos (R) & 27 \\
\hline Indústria (I) & 0 \\
\hline Agroindústria (Al) & 10 \\
\hline
\end{tabular}

Fonte: Natalia Almeida Santos Mattos, 2018.

É relevante ressaltar, no entanto, que a presença de critérios de seleção, apesar de indispensável, não garante a análise adequada das alternativas de localização, já que, em muitos casos, apesar da apresentação dos critérios, a comparação entre as alternativas ou a obtenção de dados é falha, comprometendo a clareza sobre o processo de decisão da alternativa selecionada, como será melhor explorado no tópico de Comparação e análise da seção de Análise qualitativa.

Sobre os sistemas de classificação e ponderação, entre os estudos que continham critérios de análise e seleção no estudo de alternativas, apenas $30 \%$ 
apresentaram algum tipo de sistema de classificação ou ponderação; aproximadamente 14\% adotaram um sistema de atribuição de pontos, cerca de $8 \%$ apresentaram escalas de adequabilidade, em torno de $3 \%$ continham atribuição de pontuação associada a escalda de importância de critérios, outros 3\% apresentavam escala de impactos e, por fim, aproximadamente $3 \%$ continham escala de aptidão associada a avaliação positiva e negativa dos indicadores.

Entre os aproximadamente $70 \%$ de EIAs que não apresentaram nenhum sistema de atribuição ou comparação, nenhum estudo justificou essa ausência. De acordo com Sánchez (2013), mesmo a ausência de sistemas de ponderação deve ser devidamente descrita e justificada no estudo para que se tenha uma compreensão adequada do processo de análise e comparação, logo, a grande quantidade de estudos que não a apresentaram é um ponto de atenção, o qual será melhor explorado no tópico de Análise qualitativa mais adiante.

\subsubsection{Hipótese de não-execução}

Assim como na organização do conteúdo sobre o estudo de alternativas locacionais, a hipótese de não-execução do empreendimento também apresentou variações. A organização mais frequente foi dentro do capítulo de estudos de alternativas em cerca de 33\% dos EIAs e, em 25\% dos estudos, no capítulo de justificativa do empreendimento. Em cerca de outros $25 \%$, o estudo sobre a não realização do empreendimento não foi identificado, apesar de sua obrigatoriedade exigida pela legislação. Esse conteúdo foi ainda identificado dentro do capítulo referente a prognóstico ambiental em aproximadamente $6 \%$ dos estudos, dentro do capítulo voltado a informações gerais do empreendimento em torno de $4 \%$ da amostra, outros $4 \%$ em um capítulo com título referente à justificativa e análise de alternativas no mesmo capítulo, dentro do capítulo de impactos ambientais em cerca de $2 \%$ e dentro do conteúdo de descrição do projeto também em aproximadamente $2 \%$ dos estudos. O conteúdo referente a hipótese de não-execução será melhor trabalhado no item 4.6 dentro do tópico Consistência da Análise qualitativa. 


\subsection{ANÁLISE QUALITATIVA}

Após a análise de cada EIA com o preenchimento das fichas de análise, os dados brutos foram tabulados (Apêndice $E$ ) e sistematizados em gráficos que permitem melhor interpretação visual dos resultados obtidos.

Com o intuito de sistematizar o processo de interpretação e discussão dos resultados, inicialmente os dados e as discussões são apresentados de acordo com as categorias da lista de verificação (Quadro 4), dentro das quais cada critério é melhor trabalhado. Os critérios da lista de verificação foram retomados separadamente (Quadro 6, Quadro 7, Quadro 8, Quadro 9, Quadro 10) para facilitar a leitura e interpretação dos resultados.

\subsubsection{Apresentação e descrição}

A categoria de Apresentação e descrição (Quadro 6) apresenta critérios fundamentais que estão diretamente relacionados ao fornecimento de elementos essenciais ao estudo adequado de alternativas locacionais. Apesar disso, nota-se a prevalência dos conceitos $C$ e $D$ (apresentados no quadro 5), principalmente nos critérios 1.1 e 1.2, e um maior equilíbrio na atribuição dos conceitos no critério 1.3 (Figura 2).

Quadro 6 - Categoria Apresentação e descrição da lista de verificação

\begin{tabular}{|c|c|l|c|}
\hline Categoria & \multicolumn{1}{|c|}{ Critério } & Referência \\
\hline & 1.1 & $\begin{array}{l}\text { Define metodologia para seleção das } \\
\text { alternativas a serem consideradas? }\end{array}$ & Fuggle, 1992 \\
\cline { 2 - 4 } $\begin{array}{c}\text { Apresentação e } \\
\text { descrição }\end{array}$ & 1.2 & $\begin{array}{l}\text { Descreve as alternativas de localização de modo al., 1999; } \\
\text { a caracterizar cada uma? }\end{array}$ & $\begin{array}{c}\text { Lee et } \\
\text { EUROPEAN } \\
\text { COMMISSION, 2001; } \\
\text { BRASIL, 2004; Caldas, } \\
\text { 2006; CETESB, 2014 }\end{array}$ \\
\cline { 2 - 4 } & 1.3 & $\begin{array}{l}\text { Apresenta as alternativas em representação } \\
\text { gráfica e/ou cartográfica? }\end{array}$ & $\begin{array}{c}\text { Caldas, 2006; CETESB, } \\
2014\end{array}$ \\
\hline
\end{tabular}

Fonte: Natalia Almeida Santos Mattos, 2018. 
Figura 2 - Conceitos (A-D) atribuídos aos critérios da categoria Apresentação e descrição para todos os EIAs analisados.

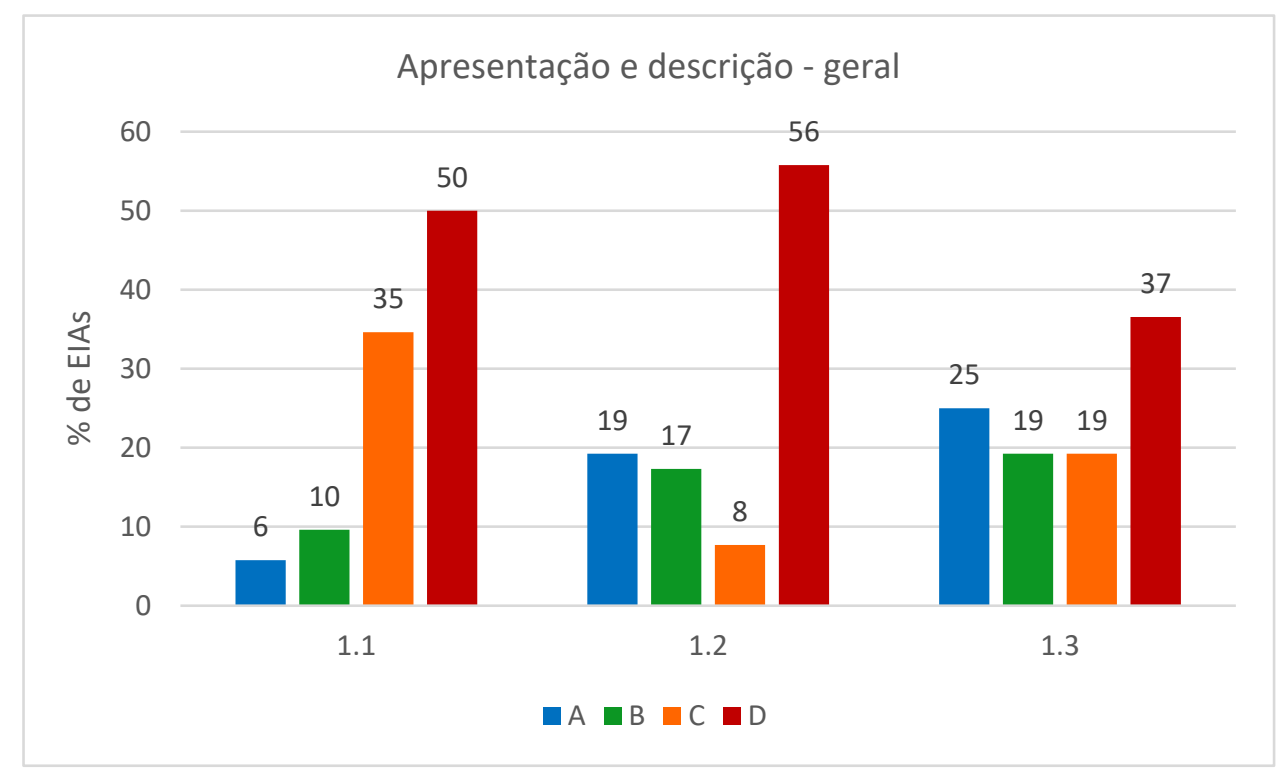

Fonte: Natalia Almeida Santos Mattos, 2018.

Especial atenção deve ser direcionada ao critério 1.1; questões já levantadas por Fuggle (1992) sobre como as alternativas deveriam ser identificadas e qual a faixa razoável de alternativas que deveriam ser consideradas estão, na realidade, diretamente relacionadas à metodologia utilizada para o levantamento de alternativas a serem consideradas para análise. Nesse sentido, a grande atribuição de conceitos insatisfatórios ( $C$ e $D$ ) é preocupante, pois indica uma falha relevante no processo do estudo de alternativas. Uma metodologia clara para o levantamento de alternativas locacionais pertinentes à análise é uma etapa fundamental para evitar um dos principais problemas apontado por diversos estudos anteriores, a apresentação de alternativas impraticáveis, inconsistentes ou reconhecidamente inferiores a selecionada (CLARK E CANTER, 1997; ZUBAIR, 2001 BRASIL, 2004; SMITH, 2007; MACHADO, 2015; FERNANDES et. al., 2017). A falta de clareza no processo de levantamento das alternativas consideradas para estudo leva ainda a outros questionamentos: há outras alternativas possíveis que não foram estudadas? Por que alternativas claramente impraticáveis foram consideradas no estudo?

Mesmo entre os EIAs que apresentaram ao menos duas alternativas locacionais (Figura 3), ou seja, desconsiderando aqueles que não apresentaram nenhuma alternativa, os conceitos do critério 1.1 se concentraram em $C$ e $D$, tornando 
ainda mais pertinente a discussão sobre como as alternativas analisadas nesses estudos foram identificadas e selecionadas para análise.

Figura 3 - Conceitos (A-D) atribuídos aos critérios da categoria Apresentação e descrição para os EIAs que apresentaram alternativas locacionais.

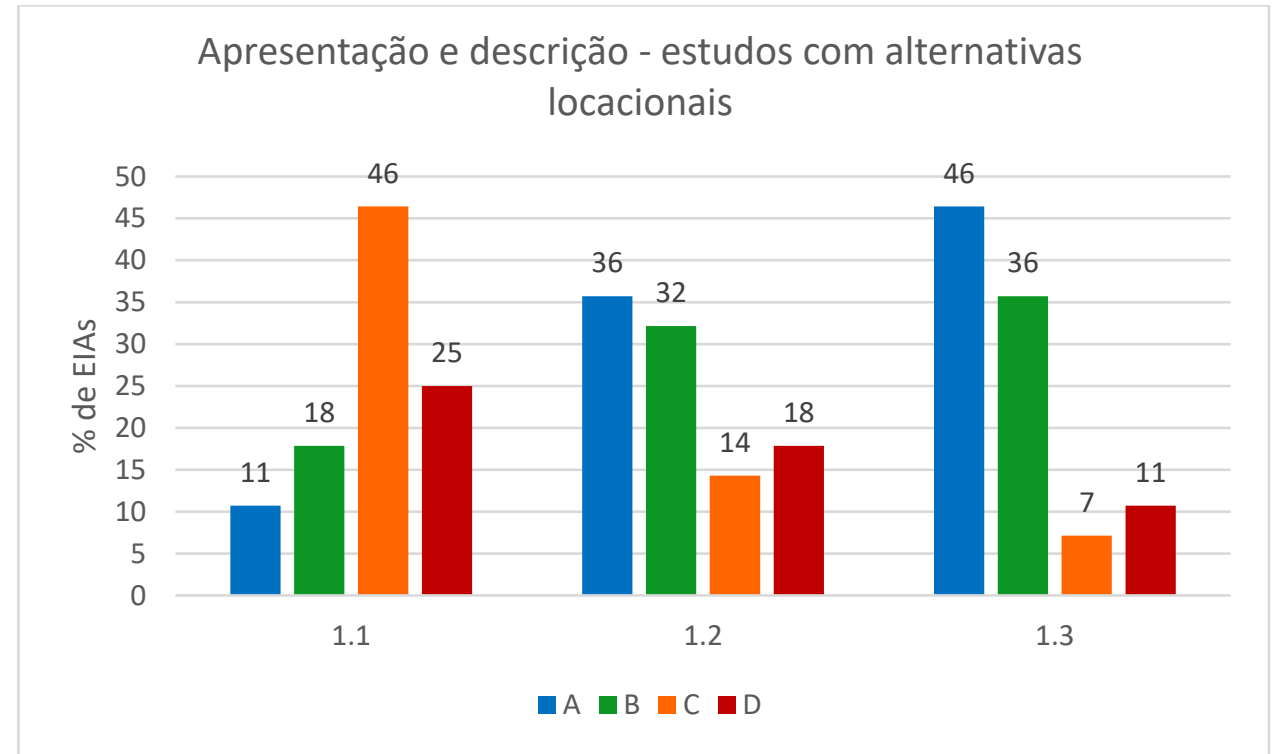

Fonte: Natalia Almeida Santos Mattos, 2018.

Já no item 1.2, que trata sobre a descrição de alternativas, apesar das maiores atribuições de conceitos $A$ e $B$, a quantidade de conceitos $D$ é notável (Figura 2). A razão dessa maioria de conceitos $D$ está relacionada a grande quantidade de EIAs que não continham alternativas locacionais, utilizando o estudo de alternativas como justificativa locacional e, assim, focando apenas na descrição e justificativa do local previamente selecionado. Como apresentado na Figura 3, ao desconsiderar na análise os empreendimentos que não apresentaram nenhuma alternativa, o cenário se inverte, indicando que parte $(68 \%)$ dos estudos que continham a análise de alternativas incluíam também as respectivas descrições de maneira satisfatória (A e B).

O critério 1.3, referente as representações visuais, foi o que apresentou melhor distribuição de conceitos nessa categoria, ainda que certa quantidade de conceitos $D$ esteja presente. Nas diretrizes propostas pelo manual da CETESB (2014), é recomendada a representação gráfica ou cartográfica das variantes, incluindo a sobreposição, o que não se traduziu nos resultados gerais encontrados. Apesar disso, uma análise direcionada para os estudos que apresentaram alternativas locacionais 
(Figura 3) mostra que, entre estes, a grande maioria (82\%) continha representação visual das alternativas com os detalhes necessários para a análise ( $A$ e $B$ ).

Ainda em relação às representações visuais, quando correlacionado com os dados descritivos, identifica-se uma particularidade para o setor agroindustrial. Apesar de este setor ter $100 \%$ dos EIAs sem alternativas locacionais do empreendimento, em 35\% dos estudos, o conteúdo da justificativa locacional foi associado a sobreposição visual do local selecionado com a representação cartográfica do Zoneamento Agroambiental para o setor sucroalcooleiro no Estado de São Paulo, indicando o zoneamento como um instrumento de suporte utilizado na avaliação locacional desse setor.

\subsubsection{Critérios considerados}

Comparando os resultados obtidos para essa categoria (Quadro 7) entre todos os EIAs analisados (Figura 4) e apenas aqueles que apresentaram alternativas locacionais (Figura 5), nota-se que a atribuição de conceitos D cai para os estudos com alternativas. A atribuição de conceitos $C$, porém, se mantém mais elevada para a maioria dos itens em ambos os casos, o que sugere que mesmo os estudos que continham alternativas locacionais, apesar de mencionarem pontos relacionados às questões dessa categoria, a maioria apresentou falhas que impossibilitavam a análise adequada dos critérios utilizados.

Quadro 7 - Categoria Critérios considerados da lista de verificação

\begin{tabular}{|c|c|c|c|}
\hline Categoria & \multicolumn{2}{|r|}{ Critério } & Referência \\
\hline \multirow{6}{*}{$\begin{array}{l}\text { Critérios } \\
\text { considerados }\end{array}$} & 2.1 & Avalia a distância das infraestruturas? & $\begin{array}{l}\text { Briassoulis, 1995; Souza, } \\
\text { 2000; Montaño et al., } 2012 .\end{array}$ \\
\hline & 2.2 & Avalia o uso e ocupação da área? & $\begin{array}{l}\text { Briassoulis, 1995; Souza } \\
\text { 2000; Santos, 2004; } \\
\text { Montaño et al., 2012, } \\
\text { Furlanetto, 2012. }\end{array}$ \\
\hline & 2.3 & $\begin{array}{l}\text { Analisa diretrizes de uso e ocupação da área de } \\
\text { acordo com os planos locais e regionais? }\end{array}$ & $\begin{array}{l}\text { Desmond, 2009; Montaño et } \\
\text { al., } 2012 \\
\end{array}$ \\
\hline & 2.4 & $\begin{array}{l}\text { Considera outros empreendimentos e avalia de } \\
\text { maneira geral os impactos cumulativos e as } \\
\text { sinergias para cada localidade? }\end{array}$ & $\begin{array}{l}\text { EUROPEAN COMMISSION, } \\
\text { 2001; BRASIL, } 2004\end{array}$ \\
\hline & 2.5 & $\begin{array}{l}\text { Determina critérios específicos de acordo com a } \\
\text { tipologia do empreendimento? }\end{array}$ & $\begin{array}{l}\text { Briassoulis, 1995; Souza } \\
\text { 2000; Santos, 2004; } \\
\text { Desmond, 2009; Montaño et } \\
\text { al., 2012; Furlanetto, } 2012 . \\
\end{array}$ \\
\hline & 2.6 & $\begin{array}{l}\text { Explicita e justifica os critérios de análise } \\
\text { considerados? }\end{array}$ & $\begin{array}{l}\text { CETESB, 2014; Sánchez, } \\
\text { 2013; IAIA, } 2015 .\end{array}$ \\
\hline
\end{tabular}

Fonte: Natalia Almeida Santos Mattos, 2018. 
Figura 4 - Conceitos (A-D) atribuídos aos itens da categoria Critérios considerados para todos os EIAs analisados.

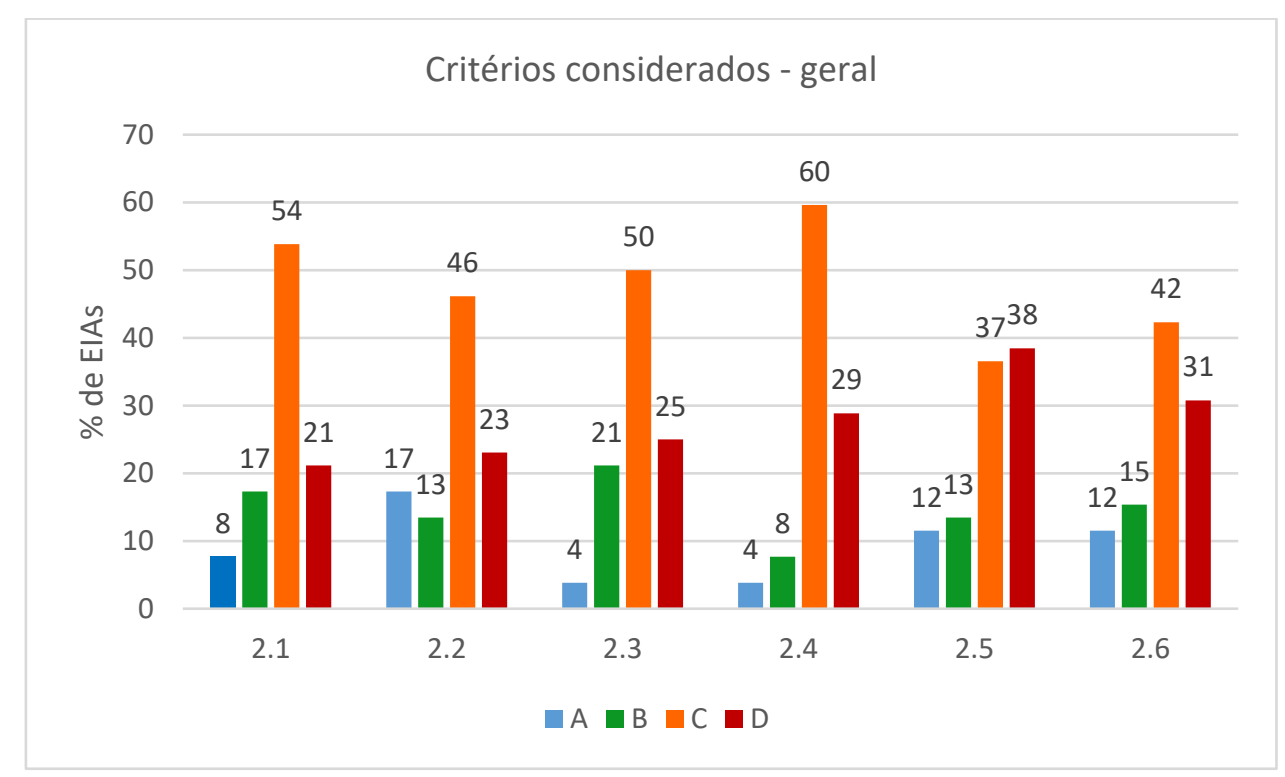

Fonte: Natalia Almeida Santos Mattos, 2018.

Figura 5 - Conceitos (A-D) atribuídos aos itens da categoria Critérios considerados para os EIAs que apresentaram alternativas locacionais.

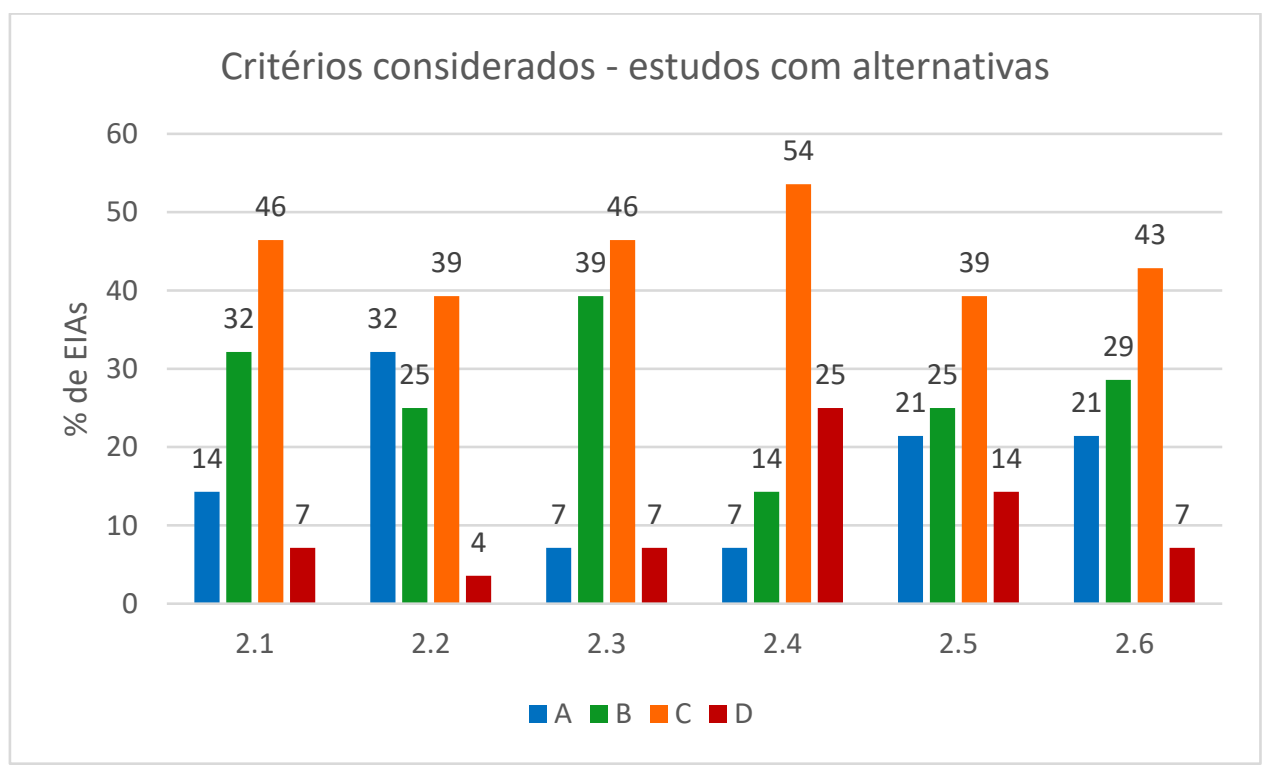

Fonte: Natalia Almeida Santos Mattos, 2018.

O estudo de alternativa locacional deve expor os dados levantados de maneira a justificar técnica, econômica e ambientalmente a alternativa selecionada, comparando-a com as demais alternativas (CETESB, 2014), para isso é necessário que critérios de análise sejam claramente definidos e permeiem esses campos de 
análise, de modo a permitir a obtenção de dados sobre cada alternativa e garantir a possibilidade de comparação. Esses critérios devem ainda ser explícitos, claros e justificados, permitindo a compreensão da análise, comparação e escolha do local (SÁNCHEZ, 2013) e garantindo a transparência do processo (IAIA,2015).

Nos critérios $2.1,2.2$ e 2.5, a maioria dos estudos obteve o conceito $C$, essa atribuição está basicamente relacionada a dois aspectos: ausência de dados - quando os estudos afirmaram considerar tais critérios ou critérios derivados desses para a análise de alternativas, porém não apresentaram os dados equivalentes a essa análise - e análise restrita a alternativa selecionada - caso em que os estudos afirmaram considerar esses critérios, porém restringiram a análise e a apresentação de dados apenas para a alternativa locacional selecionada. Essa situação é retratada na maioria $C$ do critério 2.6, que trata da apresentação de critérios de maneira geral e recai nos mesmos dois pontos apontados anteriormente, a ausência de dados, a restrição da análise para o local selecionado e ainda um terceiro fator, a ausência de justificativa na escolha dos critérios considerados.

Essas três situações - a ausência de dados, a restrição da análise ao local selecionado e a ausência de justificativas sobre os critérios considerados - implicam em uma subjetividade ao processo, que não permite a compreensão adequada da análise e não garante a transparência do processo de escolha, o que irá refletir diretamente nos resultados observados na próxima seção, referente a comparação entre as alternativas e a justificativa de seleção, já que as falhas encontradas nos critérios inviabilizam uma comparação clara e uma justificativa baseada nessa comparação.

Ainda sobre o item 2.5, determinar a aptidão de uma área para implantação de empreendimentos e atividades requer estabelecer como premissa básica o fato de características físicas, biológicas e antrópicas do meio conferirem maior ou menor potencial para a atividade em questão, dependendo de sua tipologia (MONTAÑO et al., 2012). Logo, a falta de aderência entre os critérios de análise e a tipologia representa uma falha importante que prejudica a análise, mesmo que o estudo apresente critérios e dados.

A atribuição de conceitos B no item 2.3 indica que existe uma tendência dos proponentes considerarem planos, programas e políticas na análise locacional, ainda que a maioria de conceitos $\mathrm{C}$ permita inferir que os modos como esses instrumentos 
de planejamento são utilizados nessa análise, nem sempre é adequado ou suficiente. Um ponto interessante que deve ser destacado para o setor agroindustrial é que, apesar da existência do Zoneamento Agroambiental para esse setor, ao considerar a porcentagem da atribuição total de cada conceito para a categoria de critérios como um todo de acordo com o setor (Figura 6), verifica-se que ele não obteve um bom desempenho. Esse resultado está provavelmente atrelado ao fato do setor agroindustrial não ter apresentado alternativas locacionais do empreendimento em todos os seus estudos, o que restringiu a consideração de ferramentas de planejamento apenas para o local selecionado, resultando, assim, em grande atribuição de conceitos $\mathrm{C}$. Apesar do Zoneamento Agroambiental ser uma ferramenta de estudo locacional para uma escala de planejamento, já que determina a aptidão das áreas para essa atividade, o resultado obtido nessa análise evidencia que essa ferramenta parece não ser utilizada na análise de alternativas locacionais do empreendimento em questão, sendo usada apenas como suporte à justificativa da seleção de um local pré-determinado pelo proponente.

Figura 6 - Atribuição total de conceitos (A-D) da categoria Critérios considerados por setor.

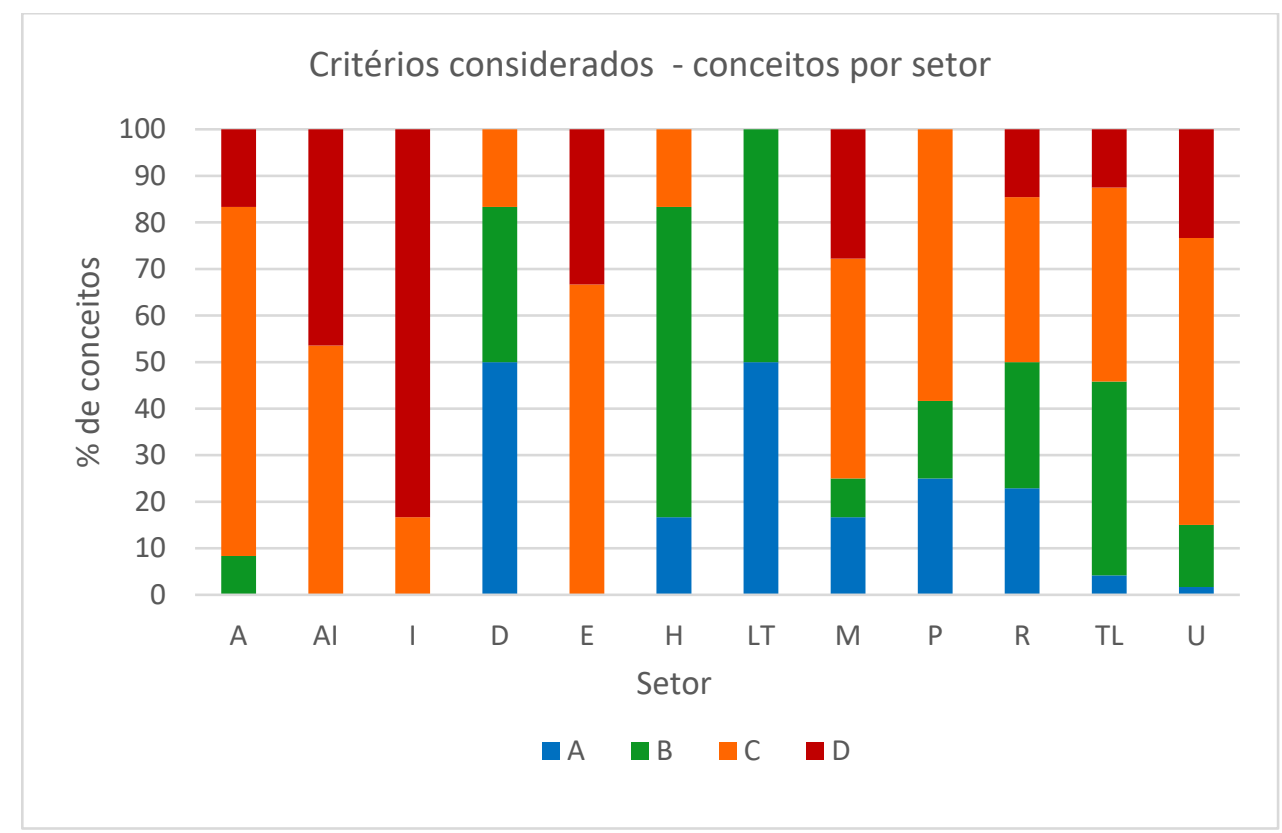

Nota: (A) Aeroportos, (Al) Agroindústria, (I) Indústria, (D) Dutos, (E) Energia, (H) Obra hidráulica, (LT) Linhas de transmissão, (M) Mineração, (P) Portos e Terminais, (R) Tratamento de resíduos, (TL) Transportes lineares, (U) Urbanização.

Fonte: Natalia Almeida Santos Mattos, 2018. 
O item 2.4, sobre a consideração de outros empreendimentos, dialoga com outro ponto frequentemente apontado na literatura, a fraca consideração da cumulatividade e sinergia de impactos ambientais (BRASIL, 2004; JHA-THAKUR; FISCHER, 2016; ALMEIDA; MONTAÑO, 2017). A avaliação de efeitos ambientais deve considerar a cumulatividade e a sinergia dos impactos ambientais, já que a associação de várias intervenções de empreendimentos e atividades distintas em uma mesma região podem agravar ou mesmo gerar novos problemas, que não são identificados nas análises individuais de cada empreendimento (BRASIL, 2004). Sendo assim, analisar a presença de outros empreendimentos no estudo de alternativas torna-se uma etapa fundamental para a escolha do local com maior viabilidade ambiental. A atribuição de conceitos insatisfatórios ( $C$ e D) indica, portanto, que essa fragilidade se estende também ao estudo de alternativas, já que a maioria dos casos analisados apenas menciona outros empreendimentos nas alternativas locacionais, sem considerar ou comparar os efeitos cumulativos e sinérgicos entre os distintos cenários de cada alternativa.

Comparando a descrição dos grupos de critérios encontrados na análise descritiva, retoma-se que o setor que apresentou a maior quantidade de critérios foi o de tratamento de resíduos. Comprando a porcentagem da atribuição total de cada conceito de acordo com o setor (Figura 6), nota-se que esse setor está também entre os que apresentam melhores conceitos ( $\mathrm{A}$ e $\mathrm{B}$ ), ficando apenas atrás dos empreendimentos de dutos, hidrelétricas e linhas de transmissão, setores estes que continham apenas 2 EIAs cada na amostra e, portanto, pouca representativa para análise. Essa aderência entre a variedade e o número de critérios considerados e o melhor desempenho do setor de resíduos na avaliação qualitativa pode ser um indicativo de que a variedade e o número de critérios estão relacionados a uma melhor qualidade desses tópicos no estudo. No entanto, seria necessária uma investigação mais focada no estudo dos critérios e com mesma representativa entre os setores para corroborar tais tendências.

\subsubsection{Comparação e análise}

A análise da categoria Comparação e análise (Quadro 8) apresenta diferenças entre a atribuição de conceitos, principalmente conceitos $D$, para todos os empreendimentos (Figura 7) e para apenas os empreendimentos com alternativas (Figura 8), já que as porcentagens de $D$ na análise geral estão relacionadas a 
quantidade de empreendimentos que não apresentaram alternativas e, portanto, não continham comparação entre opções.

Quadro 8 - Categoria Comparação e análise da lista de verificação.

\begin{tabular}{|c|c|c|c|}
\hline Categoria & & Critério & Referência \\
\hline \multirow{6}{*}{$\begin{array}{l}\text { Comparação e } \\
\text { análise }\end{array}$} & 3.1 & $\begin{array}{l}\text { Apresenta critérios comparáveis entre as } \\
\text { alternativas? }\end{array}$ & $\begin{array}{c}\text { EUROPEAN COMMISSION, } \\
\text { 2001; BRASIL, 2004; } \\
\text { CETESB, 2014; Machado, } \\
\text { 2015; IAIA, } 2015 .\end{array}$ \\
\hline & 3.2 & $\begin{array}{l}\text { Compara os indicadores dos critérios entre as } \\
\text { alternativas explicitando e descrevendo a } \\
\text { metodologia de comparação? }\end{array}$ & $\begin{array}{l}\text { Sánchez, 2013; CETESB, } \\
2014\end{array}$ \\
\hline & 3.3 & $\begin{array}{l}\text { Apresenta e justifica a ponderação relativa à } \\
\text { importância de cada critério considerado? }\end{array}$ & $\begin{array}{l}\text { Souza, 2000; Sánchez, } \\
\text { 2013; CETESB, } 2014\end{array}$ \\
\hline & 3.4 & $\begin{array}{l}\text { Apresenta uma justificativa de escolha da } \\
\text { alternativa priorizada baseada na análise } \\
\text { comparativa dos critérios? }\end{array}$ & $\begin{array}{c}\text { Brasil, 1986; Lee et al., } \\
\text { 1999; Steinemann, 2001; } \\
\text { EUROPEAN COMMISSION, } \\
\text { 2001; BRASIL, 2004; } \\
\text { Caldas, 2006; Pinho, Maia e } \\
\text { Monterroso., 2007; } \\
\text { CETESB, 2014, Sánchez, } \\
2013 \\
\end{array}$ \\
\hline & 3.5 & $\begin{array}{l}\text { Justifica as escolhas de escalas temporais de } \\
\text { acordo com a tipologia e localidade? }\end{array}$ & Souza, 2000 \\
\hline & 3.6 & $\begin{array}{l}\text { Justifica as escolhas de escalas espaciais de } \\
\text { acordo com a tipologia e localidade? }\end{array}$ & Souza, 2000; João, 2002 \\
\hline
\end{tabular}

Fonte: Natalia Almeida Santos Mattos, 2018.

Figura 7 - Conceitos (A-D) atribuídos aos critérios da categoria Comparação e análise em todos os EIAs analisados.

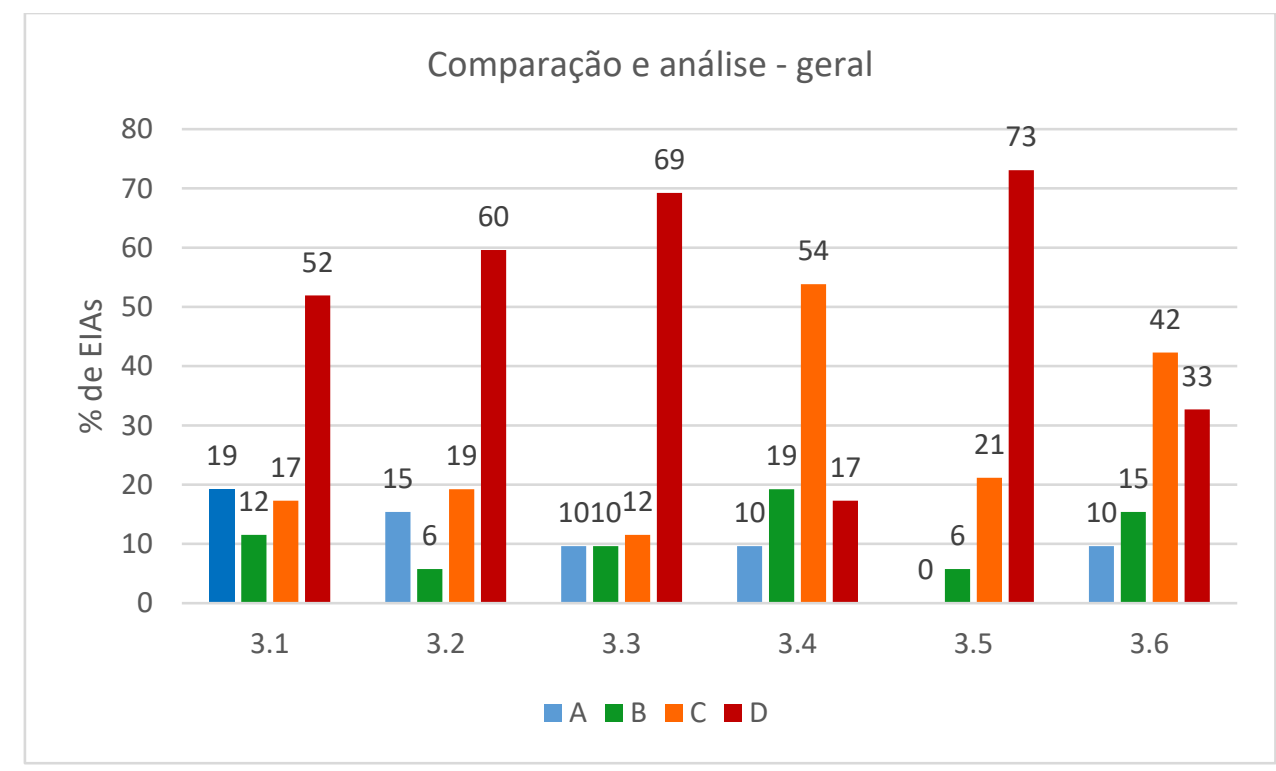

Fonte: Natalia Almeida Santos Mattos, 2018. 
Figura 8 - Conceitos (A-D) atribuídos aos critérios da categoria Comparação e análise para os EIAs que apresentaram alternativas locacionais.

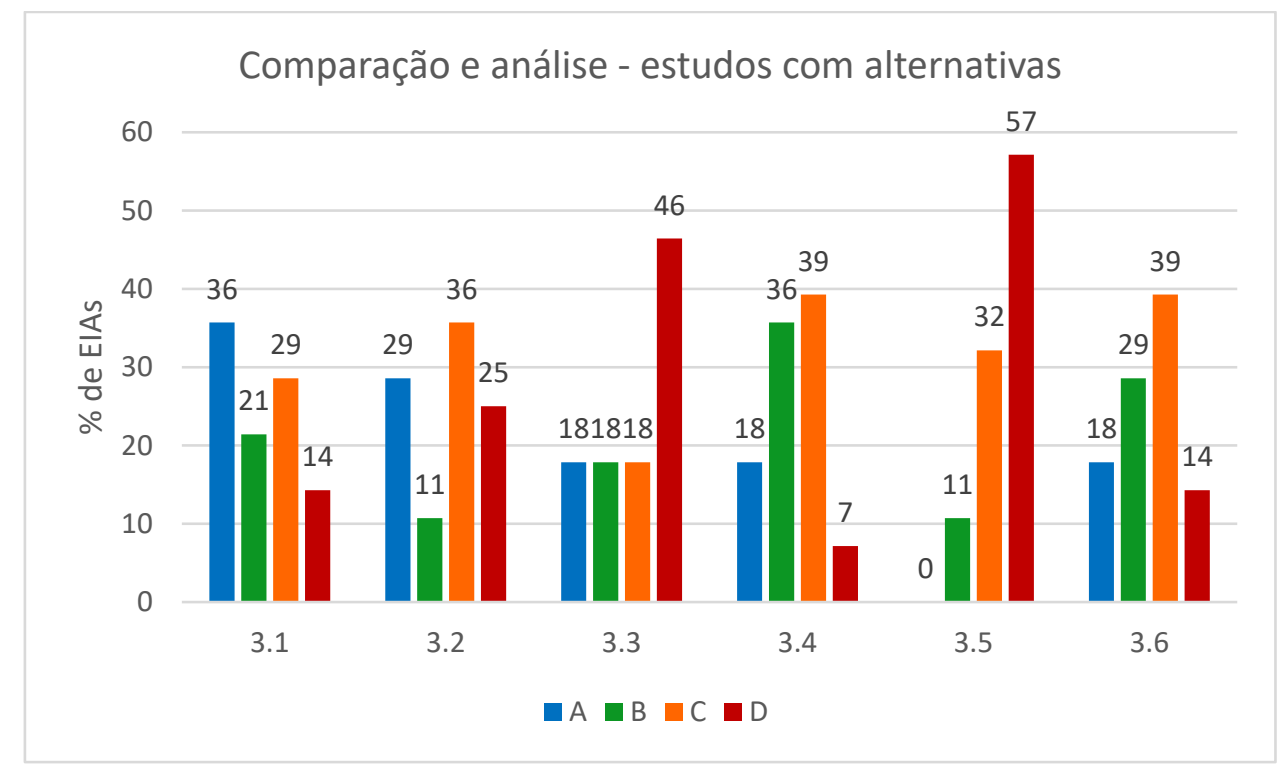

Fonte: Natalia Almeida Santos Mattos, 2018.

Como apontado na seção anterior, uma vez que se verificou falhas no processo de definição e na justificativa de critérios de análise, a comparação entre as alternativas locacionais por meio desses critérios é prejudicada, influenciando assim diretamente no resultado desta categoria, principalmente no item 3.2, que analisa o processo de comparação, e, consequentemente no item 3.4, o qual analisa a justificativa de escolha. A ausência ou comparação incompleta impossibilita uma justificativa de escolha baseada na comparação, resultando uma maior atribuição do conceito C em ambos itens. O estudo do Ministério Público Federal (BRASIL, 2004) verificou também essa relação, ao identificar que a ausência de critérios e caracterização qualitativa e quantitativa das diferentes alternativas não permitia a comparação direta de impactos entre as opções, o que resultava na exclusão de certas alternativas, até mesmo sob a alegação de menor viabilidade ambiental, porém sem clareza no processo utilizado para tal conclusão.

Além disso, a apresentação de critérios de seleção não é suficiente para garantir um estudo adequado das alternativas, somente a comparação desses critérios entre as alternativas permite compreender o processo de seleção realizado. Logo, a quantidade de conceitos $D$ e $C$ no item 3.2, que indicam a ausência de comparação ou uma comparação incompleta e falha respectivamente, pode ser interpretada como um ponto frágil relevante do processo, já que, sem uma 
comparação adequada dos critérios entre as alternativas, o processo de seleção se torna subjetivo e frágil. Tal situação também foi verificada em outros em estudos anteriores, como na análise realizada por Almeida e Montaño (2017), os quais afirmam ainda que a ausência de comparação entre as alternativas indicadas nos estudos que analisaram impossibilitou a compreensão da conclusão acerca da alternativa selecionada.

Isso se relaciona ainda com os resultados observados para o critério 3.4, já que uma vez identificada a ausência de metodologias de análise e de comparação entre as alternativas, as justificativas de escolha da alternativa priorizada tendem a se direcionar a outros aspectos alheios ao estudo de alternativas, como indicado pela quantidade de conceitos $\mathrm{C}$ para esse item, tanto na análise geral, como na análise dos estudos com alternativas. Dessa forma, pode-se afirmar que, em muitos casos, o estudo de alternativas de localização é utilizado com um propósito que se aproxima mais de uma justificativa da realização do empreendimento, do que uma justificativa de escolha locacional baseada na análise de outras opções.

De fato, em estudos anteriores, essa tendência em focar o estudo de alternativas locacionais para justificar a realização do empreendimento em determinado local previamente selecionado já havia sido identificada; Landim e Sánchez (2012), em análise temporal de estudos entre 1987 e 2010, apontam que a apresentação e a comparação de alternativas não se desenvolveram significativamente ao longo dos anos e permanecem assumindo um caráter descritivo, focando apenas na alternativa selecionada e buscando justificar tal escolha.

Ainda que alguns pontos mereçam destaque positivo, como o melhor desempenho do item 3.1 e a atribuição de conceitos $A$ no item 3.2, o que indica que uma porção de EIAs executou pontos considerados fundamentais ao processo de análise de alternativas, essa porção não se traduziu integralmente até o momento da justificativa de seleção do local, no qual a atribuição de conceitos $A$ reduziu. Esse fato pode ser um bom indicativo da fragilidade do processo, já que a comparação entre as alternativas não se expressa integralmente na justificativa de seleção, possibilitando a interpretação de certa subjetividade no processo de escolha do local.

Ressalta-se, então, que a justificativa de seleção da localização está, até certo ponto, presente na maioria dos estudos analisados (84\%), de maneira que muitos apresentam o conteúdo relativo a discussão de alternativas para explicitá-la. 0 
conteúdo da justificava, no entanto, é falho, se considerarmos um dos principais objetivos dos estudos de alternativas, que seria apresentar uma justificativa locacional baseada na comparação clara entre diferentes opções estudadas.

Tanto o item 3.5 quanto o item 3.6, acerca do uso de escalas, recaem sob um aspecto importante apresentado por Souza (2000) como essencial ao estudo de alternativas: a importância de dados e informações com necessário detalhamento e precisão. Apesar de ambos itens apresentarem baixo desempenho com maioria $\mathrm{C}$ e $D$, o item 3.6, relacionado às escalas espaciais, apresentou um melhor resultado quando comparado ao item 3.5, referente às escalas temporais. O uso de escalas espaciais adequadas são de extrema importância, já que o uso de escalas inadequadas pode mascarar ou distorcer características ambientais significativas (SOUZA, 2000), sendo assim, há a necessidade de se explicitar o processo empregado na escolha dessas escalas, tornando possível o entendimento e a relevância desse fator (SÁNCHEZ, 2013).

Já o emprego de escalas temporais do item 3.5, se relaciona ainda com outro item analisado que também obteve um conceito geral baixo: a consideração de outros empreendimentos e os impactos cumulativos. A maioria dos estudos, mesmo entre aqueles que apresentaram alternativas, desconsiderou o aspecto temporal na análise de alternativas locacionais, não avaliando a cumulatividade dos impactos no tempo entre as alternativas e não analisando cenários minimamente previsíveis para cada local. Essa fragilidade, contudo, não se restringe ao estudo de alternativas, sendo também identificada como uma deficiência do EIA como um todo (BRASIL, 2004).

Já no item 3.3, sobre ponderação e classificação, identificou-se que os estudos que apresentaram algum tipo de sistema de ponderação e classificação dos indicadores tiverem um melhor conceito no item 3.4, que é relacionado a justificativa da escolha com base na comparação das alternativas: entre os estudos com sistemas de ponderação e classificação, 50\% obtiveram o conceito A no item de justificativa, $40 \%$ conceito $B, 10 \%$ conceito $C$, sendo que nenhum estudo apresentou conceito $D$, já entre os estudos sem o emprego desse tipo de sistema, nenhum apresentou conceito A para o critério $3.4,14 \%$ obtiverem conceito $\mathrm{B}, 64 \%$ conceito $\mathrm{C}$ e, por fim, $21 \%$ conceito D. Esse resultado pode ser interpretado como um indicativo de que a definição de uma metodologia mais detalhada de comparação por meio da atribuição de classificações e ponderações possibilita um processo mais claro de comparação 
que resulta em uma conclusão final, a qual é então utilizada na justificativa de seleção. Sendo assim, o uso de tais recursos parece permitir uma melhor aderência entre o processo de comparação e a justificativa de seleção, diminuindo a subjetividade da escolha.

De maneira geral, os resultados encontrados na análise dessa categoria reforçam duas deficiências identificadas na literatura: a análise e a comparação ausentes ou incompleta das alternativas (LEE; COLLEY, 1992; LEE et al. 1999; CLARK; CANTER, 1997; GRAY; EDWARDS-JONES, 2003; BRASIL, 2004; SMITH, 2007; MEIRELES, 2011; ALMEIDA et al., 2012; PINHO; MAIA; MONTERROSO, 2007; MOMTAZ; KABIR, 2013; HAPUARACHCHI; HUGHEY; RENNIE, 2016; ALMEIDA; MONTAÑO, 2017) e a ausência ou fraca justificativa de escolha do local considerado o mais adequado (BRASIL, 2004; GRAY; EDWARDS-JONES, 2003; PINHO; MAIA; MONTERROSO, 2007; ALMEIDA; MONTAÑO, 2017; FERNANDES et al., 2017).

\subsubsection{Consistência}

Essa categoria (Quadro 9) objetiva investigar a consistência do estudo de alternativas por meio da análise de postos-chave, que não se restringem à avaliação de alternativas e devem permear todo EIA.

O primeiro item desta categoria (4.1), que trata sobre reconhecer as limitações do estudo, é o que teve o menor desempenho em toda a análise do EIA, tanto na avaliação de todos os EIAs (Figura 9), como na dos estudos com alternativas (Figura 10), com $90 \%$ dos estudos apresentando o conceito $D$ na análise geral. Isso indica que poucos EIAs analisados continham qualquer tipo de informação sobre problemas e limitações do processo, de forma que mesmo entre os que apresentavam, alguns obtiveram o conceito $C$, já que, apesar de mencionar esse tópico, não discutiam como essas limitações deveriam ser interpretadas e qual a sua relevância no resultado encontrado. A identificação de limitações e problemas é importante a medida que fornece meios para o aprendizado e o desenvolvimento da prática futura (MOMTAZ; KABIR, 2013). Gray e Edwards-Jones (2003) também já haviam reconhecido essa deficiência nos estudos como um todo, afirmando ainda, que além da maioria não identificar possíveis limitações, aqueles que mencionavam esse tópico, não elaboravam sobre as situações identificadas, limitando-se apenas a menção. Momtaz e Kabir (2013) concluem ainda que entre os poucos estudos que apresentam limitações, a maioria relata apenas a restrição de tempo do processo. 
Quadro 9 - Categoria Consistência da lista de verificação.

\begin{tabular}{|c|c|c|c|}
\hline Categoria & \multicolumn{2}{|r|}{ Critério } & Referência \\
\hline \multirow{6}{*}{ Consistência } & 4.1 & $\begin{array}{l}\text { Reconhece e explicita as limitações dos } \\
\text { métodos e justificativas? }\end{array}$ & $\begin{array}{l}\text { Lee et al., 1999; Glasson, } \\
\text { Therivel e Chadwick, } 2005\end{array}$ \\
\hline & 4.2 & $\begin{array}{l}\text { Identifica as fontes de dados sobre as } \\
\text { informações relevantes de cada alternativa? }\end{array}$ & $\begin{array}{l}\text { Souza, 2000; EUROPEAN } \\
\text { COMMISSION, 2001; } \\
\text { Sánchez, 2013; CETESB, } \\
\text { 2014; IAIA, } 2015\end{array}$ \\
\hline & 4.3 & $\begin{array}{l}\text { Identifica e descreve os profissionais } \\
\text { responsáveis pelos estudos e dados } \\
\text { apresentados na análise locacional? }\end{array}$ & $\begin{array}{l}\text { Brasil, } 1997 \text {; Sánchez, } \\
\text { 2013; CETESB, } 2014\end{array}$ \\
\hline & 4.4 & $\begin{array}{l}\text { Os estudos de alternativa locacional estão em } \\
\text { conformidade com o requisitado no TR? }\end{array}$ & $\begin{array}{l}\text { SMA, 2014; Sánchez, 2013; } \\
\text { CETESB, } 2014\end{array}$ \\
\hline & 4.5 & $\begin{array}{l}\text { Apresenta RIMA compatível com as principais } \\
\text { informações sobre a análise de alternativas } \\
\text { locacionais bem como justificativa clara sobre a } \\
\text { escolha? }\end{array}$ & $\begin{array}{l}\text { Sánchez, 2013; CETESB, } \\
2014\end{array}$ \\
\hline & 4.6 & Considera o cenário de não execução? & $\begin{array}{c}\text { CONAMA, 1986; } \\
\text { EUROPEAN COMMISSION, } \\
\text { 2001; Pinho, Maia e } \\
\text { Monterroso, 2007; IAIA } \\
2015 \\
\end{array}$ \\
\hline
\end{tabular}

Fonte: Natalia Almeida Santos Mattos, 2018.

Figura 9 - Conceitos (A-D) atribuídos aos critérios da categoria Consistência para todos os ElAs analisados.

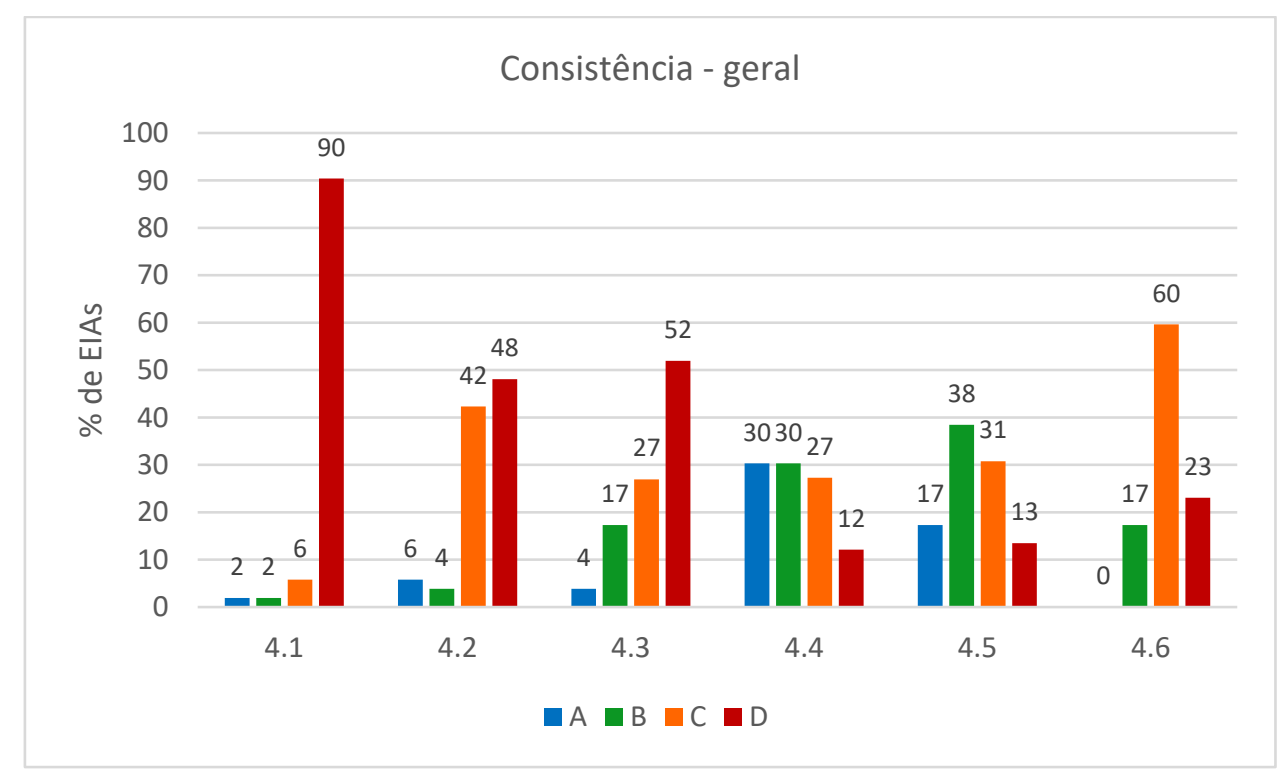

Fonte: Natalia Almeida Santos Mattos, 2018. 
Figura 10 - Conceitos (A-D) atribuídos aos critérios da categoria Consistência para os EIAs que apresentaram alternativas locacionais.

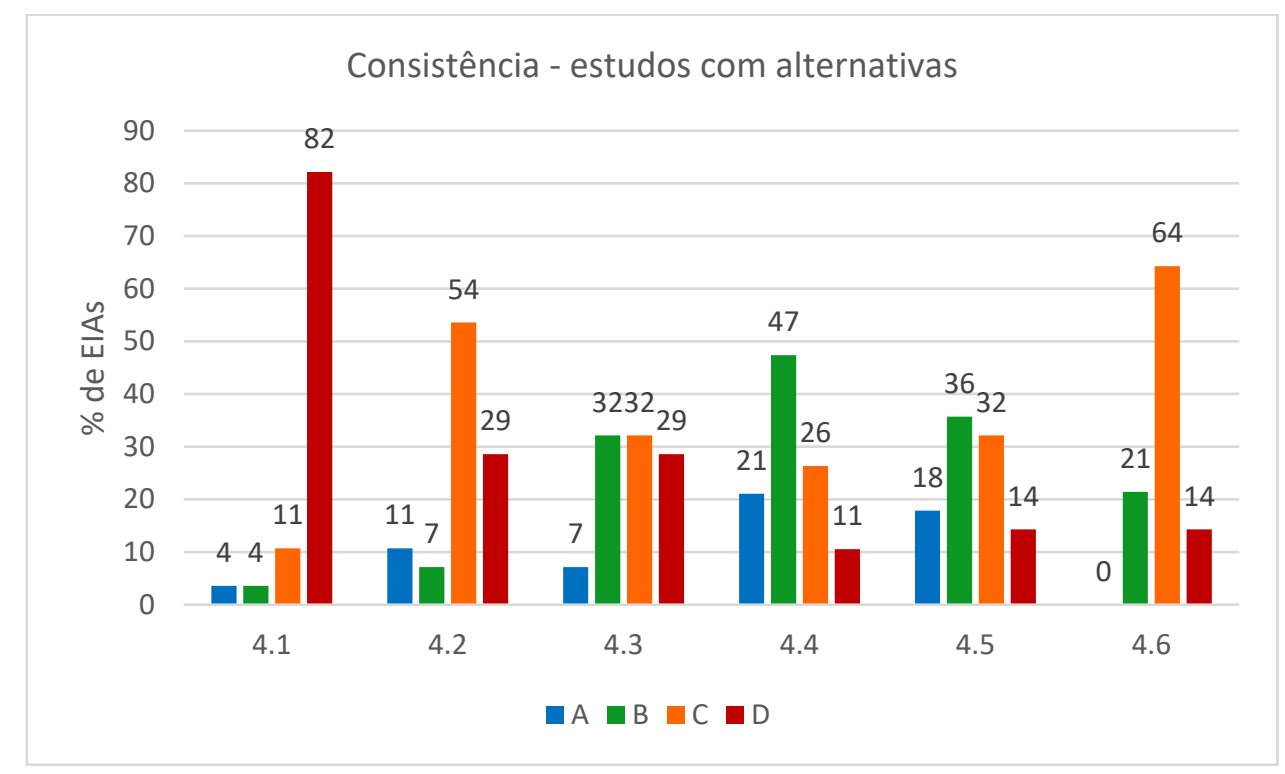

Fonte: Natalia Almeida Santos Mattos, 2018

Os itens 4.2 e 4.3, que tratam respectivamente da obtenção de dados e da equipe de profissionais envolvida na elaboração dos estudos de alternativas obteve um desempenho insatisfatório em ambos os casos, com uma melhora para os EIAs que apresentaram alternativas locacionais, especialmente no item 4.3.

O uso de informações falsas, exageradas, confusas ou omitidas é uma forma de manipulação do processo de decisão pelo proponente, com o objetivo de garantir ou justificar suas escolhas, prejudicando a integridade do processo e, portanto, sendo inaceitável dentro de qualquer etapa da AIA (ENRÍQUEZ-DE-SALAMANCA, 2018). Sendo assim, a correta identificação das fontes de dados e da equipe de trabalho para o estudo de alternativa é uma forma de minimizar a possibilidades dessas ações. A atribuição de conceitos $C$ para o item 4.3 é explicada pela prática atual da identificação da equipe envolvida na elaboração do EIA como um todo em um momento inicial do estudo, não sendo retomada ou especificada a atuação de cada integrante em sua elaboração, apesar disso, parte dos EIAs mencionou os estudos específicos realizados para a análise de alternativas. Já o cenário da identificação da fonte dos dados não apresentou esse relativo equilíbrio do item anterior, contendo uma maioria de conceitos $C$ devido, principalmente, às seguintes situações: ausência de dados equivalentes para todas as alternativas; ausência de metodologia de coleta de dados ou identificação de fontes secundárias; identificação das fontes de dados 
considerados, porém sem a apresentação direta desses dados. Todas as situações diminuem a confiança da análise e reforçam a subjetividade do processo. Segundo Sánchez (2013), cabe ao especialista a escolha do uso de dados primários ou secundários de acordo com as informações de que necessita e as informações disponíveis, contudo, esse processo deve estar claro no estudo, de maneira que seja possível identificar e compreender os métodos utilizados. A ausência das fontes de dados também já foi identificada em outros estudos sobre etapas da EIA (CALDAS, 2006; LAMONICA, 2016), assim como o uso de dados secundários desatualizados ou imprecisos (BRASIL, 2004; SÁNCHEZ, 2013).

Em relação a hipótese de não-execução do empreendimento (item 4.6), 60\% da amostra foi avaliada como C, apresentando falhas significativas no conteúdo. 23\% dos estudos foram ainda avaliados como $D$, nos quais a análise da hipótese de não realização do empreendimento não foi apresentada nos EIAs.

A grande atribuição de conceitos C é devida ao fato desse tópico ser frequentemente abordado de maneira superficial, no qual são apenas reforçadas as razões para execução do empreendimento, restringindo a análise do cenário a previsões negativas frequentemente associadas ao cenário socioeconômico no caso de não-execução. Desta forma, é comum que o conteúdo se resuma, de maneira indireta, a uma repetição das justificativas para a execução do empreendimento, sem acrescentar novas informações e avaliar os principais aspectos dos meios físico, biótico e socioeconômico.

Além da superficialidade do conteúdo, há também uma grande ausência desse tópico nos EIAs que já havia sido identificada por estudos anteriores. Na análise feita por Schoen et al. (2016), apenas 38\% da amostra de 151 EIAs apresentava discussão sobre a hipótese de não execução no documento, estando totalmente ausente nos $62 \%$ restantes.

Apesar de sua obrigatoriedade imposta pela CONAMA nํ 001 de 1986, considerando a grande ausência desse tópico nos EIAs e a superficialidade de abordagem, que frequentemente se restringe ao apoio da justificativa de execução do empreendimento, se faz necessário um questionamento sobre a real relevância dessa discussão para a análise da viabilidade ambiental, principalmente diante da prática atual sobre a abordagem desse tópico nos estudos. 
A respeito da equivalência do RIMA ao EIA, nota-se por meio da análise do item 4.5, um maior equilíbrio entre a atribuição de conceitos. Os RIMAs que obtiveram o conceito $C$ e $D$ omitiram informações relevantes à compreensão do estudo de alternativas, muitas vezes apresentado o conteúdo do estudo de localizações caracterizado como uma justificativa locacional e, portanto, focando esse conteúdo na apresentação do local selecionado. Dessa forma, tais RIMAs omitiram um dos principais objetivos do estudo de alternativas, a comparação de opções e seleção do local por meio desse processo. Considerando a acessibilidade do RIMA para os grupos de interesse, o processo de seleção locacional deve ser totalmente claro nesse documento. Ainda que precise se apresentar de forma mais resumida e acessível, ele não deve omitir informações que prejudiquem a compreensão do público sobre o entendimento do processo. Destaca-se, porém, que entre os EIAs com alternativas, mais de $50 \%$ dos estudos apresentaram RIMAs que abordaram o estudo de localizações de maneira satisfatória ou apenas com falhas pontuais.

O item 4.4, apesar de apresentar um dos melhores desempenhos desta pesquisa, representa uma das maiores fragilidades do processo. Visto que categorias fundamentais para a análise de alternativas obtiverem um baixo desempenho, como, por exemplo, nos processos de comparação e justificativa, o resultado encontrado de que a maioria dos EIAs cumpriu minimamente o que havia sido indicado no TR para esta etapa caracteriza um cenário preocupante sobre a definição do escopo. A falta de aderência entre o cumprimento do TR e a qualidade do estudo também já foi identificada em outras etapas do EIA (LAMONICA, 2016), de forma que certos aspectos foram considerados insatisfatórios para análise adequada da viabilidade ambiental, mesmo tendo atendido as diretrizes definidas no TR. Desta forma, a grande atribuição de conceitos A e B para esse item não se traduz na qualidade do estudo de alternativas, mas sim na adequabilidade desses estudo ao que foi requisitado na etapa de escopo, sendo, portanto, necessário avaliar a qualidade das diretrizes apresentadas no TR, o que será melhor explorado na próxima categoria.

É necessário ressaltar que, mesmo entre os estudos que não apresentaram alternativas, o resultado obtido para esse item se matem razoavelmente equilibrado, o que causa um estranhamento inicial sobre a razão desse desempenho. A maioria dos estudos que não apresentaram alternativas e que continham o TR disponível para análise eram de empreendimentos do setor agroindustrial (71\%), o que pode ter 
influenciado na obtenção de um bom desempenho nesse item. Isso em razão de que, com exceção de apenas um TR, nenhum outro documento deste setor exigia a análise de alternativas locacionais do empreendimento e sim apenas uma justificativa do local selecionado. Sendo assim, ainda que nenhum estudo desse setor tenha apresentado alternativas, tais diretrizes ainda possibilitaram que esses EIAs preenchessem os requisitos do escopo, mesmo sem analisar mais de uma opção locacional. Considerando ainda que esse setor foi o que mais considerou ferramentas de planejamento, o Zoneamento Agroambiental, em sua análise, levanta-se a questão sobre como propor a integração dessas ferramentas ao processo da AIA e, especificamente, a análise de alternativas, de modo a garantir uma melhor efetividade.

Estudos anteriores apontam que o desenvolvimento desse tipo de ferramenta de planejamento tem grande potencial em auxiliar o estudo de alternativas locacionais (SOUZA, 2000; MONTAÑO et al., 2007; FERNANDES et al., 2017; IAIA, 2015); a forma como ela é inserida no processo, no entanto, é fundamental para garantir sua efetividade. Almeida e Montaño (2017) já indicavam a fraca integração dessas ferramentas com o processo de AIA, mesmo quando estavam disponíveis para o setor do empreendimento em questão. Sendo assim, a definição de diretrizes mais específicas no TR sobre o uso dessas ferramentas para a análise de alternativas parece ser um modo de direcionar melhor a integração desses instrumentos, recaindo, novamente, na importância da definição do escopo para a qualidade do estudo.

Além disso, a integração desse tipo de instrumento como embasamento para o estudo de alternativas de localização deve ser feita com cautela, como destacam Gomes e Montaño (2012), em análise do Zoneamento Agroambiental do setor sucroalcooleiro para o estado de São Paulo. Nesta análise, concluem que o uso desse instrumento se restringe, na prática, ao suporte ao licenciamento dos empreendimentos desta tipologia e não como um instrumento de indução à ocupação de áreas mais favoráveis à expansão da cana-de-açúcar. Outro ponto que merece destaque é que, uma vez que o estudo de alternativas se adere a um outro instrumento, como por exemplo, o zoneamento ambiental, ressalta-se que a qualidade e a efetividade desse novo instrumento passam a ser fundamentais para a efetividade do estudo de alternativas locacionais. No caso do setor sucroenergético, por exemplo, aponta-se uma necessidade de revisão das classes e dos critérios definidos no zoneamento, de maneira a garantir uma melhor inserção da variável ambiental nesse 
instrumento e buscar uma maior participação de diferentes grupos de interesse em sua elaboração (GOMES; MONTAÑO, 2012).

\subsubsection{Análise do TR}

Tendo em vista o distanciamento entre o cumprimento das diretrizes apresentadas no TR e a qualidade verificada nos estudos de alternativa, a avaliação da categoria Análise do TR (Quadro 10) permite um melhor entendimento dessa contradição, já que os resultados observados indicam a prevalência de conceitos insatisfatórios (C e D), tanto para todos os TRs analisados (Figura 11), como para os TRs de EIAs com alternativas (Figura 12).

Quadro 10 - Categoria Análise do TR da lista de verificação.

\begin{tabular}{|c|c|c|c|}
\hline Categoria & & Critério & Referência \\
\hline \multirow{3}{*}{ Análise do TR } & 5.1 & $\begin{array}{l}\text { O TR apresenta diretrizes específicas para a } \\
\text { seleção de alternativas a serem estudadas? }\end{array}$ & $\begin{array}{l}\text { Glasson; Therivel; } \\
\text { Chadwick, 2005; Sánchez, } \\
\text { 2013, IAIA, } 2018\end{array}$ \\
\hline & 5.2 & $\begin{array}{l}\text { O TR indica a necessidade de descrição, } \\
\text { comparação e justificativa de escolha com base } \\
\text { na comparação de alternativas? }\end{array}$ & $\begin{array}{c}\text { Agra-Filho et. al., 2012; } \\
\text { Sánchez, 2013; CETESB, } \\
\text { 2014, Fernandes et al., } \\
\text { 2017; IAIA, } 2018\end{array}$ \\
\hline & 5.3 & $\begin{array}{l}\text { O TR especifica detalhes técnicos sobre a } \\
\text { profundidade e nível de detalhamento esperado } \\
\text { no estudo de alternativas? }\end{array}$ & $\begin{array}{c}\text { Agra-Filho et. al, 2012; } \\
\text { Sánchez, 2013; CETESB, } \\
\text { 2014, Fernandes et al., } \\
\text { 2017; IAIA, } 2018\end{array}$ \\
\hline
\end{tabular}

Fonte: Natalia Almeida Santos Mattos, 2018.

Figura 11 - Conceitos (A-D) atribuídos aos critérios da categoria Análise do TR para todos os TRs analisados

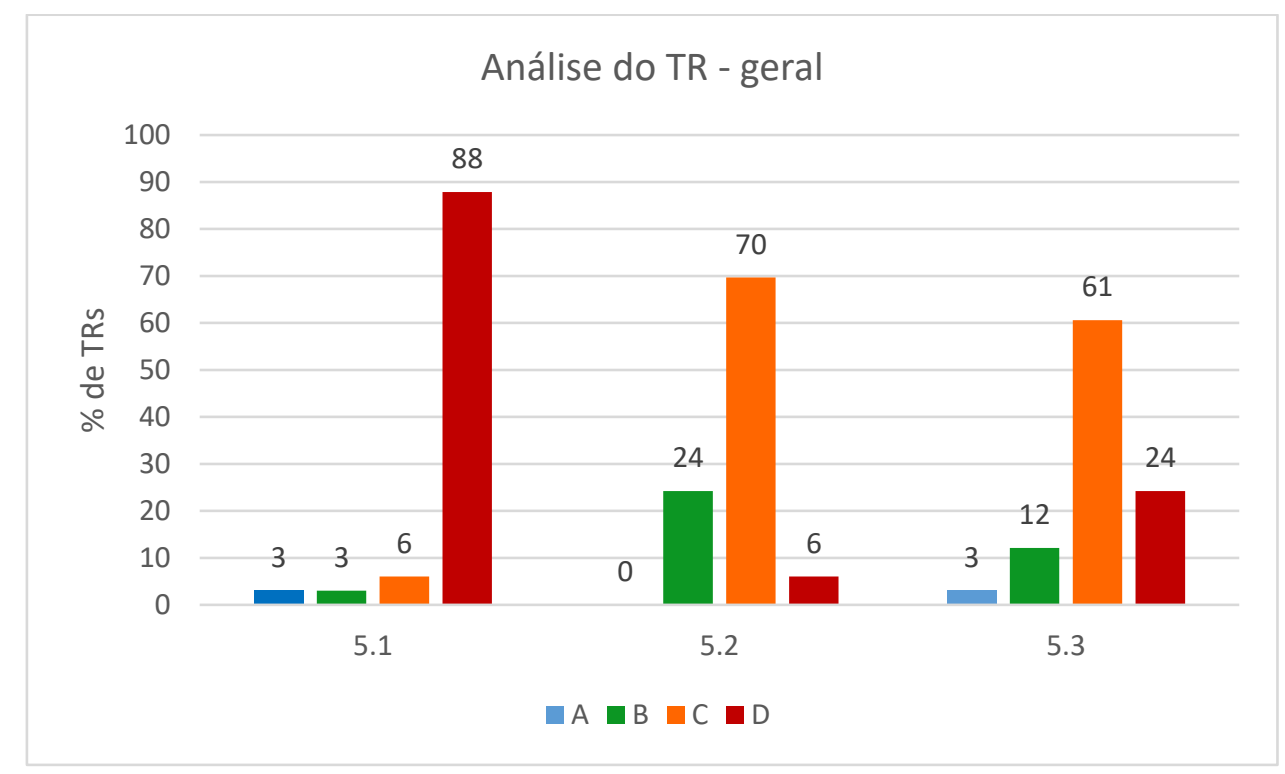

Fonte: Natalia Almeida Santos Mattos, 2018. 
Figura 12 - Conceitos (A-D) atribuídos aos critérios da categoria Análise do TR para os TRs de EIAs que apresentaram alternativas locacionais.

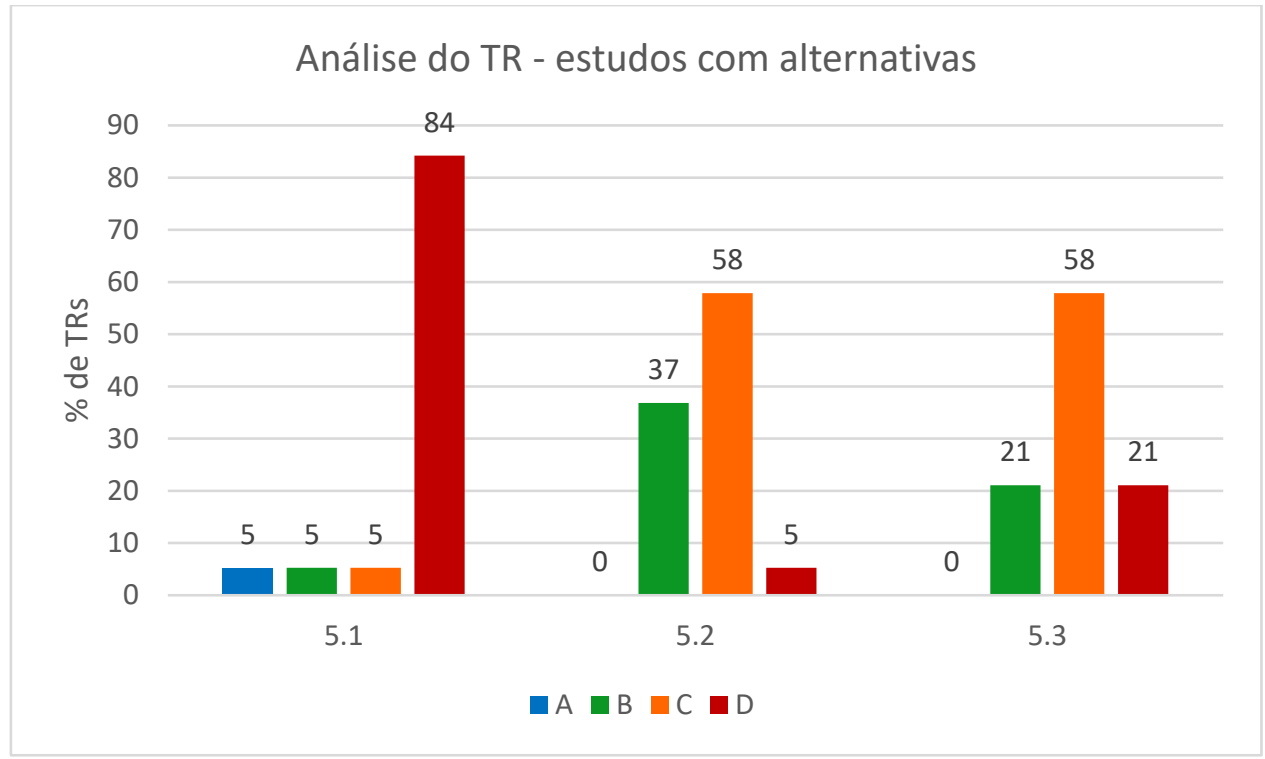

Fonte: Natalia Almeida Santos Mattos, 2018.

O item que se destaca pela baixa performance é o 5.1, sobre as diretrizes relacionadas com a definição de alternativas a serem consideradas. Retoma-se, então, que essa etapa está relacionada a um dos principais problemas identificados na análise de alternativas: a apresentação de alternativas impraticáveis, inconsistentes ou reconhecidamente inferiores a selecionada. Além disso, a ausência desse tipo de especificação nos TRs pode ser ainda associada com o baixo conceito do item 1.1, já que a falta de diretrizes específicas para tal etapa parece se traduzir na não consideração desse aspecto nos EIAs analisados. De acordo com o IAIA (2018), boas práticas na etapa de definição de escopo incluem a garantia de análise de alternativas viáveis, o que não se mostrou frequente nos EIAs ou nos TRs analisados.

Sobre os itens 5.2 e 5.3, é possível identificar certa contradição entre o proposto pelo Manual para elaboração de estudos para licenciamento com Avaliação de Impacto Ambiental (CETESB, 2014) e o conteúdo presente nos TRs. No manual de práticas da CETESB recomenda-se não somente a descrição detalhada e a comparação das alternativas, mas também o uso de sistemas de ponderação, a apresentação de indicadores, o uso de representações visuais, a sobreposição cartográfica entre outros instrumentos de análise. No entanto, essas diretrizes não 
estavam presentes nos TRs analisados ou eram abordadas de maneira muito superficial, por exemplo, exigindo apenas o confronto entre as alternativas de maneira genérica.

A presença de orientações pouco específicas para a seleção de alternativas locacionais também foi identificada em outros estudos. Agra-Filho et al. (2012) observaram que metade dos TRs que analisaram restringia as orientações do estudo de alternativas nas diretrizes gerais e poucos específicas determinadas na legislação, não especificando a necessidade de nenhuma informação complementar. Sendo assim, esses autores propõem ser imprescindível incluir no TR orientações específicas para a abordagem das alternativas no EIA, solicitando-se objetivamente a comparação de alternativas factíveis.

De maneira geral, os resultados encontrados no presente trabalho convergem com a conclusão de Borioni, Gallardo e Sánchez (2017), de que a baixa qualidade do escopo pode resultar em deficiências no EIA, sendo possível encaixar os resultados aqui observados em um dos pontos apresentados por tais autores, o aumento do risco de se negligenciar pontos relevantes que deveriam ser analisados.

\subsubsection{Análises gerais}

Por meio de uma análise geral de todos os EIAs avaliados neste estudo, percebe-se que a grande maioria recebeu conceitos insatisfatórios (C e D) (Figura 13), indicando uma baixa qualidade do estudo de alternativa locacionais como um todo, reforçando, assim, o cenário previamente identificado na literatura (GLASSON et al., 1997; GRAY; EDWARDS-JONES, 2003; CANELAS et al., 2005; PINHO; MAIA, MONTERROSO, 2007; CALDAS, 2006; MOMTAZ; KABIR, 2013). Esse desempenho, contudo, apresenta uma relativa melhora, ainda que se mantenha insatisfatório, ao focar a análise em EIAs que apresentaram alternativas de localização (Figura 14). 
Figura 13 - Distribuição total de conceitos atribuídos para todos os EIAs analisados
Figura 14 - Distribuição total de conceitos atribuídos para EIAs com alternativas

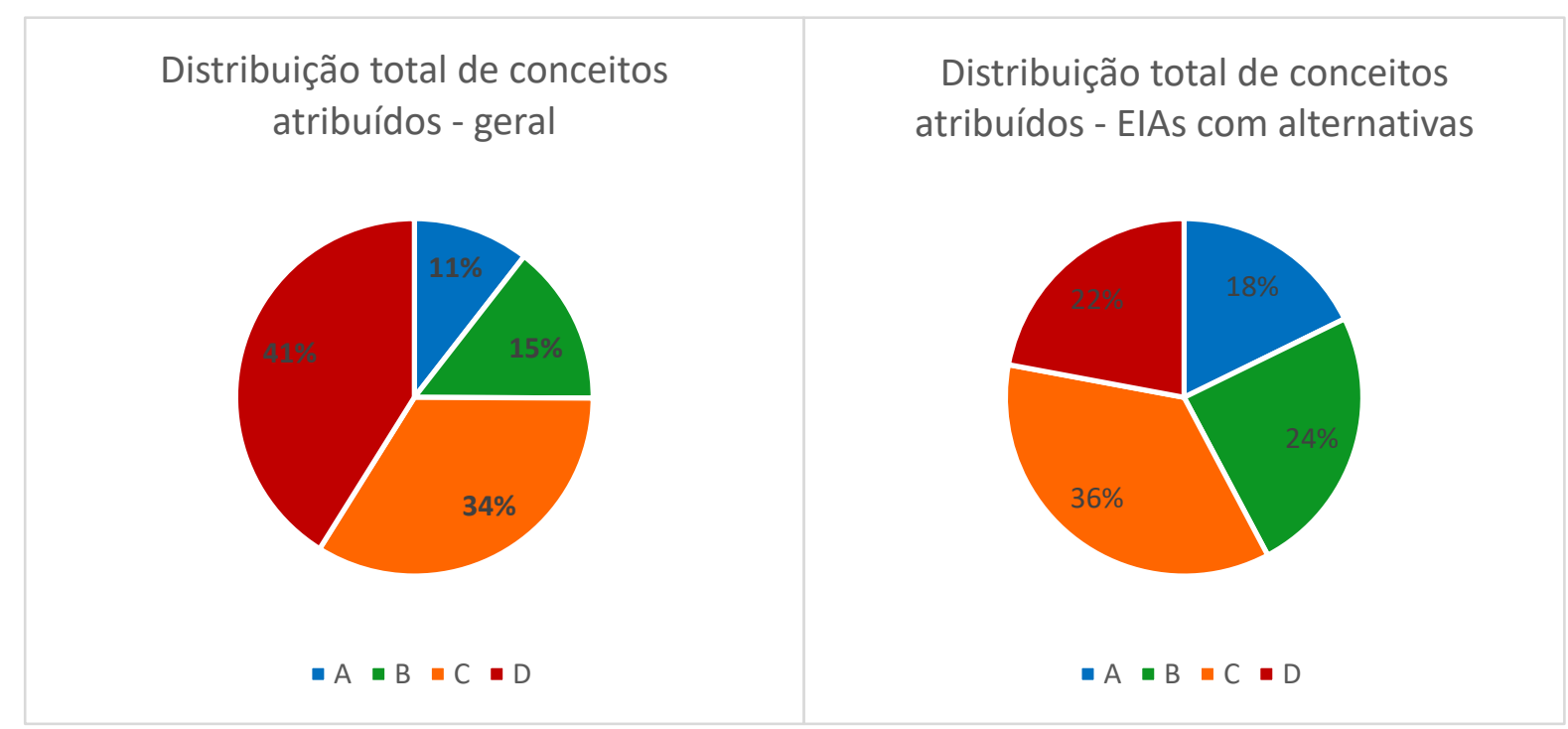

Fonte: Natalia Almeida Santos Mattos, 2018.

Ao avaliarmos as diferenças encontradas para EIAs de empreendimentos novos e ampliações (Figura 15), nota-se que os estudos locacionais de ampliações apresentaram mais conceitos insatisfatórios (C-D), quando comparado aos de novos empreendimentos. É relevante comentar que muitos desses estudos justificaram a ausência de avaliação locacional exatamente por se tratarem de ampliações, utilizando o espaço destinado ao estudo de localizações como forma de justificar a ampliação proposta, o que, como visto anteriormente, não é uma prática restrita apenas para as ampliações, mas frequentemente identificada em estudos de alternativa. Houve ainda estudos em que, ao justificar a rigidez locacional pela associação ao empreendimento existente, passaram a analisar a localização e ou o layout de estruturas do projeto dentro do espaço pré-selecionado. Outro ponto relevante a ser relatado é a ausência de qualquer diretriz específica nos TRs para esse tipo de projeto, reforçando a ideia de que o caráter genérico do conteúdo do escopo, por exemplo ao não especificar diretrizes para a análise de ampliações, parece influenciar na baixa qualidade e superficialidade dos estudos locacionais (AGRA-FILHO et al., 2012). 
Figura 15 - Comparação entre distribuição de conceitos para ElAs de empreendimentos novos e EIAs de ampliações

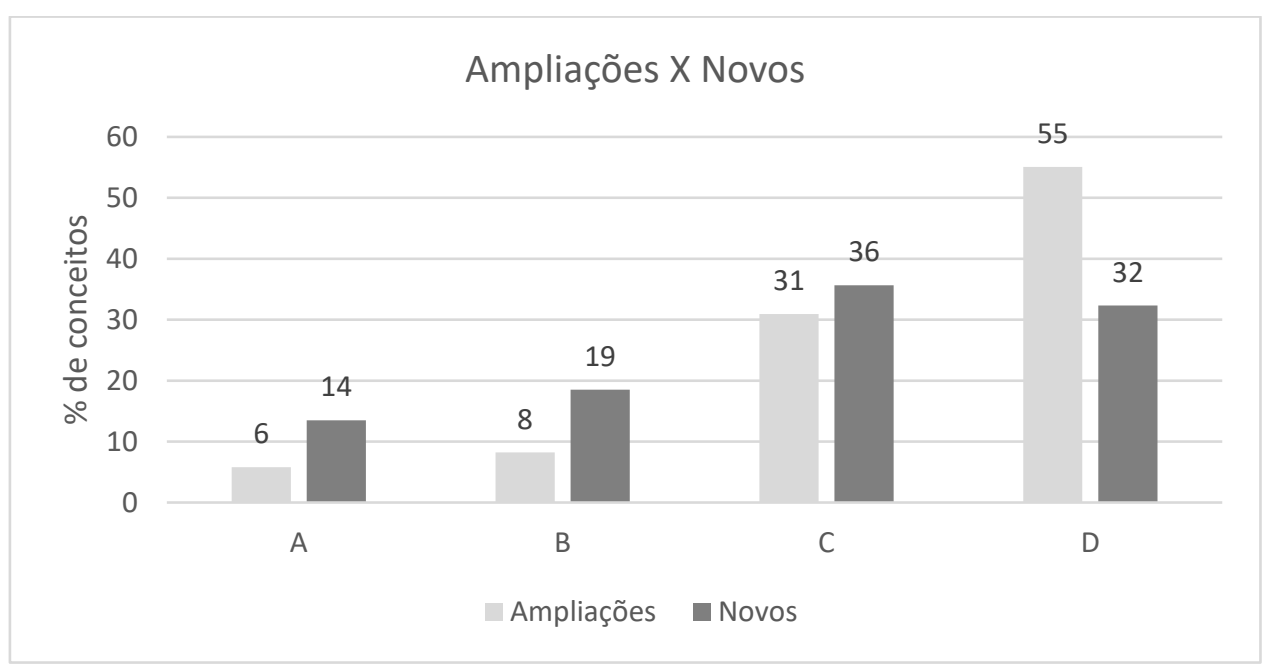

Fonte: Natalia Almeida Santos Mattos, 2018.

Em relação as categorias de análise estabelecidas pela lista de verificação, foi possível identificar que o critério que obteve o melhor desempenho foi 0 de Apresentação e descrição que, apesar da grande proporção de conceitos $\mathrm{D}$, obteve a maior proporção (32\%) de conceitos satisfatórios (A-B) em relação as demais categorias (Figura 16). Essa melhor performance foi ainda mais evidente ao focar a análise apenas nos estudos que apresentaram alternativas locacionais (Figura 17), em que a categoria Apresentação e descrição obteve $60 \%$ de conceitos satisfatórios (A-B). Esse resultado parece reforçar a ideia do reducionismo do estudo de alternativas a um caráter mais descritivo, em detrimento dos processos de comparação e seleção (LANDIM; SÁNCHEZ, 2012; ALMEIDA; MONTAÑO, 2017).

Já em relação a categoria com o pior desempenho, tanto para todos os EIAs (Figura 16) como para os ElAs com alternativas (Figura 17), a categoria Análise do TR obteve a maior proporção de conceitos insatisfatórios (C-D), com cerca de $85 \%$ e $77 \%$ respectivamente. Como discutido anteriormente, tendo em vista a importância desse documento para o direcionamento adequado do estudo de alternativas e o reflexo negativo na qualidade do EIA decorrente de deficiências do escopo, os resultados obtidos corroboram a necessidade de revisão na etapa de elaboração do TR (AGRA-FILHO et al., 2012) com o objetivo de apresentar diretrizes mais claras para a elaboração, comparação e seleção de alternativas locacionais 
Figura 16 - Comparação da distribuição de conceitos entre as categorias de análise para todos os EIAS.

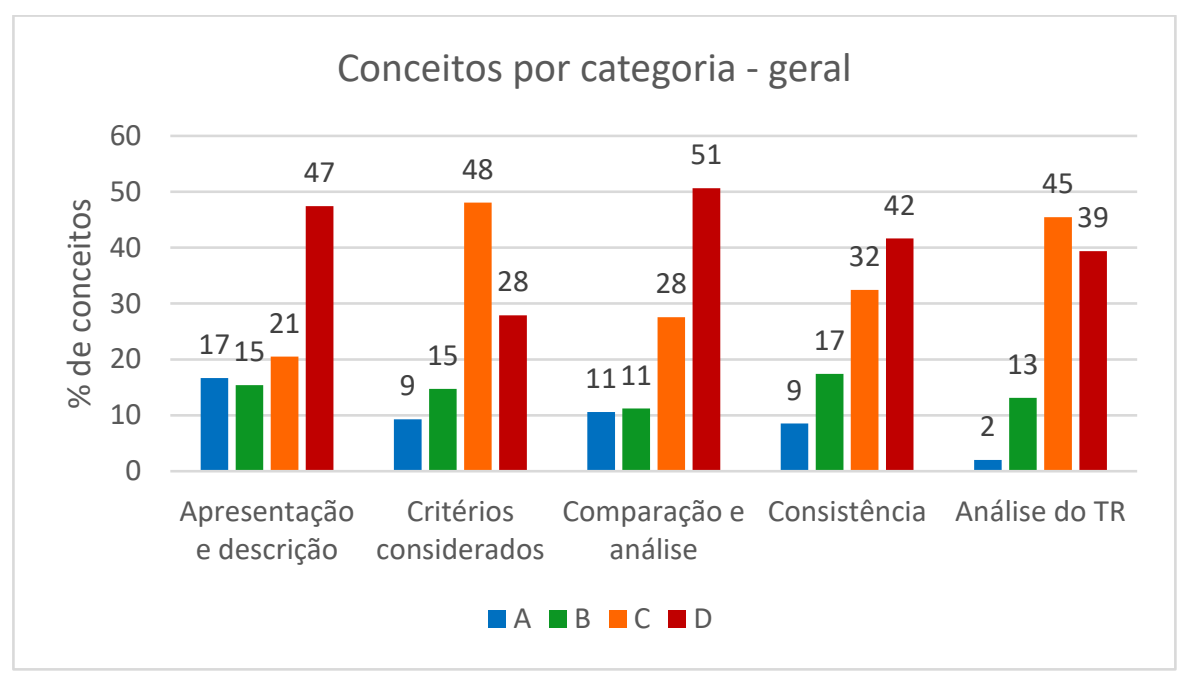

Fonte: Natalia Almeida Santos Mattos, 2018.

Figura 17 - Comparação da distribuição de conceitos entre as categorias de análise para EIAs que apresentaram alternativas locacionais.

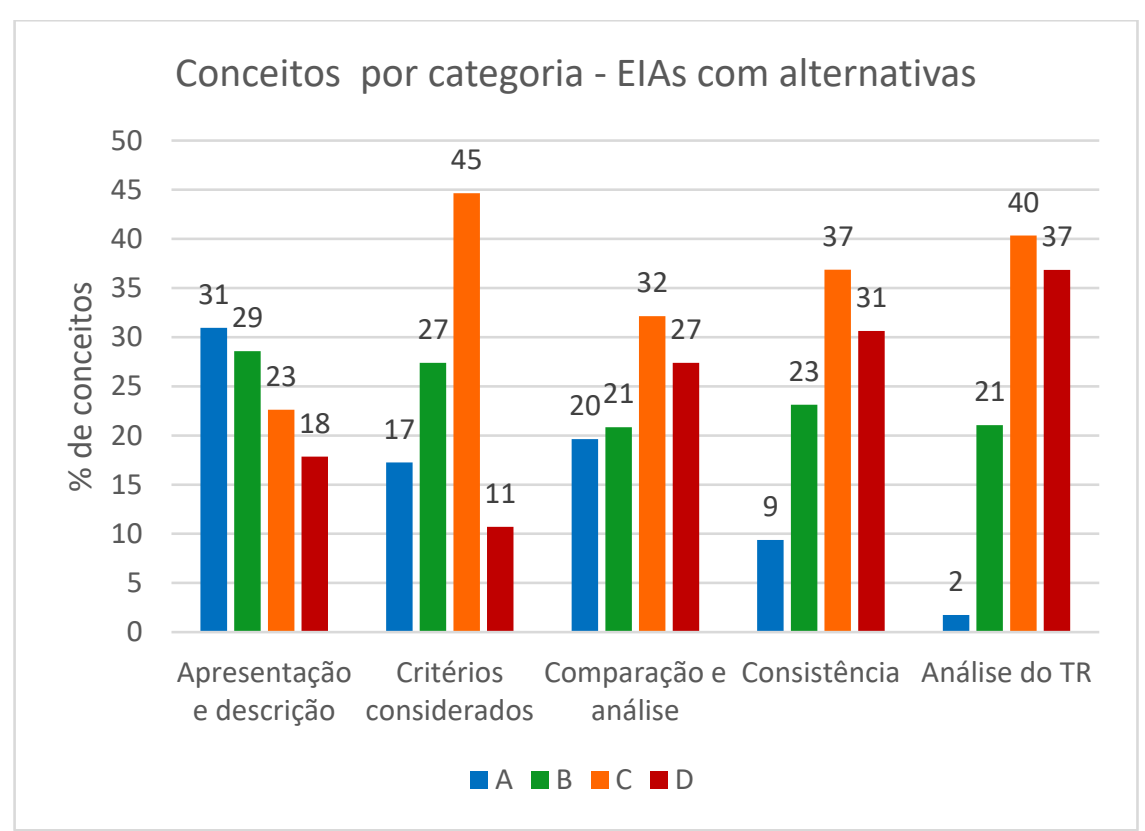

Fonte: Natalia Almeida Santos Mattos, 2018. 


\section{CONCLUSÃO}

Esse trabalho analisou estudos de alternativas locacionais presentes em EIAs do Estado de São Paulo, descrevendo algumas características referentes a apresentação do estudo locacional e das alternativas de localização dentro dos EIAs, os critérios considerados nestes estudos e seus sistemas de classificação. Além disso, essa pesquisa apresentou uma análise qualitativa desses estudos de localização, avaliando a apresentação e a descrição de alternativas, os critérios considerados, o processo de comparação, análise e seleção e a consistência do estudo, bem como de parte dos respectivos TRs.

Cabe destacar que os resultados obtidos reforçaram as deficiências previamente estabelecidas na literatura:

- A não consideração do cenário de não execução: expressa nos resultados observados no item 4.6, em que aproximadamente $23 \%$ da amostra não apresentou esse componente, ressaltando-se ainda a superficialidade do conteúdo nos estudos que apresentaram essa análise, sendo necessária uma reavaliação da abordagem de modo que permita contribuir no processo decisório;

- A ausência ou número insuficiente de alternativas: cerca de $46 \%$ dos EIAs analisados não apresentaram nenhuma alternativa locacional e, entre os que apresentaram, aproximadamente $45 \%$ se restringiu a análise de alternativas locacionais de estruturas e layouts, não discutindo a localização do empreendimento como um todo;

- A baixa qualidade dos estudos de alternativas: em torno de $75 \%$ de todos os conceitos atribuídos foram insatisfatórios (C-D), indicando a baixa qualidade dos estudos de alternativas locacionais nos EIAs analisados. Mesmo considerando os EIAs que de fato apresentaram ao menos duas opções locacionais, $58 \%$ dos conceitos foram insatisfatórios (C-D), o que indica que as deficiências da avaliação de localização não se restringem aos estudos que simplesmente não a realizam, se estendendo também entre a maioria dos que apresentaram algum tipo de alternativa locacional; 
- Análise ou comparação incompleta das alternativas: expressa de maneira mais direta pelo critério 3.2, no qual se observou 79\% dos estudos com desempenho insatisfatório para todos os EIAs. Apesar da melhor performance entre os EIAs que continham alternativas locacionais, incluindo $29 \%$ com conceito A, $61 \%$ desses estudos obtiveram conceitos $C$ e $D$, indicando que a ausência ou a fraca comparação se estende mesmo entre os estudos que apresentaram opções locacionais. Esse ponto é ainda reforçado pela avaliação insatisfatória do item 3.3, sobre sistemas de ponderação, o qual indicou que $69 \%$ dos EIAs não apresentaram esse tipo de metodologia, que objetiva sistematizar o processo de comparação. Quando avaliado de maneira geral, a categoria Comparação e análise obteve mais de $55 \%$ de conceitos insatisfatórios (C-D), tanto para todos os ElAs como para os que continham alternativas;

- Momento de decisão anterior a realização da AIA: esse ponto não se expressa diretamente por meio dos resultados deste estudo, contudo, considerando a sequência de processos na qual a AIA está inserida no estado de São Paulo, a elaboração do EIA requer, de certa forma, a seleção de uma alternativa prioritária para qual o estudo será detalhado, etapa que fica restrita ao proponente em momento anterior a própria elaboração do documento. Outro ponto que reforça esse aspecto pode ser observado indiretamente nos resultados encontrados; a tendência da discussão locacional se reduzir frequentemente a um aspecto descritivo voltado mais para uma justificativa do empreendimento, sinaliza que a real etapa de decisão ocorreu em momento anterior, de maneira que o estudo de alternativas é utilizado como meio para reforçar e justificar essa decisão prévia;

- Ausência ou fraca justificativa da escolha: apesar da ausência de justificativas não ter sido identificada em muitos casos, aproximadamente 54\% dos EIAs obtiveram conceito $C$ para $\mathrm{o}$ item que trata das justificativas (3.4). Isso indica que, apesar de estarem presentes ( $84 \%$ dos EIAs), o conteúdo das justificativas de seleção não se baseia no processo de análise e comparação locacional, recaindo, muitas vezes, no mesmo conteúdo utilizado para justificar a relevância do projeto e, portanto, não cumprindo um dos principais objetivos na avaliação locacional, a seleção da opção mais ambientalmente viável por meio 
da comparação de alternativas factíveis dentro dos objetivos do empreendimento.

Alguns estudos identificaram ainda um outro problema sobre a avaliação de alternativas: o fraco retorno dos órgãos avaliadores sobre esse conteúdo do EIA (AGRA-FILHO et al., 2012; ALMEIDA; MONTAÑO, 2017). Nesses estudos, apesar de terem sido averiguadas diversas deficiências na análise de alternativas de localização, os autores indicam não haver qualquer evidência relacionada à solicitação de informações complementares sobre a discussão locacional por parte do órgão competente (ALMEIDA; MONTAÑO, 2017) ou ainda indicam que pareceres técnicos emitidos por tais órgãos não apresentam uma abordagem analítica sobre o estudo de alternativas ou a justificativa de escolha locacional, sugerindo, assim, uma aceitação da decisão do proponente sem a devida análise (AGRA-FILHO et al., 2012).

Conclui-se, portanto, que há uma necessidade de revisão da prática atual para o estudo de alternativas dentro na AIA no estado de São Paulo, assim como para seus instrumentos de apoio, como as ferramentas de planejamento e o direcionamento do estudo por meio do escopo.

Correlacionando a abordagem do Zoneamento Agroambiental, usada pelos estudos do setor agroindustrial, com a baixa qualidade averiguada nos EIAs desse setor, sugere-se que, apesar do grande potencial das ferramentas de planejamento, a efetividade dessa aderência entre AIA e esse tipo de instrumento não se restringe na garantia de qualidade dessas ferramentas, destacando-se o papel do TR como forma de garantir que elas sejam utilizadas de modo efetivo. Um instrumento estratégico de planejamento possibilita a inserção da variável ambiental em um momento anterior a AIA (MONTAÑO et al., 2007), uma vez dispondo desse tipo de ferramenta, o estudo de alternativas locacionais no nível individual de análise, ou seja, na elaboração do EIA de um determinado empreendimento, já se iniciaria direcionado por uma diretriz locacional básica, o que embasaria principalmente a etapa de seleção das alternativas a serem consideradas para análise, potencialmente possibilitando, assim, a diminuição de estudos contendo alternativas inviáveis e reconhecidamente inferiores.

Além disso, em acordo com o proposto pela literatura (GLASSON; THERIVEL; CHADWICK, 2005; AGRA-FILHO et al., 2012; IAIA, 2015, FERNANDES et al., 2017, IAIA, 2018), os resultados observados nesse estudo reforçam a necessidade de 
orientações mais detalhadas sobre a avaliação de alternativas na etapa de escopo. $O$ TR deve apresentar diretrizes cujo objetivo seja orientar a discussão locacional para uma análise efetiva de alternativas factíveis, considerando ainda particularidades da tipologia e de certas condições, como, por exemplo, estudos de ampliações. Esse melhor direcionamento provavelmente diminuíra a possibilidade de o proponente abordar o estudo de alternativas locacionais como uma forma de apenas reforçar e justificar escolhas pré-definidas, que foram baseadas em critérios alheios a avaliação de alternativas sob a perspectiva ambiental. Uma vez que o proponente tem uma atuação relevante na definição do TR no contexto do estado de São Paulo, destacase aqui um papel importante na prática do proponente, assim como na da CETESB, para a definição do escopo dentro do processo atual.

Essas demandas observadas na literatura e corroboradas pelos resultados encontrados nesse estudo são também apontadas pelos próprios profissionais dessa área de atuação. Duarte et al. (2017), por meio de um estudo com diferentes grupos de profissionais da área, identificaram que os pontos de mudanças mais bem aceitos e vistos como necessários por esses profissionais incluem: o melhor desenvolvimento de orientação técnica; o aumento de requisitos para comparação de alternativas e para vincular o EIA com outras ferramentas de planejamento; a adoção da Avaliação Ambiental Estratégica; e o aumento da participação pública durante o escopo.

Posto isso, é possível sintetizar alguns postos-chaves na discussão sobre soluções: a necessidade de fortalecimento e o uso de ferramentas de planejamento, planos e políticas, por exemplo o Zoneamento Ambiental e a AAE, como base para as análises locacionais no processo da AIA; a necessidade de aprimoramento da etapa do escopo, com orientações mais específicas para o estudo de alternativas tanto referente a seleção de alternativas a serem avaliadas, como para os processos de descrição, comparação e seleção do local; uma maior exigência dos órgãos ambientais sobre a qualidade dos estudos de alternativas locacionais, de modo a modificar a prática de utilizar esse estudo apenas como uma justificativa locacional de uma decisão anterior, exigindo, assim, um processo claro, sistematizado e não subjetivo na análise locacional; uma maior clareza sobre a etapa do estudo locacional para empreendimentos de ampliação ou com rigidez locacional, determinando, por meio do escopo, os tipos de análise que devem ser feitos para cada caso com o objetivo de reduzir a superficialidade com que esse tópico é tratado nessas situações. 
O contexto brasileiro de pressões políticas que se consolidou nos últimos anos estabeleceu um cenário de tensão em relação ao licenciamento ambiental e AIA no pais, o que se traduziu em certa pressão legislativa a esses processos, por meio de propostas de reestruturação desse sistema (FONSECA; SÁNCHEZ; RIBEIRO, 2017). Embora a necessidade de revisão de certos aspectos seja indiscutível, as propostas apresentadas não ofereceram soluções para superar as barreiras políticas e técnicas identificadas (FONSECA; SÁNCHEZ; RIBEIRO, 2017), incluindo as deficiências na etapa de avaliação locacional. Nesse sentido, esse estudo se propôs a analisar o estudo de alternativas locacionais, dentro do contexto do estado de São Paulo, com o objetivo de fornecer elementos para discussão sobre as deficiências desta importante etapa da AIA e colaborar com o debate sobre os possíveis caminhos para propostas de aprimoramento da avaliação locacional. Considerando o cenário brasileiro de pressões políticas atuais, em concordância com Duarte, Dibo e Sánchez (2017): é indispensável o desenvolvimento de um conhecimento robusto antes de propor reformas do sistema, com o objetivo de não comprometer práticas atuais de sucesso ao se buscar o combate de suas fragilidades. 


\section{REFERÊNCIAS}

AGRA-FILHO, S. S.; MARINHO, M. M. D. O.; ORRICO, S. R. M.; SANTOS, F. C. Oportunidades de aprimoramento do processo de Avaliação de Impacto Ambiental no Estado da Bahia. Revista Brasileira de Ciências Ambientais, n.26, p. 33-43, 2012. Disponível em: http://abes-dn.org.br/publicacoes/rbciamb/PDFs/2607_Materia_4_artigos334.pdf. Acesso em: jan. 2019.

ALMEIDA, M. R. R. Análise da qualidade de Relatórios de Controle Ambiental aprovados pela Superintendência Regional de Meio Ambiente e Desenvolvimento Sustentável do Sul De Minas Gerais.2010. 154p. Dissertação (Mestrado em Meio Ambiente e Recursos Hídricos), Universidade Federal de Itajubá, 2010.

ALMEIDA, M. R. R.; MALFARÁ, D. T.; MENDES, N. C.; MORAES, M. C. P.; SOUZA, M. P. Aplicação de métodos para revisão da qualidade de estudos de impacto ambiental. Revista de Gestão Ambiental e Sustentabilidade, v.1, n.2, p. 1-28, 2012. Disponível em: https://www.redalyc.org/pdf/4716/471647097001.pdf. Acesso em: jan. 2019.

ALMEIDA, M. R. R.; MONTAÑO, M. A efetividade dos sistemas de avaliação de impacto ambiental nos estados de São Paulo e Minas Gerais. Ambiente \& Sociedade, v. 20, n. 2, p. 79-106, 2017. Disponível em:

http://www.scielo.br/pdf/asoc/v20n2/pt_1809-4422-asoc-20-02-00077.pdf. Acesso em: jan. 2019.

ASSUNÇÃO, F. N. A.; BURSZTYN, M. A. A.; ABREU, T. L. M. Participação social na avaliação de impacto ambiental: lições da experiência da Bahia. Confins. n.10, 2010. Disponível em: https://journals.openedition.org/confins/6750. Acesso em: jan. 2019

BANCO MUNDIAL. Licenciamento ambiental de empreendimentos hidrelétricos no Brasil: uma contribuição para o debate. v.2. Relatório Principal. Relatório no 40995-BR. 2008. Disponível em:

http://www.mme.gov.br/documents/10584/1139278/Relat\%C3\%B3rio+Principal+\%28 PDF\%29/8d530adb-063f-4478-9b0d-2b0fbb9ff33b. Acesso em: jan. 2019

BANHALMI-ZAKAR, Z.; GRONOW, C.; WILKINSON, L.; JENKINS, B.; POPE, J.; SQUIRES, G.; WITT, K.; WILLIANS, G.; WOMERSLEY, J. Evolution or revolution: where next for impact assessment? Impact Assessment and Project Appraisal, v. 36, n.6, p.506-515, 2018. Disponível em:

https://www.tandfonline.com/doi/full/10.1080/14615517.2018.1516846. Acesso em: jan. 2019.

BENSON, J. F. What is the alternative? Impact assessment tools and sustainable planning. Impact Assessment and Project Appraisal, v. 2, n.4, p. 261-266. 2003.Disponível em: https://www.tandfonline.com/doi/abs/10.3152/147154603781766185. Acesso em: jan. 2019. 
BOJÓRQUEZ-TAPIA, L. A.; GARCÍA, O. An approach for evaluating EIAs deficiencies of EIA in Mexico. Environmental impact assessment review, v.18, p.218-240, 1998. Disponível em:

https://www.researchgate.net/publication/223603234_An_approach_for_evaluating EIAS-deficiencies_of_EIA_in_Mexico. Acesso em: jan. 2019.

BORIONI, R.; GALLARDO, A. L. C. F.; SÁNCHEZ, L. E. Advancing scoping practice in environmental impact assessment: an examination of the Brazilian federal system. Environmental Impact Assessment and Project Appraisal, v.35, n.3, p.200-213, 2017. Disponível em:

https://www.tandfonline.com/doi/full/10.1080/14615517.2016.1271535. Acesso em: jan. 2019.

BRAGAGNOLO, C.; LEMOS, C. C.; LADLE, R. J.; PELLIN, A. Streamlining or sidestepping? Political pressure to revise environmental licensing and EIA in Brazil. Environmental Impact Assessment Review, v.65, p.86-90, 2017.

BRASIL. Constituição (1988). Constituição da República Federativa do Brasil. Brasília, DF. 5 de outubro de 1988.

BRASIL. Lei Complementar n140, de 8 de dezembro de 2011. Fixa normas, nos termos dos incisos III, VI e VII do caput e do parágrafo único do art. 23 da Constituição Federal, para a cooperação entre a União, os Estados, o Distrito Federal e os Municípios nas ações administrativas decorrentes do exercício da competência comum relativas à proteção das paisagens naturais notáveis, à proteção do meio ambiente, ao combate à poluição em qualquer de suas formas e à preservação das florestas, da fauna e da flora; e altera a Lei no 6.938, de 31 de agosto de 1981. Disponível em:

http://www.planalto.gov.br/CCIVIL_03/LEIS/LCP/Lcp140.htm. Acesso em: jan. 2019.

BRASIL. Lei no6.938, de 31 de agosto de 1981. Dispõe sobre a Política Nacional do Meio Ambiente, seus fins e mecanismos de formulação e aplicação e dá outras providências. Brasília, DF, 2 de set. 1981. Disponível em:

http://www.planalto.gov.br/ccivil_03/Leis/L6938.htm. Acesso em: jan. 2019.

BRASIL. Ministério do Meio Ambiente. Conselho Nacional do Meio Ambiente. Resolução CONAMA no 01, de 23 de agosto de 1986. Dispõe sobre critérios básicos e diretrizes gerais para a avaliação de impacto ambiental. Disponível em: http://www.mma.gov.br/port/conama/res/res86/res0186.html. Acesso em: 30 abr. 2016.

BRASIL. Ministério do Meio Ambiente. Conselho Nacional do Meio Ambiente.

Resolução CONAMA no 09, de 3 de dezembro de 1987. Dispõe sobre a realização de Audiências Públicas no processo de licenciamento ambiental. Disponível em: http://www2.mma.gov.br/port/conama/legiabre.cfm?codlegi=60. Acesso em: jan. 2019

BRASIL. Ministério do Meio Ambiente. Conselho Nacional do Meio Ambiente. Resolução CONAMA no 237, de 19 de dezembro de 1997. Dispõe sobre a revisão e 
complementação dos procedimentos e critérios utilizados para o licenciamento ambiental. Disponível em:

http://www.mma.gov.br/port/conama/res/res97/res23797.html Acesso em: 30 abr. 2016.

BRASIL. Ministério Público da União. Ministério Público Federal. 4a Câmara de Coordenação e Revisão. Deficiências em estudos de impacto ambiental: síntese de uma Experiência. Brasília, DF: ESMPU, 2004. Disponível em: http://escola.mpu.mp.br/publicacoes/obras-avulsas/e-books/deficiencias-em-estudosde-impacto-ambiental. Acesso em: jan. 2019.

BRIASSOULIS, H. Environmental criteria in industrial facility siting decisions: An analysis. Environmental Management, v. 19, n. 2, p. 297-311, 1995.

CALDAS, F. V. Estudo de impacto ambiental em empreendimentos dutoviários: análise da elaboração, acompanhamento e monitoramento durante a fase de construção. 2006. 161p. Dissertação (Mestrado em Sistemas de Gestão) - Centro tecnológico, Universidade Federal Fluminense, Niterói, 2006.

CANELAS, L.; ALMANSA, P.; MERCHAN, M.; CIFUENTES, P. Quality of environmental impact statements in Portugal and Spain. Environmental Impact Assessment Review, v. 25, n. 3, p. 217-225, 2005. Disponível em: https://www.sciencedirect.com/science/article/pii/S0195925504000411. Acesso em: jan. 2019.

CARMO, A. B. Avaliação de Impacto Ambiental em empreendimentos costeiros e marinhos no Brasil: análise dos procedimentos e aspectos institucionais e políticos. 2016. 145p. Tese (Doutorado em Oceanografia Biológica) - Instituto Oceanográfico, Universidade de São Paulo. São Paulo, 2016.

CLARK, E. R.; CANTER, L. W. Environmental policy and NEPA: Past, present, and future. Boca Raton: CRC Press, 1997.

CETESB - Companhia de Tecnologia de Saneamento Ambiental. Manual para elaboração de estudos para o licenciamento com avaliação de impacto ambiental. Anexo Único do 1ํartigo da Decisão de Diretoria no 217/2014/I de 06 de agosto de 2014. Disponível em:

http://icenciamento.cetesb.sp.gov.br/cetesb/documentos/Manual-DD-217-14.pdf Acesso em: 30 abr. 2016.

CHANCHITPRICHA, C.; BOND, A. Conceptualising the effectiveness of impact assessment processes. Environmental Impact Assessment Review, v.43 p.65-72, 2013. Disponível em:

https://www.sciencedirect.com/science/article/pii/S0195925513000668. Acesso em: jul. 2019.

COLETTI, R. N. A participação da sociedade civil em instrumentos da política ambiental brasileira. Desenvolvimento e Meio Ambiente, v. 25, p. 39-51, 2012. 
Disponível em: https://revistas.ufpr.br/made/article/viewFile/25544/18572. Acesso em: jan. 2019.

DESMOND, M. Identification and development of waste management alternatives for Strategic Environmental Assessment (SEA). Environmental Impact Assessment Review, v.29, n.1, p.51-59, 2009. Disponível em:

https://www.sciencedirect.com/science/article/pii/S0195925508000905. Acesso em: jan. 2019.

DUARTE, C. G.; DIBO, A. P. A.; SÁNCHEZ, L. E. O que diz a pesquisa acadêmica sobre avaliação de impacto e licenciamento no Brasil. Ambiente \& Sociedade, v.20, n.1, p. 245-278, 2017. Disponível em: http://www.scielo.br/pdf/asoc/v20n1/pt_18094422-asoc-20-01-00261.pdf

DUARTE, C. G.; DIBO, A. P. A.; SIQUEIRA-GAY, J.; SÁNCHEZ, L. E. Practitioners' perceptions of the Brazilian environmental impact assessment system: results from a survey. Impact Assessment and Project Appraisal, v. 35, n. 4, p. 293-309, 2017. Disponível em:

https://www.tandfonline.com/doi/full/10.1080/14615517.2017.1322813. Acesso em: jan. 2019.

ESTADOS UNIDOS. Environmental Protection Agency. Policy and procedures for the review of federal actions impacting the environment. Washington: EPA, 1984. (EPA manual; 1640)

EUROPEAN COMMISSION. Guidance on EIA. EIS review. Luxemburgo: EC, 2001, $32 p$.

FONSECA, A.; SÁNCHEZ, L. E.; RIBEIRO, J. C. J. Reforming EIA systems: A critical review of proposals in Brazil. Environmental Impact Assessment Review, v.62, p90-97, 2017.

FURLANETTO, T. Estudo de alternativas locacionais para a viabilidade ambiental de empreendimentos: o caso do aeroporto de Ribeirão Preto - SP. 2012. 76p. Dissertação (Mestrado em Ciências da Engenharia Ambiental) - Escola de Engenharia de São Carlos, Universidade de São Paulo, São Carlos, 2012.

ENRÍQUEZ-DE-SALAMANCA, A. Stakeholders' manipulation of Environmental Impact Assessment. Environmental Impact Assessment Review, v.68, p.10-18, 2018. Disponível em:

https://www.sciencedirect.com/science/article/pii/S0195925517302615. Acesso em: jan. 2019.

FERNANDES, A. H. V.; CASSIANO, M. A.; GUIMARÃES, T. C. S.; ALMEIDA, M. R. R. Alternativas locacionais em Avaliação de Impacto Ambiental de rodovias mineiras. Desenvolvimento e Meio Ambiente, v.43, p.73-90, 2017. Dsiponível em: https://revistas.ufpr.br/made/article/view/54056. Acesso em: jan. 2019. 
FUGGLE, R. Guidelines for scoping. Pretoria:Department of Environmental Affairs, South Africa, 1992.

GLASSON, J.; THERIVEL, R. CHADWICK, A. Introduction to environmental impact assessment. 3. ed. Londres: Routledge, 2005.

GLASSON, J.; THERIVEL, R.; WESTON, J.; WILSON, E.; FROST, R. EIA-learning from experience: Changes in the quality of environmental impact statements for UK planning projects. Journal of Environmental Planning and Management, v.40, n.4, p.451-464. 1997. Disponível em:

https://www.researchgate.net/publication/227619035_EIA-

Learning_from_Experience_Changes_in_the_Quality_of_Environmental_Impact_Stat ements_for_UK_Planning_Projects. Ácesso em: jan. 2019.

GIL, A. C. Métodos e técnicas de pesquisa social. 6. ed. São Paulo: Editora Atlas, 2008.

GOMES, P.M.; MONTAÑO, M. A Expansão da cana-de-açúcar e o Zoneamento Agroambiental do setor Sucroalcooleiro do estado de São Paulo. In: Congresso Brasileiro de Avaliação de Impacto, 1.; Conferência da rede de Língua Portuguesa de Avaliação de Impactos, 2. 2012, São Paulo. Anais [...]. São Paulo: Associação Brasileira de Avaliação de Impacto, 2012. Disponível em: http://avaliacaodeimpacto.org.br/wp-content/uploads/2012/10/068_zoneamento.pdf. Acesso em: nov. 2018.

GRAY, I.; EDWARD-JONES, G. A review of environmental statements in the British forest sector. Impact Assessment and Project Appraisal, v. 21, p.303-312, 2003. Disponível em:

https://www.researchgate.net/publication/247896801_A_Review_of_Environmental_ Statements_in_the_British_Forest_Sector. Acesso em: jan. 2019.

HAPUARACHCHI, A. B.; HUGHEY, K.; RENNIE, H; Effectiveness of Environmental Impact Assessment (EIA) in addressing development-induced disasters: a comparison of the EIA processes of Sri Lanka and New Zealand. Natural Hazards, v.81, n.1, p.423-445, 2016. Disponível em:

https://link.springer.com/article/10.1007\%2Fs11069-015-2089-8. Acesso em: jan. 2019.

IAIA - International Association for Impact Assessment. Principles of

Environmental Impact Assessment Best Practice. Fargo: IAIA, 1999. Disponível em: https://www.iaia.org/uploads/pdf/principlesEA_1.pdf. Acesso em: nov. 2018.

IAIA - International Association for Impact Assessment. Alternatives in Strategic Environmental Assessment of Plans and Programs. Fastips, n.7, 2014. Disponível em: http://www.iaia.org/uploads/pdf/Fastips_7SEAlternatives.pdf. Acesso em: nov. 2018.

IAIA - International Association for Impact Assessment. Alternatives in Project EIA. Fastips, n.11, 2015. Disponível em: 
http://www.iaia.org/uploads/pdf/FasTips_11_AlternativesinProjECtEIA.pdf. Acesso em: nov. 2018.

IAIA - International Association for Impact Assessment. Scoping. Fastips, n.18, 2018. Disponível em: http://www.iaia.org/uploads/pdf/Fastips_18\%20Scoping.pdf. Acesso em: nov. 2018.

JAY, S.; JONES, C.; SLINN, P.; WOOD, C. Environmental impact assessment: Retrospect and prospect. Environmental Impact Assessment Review, v.27, p. 287-300, 2007. Disponível em:

https://www.sciencedirect.com/science/article/pii/S0195925506001338. Acesso em: jan. 2019.

JHA-THAKUR, U.; FISCHER, T. B. 25 years of the UK EIA System: Strengths, weaknesses, opportunities and threats. Environmental Impact Assessment Review, v. 61, p. 19-26, 2016. Disponível em:

https://www.sciencedirect.com/science/article/pii/S0195925515300585. Acesso em: jan. 2019.

JOÃO, E. How scale affects environmental impact assessment. Environmental Impact Assessment Review, v.22, p.289-310, 2002. Disponível em: https://www.sciencedirect.com/science/article/pii/S019592550200016. Acesso em: jan. 2019.

KHOSRAVI, F.; JHA-THAKUR, U.; FISCHER, T. B. Evaluation of the environmental impact assessment system in Iran. Environmental Impact Assessment Review, v.79, p.63-72, 2019. Disponível em:

https://www.sciencedirect.com/science/article/pii/S0195925518302038. Acesso em: jan. 2019.

KRAJEWSKI L.J; RITZMAN L.P. Operations management. Boston: AddisonWesley. 1993.

LANDIM, S.N.T.; SÁNCHEZ, L.E. The contents and scope of environmental impact statements: how do they evolve over time? Impact Assessment and Project Appraisal. v.30, n.4, 217-228. 2012. Disponível em: https://www.tandfonline.com/doi/abs/10.1080/14615517.2012.746828. Acesso em: jan. 2019.

LAMONICA, L. Avaliação da qualidade do diagnóstico do meio biótico de EIAs, do Estado de São Paulo. 2016. 166p. Dissertação (Mestrado em Sustentabilidade) - Escola de Artes, Ciências e Humanidades, Universidade de São Paulo, São Paulo. 2016.

LEE, N.; BROWN, D. Quality control in environmental assessment. Project appraisal, v.7 n.1 p.41-45. 1992. Disponível em:

https://www.tandfonline.com/doi/pdf/10.1080/02688867.1992.9726837?needAccess= true. Acesso em: jan. 2019. 
LEE, N.; COLLEY, R. Reviewing the quality of environmental statements. Manchester: EIA Centre, 1992. (Occasional Paper; 24).

LEE, N.; COLLEY, R.; BONDE, J.; SIMPSOM, J. Reviewing the quality of environmental statements and environmental appraisals. Manchester: EIA Centre, 1999. (Occasional Paper; 55). Disponível em:

https://aardlink.files.wordpress.com/2013/08/op55.pdf. Acesso em: jan. 2019.

LEE, N.; GEORGE, C. Environmental Assessment in Developing and

Transitional Countries: principles, Methods and Practic. Chichester: John Wiley \& Sons, 2000.

LOOMIS, J. J.; DZIEDZIC, M. Evaluating EIA systems' effectiveness: A state of the art. Environmental Impact Assessment Review, v.68, p.29-37, 2018. Disponível em:

https://www.researchgate.net/publication/320564172_Evaluating_EIA_systems'_effe ctiveness_A_state_of_the_art. Acesso em: jan. 2009.

MACHADO, P. A. L. M. Direito Ambiental Brasileiro. 23. ed. São Paulo: Malheiros, 2015

MILES, M. B.; HUBERMAN, A. M. Qualitative data analysis: a sourcebook of new methods. Newbury Park: Sage Publications 1984.

MIRRA, A. L. V. Impacto Ambiental: aspectos da legislação brasileira. 3. ed. São Paulo: Ed.Juarez de Oliveira. 2006.

MEIRELES, A. J. A. Danos socioambientais originados pelas usinas eólicas nos campos de dunas do Nordeste brasileiro e critérios para definição de alternativas locacionais. Confins, n. 11, 2011. Disponível em:

https://journals.openedition.org/confins/6970?lang=pt. Acesso em: jan. 2019.

MONTAÑO, M.; OLIVEIRA, I.S.D; SOUZA, M.P. Avaliação Ambiental Estratégica. São Carlos: Suprema, 2009.

MONTAÑO, M.; OLIVEIRA, I. S. D.; RANIERI, V. E. L.; FONTES, A. T.; SOUZA, M. P. O zoneamento ambiental e sua importância para a localização de atividades. Revista Pesquisa e Desenvolvimento Engenharia de Produção, n.6, p. 49-64. 2007. Disponível em:

https://www.revista-ped.unifei.edu.br/documentos/V05N01/n06_art04.pdf. Acesso em: jan. 2019.

MONTAÑO, M.; RANIERI, V. E. L.; SCHALCH, V.; FONTES, A. T.; CASTRO, M. C. A. A.; SOUZA, M. P. Integração de critérios técnicos, ambientais e sociais em estudos de alternativas locacionais para implantação de aterro sanitário.

Engenharia Sanitária Ambiental, v. 17, n. 1, p. 61-70, 2012. Disponível em: http://www.scielo.br/pdf/esa/v17n1/v17n1a10. Acesso em: jan. 2019. 
MONTAÑO, M.; SOUZA, M. P.; Impact assessment research in Brazil: achievements, gaps and future directions. Journal of Environmental Assessment and Policy Management, v.17 n.1 p.1550009 (8), 2015. Disponível em: https://www.worldscientific.com/doi/pdf/10.1142/S146433321550009X. Acesso em: jan. 2019.

MOMTAZ, S; KABIR, S. M. Z. Evaluating environmental and social impact assessment in developing countries. Waltham: Elsevier, 2013.

MORGAN, R. K. Environmental impact assessment: the state of the art.

Environmental Assessment Review, v.30, n.1, p. 5-14, 2012. Disponível em: https://www.tandfonline.com/doi/abs/10.1080/14615517.2012.661557. Acesso em: jan. 2019.

NASER, H. A.; The role of environmental impact assessment in protecting coastal and marine environments in rapidly developing islands: The case of Bahrain, Arabian Gulf. Ocean \& Coastal Management journal, v.104, p.159e169, 2015. Disponível em: https://www.sciencedirect.com/science/article/pii/S0964569114003937. Acesso em: jan. 2019.

OKUBO, N. The development of the Japanese legal system for public participation in land use and environmental matters. Land Use Policy, v. 52, p. 492-500, 2016. Disponível em: www.sciencedirect.com/science/article/pii/S0264837715000526. Acesso em: jan. 2019.

OLIVEIRA, A. L.; NEVES, F. F.; SOUZA, M. P. Considerações sobre o procedimento do licenciamento ambiental no contexto da avaliação de impacto ambiental.

Derecho y Cambio Social, n.40, p. 1-25, 2015. Disponível em:

https://www.derechoycambiosocial.com/revista040/CONSIDERACOES_SOBRE_O_ PROCEDIMENTO_DO_LICENCIAMENTO_AMBIENTAL.pdf. Acesso em: jan. 2018.

PINHO, P.; MAIA, R.; MONTERROSO, A. The quality of Portuguese Environmental Impact Studies: The case of small hydropower projects. Enviromental Impact Assessment Review, v. 27, p. $189-205$, 2007. Disponível em: https://www.sciencedirect.com/science/article/pii/S0195925506001272. Acesso em jan. 2019.

POPE, J.; BOND, A.; MORRISON-SAUNDERS, A.; RETIEF, F. Advancing the theory and practice of impact assessment: Setting the research agenda. Environmental Impact Assessment Review. v.41, p. 1-9, 2013. Disponível em: https://www.sciencedirect.com/science/article/pii/S019592551300019X. Acesso em: jan. 2019.

RETIEF, F.; BOND, A.; POPE, J.; MORRISON-SAUNDERS, A.; KING, N. Global megatrends and their implications for environmental assessment practice.

Environmental Impact Assessment Review, v.61, p. 52-60, 2016. Disponível em: https://www.sciencedirect.com/science/article/pii/S0195925515300718. Acesso em: jan. 2019. 
SÁNCHEZ, L. E. Os papeis da avaliação de impacto ambiental. Revista de Direito Ambiental, v.1, p.138-157, 1993.

SÁNCHEZ, L. E. Avaliação de Impacto Ambiental: Conceitos e Métodos. 2. ed. São Paulo: Oficina de textos, 2013.

SÁNCHEZ, L. E. Avaliação de impacto para o licenciamento ambiental no Brasil: modernização fundamentada no aprendizado. In: Seminário Técnico "Propostas para Modernização do Licenciamento Ambiental no Brasil", 2, São Paulo: Associação Brasileira de Avaliação de Impacto, 2012.

SÁNCHEZ, L. E. Por que não avança a avaliação ambiental estratégica no Brasil? Estudos Avançados, v.31, n.89, p. 167-183, 2017. Disponível em: http://www.scielo.br/scielo.php?script=sci_arttext\&pid=S0103-40142017000100167. Acesso em: jan. 2019.

SÁNCHEZ, L. E.; MITCHELL, R. Conceptualizing impact assessment as a learning process. Environmental Impact Assessment Review, v.62 p. 195-204, 2017. Disponível em: https://www.sciencedirect.com/science/article/pii/S0195925516301664. Acesso em: jan. 2019.

SANDHAM, L. A.; PRETORIUS, H. M. A review of EIA report quality in the North West province of South Africa. Environmental Impact Assessment Review, v. 28, n. 4, p. 229-240, 2008. Disponível em:

https://www.sciencedirect.com/science/article/pii/S0195925507000935. Acesso em: jan. 2019.

SANTOS, R. F. Planejamento Ambiental: teoria e prática, São Paulo: Oficina de Textos, 2004.

SÃO PAULO. Secretário de Estado do Meio Ambiente. Resolução n. 54, de 30 de novembro de 2004. Dispõe sobre o licenciamento ambiental e regularização de empreendimentos urbanísticos e de saneamento básico considerados de utilidade pública e de interesse social e dá outras providências. São Paulo: SMA, 2004. Disponível em:

http://arquivos.ambiente.sp.gov.br/resolucao/2007/2007_res_est_sma_54.pdf Acesso em: 30 jul. 2017.

SÃO PAULO. Secretário de Estado do Meio Ambiente. Resolução Conjunta SMASAA n. 4, de 18 de outubro de 2008. Dispõe sobre o Zoneamento Agroambiental para o setor sucroalcooleiro no Estado de São Paulo. São Paulo: SMA, 2008.Disponível em:

<http://licenciamento.cetesb.sp.gov.br/legislacao/estadual/resolucoes/2008_Res_Co nj_SMA_SAA_4.pdf $>$. Acesso em: nov. 2018.

SÃO PAULO. Secretário de Estado do Meio Ambiente. Resolução SMA n. 49, de 28 de maio de 2014. Dispõe sobre os procedimentos para licenciamento ambiental com avaliação de impacto ambiental, no âmbito da Companhia Ambiental do Estado de 
São Paulo - CETESB. São Paulo: SMA, 2014. Disponível em: https://www.ambiente.sp.gov.br/legislacao/resolucoes-sma/resolucao-sma-49-2014/. Acesso em: jan. 2019.

SCHOEN, C.; SCHULTZ, J.; HEINZ, K.; GROTT, S. C.; PINHEIRO, A. Estudos de impacto ambiental: potencialidades, deficiências e perspectivas de elaboradores e avaliadores. Sustentabilidade em Debate, v. 7, n. 2, p. 257-270, 2016.

SMITH, G. Deliberative democracy and the environment. Londres: Routledge, 2003. $176 \mathrm{p}$.

SMITH, M. D. A Review of recent NEPA alternatives analysis case law.

Environmental Impact Assessment Review, v.27, p. 126-144. 2007. Disponível em: https://www.sciencedirect.com/science/article/pii/S0195925506001235. Acesso em: jan. 2019.

SOUZA, M. P. Instrumentos de gestão ambiental: fundamentos e prática. São Carlos: Riani Costa, 2000.

SOUZA, M.P. A base de referência e a avaliação de impacto ambiental. In: SIMPÓSIO DE GEOTECNOLOGIAS NO PANTANAL, 1. 2006, Campo Grande. Anais [...] Campo Grande: Embrapa Informática Agropecuária: INPE, 2006 p.749756. Dsiponível em:

https://www.researchgate.net/publication/237352809_A_base_de_referencia_e_a_av aliacao_de_impacto_ambiental. Acesso em: jan. $201 \overline{9}$.

STEINEMANN, A. Improving alternatives for environmental impact assessment. Environmental Impact Assessment Review, v.21, p. 3-21, 2001. Disponível em: https://cfpub.epa.gov/ncer_abstracts/index.cfm/fuseaction/display.files/filelD/12893. Acesso em: jan. 2019.

STEVENSON, W. J. Production/operations management. Homewood: Richard D. Irwin, 1993.

TICKENER, J. A.; GEISER, K. The precautionary principle stimulus for solutions and alternatives-based environmental policy. Environmental Impact Assessment Review, v.24 p. 801-824, 2004. Disponível em:

https://www.sciencedirect.com/science/article/pii/S0195925504000769. Acesso em: jan. 2019.

VALVE, $\mathrm{H}$. Frame conflicts and the formulation of alternatives: environmental assessment of na infrastructure plan. Enviromental Impact Assessment Review, v.19, p. 125-142, 1999. Disponível em:

https://www.sciencedirect.com/science/article/pii/S0195925598000365. Acesso em: jan. 2019.

ZUBAIR, L. Challenges for environmental impact assessment in Sri Lanka.

Environmental Impact Assessment Review, v.21, p.469-478, 2001. 


\section{APÊNDICE A - LISTA DE ESTUDOS DE IMPACTO AMBIENTAL DE 2005 A 2016}

Lista elaborada a partir do acervo digital da biblioteca da CETESB.

\begin{tabular}{|c|c|c|c|c|}
\hline Ano & $\begin{array}{l}\text { Proce } \\
\text { sso/L } \\
\text { ocaliz } \\
\text { ador }\end{array}$ & Empresa interessada & Empreendimento & Tipo \\
\hline $\begin{array}{c}2005 / \\
2009\end{array}$ & $\begin{array}{l}13717 \\
/ 0685\end{array}$ & Mineração Jundu Ltda., Descalvado (SP) & $\begin{array}{c}\text { Lavra de areia quartzosa Analândia e } \\
\text { Corumbataí - SP }\end{array}$ & Mineração \\
\hline $\begin{array}{l}2005 / \\
2009\end{array}$ & $\begin{array}{l}13550 \\
/ 0680\end{array}$ & Prefeitura Municipal de São José dos Campos & $\begin{array}{c}\text { Ampliação do aterro sanitário da estação de } \\
\text { tratamento de resíduos (ETRS) }\end{array}$ & $\begin{array}{l}\text { Tratamento de } \\
\text { resíduos }\end{array}$ \\
\hline $\begin{array}{l}2005 / \\
2008\end{array}$ & $\begin{array}{l}13500 \\
/ 0677\end{array}$ & $\begin{array}{l}\text { VOTORANTIM Cimento Brasil S/A, Nova } \\
\text { Campina }\end{array}$ & Lavra de calcário - Área Serrinha & Mineração \\
\hline $\begin{array}{c}2005 / \\
2008\end{array}$ & $\begin{array}{l}13735 \\
/ 0653\end{array}$ & $\begin{array}{l}\text { GSP Urbanização e Engenharia Ltda. , } \\
\text { Ourinhos }\end{array}$ & Loteamento Parque Trianon & $\begin{array}{l}\text { Loteamento/Con } \\
\text { domínio }\end{array}$ \\
\hline $\begin{array}{l}2005 / \\
2006\end{array}$ & $\begin{array}{l}13700 \\
/ 0580\end{array}$ & $\begin{array}{l}\text { DAMHA Açúcar e Álcool Industria e Comercio } \\
\text { Ltda }\end{array}$ & $\begin{array}{l}\text { Implantação da Destilaria DAHMA Açúcar e } \\
\text { Álcool Ind. e Comercio Ltda }\end{array}$ & $\begin{array}{l}\text { Agroindústria } \\
\text { Sucroenergético }\end{array}$ \\
\hline $\begin{array}{c}2005 / \\
2008\end{array}$ & $\begin{array}{l}13550 \\
/ 0636\end{array}$ & Prefeitura Municipal de São Jose dos Campos & $\begin{array}{l}\text { Ampliação do aterro sanitário da estação de } \\
\text { tratamento de resíduos sólidos - ETRS } \\
\text { administrada pela urbanizadora municipal S.A. - } \\
\text { URBAM São José dos Campos - SP }\end{array}$ & $\begin{array}{l}\text { Tratamento de } \\
\text { resíduos }\end{array}$ \\
\hline $\begin{array}{l}2005 / \\
2007\end{array}$ & $\begin{array}{l}13636 \\
/ 0581\end{array}$ & $\begin{array}{l}\text { Brasilinvest Empreendimentos e } \\
\text { Participações S/A, São Paulo, Toscana } \\
\text { Negócios e Participações AS COMURD } \\
\text { Sociedade de Projetos Urbanísticos }\end{array}$ & $\begin{array}{c}\text { Loteamento residencial Três Pontes do Atibaia e } \\
\text { acesso (prolongamento da Av. Alexandre } \\
\text { Mackenzie) }\end{array}$ & $\begin{array}{l}\text { Loteamento/Con } \\
\text { domínio }\end{array}$ \\
\hline $\begin{array}{l}2005 / \\
2006\end{array}$ & $\begin{array}{l}13701 \\
/ 0591 \\
\end{array}$ & Usina Colombo S.A. - Açúcar e Álcool & $\begin{array}{l}\text { Implantação da Destilaria de Álcool e Fabricação } \\
\text { de Açúcar Santa Albertina }\end{array}$ & $\begin{array}{c}\text { Agroindústria } \\
\text { Sucroenergético }\end{array}$ \\
\hline $\begin{array}{c}2005 / \\
2006\end{array}$ & $\begin{array}{l}13738 \\
10590 \\
\end{array}$ & Pillar Empreendimentos Ltda & $\begin{array}{l}\text { Loteamento comercial e residencial Portal dos } \\
\text { Ipes III }\end{array}$ & $\begin{array}{l}\text { Loteamento/Con } \\
\text { domínio }\end{array}$ \\
\hline $\begin{array}{l}2005 / \\
2006\end{array}$ & $\begin{array}{l}13750 \\
/ 0586 \\
\end{array}$ & Açúcar Guarani S/A - Unidade Cruz Alta & $\begin{array}{l}\text { Ampliações das Atividades Agroindustriais da } \\
\text { Açúcar Guarani S.A. Unidade Cruz Alta }\end{array}$ & $\begin{array}{c}\text { Agroindústria } \\
\text { Sucroenergético }\end{array}$ \\
\hline $\begin{array}{l}2005 / \\
2006 \\
\end{array}$ & $\begin{array}{l}13572 \\
/ 0579 \\
\end{array}$ & $\begin{array}{l}\text { Ajinomoto Biolatina Industria e Comercio } \\
\text { Ltda }\end{array}$ & $\begin{array}{c}\text { Ampliação de Unidade Industrial no Município } \\
\text { de Pederneiras }\end{array}$ & $\begin{array}{c}\text { Agroindústria } \\
\text { Sucroenergético }\end{array}$ \\
\hline $\begin{array}{c}2005 / \\
2006\end{array}$ & $\begin{array}{l}13657 \\
/ 0575\end{array}$ & Cocal Canaa Industria e Comercio Ltda & Unidade Agroindustrial Cocal II & $\begin{array}{l}\text { Agroindústria } \\
\text { Sucroenergético }\end{array}$ \\
\hline $\begin{array}{c}2005 / \\
2005\end{array}$ & $\begin{array}{l}13625 \\
/ 0610 \\
\end{array}$ & Tavares Pinheiro Industrial Ltda & $\begin{array}{l}\text { Lavra de granito, feldspato e areia para } \\
\text { construção civil e indústria cerâmica }\end{array}$ & Mineração \\
\hline $\begin{array}{c}2004 / \\
2005 \\
\end{array}$ & $\begin{array}{l}13734 \\
/ 0578 \\
\end{array}$ & Destilaria Pioneiros S/A & Destilaria Pioneiros S/A - Unidade Ilha Solteira & $\begin{array}{l}\text { Agroindústria } \\
\text { Sucroenergético }\end{array}$ \\
\hline $\begin{array}{c}2004 / \\
2005\end{array}$ & $\begin{array}{l}13654 \\
/ 0576\end{array}$ & Norfolk Distribuidora Ltda & Duto São José dos Campos - Mauá & Duto \\
\hline $\begin{array}{c}2005 / \\
2005\end{array}$ & $\begin{array}{l}13688 \\
/ 0574 \\
\end{array}$ & $\begin{array}{c}\text { TECONDI S/A - Terminal para Contêineres da } \\
\text { Margem Direita }\end{array}$ & $\begin{array}{l}\text { Ampliação da TECONDI - Terminal para } \\
\text { Contêineres da Margem Direita }\end{array}$ & $\begin{array}{c}\text { Portos e } \\
\text { terminais }\end{array}$ \\
\hline $\begin{array}{l}2005 / \\
2005\end{array}$ & $\begin{array}{l}13586 \\
/ 0573\end{array}$ & Mar Aberto Incorporações Ltda & Condomínio Penhasco das Tartarugas & $\begin{array}{l}\text { Loteamento/Con } \\
\text { domínio }\end{array}$ \\
\hline $\begin{array}{c}2002 / \\
2005 \\
\end{array}$ & $\begin{array}{l}13782 \\
/ 0572 \\
\end{array}$ & Prefeitura Municipal de Barueri & $\begin{array}{l}\text { Aterro sanitário de resíduos sólidos domiciliares: } \\
\qquad \text { Barueri, SP }\end{array}$ & $\begin{array}{l}\text { Tratamento de } \\
\text { resíduos }\end{array}$ \\
\hline $\begin{array}{c}2004 / \\
2005\end{array}$ & $\begin{array}{l}13571 \\
/ 0571\end{array}$ & AD Empreendimento Imobiliário Ltda & $\begin{array}{l}\text { Loteamento residenciais DAMHA São Jose do Rio } \\
\text { Preto - edição reelaborada }\end{array}$ & $\begin{array}{l}\text { Loteamento/Con } \\
\text { domínio }\end{array}$ \\
\hline $\begin{array}{c}2004 / \\
2005 \\
\end{array}$ & $\begin{array}{l}13707 \\
/ 0570 \\
\end{array}$ & Irmãos Biagi S.A. Açúcar e Álcool & Usina Ipê & $\begin{array}{c}\text { Agroindústria } \\
\text { Sucroenergético }\end{array}$ \\
\hline $\begin{array}{c}2002 / \\
2005\end{array}$ & $\begin{array}{l}13768 \\
/ 0569\end{array}$ & $\begin{array}{l}\text { Castor Engenharia e Comércio Ltda., São José } \\
\text { dos Campos }\end{array}$ & Loteamento Altos de São José & $\begin{array}{l}\text { Loteamento/Con } \\
\text { domínio }\end{array}$ \\
\hline $\begin{array}{l}2000 / \\
2005\end{array}$ & $\begin{array}{l}13747 \\
/ 0568\end{array}$ & $\begin{array}{c}\text { Federação das Entidades Assistencialistas de } \\
\text { Campinas - FEAC }\end{array}$ & Desenvolvimento Urbano da Fazenda Brandina & $\begin{array}{l}\text { Loteamento/Con } \\
\text { domínio }\end{array}$ \\
\hline $\begin{array}{c}2003 / \\
2005 \\
\end{array}$ & $\begin{array}{l}13554 \\
/ 0567 \\
\end{array}$ & MRS Logistica S. A., Juiz de Fora & $\begin{array}{l}\text { Otimização do transporte de cargas entre } \\
\text { Planalto e Baixada Santista }\end{array}$ & Ferroviário \\
\hline $\begin{array}{l}2005 / \\
2005\end{array}$ & $\begin{array}{l}13718 \\
/ 0566\end{array}$ & Usina Petribu Paulista Ltda & Usina Petribu Paulista Ltda & $\begin{array}{c}\text { Agroindústria } \\
\text { Sucroenergético }\end{array}$ \\
\hline $\begin{array}{c}2005 / \\
2005 \\
\end{array}$ & $\begin{array}{l}13567 \\
/ 0565 \\
\end{array}$ & $\begin{array}{l}\text { ESTRE Empresa Saneamento e Tratamento de } \\
\text { Resíduos Ltda }\end{array}$ & $\begin{array}{l}\text { Centro de Gerenciamento de Resíduos - } \\
\text { Guatapara : aterro para resíduos não perigosos }\end{array}$ & $\begin{array}{l}\text { Tratamento de } \\
\text { resíduos }\end{array}$ \\
\hline $\begin{array}{l}2005 / \\
2005\end{array}$ & $\begin{array}{l}13509 \\
/ 0564\end{array}$ & $\begin{array}{l}\text { Departamento Aeroviário do Estado Sao } \\
\text { Paulo }\end{array}$ & $\begin{array}{l}\text { Aeroporto Leite Lopes no Município de Ribeirão } \\
\text { Preto - SP }\end{array}$ & Aeroportos \\
\hline $\begin{array}{c}2005 / \\
2005 \\
\end{array}$ & $\begin{array}{l}13600 \\
/ 0563 \\
\end{array}$ & $\begin{array}{l}\text { CJ do Brasil Industria e Comercio de Produtos } \\
\text { Alimentícios Ltda }\end{array}$ & Fabricação de aminoácido lisina & Indústria \\
\hline $\begin{array}{l}2005 / \\
2005\end{array}$ & $\begin{array}{l}13723 \\
/ 0561\end{array}$ & $\begin{array}{l}\text { Trump Realty Brazil Empreendimentos e } \\
\text { Participações Sa. }\end{array}$ & Villa Trump & $\begin{array}{l}\text { Loteamento/ } \\
\text { Condomínio }\end{array}$ \\
\hline
\end{tabular}




\begin{tabular}{|c|c|c|c|c|}
\hline $\begin{array}{l}2005 / \\
2005\end{array}$ & $\begin{array}{l}13550 \\
/ 0560\end{array}$ & Refinaria de Paulínia û REPLAN, Paulínia & $\begin{array}{l}\text { Projeto de otimização da produção da refinaria } \\
\text { de Paulínia - REPLAN }\end{array}$ & Indústria \\
\hline $\begin{array}{l}2005 / \\
2005\end{array}$ & $\begin{array}{l}13728 \\
/ 0559\end{array}$ & Petrobras - Petróleo Brasileiro S.A. & $\begin{array}{l}\text { Refinaria Presidente Bernardes de Cubatão - } \\
\text { RPBC : melhorias tecnológicas e ambientais - } \\
\text { carteira de gasolina }\end{array}$ & Indústria \\
\hline $\begin{array}{c}2005 / \\
2005\end{array}$ & $\begin{array}{c}? / 055 \\
8 \\
\end{array}$ & Frey \& Stuchi Ltda - Ligas de Chumbo & Aterro para resíduos classe I & $\begin{array}{l}\text { Tratamento de } \\
\text { resíduos }\end{array}$ \\
\hline $\begin{array}{c}2005 / \\
2005\end{array}$ & $\begin{array}{l}13683 \\
/ 0557\end{array}$ & Usina Ouroeste Açúcar e Alcool Ltda & Implantação de usina de açúcar e álcool & $\begin{array}{l}\text { Agroindústria } \\
\text { Sucroenergético }\end{array}$ \\
\hline $\begin{array}{l}2005 / \\
2005\end{array}$ & $\begin{array}{l}13720 \\
/ 0556\end{array}$ & $\begin{array}{l}\text { EMTU Empresa Metropolitana de Transporte } \\
\text { Urbano }\end{array}$ & $\begin{array}{l}\text { Corredor Metropolitano Noroeste - Lote } 1 \text { : } \\
\text { Estudos Ambientais e Consolidação de Projeto } \\
\text { Funcional }\end{array}$ & Rodoviário \\
\hline $\begin{array}{l}2005 / \\
2005\end{array}$ & $\begin{array}{l}13744 \\
/ 0555 \\
\end{array}$ & Serveng Civilsan S.A. & Loteamento Misto Aquarius & $\begin{array}{l}\text { Loteamento/ } \\
\text { Condomínio }\end{array}$ \\
\hline $\begin{array}{l}2003 / \\
2005\end{array}$ & $\begin{array}{l}13568 \\
/ 0553\end{array}$ & Construtora Queiroz Galvão, São Paulo & $\begin{array}{l}\text { CENTRES: Centro de tratamento de resíduos : } \\
\text { aterro sanitário com disposição para resíduo } \\
\text { industrial classe II A }\end{array}$ & $\begin{array}{l}\text { Tratamento de } \\
\text { resíduos }\end{array}$ \\
\hline $\begin{array}{c}2002 / \\
2005\end{array}$ & $\begin{array}{l}13794 \\
/ 0552 \\
\end{array}$ & Prefeitura de Presidente Prudente & $\begin{array}{c}\text { Aterro sanitário de Presidente Prudente - edição } \\
\text { reelaborada }\end{array}$ & $\begin{array}{l}\text { Tratamento de } \\
\text { resíduos }\end{array}$ \\
\hline 2005 & $\begin{array}{c}? / 055 \\
1 \\
\end{array}$ & Granvisa Marmores e Granitos Ltda & $\begin{array}{c}\text { Jazida Cachoeira - Lavra experimental de granito } \\
\text { ornamental na Fazenda Cachoeira }\end{array}$ & Mineração \\
\hline 2005 & $\begin{array}{c}? / 055 \\
0\end{array}$ & Pedreira Sargon Ltda & Ampliação da área de lavra & Mineração \\
\hline $\begin{array}{c}2006 / \\
2013\end{array}$ & $\begin{array}{l}13709 \\
/ 0705 \\
\end{array}$ & $\begin{array}{l}\text { Uilson Romanha E Cia Ltda. Ltda., } \\
\text { Itapetininga }\end{array}$ & Mineração de areia a céu aberto & Mineração \\
\hline $\begin{array}{c}2006 / \\
2009\end{array}$ & $\begin{array}{l}13777 \\
/ 0725 \\
\end{array}$ & $\begin{array}{l}\text { Prefeitura Municipal de Campinas/ SANASA } \\
\text { Campinas }\end{array}$ & Aterro Sanitário Delta B & $\begin{array}{l}\text { Tratamento de } \\
\text { resíduos }\end{array}$ \\
\hline $\begin{array}{r}2006 / \\
2009\end{array}$ & $\begin{array}{l}13520 \\
/ 0723 \\
\end{array}$ & $\begin{array}{l}\text { SF Produção de Energia Elétrica Ltda., } \\
\text { Amparo }\end{array}$ & $\begin{array}{l}\text { Pequena central hidrelétrica São Francisco - Rio } \\
\text { Pardo }\end{array}$ & Hidrelétrica \\
\hline $\begin{array}{c}2006 / \\
2009\end{array}$ & $\begin{array}{l}13626 \\
/ 0721 \\
\end{array}$ & $\begin{array}{l}\text { PB Produção de Energia Elétrica Ltda., Rio } \\
\text { Pardo }\end{array}$ & $\begin{array}{c}\text { Pequena central hidrelétrica Ponte Branca - Rio } \\
\text { Pardo: laras e Águas de Santa Barbara }\end{array}$ & Hidrelétrica \\
\hline $\begin{array}{c}2006 / \\
2009\end{array}$ & $\begin{array}{l}13609 \\
/ 0710 \\
\end{array}$ & Usina Noroeste Paulista Ltda & $\begin{array}{c}\text { Ampliação industrial e agrícola da usina } \\
\text { Noroeste Paulista Ltda }\end{array}$ & $\begin{array}{l}\text { Agroindústria } \\
\text { Sucroenergético }\end{array}$ \\
\hline $\begin{array}{l}2006 / \\
2008\end{array}$ & $\begin{array}{l}13639 \\
/ 0678 \\
\end{array}$ & $\begin{array}{c}\text { Empresa Bragantina de Varrição e Coleta de } \\
\text { Lixo - EMBRALIXO }\end{array}$ & $\begin{array}{l}\text { Ampliação do aterro sanitário de Bragança } \\
\text { Paulista }\end{array}$ & $\begin{array}{l}\text { Tratamento de } \\
\text { resíduos }\end{array}$ \\
\hline $\begin{array}{c}2006 / \\
2008\end{array}$ & $\begin{array}{c}13814 \\
\mathrm{z} / 067 \\
6\end{array}$ & $\begin{array}{c}\text { Usina Colombo S/A Açúcar e Álcool û } \\
\text { Unidade Santa Clara D'Oeste }\end{array}$ & Implantação industrial e agrícola & $\begin{array}{l}\text { Agroindústria } \\
\text { Sucroenergético }\end{array}$ \\
\hline $\begin{array}{r}2006 / \\
2008\end{array}$ & $\begin{array}{l}13801 \\
/ 0668 \\
\end{array}$ & Mineração Descalvado Ltda, Descalvado & Extração de areia quartzosa & Mineração \\
\hline $\begin{array}{c}2006 / \\
2008\end{array}$ & $\begin{array}{l}13813 \\
/ 0661 \\
\end{array}$ & $\begin{array}{c}\text { Açúcar Guarani S/A - Unidade Industrial } \\
\text { Tanabi, Tanabi }\end{array}$ & $\begin{array}{l}\text { Ampliação industrial e agrícola da Unidade de } \\
\text { Tanabi }\end{array}$ & $\begin{array}{l}\text { Agroindústria } \\
\text { Sucroenergético }\end{array}$ \\
\hline $\begin{array}{r}2006 / \\
2008\end{array}$ & $\begin{array}{l}13821 \\
/ 0659 \\
\end{array}$ & Iberia Indústria e Comércio Ltda., Borá & $\begin{array}{l}\text { Ampliação Industrial e agrícola da Iberia } \\
\text { Industrial e Comercial Ltda. }\end{array}$ & $\begin{array}{l}\text { Agroindústria } \\
\text { Sucroenergético }\end{array}$ \\
\hline $\begin{array}{l}2006 / \\
2008\end{array}$ & $\begin{array}{l}13860 \\
/ 0650\end{array}$ & Constroleo Lubrificantes Ltda & $\begin{array}{l}\text { Obras de implantação da unidade industrial de } \\
\text { rerrefino de óleos lubrificantes Constroleo } \\
\text { Lubrificantes Ltda - Município de Galia - SP }\end{array}$ & Indústria \\
\hline $\begin{array}{r}2006 / \\
2008\end{array}$ & $\begin{array}{l}13806 \\
/ 0649 \\
\end{array}$ & Prefeitura de Santo André & $\begin{array}{l}\text { Ampliação da central de tratamento e } \\
\text { destinação final de resíduos sólidos }\end{array}$ & $\begin{array}{l}\text { Tratamento de } \\
\text { resíduos }\end{array}$ \\
\hline $\begin{array}{r}2006 / \\
2008\end{array}$ & $\begin{array}{l}13676 \\
/ 0648 \\
\end{array}$ & Usina Sao Jose da Estiva S/A & $\begin{array}{c}\text { Ampliação industrial e cogeração de energia } \\
\text { eletrica }\end{array}$ & $\begin{array}{l}\text { Agroindústria } \\
\text { Sucroenergético }\end{array}$ \\
\hline $\begin{array}{l}2006 / \\
2008 \\
\end{array}$ & $\begin{array}{l}13782 \\
/ 0646 \\
\end{array}$ & Alphaville Urbanismo S.A. & $\begin{array}{c}\text { Implantação dos loteamentos Alphaville Dom } \\
\text { Pedro II e Dom Pedro III }\end{array}$ & $\begin{array}{l}\text { Loteamento/ } \\
\text { Condomínio }\end{array}$ \\
\hline $\begin{array}{l}2006 / \\
2008\end{array}$ & $\begin{array}{l}13872 \\
/ 0645 \\
\end{array}$ & & $\begin{array}{l}\text { Ampliação Industrial e Agrícola da Antonio } \\
\text { Ruette Agroindustrial Ltda. }\end{array}$ & $\begin{array}{l}\text { Agroindústria } \\
\text { Sucroenergético }\end{array}$ \\
\hline $\begin{array}{c}2006 / \\
2008 \\
\end{array}$ & $\begin{array}{l}13812 \\
/ 0642 \\
\end{array}$ & Viralcool Açúcar e Álcool Ltda & Ampliacao industrial e agrícola da Viralcool & $\begin{array}{l}\text { Agroindústria } \\
\text { Sucroenergético }\end{array}$ \\
\hline $\begin{array}{l}2006 / \\
2008\end{array}$ & $\begin{array}{l}13811 \\
/ 0641 \\
\end{array}$ & Usina Mandu S.A., Guaíra & Usina Mandu S/A & $\begin{array}{l}\text { Agroindústria } \\
\text { Sucroenergético }\end{array}$ \\
\hline $\begin{array}{l}2006 / \\
2007\end{array}$ & $\begin{array}{l}13513 \\
/ 0633 \\
\end{array}$ & CAS Construtora Ltda. & Plano Urbanístico Castello 90 & $\begin{array}{c}\text { Loteamento/ } \\
\text { Condomínio }\end{array}$ \\
\hline $\begin{array}{c}2006 / \\
2006\end{array}$ & $\begin{array}{l}13535 \\
/ 0738 \\
\end{array}$ & Usina Bela Vista S.A., Pontal & Ampliação da Usina Bela Vista S.A. Pontal/SP & $\begin{array}{c}\text { Agroindústria } \\
\text { Sucroenergético }\end{array}$ \\
\hline $\begin{array}{c}2006 / \\
2006\end{array}$ & $\begin{array}{l}13500 \\
/ 0632 \\
\end{array}$ & Prefeitura Municipal de Sorocaba & $\begin{array}{l}\text { Implantação do aterro sanitário Municipal de } \\
\text { Sorocaba }\end{array}$ & $\begin{array}{c}\text { Tratamento de } \\
\text { resíduos }\end{array}$ \\
\hline $\begin{array}{l}2006 / \\
2006\end{array}$ & $\begin{array}{l}13606 \\
/ 0630\end{array}$ & Prefeitura Municipal de São Paulo - SIURB & $\begin{array}{l}\text { Projeto básico viário de prolongamento da } \\
\text { Av.Jacú Pêssego - Trecho: desde Av.Ragueb } \\
\text { Choffi até Av.do Estado no município de Mauá }\end{array}$ & Rodoviário \\
\hline
\end{tabular}




\begin{tabular}{|c|c|c|c|c|}
\hline $\begin{array}{l}2006 / \\
2006\end{array}$ & $\begin{array}{l}13826 \\
/ 0627\end{array}$ & Açucareira Quatá S/A, Quatá & Ampliação da produção e áreas de plantio & $\begin{array}{l}\text { Agroindústria } \\
\text { Sucroenergético }\end{array}$ \\
\hline $\begin{array}{c}2006 / \\
2006\end{array}$ & $\begin{array}{l}13889 \\
/ 0626 \\
\end{array}$ & $\begin{array}{l}\text { ODEBRECHT Empreendimentos Imobiliários } \\
\text { Ltda, São Paulo }\end{array}$ & $\begin{array}{c}\text { Implantação de condomínio residencial } \\
\text { denominado Nova Capivari }\end{array}$ & $\begin{array}{c}\text { Loteamento/ } \\
\text { Condomínio }\end{array}$ \\
\hline $\begin{array}{l}2006 / \\
2006\end{array}$ & $\begin{array}{l}13608 \\
/ 0612\end{array}$ & CBA - Companhia Brasileira de Alumínio & UHE Tijuco Alto & Hidrelétrica \\
\hline $\begin{array}{c}2002 / \\
2006\end{array}$ & $\begin{array}{l}13728 \\
/ 0592\end{array}$ & Companhia de Cimento Portland Itaú, Itapeva & Minas Salto 1, 2, 3 e 4 Bom Sucesso de Itararé & Mineração \\
\hline $\begin{array}{c}2004 / \\
2006\end{array}$ & $\begin{array}{l}13682 \\
/ 0589 \\
\end{array}$ & Carbocloro S.A. Industrias Químicas & $\begin{array}{l}\text { Construção de um terminal marítimo para sal, } \\
\text { em Santos e Cubatão }\end{array}$ & $\begin{array}{l}\text { Portos e } \\
\text { terminais }\end{array}$ \\
\hline $\begin{array}{c}2000 / \\
2006\end{array}$ & $\begin{array}{l}13528 \\
/ 0588\end{array}$ & Yunes Minerios Ltda & Extração de areia para construção civil & Mineração \\
\hline $\begin{array}{l}2004 / \\
2006 \\
\end{array}$ & $\begin{array}{l}13558 \\
/ 0587 \\
\end{array}$ & Alphaville Urbanismo S.A. & Loteamento Alphaville Sao Jose dos Campos & $\begin{array}{l}\text { Loteamento/ } \\
\text { Condomínio }\end{array}$ \\
\hline 2006 & $\begin{array}{c}? / 058 \\
5\end{array}$ & Brasfanta Indústria e Comércio Ltda & $\begin{array}{c}\text { Loteamento residencial e complexo turístico - } \\
\text { município de Bertioga }\end{array}$ & $\begin{array}{l}\text { Loteamento/ } \\
\text { Condomínio }\end{array}$ \\
\hline $\begin{array}{l}1996 / \\
2006\end{array}$ & $\begin{array}{l}13562 \\
/ 0584\end{array}$ & $\begin{array}{c}\text { Brasterra Empreendimentos Imobiliários } \\
\text { Ltda., Cubatão, JGP Consultoria e } \\
\text { Participações Ltda }\end{array}$ & $\begin{array}{c}\text { Programa de desenvolvimento urbano da zona } \\
\text { de interesse público IP-8 (antigo sub-setor 10.2) } \\
\text { no município de Cubatão }\end{array}$ & $\begin{array}{l}\text { Loteamento/ } \\
\text { Condomínio }\end{array}$ \\
\hline $\begin{array}{l}2004 / \\
2006\end{array}$ & $\begin{array}{l}13522 \\
/ 0583\end{array}$ & Prefeitura do Município de Piracicaba & $\begin{array}{c}\text { Central de triagem, de tratamento e de } \\
\text { disposição final de resíduos sólidos domiciliares } \\
\text { do município de Piracicaba - SP }\end{array}$ & $\begin{array}{l}\text { Tratamento de } \\
\text { resíduos }\end{array}$ \\
\hline $\begin{array}{c}2006 / \\
2006\end{array}$ & $\begin{array}{l}13548 \\
/ 0582 \\
\end{array}$ & Refinaria de Paulínia - REPLAN, Paulínia & $\begin{array}{l}\text { Projeto de modernização da Refinaria de } \\
\text { Paulínia - REPLAN }\end{array}$ & Indústria \\
\hline 2006 & $\begin{array}{l}13627 \\
/ 0577\end{array}$ & Equipav S/A Açúcar e Álcool & $\begin{array}{l}\text { Ampliações da Equipav S/A Açúcar e Álcool : } \\
\text { Promissão }\end{array}$ & $\begin{array}{c}\text { Agroindústria } \\
\text { Sucroenergético }\end{array}$ \\
\hline $\begin{array}{l}2004 / \\
2006\end{array}$ & $\begin{array}{l}13604 \\
/ 0562\end{array}$ & Encalso Construcoes Ltda & $\begin{array}{c}\text { Plano urbanístico - Condomínios residenciais } \\
\text { ecoesportivos DAMHA São Carlos - edição } \\
\text { reelaborada em abril }\end{array}$ & $\begin{array}{l}\text { Loteamento/ } \\
\text { Condomínio }\end{array}$ \\
\hline $\begin{array}{l}2004 / \\
2006 \\
\end{array}$ & $\begin{array}{l}13792 \\
/ 0554 \\
\end{array}$ & RESITEC Tecnologia em Residuos Ltda & $\begin{array}{l}\text { Aterro sanitário em regime de disposição com } \\
\text { resíduos industriais classe Il e autoclave }\end{array}$ & $\begin{array}{l}\text { Tratamento de } \\
\text { resíduos }\end{array}$ \\
\hline $\begin{array}{c}2006 / \\
1989 \\
\end{array}$ & $\begin{array}{l}13608 \\
/ 0132 \\
\end{array}$ & CIA.BRASILEIRA DE ALUMÍNIO, São Paulo & Aproveitamento Hidrelétrico Tijuco Alto & Hidrelétrica \\
\hline $\begin{array}{l}2006 / \\
2007\end{array}$ & $\begin{array}{l}13853 \\
/ 0629 \\
\end{array}$ & $\begin{array}{l}\text { Petrobrás - Petroleo Brasileiro S/A, Rio de } \\
\text { Janeiro }\end{array}$ & Plano diretor de dutos de São Paulo & Duto \\
\hline $\begin{array}{r}2007 / \\
2014\end{array}$ & $\begin{array}{l}13536 \\
/ 0832\end{array}$ & Alphaville Urbanismo S.A, São Paulo & $\begin{array}{c}\text { Loteamento residencial Alphaville Vila Florestal - } \\
\text { Reserva Cotia: Estudo de Impacto Ambiental - } \\
\text { Consolidado }\end{array}$ & $\begin{array}{l}\text { Loteamento/ } \\
\text { Condomínio }\end{array}$ \\
\hline $\begin{array}{r}2007 / \\
2012 \\
\end{array}$ & $\begin{array}{l}13631 \\
/ 0790 \\
\end{array}$ & Dirceu Luis Bovi, Ocauçu & $\begin{array}{c}\text { Dirceu Luis Bovi: usina de açúcar, etanol e } \\
\text { energia }\end{array}$ & $\begin{array}{c}\text { Agroindústria } \\
\text { Sucroenergético }\end{array}$ \\
\hline $\begin{array}{c}2007 / \\
2011\end{array}$ & $\begin{array}{l}13523 \\
/ 0772 \\
\end{array}$ & DER, São Paulo; DERSA, São Paulo & $\begin{array}{l}\text { Duplicação da Rodovia dos Tamoios (SP-99) } \\
\text { subtrecho Planalto Km 11+500 ao KM 60+480 }\end{array}$ & Rodoviário \\
\hline $\begin{array}{r}2007 / \\
2010 \\
\end{array}$ & $\begin{array}{l}13755 \\
/ 0745 \\
\end{array}$ & $\begin{array}{c}\text { Da Mata S/A Açúcar e Álcool Filial Santa } \\
\text { Marina }\end{array}$ & Da Mata Açúcar e Álcool Filial Santa Marina & $\begin{array}{c}\text { Agroindústria } \\
\text { Sucroenergético }\end{array}$ \\
\hline $\begin{array}{r}2007 / \\
2010 \\
\end{array}$ & $\begin{array}{l}13828 \\
/ 0729 \\
\end{array}$ & $\begin{array}{l}\text { Montante Incorporações Ltda., São José dos } \\
\text { Campos }\end{array}$ & Loteamento Residencial Bela Aliança & $\begin{array}{c}\text { Loteamento/ } \\
\text { Condomínio }\end{array}$ \\
\hline $\begin{array}{c}2007 / \\
2009 \\
\end{array}$ & $\begin{array}{l}13831 \\
/ 0726 \\
\end{array}$ & $\begin{array}{l}\text { Petróleo Brasileiro S.A. û PETROBRAS, } \\
\text { Cubatão }\end{array}$ & $\begin{array}{c}\text { Carteira de diesel da Refinaria Presidente } \\
\text { Bernardes - Cubatão }\end{array}$ & Indústria \\
\hline $\begin{array}{c}2007 / \\
2009 \\
\end{array}$ & $\begin{array}{l}13775 \\
/ 0724 \\
\end{array}$ & Ibiuna Marina Golf Club Ltda & Ibiuna Marina Golf Club Loteamento residencial & $\begin{array}{l}\text { Loteamento/ } \\
\text { Condomínio }\end{array}$ \\
\hline $\begin{array}{l}2007 / \\
2009\end{array}$ & $\begin{array}{l}13608 \\
/ 0712\end{array}$ & $\begin{array}{l}\text { Brasil Ambiental Tratamento de Resíduos } \\
\qquad \text { S/A, Serra- ES }\end{array}$ & $\begin{array}{l}\text { Implantação da Central de Tratamento de } \\
\text { Resíduos Classe I (perigosos) e Classe II û NBR } \\
\text { 10.004 - CTR, no município de Guará û SP }\end{array}$ & $\begin{array}{l}\text { Tratamento de } \\
\text { resíduos }\end{array}$ \\
\hline $\begin{array}{c}2007 / \\
2009\end{array}$ & $\begin{array}{l}13767 \\
/ 0702\end{array}$ & $\begin{array}{c}\text { Clealco Açúcar e Álcool Ltda - Unidade } \\
\text { Queiroz }\end{array}$ & $\begin{array}{c}\text { Ampliação agrícola e industrial de unidade do } \\
\text { setor de açúcar e álcool da Clealco - Unidade } \\
\text { Queiroz }\end{array}$ & $\begin{array}{l}\text { Agroindústria } \\
\text { Sucroenergético }\end{array}$ \\
\hline $\begin{array}{c}2007 / \\
0699 \\
\end{array}$ & $\begin{array}{l}13771 \\
/ 0699 \\
\end{array}$ & Pedra Agroindustrial S/A - Usina Buriti & $\begin{array}{c}\text { Ampliacao de Pedra Agroindustrial S/A. Usina } \\
\text { Buriti }\end{array}$ & $\begin{array}{c}\text { Agroindústria } \\
\text { Sucroenergético }\end{array}$ \\
\hline $\begin{array}{c}2007 / \\
2009\end{array}$ & $\begin{array}{l}13549 \\
/ 0694 \\
\end{array}$ & $\begin{array}{l}\text { Usina Moema Açúcar e Álcool Ltda., } \\
\text { Orindiúva }\end{array}$ & $\begin{array}{l}\text { Ampliação agrícola e industrial de unidade do } \\
\text { setor de açúcar e álcool }\end{array}$ & $\begin{array}{c}\text { Agroindústria } \\
\text { Sucroenergético }\end{array}$ \\
\hline $\begin{array}{r}2007 / \\
2009 \\
\end{array}$ & $\begin{array}{l}13854 \\
/ 0692 \\
\end{array}$ & Usina lacanga de Acucar e Alcool Ltda & Ampliação Usina lacanga de açúcar e alcool Ltda & $\begin{array}{c}\text { Agroindústria } \\
\text { Sucroenergético }\end{array}$ \\
\hline $\begin{array}{c}2007 / \\
2009 \\
\end{array}$ & $\begin{array}{l}13760 \\
/ 0691 \\
\end{array}$ & $\begin{array}{l}\text { Vale Soluções Ambientais Ltda., Cachoeira } \\
\text { Paulista }\end{array}$ & Aterro Sanitário Vale Soluções Ambientais Ltda. & $\begin{array}{l}\text { Tratamento de } \\
\text { resíduos }\end{array}$ \\
\hline $\begin{array}{l}2007 / \\
2009\end{array}$ & $\begin{array}{l}13700 \\
/ 0690\end{array}$ & $\begin{array}{l}\text { Agra Loteadora S/A, Agropecuária Santa Rosa } \\
\qquad \text { Ltda, Itatiba }\end{array}$ & $\begin{array}{l}\text { Loteamento comercial e residencial Fazenda } \\
\text { Santa Rosa }\end{array}$ & $\begin{array}{l}\text { Loteamento/ } \\
\text { Condomínio }\end{array}$ \\
\hline $\begin{array}{r}2007 / \\
2009 \\
\end{array}$ & $\begin{array}{l}13853 \\
/ 0688 \\
\end{array}$ & $\begin{array}{c}\text { Cia Boa Vista de Desenvolvimento } \\
\text { Imobiliário, São Paulo } \\
\end{array}$ & Loteamento misto Fazenda Boa Vista - Fase 2 & $\begin{array}{c}\text { Loteamento/ } \\
\text { Condomínio }\end{array}$ \\
\hline
\end{tabular}




\begin{tabular}{|c|c|c|c|c|}
\hline $\begin{array}{l}2007 / \\
2009\end{array}$ & $\begin{array}{l}13518 \\
/ 0687\end{array}$ & $\begin{array}{l}\text { ARALCO S.A Indústria e Comércio, Santo } \\
\text { Antônio do Aracanguá }\end{array}$ & Ampliação industrial e agrícola & $\begin{array}{l}\text { Agroindústria } \\
\text { Sucroenergético }\end{array}$ \\
\hline $\begin{array}{c}2007 / \\
2009\end{array}$ & $\begin{array}{l}13816 \\
/ 0684\end{array}$ & COPLASA Açúcar e Álcool Ltda., Planalto & Ampliação industrial e agrícola & $\begin{array}{l}\text { Agroindústria } \\
\text { Sucroenergético }\end{array}$ \\
\hline $\begin{array}{c}2007 / \\
2009\end{array}$ & $\begin{array}{l}13628 \\
/ 0682 \\
\end{array}$ & DA MATA S/A. Açúcar e Álcool & $\begin{array}{c}\text { Ampliação industrial da usina Da Mata S/A } \\
\text { Açúcar e Álcool }\end{array}$ & $\begin{array}{c}\text { Agroindústria } \\
\text { Sucroenergético }\end{array}$ \\
\hline $\begin{array}{c}2007 / \\
2009\end{array}$ & $\begin{array}{l}13818 \\
/ 0681\end{array}$ & Atena Tecnologias em Energia Natural Ltda & $\begin{array}{c}\text { Ampliação industrial e agrícola e de produção de } \\
\text { energia elétrica da Atena Tecnologias em } \\
\text { Energia Natural Ltda }\end{array}$ & $\begin{array}{l}\text { Agroindústria } \\
\text { Sucroenergético }\end{array}$ \\
\hline $\begin{array}{c}2007 / \\
2008\end{array}$ & $\begin{array}{l}13845 \\
/ 0679\end{array}$ & $\begin{array}{l}\text { Secretaria de Estado dos Transportes } \\
\text { Metropolitanos }\end{array}$ & $\begin{array}{c}\text { Implantação do sistema integrado } \\
\text { Metropolitano - SIM e do veículo leve sobre } \\
\text { trilhos - VLT da Região Metropolitana da Baixada } \\
\text { Santista - RMBS. }\end{array}$ & Ferroviário \\
\hline $\begin{array}{c}2007 / \\
2008\end{array}$ & $\begin{array}{l}13573 \\
/ 0675 \\
\end{array}$ & Prefeitura Municipal do Guarujá & $\begin{array}{l}\text { Recuperação socioambiental e urbanização de } \\
\text { Santa Cruz dos Navegantes }\end{array}$ & $\begin{array}{c}\text { Projeto } \\
\text { Urbanístico }\end{array}$ \\
\hline $\begin{array}{c}2007 / \\
2008\end{array}$ & $\begin{array}{l}13584 \\
/ 0674\end{array}$ & $\begin{array}{c}\text { Votorantim Cimentos Brasil S.A., } \\
\text { Araçariguama }\end{array}$ & Extração de calcário para brita & Mineração \\
\hline $\begin{array}{c}2007 / \\
2008\end{array}$ & $\begin{array}{l}13815 \\
/ 0671\end{array}$ & Usina Dracena açúcar e álcool Ltda., Dracena & Ampliação Usina Dracena açúcar e álcool & $\begin{array}{c}\text { Agroindústria } \\
\text { Sucroenergético }\end{array}$ \\
\hline $\begin{array}{c}2007 / \\
2008\end{array}$ & $\begin{array}{l}13735 \\
/ 0670 \\
\end{array}$ & $\begin{array}{c}\text { CPTM : Companhia Paulista de Trens } \\
\text { Metropolitano }\end{array}$ & $\begin{array}{c}\text { Expresso aeroporto e trem de Guarulhos - } \\
\text { revisado }\end{array}$ & Ferroviário \\
\hline $\begin{array}{l}2007 / \\
2008\end{array}$ & $\begin{array}{l}13754 \\
/ 0667\end{array}$ & ENGEP Engenharia e Pavimentação Ltda & $\begin{array}{c}\text { Aterro industrial para resíduos classe II A e II B } \\
\text { em regime de disposição com resíduos sólidos } \\
\text { domiciliares }\end{array}$ & $\begin{array}{l}\text { Tratamento de } \\
\text { resíduos }\end{array}$ \\
\hline $\begin{array}{c}2007 / \\
2008\end{array}$ & $\begin{array}{l}13720 \\
/ 0666 \\
\end{array}$ & $\begin{array}{l}\text { S F Desenvolvimento Imobiliário Ltda., } \\
\text { Campinas }\end{array}$ & Loteamento residencial Ville Sainte - Helene II & $\begin{array}{l}\text { Loteamento/ } \\
\text { Condomínio }\end{array}$ \\
\hline $\begin{array}{c}2007 / \\
2008\end{array}$ & $\begin{array}{l}13813 \\
/ 0664 \\
\end{array}$ & Usina Batatais S/A - Açúcar e Álcool, Batatais & $\begin{array}{c}\text { Ampliação da produção e das áreas de plantio da } \\
\text { Usina Batatais S/A }\end{array}$ & $\begin{array}{c}\text { Agroindústria } \\
\text { Sucroenergético }\end{array}$ \\
\hline $\begin{array}{l}2007 / \\
2008\end{array}$ & $\begin{array}{l}13812 \\
/ 0662\end{array}$ & Usinas Batatais S/A, Lins & $\begin{array}{c}\text { Ampliação Industrial da produção e das áreas de } \\
\text { plantio : Usina Batatais S/A. Açúcar e Álcool - } \\
\text { Unidade Lins }\end{array}$ & $\begin{array}{l}\text { Agroindústria } \\
\text { Sucroenergético }\end{array}$ \\
\hline $\begin{array}{c}2007 / \\
2008\end{array}$ & $\begin{array}{l}13694 \\
/ 0660\end{array}$ & $\begin{array}{l}\text { Agropecuária Guatambu e Heber } \\
\text { Participações Ltda., Buri }\end{array}$ & $\begin{array}{c}\text { Ampliação Industrial da produção e das áreas de } \\
\text { plantio : Usina Batatais S/A. Açúcar e Álcool - } \\
\text { Unidade Lins }\end{array}$ & $\begin{array}{l}\text { Agroindústria } \\
\text { Sucroenergético }\end{array}$ \\
\hline $\begin{array}{c}2007 / \\
2008\end{array}$ & $\begin{array}{l}13766 \\
/ 0658\end{array}$ & Usina Guariroba Ltda., Pontes de Gestal & $\begin{array}{c}\text { Destilaria de álcool, fabricação de açúcar e } \\
\text { cogeração de energia (consumo próprio) - Usina } \\
\text { Guariroba }\end{array}$ & $\begin{array}{l}\text { Agroindústria } \\
\text { Sucroenergético }\end{array}$ \\
\hline $\begin{array}{c}2007 / \\
2008\end{array}$ & $\begin{array}{l}13546 \\
/ 0657\end{array}$ & Usina ARALCO S/A, Auriflama & $\begin{array}{c}\text { Implantação Industrial e agrícola - Usina Aralco } \\
\text { S.A }\end{array}$ & $\begin{array}{c}\text { Agroindústria } \\
\text { Sucroenergético }\end{array}$ \\
\hline $\begin{array}{c}2007 / \\
2008\end{array}$ & $\begin{array}{l}13735 \\
10656 \\
\end{array}$ & $\begin{array}{l}\text { CPTM - Companhia Paulista de Trens } \\
\text { Metropolitanos }\end{array}$ & Expresso aeroporto e trem de Guarulhos & Ferroviário \\
\hline $\begin{array}{c}2007 / \\
2008\end{array}$ & $\begin{array}{l}13587 \\
/ 0655\end{array}$ & $\begin{array}{l}\text { ASPACER - Associação Paulista de Cerâmicas } \\
\text { de Revestimento, Santa Gertrudes }\end{array}$ & Complexo argileiro de Santa Gertrudes - SP. & Mineração \\
\hline $\begin{array}{c}2007 / \\
2008 \\
\end{array}$ & $\begin{array}{l}13725 \\
/ 0654 \\
\end{array}$ & $\begin{array}{c}\text { Usina Santa Adélia S.A : Filial Usina } \\
\text { Interlagos, Jaboticabal }\end{array}$ & $\begin{array}{l}\text { Ampliação da produção e das áreas de plantios: } \\
\text { Usina Santa Adelia S.A - Filial Usina Interlagos }\end{array}$ & $\begin{array}{c}\text { Agroindústria } \\
\text { Sucroenergético }\end{array}$ \\
\hline $\begin{array}{l}2007 / \\
2008\end{array}$ & $\begin{array}{l}13763 \\
/ 0651\end{array}$ & COSIPA - Empresa do Sistema Usiminas & $\begin{array}{l}\text { Melhorias tecnológicas, ambientais e ampliação } \\
\text { da produção da Companhia Siderúrgica - Paulista } \\
\text { - COSIPA }\end{array}$ & Indústria \\
\hline $\begin{array}{c}2007 / \\
2008 \\
\end{array}$ & $\begin{array}{l}13704 \\
/ 0643 \\
\end{array}$ & Usina Pau DïAlho S/A & $\begin{array}{c}\text { Ampliação dos setores industrial e agrícola da } \\
\text { Usina Pau DïAlho }\end{array}$ & $\begin{array}{c}\text { Agroindústria } \\
\text { Sucroenergético }\end{array}$ \\
\hline $\begin{array}{r}2007 / \\
2007\end{array}$ & $\begin{array}{l}13695 \\
/ 0644 \\
\end{array}$ & Usina Caete S/A & Ampliação industrial e agrícola da Usina Caete & $\begin{array}{c}\text { Agroindústria } \\
\text { Sucroenergético }\end{array}$ \\
\hline $\begin{array}{c}2007 / \\
2007\end{array}$ & $\begin{array}{l}13536 \\
/ 0638 \\
\end{array}$ & $\begin{array}{c}\text { Consórcio Alphaville Cotia, Barueri; Alpha } \\
\text { Ville Urbanismo S.A., Barueri }\end{array}$ & Projeto Vila Florestal - Reserva de Cotia & $\begin{array}{l}\text { Loteamento/ } \\
\text { Condomínio }\end{array}$ \\
\hline $\begin{array}{c}2007 / \\
2007\end{array}$ & $\begin{array}{l}13503 \\
/ 0637 \\
\end{array}$ & $\begin{array}{c}\text { F.F.E. Construções, Incorporações e } \\
\text { Participações Ltda }\end{array}$ & Loteamento Ibiti Reserva & $\begin{array}{c}\text { Loteamento/ } \\
\text { Condomínio }\end{array}$ \\
\hline $\begin{array}{c}2007 / \\
2007\end{array}$ & $\begin{array}{l}13680 \\
/ 0635 \\
\end{array}$ & Central Energética Vale do Sapucai Ltda. & $\begin{array}{l}\text { Ampliação de moagem e áreas de cultivo de } \\
\text { cana-de-açúcar }\end{array}$ & $\begin{array}{c}\text { Agroindústria } \\
\text { Sucroenergético }\end{array}$ \\
\hline $\begin{array}{c}2000 / \\
2007\end{array}$ & $\begin{array}{l}13785 \\
/ 0634 \\
\end{array}$ & Cimento Rio Branco S/A, Salto de Pirapora & Mina de Xisto Argiloso DNPM - 803.460/1975 & Mineração \\
\hline $\begin{array}{c}2007 / \\
2007\end{array}$ & $\begin{array}{l}13576 \\
/ 0631 \\
\end{array}$ & Alpha Ville Urbanismo S.A. & $\begin{array}{c}\text { Loteamento urbanístico residencial e comercial } \\
\text { denominado Alphaville Jundiaí }\end{array}$ & $\begin{array}{l}\text { Loteamento/ } \\
\text { Condomínio }\end{array}$ \\
\hline $\begin{array}{c}2007 / \\
2007\end{array}$ & $\begin{array}{l}13602 \\
/ 0628 \\
\end{array}$ & Petrobrás - Petróleo Brasileiro S/A & Sistema de transferência C5 + UTGCA - TEBAR & $\begin{array}{l}\text { Portos e } \\
\text { terminais }\end{array}$ \\
\hline $\begin{array}{l}2006 / \\
2007\end{array}$ & $\begin{array}{c}13619 \\
/ 0626 \\
*\end{array}$ & Prefeitura Municipal de Cubatão & $\begin{array}{l}\text { Programa de Gestão Ambiental e renovação } \\
\text { urbana de Cubatão projeto Guara Vermelho }\end{array}$ & $\begin{array}{l}\text { Projeto } \\
\text { Urbanístico }\end{array}$ \\
\hline
\end{tabular}




\begin{tabular}{|c|c|c|c|c|}
\hline $\begin{array}{l}2007 / \\
2007\end{array}$ & $\begin{array}{l}13586 \\
/ 0624\end{array}$ & Proactiva Meio Ambiente Brasil Ltda & $\begin{array}{l}\text { Central de gerenciamento ambiental para } \\
\text { resíduos sólidos industriais }\end{array}$ & $\begin{array}{l}\text { Tratamento de } \\
\text { resíduos }\end{array}$ \\
\hline $\begin{array}{l}2007 / \\
2007\end{array}$ & $\begin{array}{l}13713 \\
/ 0622 \\
\end{array}$ & Usina Colombo S.A. Açúcar e Álcool & $\begin{array}{l}\text { Implantação industrial e ampliação de moagem } \\
\text { de cultivo de cana-de-açúcar }\end{array}$ & $\begin{array}{c}\text { Agroindústria } \\
\text { Sucroenergético }\end{array}$ \\
\hline $\begin{array}{l}2007 / \\
2007\end{array}$ & $\begin{array}{l}13645 \\
/ 0621\end{array}$ & Furnas Centrais Elétricas S/A & $\begin{array}{c}\text { Implantação de linha de transmissão } 345 \text { kV } \\
\text { Tijuco Preto - Itapeti - Nordeste }\end{array}$ & $\begin{array}{c}\text { Linhas de } \\
\text { transmissão }\end{array}$ \\
\hline $\begin{array}{l}2007 / \\
2007\end{array}$ & $\begin{array}{l}13650 \\
/ 0620\end{array}$ & Usina Cerradinho Açúcar e Álcool S.A. & $\begin{array}{c}\text { Ampliação industrial e agrícola da Usina } \\
\text { Cerradinho para produção de açúcar e álcool e } \\
\text { de moagem de cana }\end{array}$ & $\begin{array}{l}\text { Agroindústria } \\
\text { Sucroenergético }\end{array}$ \\
\hline $\begin{array}{l}2007 / \\
2007\end{array}$ & $\begin{array}{l}13651 \\
/ 0619\end{array}$ & Usina Cerradinho Açúcar e Álcool S.A. & Ampliação industrial na Fazenda São Domingos & $\begin{array}{c}\text { Agroindústria } \\
\text { Sucroenergético }\end{array}$ \\
\hline $\begin{array}{c}2007 / \\
2007\end{array}$ & $\begin{array}{l}13638 \\
/ 0618\end{array}$ & CBC Indústrias Pesadas S.A., Jundiaí & $\begin{array}{l}\text { Loteamento industrial Multivias II Polo Industrial } \\
\text { e Logistico }\end{array}$ & $\begin{array}{l}\text { Loteamento/ } \\
\text { Condomínio }\end{array}$ \\
\hline $\begin{array}{l}2007 / \\
2007\end{array}$ & $\begin{array}{l}13627 \\
/ 0617\end{array}$ & EcoUrbis Ambiental S/A & $\begin{array}{c}\text { Aterro sanitário Central de Tratamento de } \\
\text { Resíduos Leste do Município de São Paulo - CLT }\end{array}$ & $\begin{array}{l}\text { Tratamento de } \\
\text { resíduos }\end{array}$ \\
\hline $\begin{array}{l}2007 / \\
2007\end{array}$ & $\begin{array}{l}13633 \\
/ 0616\end{array}$ & $\begin{array}{c}\text { Ciclo Ambiental Consultoria Técnica em Meio } \\
\text { Ambiente }\end{array}$ & $\begin{array}{c}\text { Ampliação da produção de açúcar e álcool e } \\
\text { cogeração de energia localizada a Rodovia SP } \\
304\end{array}$ & $\begin{array}{l}\text { Agroindústria } \\
\text { Sucroenergético }\end{array}$ \\
\hline $\begin{array}{l}2007 / \\
2007\end{array}$ & $\begin{array}{l}13724 \\
/ 0623\end{array}$ & DSG Mineração Ltda & Instalação de central termoelétrica & Termoelétrica \\
\hline $\begin{array}{r}2007 / \\
2007\end{array}$ & $\begin{array}{l}13607 \\
/ 0615\end{array}$ & Imobiliária Parati Ltda & Loteamento residencial Ana Dorotheia II & $\begin{array}{l}\text { Loteamento/ } \\
\text { Condomínio }\end{array}$ \\
\hline $\begin{array}{r}2007 / \\
2007\end{array}$ & $\begin{array}{l}13601 \\
/ 0614 \\
\end{array}$ & $\begin{array}{l}\text { Grupo Ivo Zarzur Administração e } \\
\text { Participações Ltda., São Paulo }\end{array}$ & Loteamento Residencial Figueira Garden II & $\begin{array}{c}\text { Loteamento/ } \\
\text { Condomínio }\end{array}$ \\
\hline $\begin{array}{l}2007 / \\
2007\end{array}$ & $\begin{array}{l}13575 \\
/ 0613\end{array}$ & Companhia Cimento Portland Itaú, Itapeva & $\begin{array}{c}\text { Ampliação da área de extração de calcário na } \\
\text { Fazenda Lavrinhas }\end{array}$ & Mineração \\
\hline $\begin{array}{r}2007 / \\
2007\end{array}$ & $\begin{array}{l}13530 \\
/ 0609\end{array}$ & Usina Continental S.A & $\begin{array}{l}\text { Ampliação da unidade agroindustrial da Usina } \\
\text { Continental S.A para produção de açúcar e álcool }\end{array}$ & $\begin{array}{c}\text { Agroindústria } \\
\text { Sucroenergético }\end{array}$ \\
\hline $\begin{array}{r}2007 / \\
2007\end{array}$ & $\begin{array}{l}13534 \\
/ 0607 \\
\end{array}$ & Viterbo Machado Luz Mineração Ltda & $\begin{array}{c}\text { Projeto de lavra e beneficiamento de granito } \\
\text { para a produção de brita }\end{array}$ & Mineração \\
\hline $\begin{array}{l}2007 / \\
2007\end{array}$ & $\begin{array}{l}13522 \\
/ 0606\end{array}$ & Loga Logistica Ambiental de São Paulo S/A & $\begin{array}{c}\text { Modernização da estação de transbordo de } \\
\text { resíduos Ponte Pequena }\end{array}$ & $\begin{array}{l}\text { Tratamento de } \\
\text { resíduos }\end{array}$ \\
\hline $\begin{array}{r}2007 / \\
2007\end{array}$ & $\begin{array}{l}13523 \\
/ 0605\end{array}$ & $\begin{array}{c}\text { DER - Departamento de Estradas de Rodagem } \\
\text { do Estado de São Paulo }\end{array}$ & $\begin{array}{c}\text { Duplicação do sub-trecho Planalto da Rodovia } \\
\text { dos Tamoios (SP-099) }\end{array}$ & Rodoviário \\
\hline $\begin{array}{l}2007 / \\
2007\end{array}$ & $\begin{array}{l}13520 \\
/ 0604\end{array}$ & FBA - Franco Brasileira S/A Açúcar e Álcool & $\begin{array}{c}\text { Ampliação da usina de açúcar e álcool da } \\
\text { unidade GASA }\end{array}$ & $\begin{array}{c}\text { Agroindústria } \\
\text { Sucroenergético }\end{array}$ \\
\hline $\begin{array}{l}2007 / \\
2007\end{array}$ & $\begin{array}{l}13544 \\
/ 0603\end{array}$ & Companhia Energética Sao Jose & $\begin{array}{l}\text { Ampliação de unidade industrial produtora de } \\
\text { açúcar, instalação de uma destilaria e ampliação } \\
\text { da geração de energia elétrica }\end{array}$ & $\begin{array}{l}\text { Agroindústria } \\
\text { Sucroenergético }\end{array}$ \\
\hline $\begin{array}{l}2007 / \\
2007\end{array}$ & $\begin{array}{l}13562 \\
/ 0602\end{array}$ & Usina Zanin Açúcar e Álcool Ltda., Araraquara & $\begin{array}{l}\text { Ampliação industrial e agrícola para aumento da } \\
\text { produção de açúcar e de álcool }\end{array}$ & $\begin{array}{c}\text { Agroindústria } \\
\text { Sucroenergético }\end{array}$ \\
\hline $\begin{array}{l}2007 / \\
2007\end{array}$ & $\begin{array}{l}13555 \\
/ 0601\end{array}$ & Alphaville Urbanismo S/A & $\begin{array}{c}\text { Loteamento Alphaville Ribeirão Preto/Fazenda } \\
\text { Boa Esperança, Distrito de Bonfim Paulista }\end{array}$ & $\begin{array}{l}\text { Loteamento/ } \\
\text { Condomínio }\end{array}$ \\
\hline $\begin{array}{l}2007 / \\
2007\end{array}$ & $\begin{array}{l}13565 \\
/ 0600\end{array}$ & Usina Colombo S.A. Açúcar e Álcool & $\begin{array}{l}\text { Ampliação de moagem e áreas de cultivo de } \\
\text { cana de açúcar }\end{array}$ & $\begin{array}{c}\text { Agroindústria } \\
\text { Sucroenergético }\end{array}$ \\
\hline $\begin{array}{c}2007 / \\
2007\end{array}$ & $\begin{array}{l}13545 \\
/ 0597\end{array}$ & $\begin{array}{c}\text { BIOCAPITAL Consultoria Empresarial e } \\
\text { Participações; CEBRARCOM Químicos e } \\
\text { Essências Ltda, Charqueada }\end{array}$ & $\begin{array}{c}\text { Ampliação industrial - produção de biodiesel e } \\
\text { de solventes }\end{array}$ & Indústria \\
\hline $\begin{array}{c}2008 / \\
2011 / \\
2013\end{array}$ & $\begin{array}{l}00552 \\
/ 0818\end{array}$ & $\begin{array}{l}\text { Massari Mineração Participações Ltda., } \\
\text { Sorocaba }\end{array}$ & Extração mineral de calcário & Mineração \\
\hline $\begin{array}{l}2008 / \\
2012 \\
\end{array}$ & $\begin{array}{l}02073 \\
/ 0804 \\
\end{array}$ & $\begin{array}{c}\text { CTEEP - Companhia de Transmissão de } \\
\text { Energia Elétrica Paulista, São Paulo }\end{array}$ & $\begin{array}{c}\text { Linha de Transmissão (LT) } 345 \text { kV Alto da Serra - } \\
\text { SE Sul }\end{array}$ & $\begin{array}{l}\text { Linhas de } \\
\text { transmissão }\end{array}$ \\
\hline $\begin{array}{l}2008 / \\
2012\end{array}$ & $\begin{array}{l}01632 \\
/ 0795\end{array}$ & $\begin{array}{c}\text { Companhia Fazenda Acaraú, São Paulo; } \\
\text { Companhia City de Desenvolvimento, São } \\
\text { Paulo; Anastácio Empreendimentos } \\
\text { Imobiliários e Participações Ltda., São Paulo }\end{array}$ & City Fazenda Acaraú & $\begin{array}{l}\text { Loteamento/ } \\
\text { Condomínio }\end{array}$ \\
\hline $\begin{array}{l}2008 / \\
2010\end{array}$ & $\begin{array}{l}00150 \\
/ 0757\end{array}$ & Consórcio Urbanização Atibaia II, São Paulo & Loteamento residencial Fazenda do Porto & $\begin{array}{l}\text { Loteamento/ } \\
\text { Condomínio }\end{array}$ \\
\hline $\begin{array}{c}2008 / \\
2010\end{array}$ & $\begin{array}{l}02071 \\
/ 0753\end{array}$ & Mineração Horical Ltda., Guapiara & $\begin{array}{l}\text { Ampliação da mina de calcário da Mineração } \\
\text { HORICAL Ltda. }\end{array}$ & Mineração \\
\hline $\begin{array}{c}2008 / \\
2010\end{array}$ & $\begin{array}{l}02142 \\
/ 0752 \\
\end{array}$ & Jaguari Comercial e Agrícola Ltda & Loteamento Sant'Anna da Grama & $\begin{array}{l}\text { Loteamento/ } \\
\text { Condomínio }\end{array}$ \\
\hline $\begin{array}{c}2008 / \\
2010\end{array}$ & $\begin{array}{l}01146 \\
/ 0751\end{array}$ & Agrical S.A., Ribeirão Branco & $\begin{array}{l}\text { Empreendimento minerário para produção de } \\
\text { calcário industrial }\end{array}$ & Mineração \\
\hline $\begin{array}{c}2008 / \\
2010\end{array}$ & $\begin{array}{l}02140 \\
/ 0746\end{array}$ & AGRE Urbanismo S/A, São Paulo & Loteamento Residencial Sete Lagos & $\begin{array}{l}\text { Loteamento/ } \\
\text { Condomínio }\end{array}$ \\
\hline
\end{tabular}




\begin{tabular}{|c|c|c|c|c|}
\hline $\begin{array}{c}2008 / \\
2010\end{array}$ & $\begin{array}{l}01668 \\
/ 0741\end{array}$ & $\begin{array}{l}\text { ICIPAR Empreendimentos e Participações } \\
\text { Ltda., São Paulo }\end{array}$ & Complexo empresarial Andaraguá & $\begin{array}{l}\text { Loteamento/ } \\
\text { Condomínio }\end{array}$ \\
\hline $\begin{array}{l}2008 / \\
2010\end{array}$ & $\begin{array}{l}01145 \\
/ 0730\end{array}$ & Companhia Energética Cravinhos S.A, & $\begin{array}{c}\text { Implantação de unidade industrial, produção e } \\
\text { áreas de plantio da Companhia Energética } \\
\text { Cravinhos S/A }\end{array}$ & $\begin{array}{l}\text { Agroindústria } \\
\text { Sucroenergético }\end{array}$ \\
\hline $\begin{array}{c}2008 / \\
2010\end{array}$ & $\begin{array}{l}02219 \\
/ 0718\end{array}$ & Prefeitura Municipal de São Carlos & $\begin{array}{c}\text { Aterro sanitário para disposição final de resíduos } \\
\text { sólidos domiciliares do município de São } \\
\text { Carlos/SP }\end{array}$ & $\begin{array}{l}\text { Tratamento de } \\
\text { resíduos }\end{array}$ \\
\hline $\begin{array}{c}2008 / \\
2009\end{array}$ & $\begin{array}{l}\text { Ibama } \\
\text { /0799 }\end{array}$ & $\begin{array}{l}\text { Santa Rita S.A. Terminais Portuários, São } \\
\text { Paulo }\end{array}$ & Brasil Intermodal Terminal Santos - Brites & $\begin{array}{l}\text { Portos e } \\
\text { terminais }\end{array}$ \\
\hline $\begin{array}{c}2008 / \\
2009\end{array}$ & $\begin{array}{l}00470 \\
/ 0731\end{array}$ & $\begin{array}{c}\text { ARTESP - Agência Reguladora de Serviços } \\
\text { Públicos Delegados de Transporte do Estado } \\
\text { de São Paulo }\end{array}$ & $\begin{array}{c}\text { Estudo de impacto ambiental referente à } \\
\text { duplicação da Rodovia Raposo Tavares - SP-270,: } \\
\text { no trecho entre os km 115+500 e km 158+400 }\end{array}$ & Rodoviário \\
\hline $\begin{array}{l}2008 / \\
2009\end{array}$ & $\begin{array}{l}00462 \\
/ 0728 \\
\end{array}$ & NAG : Núcleo de Apoio a Gestão Ltda., Itu & Implantação do Poliduto Oeste Paulista & Duto \\
\hline $\begin{array}{c}2008 / \\
2009\end{array}$ & $\begin{array}{l}02240 \\
/ 0717\end{array}$ & Baldin Bioenergia S/A, Pirassununga, SP & $\begin{array}{c}\text { Baldin Bioenergia S/A - aumento de } \\
\text { processamento de cana e produção de álcool e } \\
\text { açúcar }\end{array}$ & $\begin{array}{l}\text { Agroindústria } \\
\text { Sucroenergético }\end{array}$ \\
\hline $\begin{array}{c}2008 / \\
2009\end{array}$ & $\begin{array}{l}02236 \\
/ 0715 \\
\end{array}$ & $\begin{array}{l}\text { HYUNDAI Motor Brasil Montadora de } \\
\text { Automóveis Ltda }\end{array}$ & $\begin{array}{c}\text { Implantação de nova unidade automobilística da } \\
\text { Hyundai }\end{array}$ & Indústria \\
\hline $\begin{array}{c}2008 / \\
2009\end{array}$ & $\begin{array}{l}01776 \\
/ 0714 \\
\end{array}$ & Empreiteira Pajoan Ltda, Itaquaquecetuba & $\begin{array}{c}\text { Ampliação do aterro sanitário : Eco Espaço } \\
\text { Soluções Ambientais }\end{array}$ & $\begin{array}{l}\text { Tratamento de } \\
\text { resíduos }\end{array}$ \\
\hline $\begin{array}{c}2008 / \\
2009\end{array}$ & $\begin{array}{l}01687 \\
/ 0709\end{array}$ & Usina Santa Fé S/A, Nova Europa & $\begin{array}{c}\text { Ampliação da produção e das áreas de plantio: } \\
\text { Usina Santa Fé }\end{array}$ & $\begin{array}{l}\text { Agroindústria } \\
\text { Sucroenergético }\end{array}$ \\
\hline $\begin{array}{c}2008 / \\
2009\end{array}$ & $\begin{array}{l}02138 \\
/ 0711 \\
\end{array}$ & Usina Açucareira Guaíra Ltda., Guaíra & $\begin{array}{c}\text { Ampliação industrial e agrícola de unidade de } \\
\text { açúcar e álcool }\end{array}$ & $\begin{array}{l}\text { Agroindústria } \\
\text { Sucroenergético }\end{array}$ \\
\hline $\begin{array}{l}2008 / \\
2009\end{array}$ & $\begin{array}{c}195 / 0 \\
708\end{array}$ & Unialco S.A. Álcool e Açúcar & $\begin{array}{c}\text { Ampliação da capacidade de produção agrícola e } \\
\text { industrial do empreendimento sucroalcooleiro } \\
\text { Unialco S.A. }\end{array}$ & $\begin{array}{l}\text { Agroindústria } \\
\text { Sucroenergético }\end{array}$ \\
\hline $\begin{array}{c}2008 / \\
2009\end{array}$ & $\begin{array}{c}1152 / \\
0707\end{array}$ & $\begin{array}{l}\text { ESTRE - Engenharia Saneamento e } \\
\text { Tratamento de Resíduos Ltda }\end{array}$ & $\begin{array}{c}\text { Centro de gerenciamento de resíduos de } \\
\text { Sorocaba }\end{array}$ & $\begin{array}{l}\text { Tratamento de } \\
\text { resíduos }\end{array}$ \\
\hline $\begin{array}{c}2008 / \\
2009\end{array}$ & $\begin{array}{l}00106 \\
/ 0706\end{array}$ & $\begin{array}{l}\text { SPLF - Investimentos e Participações Ltda., } \\
\text { São Paulo }\end{array}$ & Plano urbanístico da reserva da Serra de Itapety & $\begin{array}{l}\text { Loteamento/ } \\
\text { Condomínio }\end{array}$ \\
\hline $\begin{array}{c}2008 / \\
2009\end{array}$ & $\begin{array}{l}01563 \\
/ 0703\end{array}$ & $\begin{array}{c}\text { Incorporadora Leonardi Ltda., Presidente } \\
\text { Venceslau }\end{array}$ & Loteamento Aldeia do Lago III & $\begin{array}{l}\text { Loteamento/ } \\
\text { Condomínio }\end{array}$ \\
\hline $\begin{array}{c}2008 / \\
2009\end{array}$ & $\begin{array}{l}02243 \\
/ 0701\end{array}$ & AAMD - Agroenergia S.A & $\begin{array}{c}\text { Instalação de nova unidade industrial e } \\
\text { ampliação da produção e das áreas de plantio - } \\
\text { Alfa agroenergia - AAMD Agroenergia S.A - } \\
\text { Pirassununga }\end{array}$ & $\begin{array}{l}\text { Agroindústria } \\
\text { Sucroenergético }\end{array}$ \\
\hline $\begin{array}{c}2008 / \\
2009\end{array}$ & $\begin{array}{l}02244 \\
10700 \\
\end{array}$ & $\begin{array}{c}\text { Destilaria Paranapaema S/A - Unidade II, } \\
\text { Sandovalina }\end{array}$ & $\begin{array}{c}\text { Ampliação da produção e das áreas de plantio - } \\
\text { Destilaria Paranapanema S/A - Unidade } 2\end{array}$ & $\begin{array}{l}\text { Agroindústria } \\
\text { Sucroenergético }\end{array}$ \\
\hline $\begin{array}{c}2008 / \\
2009\end{array}$ & $\begin{array}{l}00608 \\
/ 0697\end{array}$ & $\begin{array}{c}\text { Transportadora de gás do Brasil Central - } \\
\text { TGBC, Goiânia }\end{array}$ & Gasoduto do Brasil Central & Duto \\
\hline $\begin{array}{c}2008 / \\
2009\end{array}$ & $\begin{array}{l}01392 \\
/ 0696\end{array}$ & Açucareira Virgulino de Oliveira S/A & $\begin{array}{c}\text { Ampliação da produção e das áreas de plantio } \\
\text { açucareira Virgulino de Oliveira S/A - Unidade } \\
\text { Moncoes }\end{array}$ & $\begin{array}{l}\text { Agroindústria } \\
\text { Sucroenergético }\end{array}$ \\
\hline $\begin{array}{l}2008 / \\
2009\end{array}$ & $\begin{array}{l}01984 \\
/ 0695 \\
\end{array}$ & ESTRE Ambiental S.A. & $\begin{array}{c}\text { CGR - Piratininga, Centro de Gerenciamento de } \\
\text { Resíduos }\end{array}$ & $\begin{array}{l}\text { Tratamento de } \\
\text { resíduos }\end{array}$ \\
\hline $2008 /$ & $\begin{array}{l}01686 \\
/ 0693\end{array}$ & Nardini Agroindustria Ltda & Ampliação industrial e agrícola & $\begin{array}{l}\text { Agroindústria } \\
\text { Sucroenergético }\end{array}$ \\
\hline $\begin{array}{c}2008 / \\
2009\end{array}$ & $\begin{array}{l}00170 \\
/ 0686\end{array}$ & $\begin{array}{l}\text { Larissa Empreendimentos Imobiliários Ltda. } \\
\text { São Paulo }\end{array}$ & $\begin{array}{l}\text { Loteamento residencial fazenda Santo Antônio - } \\
\text { Haras Larissa }\end{array}$ & $\begin{array}{l}\text { Loteamento/ } \\
\text { Condomínio }\end{array}$ \\
\hline $\begin{array}{c}2008 / \\
2009\end{array}$ & $\begin{array}{l}00816 \\
/ 0683\end{array}$ & $\begin{array}{l}\text { METRÔ - Companhia do Metropolitano de } \\
\text { São Paul }\end{array}$ & $\begin{array}{l}\text { Implantação da linha } 5 \text { - Lilás - trecho Adolfo } \\
\text { Pinheiro - Chácara Klabin com Pátio Guido Caloi }\end{array}$ & Ferroviário \\
\hline $\begin{array}{c}2008 / \\
2008\end{array}$ & $\begin{array}{l}01891 \\
/ 0743\end{array}$ & UNIDUTO Logistica S.A., São Paulo & Projeto Uniduto & Duto \\
\hline $\begin{array}{c}2008 / \\
2008\end{array}$ & $\begin{array}{l}00072 \\
/ 0673\end{array}$ & Encalso Construções Ltda., São Carlos & $\begin{array}{c}\text { Empreendimento Urbanístico DAMHA } \\
\text { Araraquara }\end{array}$ & $\begin{array}{c}\text { Loteamento/ } \\
\text { Condomínio }\end{array}$ \\
\hline $\begin{array}{c}2008 / \\
2008\end{array}$ & $\begin{array}{l}00626 \\
/ 0672\end{array}$ & Usina do Pontal S/A & $\begin{array}{c}\text { Ampliação Industrial e agrícola: Usina Conquista } \\
\text { do Pontal S/A }\end{array}$ & $\begin{array}{l}\text { Agroindústria } \\
\text { Sucroenergético }\end{array}$ \\
\hline $\begin{array}{c}2000 / \\
2008\end{array}$ & $\begin{array}{l}13784 \\
/ 0669\end{array}$ & $\begin{array}{l}\text { INFRAERO : Empresa Brasileira de Infra - } \\
\text { estrutura Aeroportuária, Campinas }\end{array}$ & $\begin{array}{c}\text { Ampliação do aeroporto Internacional de } \\
\text { Viracopos }\end{array}$ & Aeroportos \\
\hline $\begin{array}{c}2008 / \\
2008\end{array}$ & $\begin{array}{l}00211 \\
/ 0665\end{array}$ & $\begin{array}{c}\text { Usina BIOVAP S. A. Açúcar e Álcool, Brejo } \\
\text { Alegre }\end{array}$ & $\begin{array}{c}\text { Ampliação do processo produtivo do } \\
\text { empreendimento e das áreas cultivadas com } \\
\text { cana de açúcar }\end{array}$ & $\begin{array}{l}\text { Agroindústria } \\
\text { Sucroenergético }\end{array}$ \\
\hline $\begin{array}{c}2008 / \\
2008\end{array}$ & $\begin{array}{l}01683 \\
/ 0663\end{array}$ & $\begin{array}{l}\text { TOYOTA do Brasil Ltda, São Bernardo do } \\
\text { Campo }\end{array}$ & $\begin{array}{c}\text { Implantação da nova unidade automobilística da } \\
\text { TOYOTA do Brasil - TDB }\end{array}$ & Indústria \\
\hline
\end{tabular}




\begin{tabular}{|c|c|c|c|c|}
\hline 2008 & $\begin{array}{l}01338 \\
/ 0704\end{array}$ & $\begin{array}{l}\text { Campos Elíseos Participação e Administração } \\
\text { Ltda }\end{array}$ & $\begin{array}{c}\text { Central de gerenciamento de resíduos - CGR. } \\
\text { OASIS no Município de Piracicaba }\end{array}$ & $\begin{array}{l}\text { Tratamento de } \\
\text { resíduos }\end{array}$ \\
\hline $\begin{array}{c}2009 / \\
2013\end{array}$ & $\begin{array}{l}08447 \\
/ 0236 \\
\end{array}$ & Leão Engenharia S.A, Ribeirão Preto & Ampliação de área de lavra de basalto & Mineração \\
\hline $\begin{array}{c}2009 / \\
2013\end{array}$ & $\begin{array}{l}00042 \\
/ 0235\end{array}$ & Mineração Fronteira Ltda., Itapeva & $\begin{array}{c}\text { Jazida de talco e dolomito da Mineração } \\
\text { Fronteira, Ltda: Nova Campina/ SP e Ribeirão } \\
\text { Branco/ SP }\end{array}$ & Mineração \\
\hline $\begin{array}{c}2009 / \\
2013\end{array}$ & $\begin{array}{c}00008 \\
9 / 081 \\
6\end{array}$ & Mineração Fronteira Ltda., Itapeva & $\begin{array}{c}\text { Ampliação da Mina de filito, areia, argila e } \\
\text { cascalho }\end{array}$ & Mineração \\
\hline $\begin{array}{c}2009 / \\
2012\end{array}$ & $\begin{array}{c}00194 \\
0 / 080 \\
5\end{array}$ & $\begin{array}{l}\text { METRÔ - Companhia do Metropolitano de } \\
\text { São Paulo }\end{array}$ & Linha 2 - Verde: Trecho Vila Prudente - Dutra & Ferroviário \\
\hline $\begin{array}{c}2009 / \\
2011\end{array}$ & $\begin{array}{l}08625 \\
/ 0769\end{array}$ & $\begin{array}{l}\text { DEPLAN Desenvolvimento e Planejamento } \\
\text { Imobiliário Ltda., São Paulo }\end{array}$ & $\begin{array}{l}\text { Parcelamento de solo urbano para o uso, } \\
\text { predominantemente, residencial e multifamiliar } \\
\text { : estância balneária de Praia Grande - SP }\end{array}$ & $\begin{array}{l}\text { Loteamento/ } \\
\text { Condomínio }\end{array}$ \\
\hline $\begin{array}{l}2009 / \\
2010\end{array}$ & $\begin{array}{l}00085 \\
/ 0760\end{array}$ & $\begin{array}{c}\text { TONON Bioenergia S. A Filial Santa Cândida, } \\
\text { Jaú }\end{array}$ & $\begin{array}{c}\text { Ampliação da TONON Bioenergia S.A. Santa } \\
\text { Cândida }\end{array}$ & $\begin{array}{l}\text { Agroindústria } \\
\text { Sucroenergético }\end{array}$ \\
\hline $\begin{array}{l}2009 / \\
2010\end{array}$ & $\begin{array}{l}08016 \\
/ 0759\end{array}$ & Alphaville Urbanismo S.A, São Paulo & $\begin{array}{c}\text { Loteamento Alphaville Nova Esplanada } \\
\text { Votorantim }\end{array}$ & $\begin{array}{l}\text { Loteamento/ } \\
\text { Condomínio }\end{array}$ \\
\hline $\begin{array}{c}2009 / \\
2010\end{array}$ & $\begin{array}{l}00084 \\
/ 0758\end{array}$ & $\begin{array}{l}\text { Abengoa Bioenergia e Agroindústria Ltda., } \\
\text { Pirassununga }\end{array}$ & $\begin{array}{l}\text { Ampliação da área agrícola (cana) e produção } \\
\text { industrial : açúcar, álcool e energia }\end{array}$ & $\begin{array}{l}\text { Agroindústria } \\
\text { Sucroenergético }\end{array}$ \\
\hline $\begin{array}{c}2009 / \\
2010\end{array}$ & $\begin{array}{l}10730 \\
/ 0755\end{array}$ & $\begin{array}{l}\text { Brazil Flex Energy Açúcar e Álcool, Ltda, São } \\
\text { Paulo }\end{array}$ & $\begin{array}{l}\text { Implantação industrial e agrícola de unidade do } \\
\text { setor de açúcar e álcool }\end{array}$ & $\begin{array}{l}\text { Agroindústria } \\
\text { Sucroenergético }\end{array}$ \\
\hline $\begin{array}{c}2009 / \\
2010\end{array}$ & $\begin{array}{l}03661 \\
/ 0750\end{array}$ & $\begin{array}{l}\text { Consórcio de Urbanização Paulínia III, São } \\
\text { Paulo }\end{array}$ & Loteamento residencial Lago Azul - Paulínia & $\begin{array}{l}\text { Loteamento/ } \\
\text { Condomínio }\end{array}$ \\
\hline $\begin{array}{c}2009 / \\
2010\end{array}$ & $\begin{array}{l}02975 \\
/ 0748\end{array}$ & $\begin{array}{l}\text { Fasciata Empreendimentos Imobiliários Ltda., } \\
\text { São Paulo }\end{array}$ & Plano urbanístico Gleba A2, Campinas - SP & $\begin{array}{l}\text { Loteamento/ } \\
\text { Condomínio }\end{array}$ \\
\hline $\begin{array}{c}2009 / \\
2010\end{array}$ & $\begin{array}{l}00256 \\
/ 0742\end{array}$ & Hidrotérmica S.A., São Paulo & $\begin{array}{l}\text { Pequenas centrais hidrelétricas Santana, Figueira } \\
\text { Branca e Niagara }\end{array}$ & Hidrelétrica \\
\hline $\begin{array}{c}2009 / \\
2010\end{array}$ & $\begin{array}{l}00033 \\
/ 0740\end{array}$ & $\begin{array}{l}\text { CGR Catanduva Centro de Gerenciamento de } \\
\text { Resíduos Ltda., Catanduva }\end{array}$ & $\begin{array}{c}\text { Centro de Gerenciamento de Resíduos: } \\
\text { ampliação do aterro sanitário e instalação de } \\
\text { novos equipamentos - Catanduva }\end{array}$ & $\begin{array}{l}\text { Tratamento de } \\
\text { resíduos }\end{array}$ \\
\hline $\begin{array}{c}2009 / \\
2010\end{array}$ & $\begin{array}{l}00016 \\
/ 0739 \\
\end{array}$ & Usina açucareira S.Manoel S/A & Usina açucareira S.Manoel S/A & $\begin{array}{l}\text { Agroindústria } \\
\text { Sucroenergético }\end{array}$ \\
\hline $\begin{array}{c}2009 / \\
2010\end{array}$ & $\begin{array}{l}03827 \\
/ 0735\end{array}$ & $\begin{array}{c}\text { Rio Vermelho Açúcar e Álcool S.A., } \\
\text { Junqueirópolis }\end{array}$ & $\begin{array}{l}\text { Ampliação industrial e agrícola de unidade do } \\
\text { setor de açúcar e álcool }\end{array}$ & $\begin{array}{l}\text { Agroindústria } \\
\text { Sucroenergético }\end{array}$ \\
\hline $\begin{array}{c}2009 / \\
2010\end{array}$ & $\begin{array}{l}00062 \\
/ 0733\end{array}$ & $\begin{array}{c}\text { Departamento de Estradas de Rodagem do } \\
\text { Estado de São Paulo - DER Secretaria de } \\
\text { Estado dos Transportes }\end{array}$ & $\begin{array}{c}\text { Contornos : Sul de Caraguatatuba e de São } \\
\text { Sebastião }\end{array}$ & Rodoviário \\
\hline $\begin{array}{c}2009 / \\
2010\end{array}$ & $\begin{array}{l}09806 \\
/ 0732 \\
\end{array}$ & $\begin{array}{l}\text { ENGEP û Engenharia e Pavimentação Ltda., } \\
\text { Limeira }\end{array}$ & $\begin{array}{c}\text { Unidade de tratamento e gestão de resíduos de } \\
\text { Jambeiro - UTGR }\end{array}$ & $\begin{array}{l}\text { Tratamento de } \\
\text { resíduos }\end{array}$ \\
\hline $\begin{array}{c}2009 / \\
2010\end{array}$ & $\begin{array}{l}00012 \\
/ 0727\end{array}$ & Açúcar Guarani S/A - Unidade Cruz Alta & $\begin{array}{c}\text { Ampliação das atividades agroindustriais da } \\
\text { açúcar Guarani S/A unidade de Cruz Alta }\end{array}$ & $\begin{array}{l}\text { Agroindústria } \\
\text { Sucroenergético }\end{array}$ \\
\hline $\begin{array}{c}2009 / \\
2010\end{array}$ & $\begin{array}{l}03799 \\
/ 0736 \\
\end{array}$ & LDC Bioenergia S/A, Leme & $\begin{array}{c}\text { Ampliação industrial LDC Bioenergia S/A } \\
\text { Unidade Leme }\end{array}$ & $\begin{array}{l}\text { Agroindústria } \\
\text { Sucroenergético }\end{array}$ \\
\hline $\begin{array}{c}2009 / \\
2009\end{array}$ & $\begin{array}{l}00702 \\
/ 0737\end{array}$ & Encalso Construções Ltda., São Paulo & $\begin{array}{l}\text { Pequena Central Hidrelétrica de Talhado e PCH } \\
\text { Foz do Preto }\end{array}$ & Hidrelétrica \\
\hline $\begin{array}{c}2009 / \\
2009\end{array}$ & $\begin{array}{l}05204 \\
/ 0734\end{array}$ & $\begin{array}{l}\text { CGR Jardinópolis Centro de Gerenciamento } \\
\text { de Resíduos Ltda., Jardinópolis }\end{array}$ & $\begin{array}{c}\text { CGR Jardinópolis Centro de Gerenciamento de } \\
\text { Resíduos - Jardinópolis: Aterro Sanitário }\end{array}$ & $\begin{array}{l}\text { Tratamento de } \\
\text { resíduos }\end{array}$ \\
\hline $\begin{array}{c}2009 / \\
2009\end{array}$ & $\begin{array}{l}00013 \\
/ 0722\end{array}$ & Açúcar Guarani S/A Unidade Severinia & Açúcar Guarani unidade industrial Severinia & $\begin{array}{l}\text { Agroindústria } \\
\text { Sucroenergético }\end{array}$ \\
\hline $\begin{array}{c}2009 / \\
2009\end{array}$ & $\begin{array}{l}07023 \\
/ 0720\end{array}$ & $\begin{array}{l}\text { Usina Noroeste Paulista Ltda., } \\
\text { Sebastianópolis do Sul }\end{array}$ & $\begin{array}{c}\text { Ampliação agrícola e industrial de unidade do } \\
\text { setor de açúcar e álcool - Usina Noroeste } \\
\text { Paulista }\end{array}$ & $\begin{array}{l}\text { Agroindústria } \\
\text { Sucroenergético }\end{array}$ \\
\hline $\begin{array}{c}2009 / \\
2009\end{array}$ & $\begin{array}{l}05244 \\
/ 0719\end{array}$ & $\begin{array}{l}\text { Agro-Pecuária Tinamú Ltda., São José do Rio } \\
\text { Preto }\end{array}$ & $\begin{array}{c}\text { Implantação agrícola e industrial de unidade do } \\
\text { setor de açúcar e álcool }\end{array}$ & $\begin{array}{l}\text { Agroindústria } \\
\text { Sucroenergético }\end{array}$ \\
\hline $\begin{array}{l}2003 / \\
2009\end{array}$ & $\begin{array}{l}13623 \\
/ 0716\end{array}$ & BUNGE Fertilizantes S/A, Cajati & $\begin{array}{c}\text { Ampliação das atuais áreas de lavra de rocha } \\
\text { fosfática da BUNGE Fertilizantes S/A }\end{array}$ & Mineração \\
\hline $\begin{array}{c}2009 / \\
2009\end{array}$ & $\begin{array}{c}8304 / \\
2009\end{array}$ & Destilaria Alcidia S/A & Destilaria Alcidia S/A - Teodoro Sampaio & $\begin{array}{l}\text { Agroindústria } \\
\text { Sucroenergético }\end{array}$ \\
\hline $\begin{array}{c}2009 / \\
2009\end{array}$ & $\begin{array}{l}08767 \\
/ 0698 \\
\end{array}$ & $\begin{array}{c}\text { PETROBRÁS - Petróleo Brasileiro S/A, Rio de } \\
\text { Janeiro }\end{array}$ & $\begin{array}{c}\text { Sistema de escoamento dutoviário de álcool e } \\
\text { derivados - SEDA }\end{array}$ & Duto \\
\hline $\begin{array}{c}2009 / \\
2009\end{array}$ & $\begin{array}{l}06563 \\
/ 0689\end{array}$ & $\begin{array}{l}\text { DERSA - Desenvolvimento Rodoviário S.A, São } \\
\text { Paulo }\end{array}$ & $\begin{array}{c}\text { Programa Rodoanel Mario Covas Trecho Leste: } \\
\text { Trecho Leste }\end{array}$ & Rodoviário \\
\hline $\begin{array}{c}2010 / \\
2014\end{array}$ & $\begin{array}{l}00044 \\
/ 0837\end{array}$ & $\begin{array}{l}01 \text { FS Empreendimentos Imobiliários SPE } \\
\text { Ltda., Campinas }\end{array}$ & Residencial Quinta das Águas, Valinhos & $\begin{array}{l}\text { Loteamento/ } \\
\text { Condomínio }\end{array}$ \\
\hline
\end{tabular}




\begin{tabular}{|c|c|c|c|c|}
\hline $\begin{array}{l}2010 / \\
2013\end{array}$ & $\begin{array}{l}00230 \\
/ 0824\end{array}$ & $\begin{array}{c}\text { SBC Valorização de Resíduos S/A, São } \\
\text { Bernardo do Campo }\end{array}$ & $\begin{array}{c}\text { Sistema de processamento e aproveitamento de } \\
\text { resíduos e unidade de recuperação de energia - } \\
\text { SPAR-URE: Município de São Bernardo do } \\
\text { Campo }\end{array}$ & $\begin{array}{l}\text { Tratamento de } \\
\text { resíduos }\end{array}$ \\
\hline $\begin{array}{c}2010 / \\
2013\end{array}$ & $\begin{array}{l}00278 \\
/ 0652\end{array}$ & $\begin{array}{l}\text { Brookfield São Paulo Empreendimentos } \\
\text { Imobiliários S.A., São Paulo }\end{array}$ & $\begin{array}{l}\text { Loteamento residencial Fazenda Santo Ângelo: } \\
\text { Americana - SP }\end{array}$ & $\begin{array}{l}\text { Loteamento/ } \\
\text { Condomínio }\end{array}$ \\
\hline $\begin{array}{c}2010 / \\
2013 \\
\end{array}$ & $\begin{array}{l}00115 \\
/ 0232 \\
\end{array}$ & JCR Construção Civil Ltda., São Paulo & Loteamento misto Jardins de Samantha IV & $\begin{array}{l}\text { Loteamento/ } \\
\text { Condomínio }\end{array}$ \\
\hline $\begin{array}{c}2010 / \\
2012\end{array}$ & $\begin{array}{l}00022 \\
/ 0793\end{array}$ & Votorantim Cimentos S.A, Votorantim & Ampliação das minas Ponte Alta e Salto & Mineração \\
\hline $\begin{array}{l}2010 / \\
2012 \\
\end{array}$ & $\begin{array}{l}00043 \\
/ 0789 \\
\end{array}$ & $\begin{array}{c}\text { Destilaria São Jorge Ltda., Santana da Ponte } \\
\text { Pensa }\end{array}$ & $\begin{array}{c}\text { Destilaria São Jorge: ampliação de unidade } \\
\text { agroindustrial }\end{array}$ & $\begin{array}{c}\text { Agroindústria } \\
\text { Sucroenergético }\end{array}$ \\
\hline $\begin{array}{l}2010 / \\
2012\end{array}$ & $\begin{array}{l}00252 \\
/ 0784\end{array}$ & $\begin{array}{c}\text { Brazil Flex Energy Açúcar e Álcool Ltda., } \\
\text { Piquerobi }\end{array}$ & Implantação industrial e agrícola & $\begin{array}{l}\text { Agroindústria } \\
\text { Sucroenergético }\end{array}$ \\
\hline $\begin{array}{c}2010 / \\
2011\end{array}$ & $\begin{array}{l}00116 \\
/ 0782\end{array}$ & $\begin{array}{l}\text { Companhia Metropolitano de São Paulo - } \\
\text { METRÔ, São Paulo }\end{array}$ & $\begin{array}{c}\text { Linha } 6 \text { - Laranja : trecho São Joaquim - } \\
\text { Brasilândia }\end{array}$ & Ferroviário \\
\hline $\begin{array}{c}2010 / \\
2011\end{array}$ & $\begin{array}{l}00069 \\
/ 0778\end{array}$ & Usina Açucareira Furlan S/A, Avaré & Usina Açucareira Furlan S/A : unidade Avaré & $\begin{array}{c}\text { Agroindústria } \\
\text { Sucroenergético }\end{array}$ \\
\hline $\begin{array}{l}2010 / \\
2011\end{array}$ & $\begin{array}{l}00199 \\
/ 0775\end{array}$ & $\begin{array}{l}\text { ALCOESTE Destilaria Fernandópolis S/A, } \\
\text { Fernandópolis }\end{array}$ & Alcoeste Destilaria Fernandópolis S/A & $\begin{array}{l}\text { Agroindústria } \\
\text { Sucroenergético }\end{array}$ \\
\hline $\begin{array}{c}2010 / \\
2011\end{array}$ & $\begin{array}{l}00262 \\
/ 0774\end{array}$ & $\begin{array}{c}\text { Buriqui Costa Nativa Empreendimentos } \\
\text { Imobiliários Ltda, São Paulo }\end{array}$ & $\begin{array}{c}\text { Empreendimento Buriqui Costa Nativa : } \\
\text { loteamento residencial e complexo turístico }\end{array}$ & $\begin{array}{l}\text { Loteamento/ } \\
\text { Condomínio }\end{array}$ \\
\hline $\begin{array}{c}2010 / \\
2011\end{array}$ & $\begin{array}{l}00268 \\
/ 0773\end{array}$ & $\begin{array}{l}\text { ULTRAFÉRTIL S/A Terminal Marítimo - TUF, } \\
\text { Santo }\end{array}$ & $\begin{array}{c}\text { Ampliação do terminal marítimo da } \\
\text { ULTRAFÉRTIL S.A. }\end{array}$ & $\begin{array}{c}\text { Portos e } \\
\text { terminais }\end{array}$ \\
\hline $\begin{array}{c}2010 / \\
2011\end{array}$ & $\begin{array}{c}40 / 07 \\
71\end{array}$ & $\begin{array}{c}\text { Branco Peres Açúcar e Álcool S/A, } \\
\text { Adamantina }\end{array}$ & $\begin{array}{c}\text { Licenciamento ambiental para ampliação } \\
\text { industrial e agrícola de unidade do setor de } \\
\text { açúcar e álcool }\end{array}$ & $\begin{array}{l}\text { Agroindústria } \\
\text { Sucroenergético }\end{array}$ \\
\hline $\begin{array}{c}2010 / \\
2011\end{array}$ & $\begin{array}{l}00067 \\
/ 0767\end{array}$ & $\begin{array}{l}\text { RESICONTROL Soluções Ambientais, } \\
\text { Tremenbé }\end{array}$ & $\begin{array}{c}\text { Ampliação do aterro classe I : RESICONTROL } \\
\text { unidade Tremembé }\end{array}$ & $\begin{array}{l}\text { Tratamento de } \\
\text { resíduos }\end{array}$ \\
\hline $\begin{array}{c}2010 / \\
2011 \\
\end{array}$ & $\begin{array}{l}00171 \\
/ 0766 \\
\end{array}$ & Usina Rio Pardo, Cerqueira César & $\begin{array}{l}\text { Ampliação do parque industrial da Usina Rio } \\
\text { Pardo e expansão das áreas agrícolas }\end{array}$ & $\begin{array}{c}\text { Agroindústria } \\
\text { Sucroenergético }\end{array}$ \\
\hline $\begin{array}{c}2010 / \\
2011\end{array}$ & $\begin{array}{l}00002 \\
/ 0765\end{array}$ & Proativa Meio Ambiente Brasil Ltda, Barueri & $\begin{array}{l}\text { CGA Central de gerenciamento ambiental de } \\
\text { Araçariguama : disposição de resíduos sólidos } \\
\text { industriais classe IIA e IIB em regime de } \\
\text { codisposição com resíduos domiciliares }\end{array}$ & $\begin{array}{l}\text { Tratamento de } \\
\text { resíduos }\end{array}$ \\
\hline $\begin{array}{c}2010 / \\
2011\end{array}$ & $\begin{array}{l}00021 \\
/ 0763\end{array}$ & $\begin{array}{c}\text { SABESP Cia de Saneamento Básico do Estado } \\
\text { de São Paulo; Prime Engenharia e Comércio } \\
\text { Ltda., São Paulo }\end{array}$ & $\begin{array}{c}\text { Estudo de concepção e projeto básico do sistema } \\
\text { produtor São Lourenço - SPSL }\end{array}$ & Obra Hidráulica \\
\hline $\begin{array}{c}2010 / \\
2011\end{array}$ & $\begin{array}{l}00204 \\
/ 0762\end{array}$ & $\begin{array}{c}\text { Santa Cruz S/A Açúcar e Álcool, Américo } \\
\text { Brasiliense }\end{array}$ & Ampliação da usina Santa Cruz & $\begin{array}{c}\text { Agroindústria } \\
\text { Sucroenergético }\end{array}$ \\
\hline $\begin{array}{c}2010 / \\
2011\end{array}$ & $\begin{array}{l}00173 \\
/ 0761\end{array}$ & $\begin{array}{l}\text { Companhia de Gás de São Paulo - COMGÁS, } \\
\text { São Paulo }\end{array}$ & Reforço da rede tubular de alta pressão - RETAP & Duto \\
\hline $\begin{array}{c}2010 / \\
2011\end{array}$ & $\begin{array}{l}00065 \\
/ 0756\end{array}$ & AES Tiete S/A., São Paulo & Usina termoelétrica : Termo São Paulo & Termoelétrica \\
\hline $\begin{array}{c}2010 / \\
2011\end{array}$ & $\begin{array}{l}00198 \\
/ 0785\end{array}$ & $\begin{array}{c}\text { TGM Destilaria de Álcool e Aguardente Ltda., } \\
\text { Cerqueira César }\end{array}$ & $\begin{array}{l}\text { TGM Indústria e Comércio de Álcool e } \\
\text { Aguardente Ltda. }\end{array}$ & $\begin{array}{c}\text { Agroindústria } \\
\text { Sucroenergético }\end{array}$ \\
\hline $\begin{array}{c}2010 / \\
2010\end{array}$ & $\begin{array}{l}00167 \\
/ 0848\end{array}$ & $\begin{array}{l}\text { CBE-Companhia Brasileira de Equipamento, } \\
\text { Ribeirão Grande }\end{array}$ & Mina Projeto SP-106/12A Ribeirão Grande-SP & Mineração \\
\hline $\begin{array}{c}2010 / \\
2010\end{array}$ & $\begin{array}{l}00063 \\
/ 0792 \\
\end{array}$ & Votorantim Cimentos S.A, Votorantim & $\begin{array}{c}\text { Ampliação das minas Pastinho, Placa e Baltar } \\
\text { (subterrânea) }\end{array}$ & Mineração \\
\hline $\begin{array}{c}2010 / \\
2010\end{array}$ & $\begin{array}{l}00246 \\
/ 0768\end{array}$ & Ferrari Agroindústria S/A, Pirassununga & $\begin{array}{c}\text { Ampliação das áreas de plantio de cana-de- } \\
\text { açúcar e da produção de açúcar, álcool e energia } \\
\text { elétrica }\end{array}$ & $\begin{array}{l}\text { Agroindústria } \\
\text { Sucroenergético }\end{array}$ \\
\hline $\begin{array}{c}2010 / \\
2010\end{array}$ & $\begin{array}{l}00042 \\
/ 0754 \\
\end{array}$ & REVITA Engenharia S.A & $\begin{array}{c}\text { Centro de Tratamento e Disposição de Resíduos } \\
\text { de Caraguatatuba - CTR Caraguatatuba }\end{array}$ & $\begin{array}{l}\text { Tratamento de } \\
\text { resíduos }\end{array}$ \\
\hline $\begin{array}{c}2010 / \\
2010\end{array}$ & $\begin{array}{l}00130 \\
/ 0749\end{array}$ & $\begin{array}{c}\text { Companhia de Saneamento Básico do Estado } \\
\text { de São Paulo S.A. - SABESP }\end{array}$ & $\begin{array}{l}\text { Obras de implantação do sistema de } \\
\text { esgotamento sanitário de Campos de Jordao/SP }\end{array}$ & $\begin{array}{l}\text { Tratamento de } \\
\text { resíduos }\end{array}$ \\
\hline $\begin{array}{l}2010 / \\
2010\end{array}$ & $\begin{array}{l}00208 \\
/ 0747\end{array}$ & $\begin{array}{l}\text { DERSA - Desenvolvimento Rodoviário S.A. } \\
\text { Secretaria dos Transportes, São Paulo }\end{array}$ & Programa Rodoanel Mario Covas trecho Norte & Rodoviário \\
\hline $\begin{array}{c}2010 / \\
2010\end{array}$ & $\begin{array}{l}00152 \\
/ 0744\end{array}$ & $\begin{array}{c}\text { Penido Construtora e Pavimentadora Ltda., } \\
\text { São José dos Campos }\end{array}$ & Centro Empresarial Aeroespacial Caçapava - CEA & Aeroportos \\
\hline $\begin{array}{c}2011 / \\
2016\end{array}$ & $\begin{array}{l}00161 \\
/ 0873\end{array}$ & $\begin{array}{c}\text { Guapiara Mineração Indústria e Comércio } \\
\text { Ltda., Salto de Pirapora }\end{array}$ & $\begin{array}{l}\text { Guapiara Mineração Indústria e Comércio û } \\
\text { GMIC }\end{array}$ & Mineração \\
\hline $\begin{array}{c}2011 / \\
2015\end{array}$ & $\begin{array}{l}00139 \\
/ 0849\end{array}$ & $\begin{array}{l}\text { MARPI Empreendimentos e Participações } \\
\text { Ltda., Valinhos }\end{array}$ & $\begin{array}{c}\text { Loteamento Residencial Haras Patente - Fase } 2 \\
\text { Jaguariúna - SP }\end{array}$ & $\begin{array}{l}\text { Loteamento/ } \\
\text { Condomínio }\end{array}$ \\
\hline $\begin{array}{c}2011 / \\
2014\end{array}$ & $\begin{array}{l}00126 \\
/ 0830\end{array}$ & Petróleo Brasileiro S.A. û PETROBRAS & Gasoduto Rota 3 & Duto \\
\hline
\end{tabular}




\begin{tabular}{|c|c|c|c|c|}
\hline $\begin{array}{l}2011 / \\
2013\end{array}$ & $\begin{array}{l}00016 \\
2 / 082 \\
6\end{array}$ & EMBU S. A. Engenharia e Comércio, São Paulo & $\begin{array}{l}\text { Ampliação da área de lavra de granito e saibro } \\
\text { Pedreira Itapeti, Mogi das Cruzes - SP }\end{array}$ & Mineração \\
\hline $\begin{array}{c}2011 / \\
2013\end{array}$ & $\begin{array}{l}00187 \\
/ 0820\end{array}$ & $\begin{array}{l}\text { ACS Jaguariúna Empreendimentos } \\
\text { Imobiliários Ltda, Campinas }\end{array}$ & Loteamento residencial Kaloré & $\begin{array}{l}\text { Loteamento/ } \\
\text { Condomínio }\end{array}$ \\
\hline $\begin{array}{l}2011 / \\
2013\end{array}$ & $\begin{array}{l}00191 \\
/ 0233\end{array}$ & Petrobrás Transportes S.A. (TRANSPETRO) & Novo Píer do TEBAR & $\begin{array}{l}\text { Portos e } \\
\text { terminais }\end{array}$ \\
\hline $\begin{array}{l}2011 / \\
2012\end{array}$ & $\begin{array}{l}00101 \\
/ 0034\end{array}$ & $\begin{array}{l}\text { Santorini Terminais e Armazéns Gerais Ltda., } \\
\text { São Paulo }\end{array}$ & $\begin{array}{c}\text { Terminal de granéis sólidos e líquidos: Sítio } \\
\text { Guarapá }\end{array}$ & $\begin{array}{l}\text { Portos e } \\
\text { terminais }\end{array}$ \\
\hline $\begin{array}{l}2011 / \\
2012\end{array}$ & $\begin{array}{l}00006 \\
/ 0810\end{array}$ & Renuka do Brasil S/A, Promissão & Renuka do Brasil S/A & $\begin{array}{l}\text { Agroindústria } \\
\text { Sucroenergético }\end{array}$ \\
\hline $\begin{array}{l}2011 / \\
2012\end{array}$ & $\begin{array}{l}00030 \\
/ 0806\end{array}$ & ESTRE Ambiental S/A., São Paulo & $\begin{array}{l}\text { Obras de ampliação do aterro sanitário : Centro } \\
\text { de Gerenciamento de Resíduos CGR Paulínia }\end{array}$ & $\begin{array}{l}\text { Tratamento de } \\
\text { resíduos }\end{array}$ \\
\hline $\begin{array}{l}2011 / \\
2012\end{array}$ & $\begin{array}{c}41 / 07 \\
98\end{array}$ & $\begin{array}{l}\text { Abengoa Bioenergia Agroindústria Ltda., } \\
\text { Pirassununga }\end{array}$ & $\begin{array}{c}\text { ABENGOA Bioenergia Agroindústria Ltda: } \\
\text { unidade São Luiz }\end{array}$ & $\begin{array}{l}\text { Agroindústria } \\
\text { Sucroenergético }\end{array}$ \\
\hline $\begin{array}{l}2011 / \\
2012\end{array}$ & $\begin{array}{l}00132 \\
/ 0796\end{array}$ & $\begin{array}{l}\text { METRÔ - Companhia do Metropolitano de } \\
\text { São Paulo }\end{array}$ & $\begin{array}{c}\text { Linha } 18 \text { BRONZE: trecho Tamanduateí - } \\
\text { Alvarengas : implantação }\end{array}$ & Ferroviário \\
\hline $2011 /$ & $\begin{array}{l}00032 \\
10787\end{array}$ & Paraiso Bioenergia S.A., Brotas & $\begin{array}{c}\text { Ampliação da produção de açúcar e etanol e das } \\
\text { áreas agrícolas }\end{array}$ & $\begin{array}{l}\text { Agroindústria } \\
\text { Sucroenergético }\end{array}$ \\
\hline $\begin{array}{l}2011 / \\
2012\end{array}$ & $\begin{array}{l}00124 \\
/ 0813\end{array}$ & $\begin{array}{c}\text { Concessionária das Rodovias Ayrton Senna e } \\
\text { Carvalho Pinto S/A - ECOPISTAS, } \\
\text { Itaquaquecetuba }\end{array}$ & $\begin{array}{l}\text { Prolongamento da Rodovia Governador } \\
\text { Carvalho Pinto (SP-070) }\end{array}$ & Rodoviário \\
\hline $\begin{array}{l}2011 / \\
2011\end{array}$ & $\begin{array}{l}00046 \\
/ 0836\end{array}$ & $\begin{array}{l}\text { EPPO/ITU Soluções Ambientais S/A Limpeza } \\
\text { Pública e Gestão de Resíduos, Itu }\end{array}$ & Central de tratamento de resíduos - CTR Itu & $\begin{array}{l}\text { Tratamento de } \\
\text { resíduos }\end{array}$ \\
\hline $\begin{array}{c}2011 / \\
2011\end{array}$ & $\begin{array}{l}00098 \\
/ 0808\end{array}$ & $\begin{array}{c}\text { DER - Departamento de Estradas de Rodagem } \\
\text { do Estado de São Paulo; DERSA;JGP } \\
\text { Consultoria e Participações Ltda.,. Ambiente } \\
\text { Brasil Engenharia; Consórcio ENGEVIX - } \\
\text { THEMAG }\end{array}$ & $\begin{array}{l}\text { Rodovia dos Tamoios (SP-099): duplicação do } \\
\text { trecho Serra Km 60,48 ao Km 82,00 }\end{array}$ & Rodoviário \\
\hline $\begin{array}{l}2011 / \\
2011\end{array}$ & $\begin{array}{l}00067 \\
/ 0786\end{array}$ & $\begin{array}{c}\text { CGR Guatapará - Centro de Gerenciamento } \\
\text { de Resíduos Ltda., Guatapará }\end{array}$ & $\begin{array}{l}\text { Implantação do centro de gerenciamento de } \\
\text { resíduos: CGR Araçatuba }\end{array}$ & $\begin{array}{l}\text { Tratamento de } \\
\text { resíduos }\end{array}$ \\
\hline $\begin{array}{c}2011 / \\
2011\end{array}$ & $\begin{array}{l}00097 \\
/ 0783\end{array}$ & $\begin{array}{l}\text { DER-SP Departamento de Estradas de } \\
\text { Rodagem do Estado de São Paulo; DERSA }\end{array}$ & Contorno norte de Caraguatatuba & Rodoviário \\
\hline $\begin{array}{l}2011 / \\
2011\end{array}$ & $\begin{array}{l}00111 \\
/ 0781\end{array}$ & $\begin{array}{c}\text { COSAN S/A Açúcar e Álcool filial UNIVALEM, } \\
\text { Valparaíso }\end{array}$ & Ampliação da produção e das áreas agrícolas & $\begin{array}{l}\text { Agroindústria } \\
\text { Sucroenergético }\end{array}$ \\
\hline $2011 /$ & $\begin{array}{l}00141 \\
/ 0780\end{array}$ & $\begin{array}{c}\text { Consórcio Intermunicipal do Ribeirão do Piraí } \\
\text { - CONIRPI, Salto }\end{array}$ & $\begin{array}{c}\text { Barragem do Ribeirão Piraí : municípios de Salto } \\
\text { e Itu (SP) }\end{array}$ & Obra Hidráulica \\
\hline $\begin{array}{l}2011 / \\
2011\end{array}$ & $\begin{array}{l}00129 \\
/ 0779\end{array}$ & LWARCEL Celulose Ltda., Lençóis Paulista & Expansão da unidade industrial & Indústria \\
\hline $\begin{array}{c}2011 / \\
2011\end{array}$ & $\begin{array}{l}00126 \\
/ 0777\end{array}$ & Prefeitura Municipal de Limeira & $\begin{array}{l}\text { Aterro de resíduos sólidos domiciliares e } \\
\text { industriais classe II A e unidade de redução de } \\
\text { volumes }\end{array}$ & $\begin{array}{l}\text { Tratamento de } \\
\text { resíduos }\end{array}$ \\
\hline $\begin{array}{c}2011 / \\
2011\end{array}$ & $\begin{array}{l}00155 \\
/ 0776\end{array}$ & $\begin{array}{l}\text { HDAUFF Empreendimentos Imobiliários Ltda, } \\
\text { São José do Rio Preto }\end{array}$ & Loteamento residencial Quinta do Golfe & $\begin{array}{l}\text { Loteamento/ } \\
\text { Condomínio }\end{array}$ \\
\hline $\begin{array}{c}2011 / \\
2011\end{array}$ & $\begin{array}{l}00193 \\
/ 0764\end{array}$ & Copel Geração e Transmissão S.A., Curitiba & $\begin{array}{c}\text { Linha de transmissão } 500 \text { KV Araraquara II } \\
\text { /Taubaté }\end{array}$ & $\begin{array}{l}\text { Linhas de } \\
\text { transmissão }\end{array}$ \\
\hline $\begin{array}{l}2012 / \\
2015\end{array}$ & $\begin{array}{l}00089 \\
/ 0815\end{array}$ & Prefeitura Municipal de Osasco & Aterro sanitário de Osasco & $\begin{array}{l}\text { Tratamento de } \\
\text { resíduos }\end{array}$ \\
\hline $\begin{array}{c}2012 / \\
2013\end{array}$ & $\begin{array}{l}00202 \\
/ 0819\end{array}$ & $\begin{array}{l}\text { DERSA - Desenvolvimento Rodoviário S.A., } \\
\text { São Paulo; DER - Departamento de Estradas } \\
\text { de Rodagem do Estado de São Paulo }\end{array}$ & Submerso: túnel Santos - Guarujá & Rodoviário \\
\hline $\begin{array}{l}2012 / \\
2013\end{array}$ & $\begin{array}{l}00096 \\
10479 \\
\end{array}$ & $\begin{array}{l}\text { Imerys Ceramics Brasil - Minérios para } \\
\text { Cerâmicas Ltda, Embu-Guaçú }\end{array}$ & $\begin{array}{c}\text { Unidade de mineração e beneficiamento de } \\
\text { caulim }\end{array}$ & Mineração \\
\hline $\begin{array}{c}2012 / \\
2013\end{array}$ & $\begin{array}{l}00069 \\
/ 0812\end{array}$ & JHSF Incorporações Ltda., São Paulo & $\begin{array}{c}\text { Catarina - Aeroporto Executivo Fashion Outlet e } \\
\text { Corporate Center: São Roque - SP }\end{array}$ & Aeroportos \\
\hline $\begin{array}{l}2012 / \\
2012\end{array}$ & $\begin{array}{l}00185 \\
/ 0823\end{array}$ & $\begin{array}{c}\text { Departamento Hidroviário - Secretaria } \\
\text { Estadual de Logística e Transporte do Estado } \\
\text { de São Paulo }\end{array}$ & Aproveitamento múltiplo Santa Maria da Serra & Hidroviário \\
\hline $\begin{array}{l}2012 / \\
2012\end{array}$ & $\begin{array}{l}00026 \\
/ 0817\end{array}$ & Harpia Logística Ltda, São Paulo & $\begin{array}{c}\text { Aeródromo Harpia: Distrito de Parelheiros - } \\
\text { Município de São Paulo - SP }\end{array}$ & Aeroportos \\
\hline $\begin{array}{l}2012 / \\
2012\end{array}$ & $\begin{array}{l}00100 \\
/ 0811\end{array}$ & $\begin{array}{l}\text { Concessionária Rota das Bandeiras S.A., } \\
\text { Itatiba }\end{array}$ & $\begin{array}{c}\text { Prolongamento da rodovia José Roberto } \\
\text { Magalhães Teixeira (SP-083), no trecho } \\
\text { compreendido entre SP-330 (Rodovia } \\
\text { Anhanguera) e a SP-324 (Rodovia Miguel } \\
\text { Melhado Campos) : municípios de Campinas e } \\
\text { Valinhos }\end{array}$ & Rodoviário \\
\hline $\begin{array}{l}2012 / \\
2012\end{array}$ & $\begin{array}{l}00044 \\
/ 0809\end{array}$ & $\begin{array}{l}\text { SCOPEL Desenvolvimento Urbano S/A, São } \\
\text { Paulo }\end{array}$ & Loteamento residencial Santa Maria III & $\begin{array}{l}\text { Loteamento/ } \\
\text { Condomínio }\end{array}$ \\
\hline
\end{tabular}




\begin{tabular}{|c|c|c|c|c|}
\hline $\begin{array}{c}2012 / \\
2012\end{array}$ & $\begin{array}{l}00018 \\
/ 0803\end{array}$ & FOXX URE-BA Ambiental Ltda., Barueri & $\begin{array}{l}\text { Projeto URE de Barueri: tratamento térmico de } \\
\text { resíduos sólidos urbanos para geração de } \\
\text { energia }\end{array}$ & Termoelétrica \\
\hline $\begin{array}{c}2012 / \\
2012\end{array}$ & $\begin{array}{l}00051 \\
/ 0800\end{array}$ & $\begin{array}{l}\text { Saipem do Brasil Serviços de Petróleo Ltda., } \\
\text { Rio de Janeiro }\end{array}$ & $\begin{array}{l}\text { CTCO Centro de Tecnologia e Construção } \\
\text { Offshore }\end{array}$ & Indústria \\
\hline $\begin{array}{c}2012 / \\
2012\end{array}$ & $\begin{array}{l}00013 \\
/ 0797\end{array}$ & $\begin{array}{l}\text { Mineral Engenharia e Meio Ambiente Ltda., } \\
\text { São Paulo }\end{array}$ & $\begin{array}{c}\text { Raízen Paraguaçu S/A: unidade Paraguaçu } \\
\text { Paulista }\end{array}$ & $\begin{array}{l}\text { Agroindústria } \\
\text { Sucroenergético }\end{array}$ \\
\hline $\begin{array}{c}2012 / \\
2012\end{array}$ & $\begin{array}{l}00107 \\
/ 0794\end{array}$ & Terrestre Ambiental Ltda, Santos & $\begin{array}{c}\text { Ampliação do aterro sanitário do centro de } \\
\text { gerenciamento de resíduos }\end{array}$ & $\begin{array}{l}\text { Tratamento de } \\
\text { resíduos }\end{array}$ \\
\hline $\begin{array}{c}2013 / \\
2016\end{array}$ & $\begin{array}{l}00226 \\
/ 0870\end{array}$ & $\begin{array}{l}\text { VECE Incorporadora Ltda., São José dos } \\
\text { Campos }\end{array}$ & $\begin{array}{c}\text { Loteamento Fazenda Santa Cruz dos } \\
\text { Bandeirantes. }\end{array}$ & $\begin{array}{l}\text { Loteamento/ } \\
\text { Condomínio }\end{array}$ \\
\hline $\begin{array}{c}2013 / \\
2016\end{array}$ & $\begin{array}{l}00329 \\
/ 0869\end{array}$ & $\begin{array}{l}\text { Basalto Pedreira e Pavimentação Ltda., } \\
\text { Jaguariúna }\end{array}$ & $\begin{array}{c}\text { Regularização e ampliação de lavra para } \\
\text { extração de diabásio }\end{array}$ & Mineração \\
\hline $\begin{array}{c}2013 / \\
2015\end{array}$ & $\begin{array}{l}00081 \\
/ 0846\end{array}$ & $\begin{array}{c}\text { Jardim Fazenda Cantagalo - } \\
\text { Empreendimentos Imobiliários SPE Ltda., } \\
\text { Ribeirão Preto }\end{array}$ & $\begin{array}{l}\text { Loteamento residencial e comercial Jardim } \\
\text { Fazenda Cantagalo }\end{array}$ & $\begin{array}{l}\text { Loteamento/ } \\
\text { Condomínio }\end{array}$ \\
\hline $\begin{array}{c}2013 / \\
2015\end{array}$ & $\begin{array}{l}00089 \\
/ 0835\end{array}$ & $\begin{array}{l}\text { EMTU - Empresa Metropolitana de } \\
\text { Transportes Urbanos de São Paulo }\end{array}$ & $\begin{array}{c}\text { Implantação do SIM-VLT (fase 2): trecho } \\
\text { Conselheiro Nébias-Valongo }\end{array}$ & Ferroviário \\
\hline $\begin{array}{l}2013 / \\
2014\end{array}$ & $\begin{array}{l}00186 \\
/ 0841\end{array}$ & Prefeitura Municipal de Guarujá & $\begin{array}{l}\text { Interconexão viária entre as praias da Enseada e } \\
\text { de Pernambuco }\end{array}$ & Rodoviário \\
\hline $\begin{array}{c}2013 / \\
2014\end{array}$ & $\begin{array}{l}00194 \\
/ 0839\end{array}$ & Piracicaba Ambiental S/A, São Paulo & Aterro sanitário CTR - Palmeiras & $\begin{array}{l}\text { Tratamento de } \\
\text { resíduos }\end{array}$ \\
\hline $\begin{array}{c}2013 / \\
2014\end{array}$ & $\begin{array}{l}00258 \\
/ 0833\end{array}$ & $\begin{array}{l}\text { Canárias Administradora de Bens Ltda., São } \\
\text { Paulo }\end{array}$ & Loteamento misto Canárias & $\begin{array}{l}\text { Loteamento/ } \\
\text { Condomínio }\end{array}$ \\
\hline $\begin{array}{c}2013 / \\
2014\end{array}$ & $\begin{array}{l}00124 \\
/ 0831\end{array}$ & Prefeitura Municipal de São José dos Campos & $\begin{array}{l}\text { Programa de estruturação urbana de São José } \\
\text { dos Campos }\end{array}$ & $\begin{array}{c}\text { Projeto } \\
\text { Urbanístico }\end{array}$ \\
\hline $\begin{array}{l}2013 / \\
2014\end{array}$ & $\begin{array}{l}00087 \\
/ 0829\end{array}$ & $\begin{array}{c}\text { Paiva Ramos Empreendimentos Imobiliários } \\
\text { S.A., São Paulo }\end{array}$ & Projeto urbanístico Fazenda Paiva Ramos. & $\begin{array}{l}\text { Loteamento/ } \\
\text { Condomínio }\end{array}$ \\
\hline $\begin{array}{c}2013 / \\
2014\end{array}$ & $\begin{array}{l}00182 \\
/ 0828\end{array}$ & LOGUM Logística S.A., Rio de Janeiro & Projeto LOGUM: trecho Paulínia - RMSP - Santos & Duto \\
\hline $\begin{array}{c}2013 / \\
2013\end{array}$ & $\begin{array}{l}00299 \\
/ 0857\end{array}$ & InterCement Brasil S.A., Pedro Leopoldo - MG & Ampliação das atividades da Mina Serrinha & Mineração \\
\hline $\begin{array}{c}2013 / \\
2013\end{array}$ & $\begin{array}{l}00426 \\
/ 0856\end{array}$ & Fazenda Santa Esperança Ltda - ME, Itatiba & Fazenda Santa Esperança & Mineração \\
\hline $\begin{array}{c}2013 / \\
2015\end{array}$ & $\begin{array}{l}00229 \\
/ 0853\end{array}$ & $\begin{array}{c}\text { Empresa Litorânea de Transmissão de } \\
\text { Energia S. A. - ELTE, São Paulo }\end{array}$ & $\begin{array}{l}\text { Linha de transmissão } 345 \text { Kv CD - Domênico } \\
\text { Rangoni - Seccionamento Tijuco Preto - Baixada } \\
\text { Santista e Subestação Domênico Rangoni }\end{array}$ & $\begin{array}{l}\text { Linhas de } \\
\text { transmissão }\end{array}$ \\
\hline $\begin{array}{l}2013 / \\
2013\end{array}$ & $\begin{array}{l}00230 \\
/ 0852\end{array}$ & $\begin{array}{c}\text { Empresa Litorânea de Transmissão de } \\
\text { Energia S. A. - ELTE, São Paulo }\end{array}$ & $\begin{array}{c}\text { Linha de transmissão } 230 \text { Kv CD Henry Borden - } \\
\text { Manoel da Nóbrega e Subestação Manoel da } \\
\text { Nóbrega }\end{array}$ & $\begin{array}{l}\text { Linhas de } \\
\text { transmissão }\end{array}$ \\
\hline $\begin{array}{c}2013 / \\
2013\end{array}$ & $\begin{array}{l}00189 \\
/ 0850\end{array}$ & $\begin{array}{c}\text { Departamento de Águas e Energia Elétrica - } \\
\text { DAEE, São Paulo }\end{array}$ & Barragens Pedreira e Duas Pontes & Obra Hidráulica \\
\hline $\begin{array}{c}2013 / \\
2013\end{array}$ & $\begin{array}{l}00416 \\
/ 0843\end{array}$ & Mineração Jundu Ltda., Descalvado & $\begin{array}{c}\text { Ampliação da área de lavra Mina Olho D'Água - } \\
\text { Bom Sucesso de Itararé }\end{array}$ & Mineração \\
\hline $\begin{array}{c}2013 / \\
2013\end{array}$ & $\begin{array}{l}00185 \\
/ 0842 \\
\end{array}$ & $\begin{array}{l}\text { ECO Lotes Empreendimentos Imobiliários SPE } \\
\text { Ltda., São Paulo }\end{array}$ & Loteamento residencial Estância Ayres & $\begin{array}{l}\text { Loteamento/ } \\
\text { Condomínio }\end{array}$ \\
\hline $\begin{array}{c}2013 / \\
2013\end{array}$ & $\begin{array}{l}00030 \\
/ 0827\end{array}$ & $\begin{array}{l}\text { TCL - Tecnologia e Construções Ltda., São } \\
\text { José do Rio Preto }\end{array}$ & CTDR - Amparo & $\begin{array}{l}\text { Tratamento de } \\
\text { resíduos }\end{array}$ \\
\hline $\begin{array}{c}2013 / \\
2013\end{array}$ & $\begin{array}{l}00088 \\
/ 0825\end{array}$ & $\begin{array}{l}\text { Logística Ambiental de São Paulo S/A - LOGA, } \\
\text { São Paulo }\end{array}$ & Estação de transbordo Anhanguera & $\begin{array}{l}\text { Tratamento de } \\
\text { resíduos }\end{array}$ \\
\hline $\begin{array}{l}2013 / \\
2013 \\
\end{array}$ & $\begin{array}{l}00015 \\
/ 0821 \\
\end{array}$ & EcoUrbis Ambiental S.A., São Paulo & $\begin{array}{l}\text { Ampliação da central de tratamento de resíduos } \\
\text { leste - CTL: São Paulo CPEA } 1917 \text { setembro } 2013\end{array}$ & $\begin{array}{l}\text { Tratamento de } \\
\text { resíduos }\end{array}$ \\
\hline $\begin{array}{c}2013 / \\
2012\end{array}$ & $\begin{array}{l}00003 \\
/ 0814\end{array}$ & $\begin{array}{l}\text { Gmic - Guapiara Mineração Indústria e } \\
\text { Comércio Ltda, Guapiara }\end{array}$ & Mina do Coqueiro & Mineração \\
\hline $\begin{array}{c}2014 / \\
2016\end{array}$ & $\begin{array}{l}00365 \\
/ 0868\end{array}$ & $\begin{array}{c}\text { Bellavista Desenvolvimento Imobiliário Ltda., } \\
\text { Botucatu }\end{array}$ & PIB - Parque Inovador de Botucatu & $\begin{array}{l}\text { Loteamento/ } \\
\text { Condomínio }\end{array}$ \\
\hline $\begin{array}{c}2014 / \\
2016\end{array}$ & $\begin{array}{l}00342 \\
/ 0866 \\
\end{array}$ & $\begin{array}{l}\text { GEO Vision Soluções Ambientais e Energia } \\
\text { S.A. - Grupo Estre, São Paulo } \\
\end{array}$ & $\begin{array}{l}\text { Centro de Gerenciamento de Resíduos - CGR - } \\
\text { Presidente Prudente }\end{array}$ & $\begin{array}{l}\text { Tratamento de } \\
\text { resíduos }\end{array}$ \\
\hline $\begin{array}{l}2014 / \\
2016\end{array}$ & $\begin{array}{l}00205 \\
/ 0863\end{array}$ & $\begin{array}{c}\text { TCL - Tecnologia e Construções Ltda.,São José } \\
\text { do Rio Preto }\end{array}$ & $\begin{array}{c}\text { Central de tratamento e destinação de resíduos } \\
\text { sólidos domiciliares em regime de codisposição } \\
\text { com resíduos industriais classes IIA e IIB, } \\
\text { resíduos perigosos - classe I, central de triagem, } \\
\text { britador e autoclave. CTDR CASA BRANCA }\end{array}$ & $\begin{array}{l}\text { Tratamento de } \\
\text { resíduos }\end{array}$ \\
\hline $\begin{array}{c}2014 / \\
2015\end{array}$ & $\begin{array}{l}00053 \\
/ 0845\end{array}$ & $\begin{array}{l}\text { TCL - Tecnologia e Construções Ltda., São } \\
\text { José do Rio Preto }\end{array}$ & CTDR Adamantina & $\begin{array}{l}\text { Tratamento de } \\
\text { resíduos }\end{array}$ \\
\hline $\begin{array}{c}2014 / \\
2014\end{array}$ & $\begin{array}{l}00056 \\
/ 0860\end{array}$ & Mineradora Pedrix Ltda., Caieiras & $\begin{array}{c}\text { Ampliação de atividade de extração de granito } \\
\text { no município de Caieiras }\end{array}$ & Mineração \\
\hline
\end{tabular}




\begin{tabular}{|c|c|c|c|c|}
\hline $\begin{array}{l}2014 / \\
2014\end{array}$ & $\begin{array}{l}00238 \\
/ 0858\end{array}$ & Ipiranga Agroindustrial S.A., Mococa & Ipiranga Agroindustrial SA Filial Mococa & $\begin{array}{c}\text { Agroindústria } \\
\text { Sucroenergético }\end{array}$ \\
\hline $\begin{array}{c}2014 / \\
2014\end{array}$ & $\begin{array}{l}00262 \\
/ 0854 \\
\end{array}$ & REVITA Engenharia Ltda., São Paulo & $\begin{array}{l}\text { Indústria de tratamento e valorização de } \\
\text { resíduos Marília (ITVR Marília) }\end{array}$ & $\begin{array}{l}\text { Tratamento de } \\
\text { resíduos }\end{array}$ \\
\hline $\begin{array}{c}2014 / \\
2014\end{array}$ & $\begin{array}{l}00345 \\
/ 0851 \\
\end{array}$ & $\begin{array}{l}\text { Lote } 5 \text { Desenvolvimento Urbano S.A., São } \\
\text { Paulo }\end{array}$ & Empreendimento Urbanístico Campo Verde & $\begin{array}{l}\text { Loteamento/ } \\
\text { Condomínio }\end{array}$ \\
\hline $\begin{array}{l}2014 / \\
2014\end{array}$ & $\begin{array}{l}00115 \\
/ 0847\end{array}$ & $\begin{array}{l}\text { Concessionária Rota das Bandeiras S.A., } \\
\text { Itatiba }\end{array}$ & $\begin{array}{l}\text { Perimetral de Itatiba (SPI081/360): segmento } \\
\text { rodoviário entre o cruzamento das rodovias } \\
\text { Romildo Prado (SP-063) e Eng. Constâncio Cintra } \\
\text { (SP-360) até a rodovia Dom Pedro I (SP-065) }\end{array}$ & Rodoviário \\
\hline $\begin{array}{c}2014 / \\
2014\end{array}$ & $\begin{array}{l}00113 \\
/ 0844 \\
\end{array}$ & $\begin{array}{c}\text { Companhia de Saneamento Básico do Estado } \\
\text { de São Paulo S.A. - SABESP }\end{array}$ & $\begin{array}{c}\text { Interligação entre as represas Jaguari (Bacia do } \\
\text { Paraíba do Sul) e Atibainha (Bacias PCJ) }\end{array}$ & Obra Hidráulica \\
\hline $\begin{array}{c}2014 / \\
2014\end{array}$ & $\begin{array}{l}00160 \\
/ 0840\end{array}$ & $\begin{array}{l}\text { Pacaembu Empreendimentos e Construções } \\
\text { Ltda., São Paulo }\end{array}$ & Loteamento Jardim Cristo Redentor & $\begin{array}{l}\text { Loteamento/ } \\
\text { Condomínio }\end{array}$ \\
\hline $\begin{array}{c}2014 / \\
2014\end{array}$ & $\begin{array}{l}00321 \\
/ 0834\end{array}$ & VOTORANTIM Cimentos S. A & $\begin{array}{l}\text { Plano diretor de mineração - PDM da unidade } \\
\text { Itapecerica da Serra da Votorantim Cimentos } \\
\text { S.A., Itapecerica da Serra - S.P. }\end{array}$ & Mineração \\
\hline $\begin{array}{c}2015 / \\
2016\end{array}$ & $\begin{array}{l}00114 \\
/ 0872 \\
\end{array}$ & $\begin{array}{l}\text { Parque Prado Guarujá Participações Ltda., } \\
\text { São Paulo }\end{array}$ & Loteamento Parque Prado Guarujá & $\begin{array}{l}\text { Loteamento/ } \\
\text { Condomínio }\end{array}$ \\
\hline $\begin{array}{c}2015 / \\
2016\end{array}$ & $\begin{array}{l}00190 \\
/ 0864\end{array}$ & $\begin{array}{c}\text { Embu S.A. Engenharia e Comércio - Pedreira } \\
\text { Viracopos, Itupeva }\end{array}$ & $\begin{array}{c}\text { Ampliação de lavra de granito e saibro e } \\
\text { implantação de depósito de estéreis. }\end{array}$ & Mineração \\
\hline $\begin{array}{l}2015 / \\
2015\end{array}$ & $\begin{array}{l}00179 \\
/ 0862\end{array}$ & $\begin{array}{l}\text { EMTU - Empresa Metropolitana de } \\
\text { Transportes Urbanos de São Paulo S. A }\end{array}$ & $\begin{array}{l}\text { Corredor metropolitano Vereador Biléo Soares: } \\
\text { variante do trecho Hortolândia-Sumaré } \\
\qquad 25 / 02 / 2016\end{array}$ & Rodoviário \\
\hline $\begin{array}{l}2015 / \\
2015\end{array}$ & $\begin{array}{l}00268 \\
/ 0859\end{array}$ & $\begin{array}{l}\text { Companhia de Saneamento Básico do Estado } \\
\text { de São Paulo (Sabesp), Vale do Ribeira }\end{array}$ & $\begin{array}{c}\text { Obras de reversão do Alto Juquiá para o ribeirão } \\
\text { Santa Rita, na bacia da represa do reservatório } \\
\text { Guarapiranga }\end{array}$ & Obra Hidráulica \\
\hline $\begin{array}{c}2015 / \\
2015\end{array}$ & $\begin{array}{l}00166 \\
/ 0855\end{array}$ & $\begin{array}{c}\text { Companhia de Saneamento Básico do Estado } \\
\text { de São Paulo - Sabesp, São Paulo }\end{array}$ & $\begin{array}{l}\text { Obras de Aproveitamento da Bacia do Rio } \\
\text { Itapanhaú para Abastecimento da RMSP }\end{array}$ & Obra Hidráulica \\
\hline $\begin{array}{c}2016 / \\
2016\end{array}$ & $\begin{array}{l}00077 \\
/ 0871 \\
\end{array}$ & Prefeitura Municipal de Guarulhos & $\begin{array}{l}\text { Ampliação do aterro sanitário de Guarulhos - } \\
\text { fase } 10\end{array}$ & $\begin{array}{l}\text { Tratamento de } \\
\text { resíduos }\end{array}$ \\
\hline $\begin{array}{c}2016 / \\
2016\end{array}$ & $\begin{array}{l}00047 \\
/ 0867 \\
\end{array}$ & $\begin{array}{l}\text { Anastácio Empreendimentos Imobiliários e } \\
\text { Participações Ltda., São Paulo }\end{array}$ & Plano Urbanístico City São Paulo & $\begin{array}{l}\text { Loteamento/ } \\
\text { Condomínio }\end{array}$ \\
\hline $\begin{array}{l}2016 / \\
2016\end{array}$ & $\begin{array}{l}00032 \\
/ 0865\end{array}$ & Essencis Soluções Ambientais Ltda., Caieiras & $\begin{array}{l}\text { Ampliação da central de tratamento e } \\
\text { valorização ambiental - CTVA Caieiras: aterros de } \\
\text { resíduos domiciliares e industriais }\end{array}$ & $\begin{array}{l}\text { Tratamento de } \\
\text { resíduos }\end{array}$ \\
\hline $\begin{array}{c}2016 / \\
2016\end{array}$ & $\begin{array}{l}00025 \\
/ 0861\end{array}$ & $\begin{array}{l}\text { Concessionária Rota das Bandeiras S.A., } \\
\text { Itatiba }\end{array}$ & Prolongamento da Rodovia SP-083 fase 2 & Rodoviário \\
\hline $\begin{array}{r}2016 / \\
2017\end{array}$ & $\begin{array}{l}00275 \\
/ 0883 \\
\end{array}$ & São Martinho S/A., Pradópolis & São Martinho & $\begin{array}{l}\text { Agroindústria } \\
\text { Sucroenergético }\end{array}$ \\
\hline $\begin{array}{l}2016 / \\
2017\end{array}$ & $\begin{array}{l}00115 \\
/ 0880\end{array}$ & $\begin{array}{l}\text { Espaço Gaia Empreendimentos Imob. SPE } \\
\text { Ltda., Água Azul Incorporação Immob. SPE } \\
\text { Ltda., Sol y Terra E. Imob.SPE Ltda,Théia } \\
\text { Empreendimento }\end{array}$ & $\begin{array}{l}\text { Centro empresarial Espaço Gaia Théia e outros } \\
\text { condomínios }\end{array}$ & $\begin{array}{l}\text { Loteamento/ } \\
\text { Condomínio }\end{array}$ \\
\hline
\end{tabular}




\section{APÊNDICE B - QUADRO DE INDICADORES DE CLASSIFICAÇÃO DOS CONCEITOS PARA CADA CRITÉRIO}

\begin{tabular}{|c|c|c|c|c|}
\hline & A & B & C & D \\
\hline 1.1 & $\begin{array}{l}\text { Apresenta a metodologia utilizada } \\
\text { para a seleção de quais alternativas } \\
\text { foram levantadas para análise, } \\
\text { deixando claro quais são os critérios } \\
\text { utilizados. Justifica a metodologia de } \\
\text { acordo com tipo de empreendimento } \\
\text { e a disponibilidade locacional. }\end{array}$ & $\begin{array}{l}\text { Apresenta a metodologia utilizada para seleção de quais } \\
\text { alternativas foram levantadas para análise, deixando } \\
\text { claro quais são os critérios utilizados. Não justifica a } \\
\text { metodologia ou há critérios subjetivos. }\end{array}$ & $\begin{array}{l}\text { Apresenta critérios relevantes } \\
\text { considerados na seleção de } \\
\text { alternativas, porém não explicita a } \\
\text { metodologia utilizada. Há critérios } \\
\text { subjetivos de seleção. Explica de } \\
\text { maneira superficial a metodologia, } \\
\text { sem detalhar critérios ou justificativas. }\end{array}$ & $\begin{array}{l}\text { Não apresenta os critérios } \\
\text { ou a metodologia utilizada } \\
\text { para a seleção das } \\
\text { alternativas a serem } \\
\text { consideradas. }\end{array}$ \\
\hline 1.2 & $\begin{array}{l}\text { Descreve todas as alternativas com } \\
\text { o mesmo nível de detalhe, } \\
\text { considerando os mesmos critérios. }\end{array}$ & $\begin{array}{l}\text { Descreve todas as alternativas considerando os } \\
\text { mesmos critérios, porém com pequenas diferenças no } \\
\text { nível de detalhe e/ou na presença de dados entre as } \\
\text { alternativas. }\end{array}$ & $\begin{array}{l}\text { Descreve todas as alternativas de } \\
\text { maneira pouco equilibrada. Não } \\
\text { considera os mesmos critérios ou o } \\
\text { mesmo nível de detalhe ou dados para } \\
\text { todas as opções apresentadas. }\end{array}$ & $\begin{array}{l}\text { Não descreve todas as } \\
\text { alternativas. }\end{array}$ \\
\hline 1.3 & $\begin{array}{l}\text { Apresenta todas alternativas em } \\
\text { representação gráfica e cartográfica } \\
\text { no mesmo nível de detalhe, incluindo } \\
\text { a comparação visual das } \\
\text { alternativas. }\end{array}$ & $\begin{array}{l}\text { Apresenta todas alternativas em representação gráfica } \\
\text { e/ou cartográfica de maneira semelhante com pequenas } \\
\text { divergências de detalhe ou sem comparação visual das } \\
\text { opções quando relevante. }\end{array}$ & $\begin{array}{l}\text { Apresenta alternativas em } \\
\text { representação gráfico e/ou } \\
\text { cartográfica com diferentes níveis de } \\
\text { detalhe que dificultam a comparação } \\
\text { ou não apresenta para todas as } \\
\text { alternativas. } \\
\end{array}$ & $\begin{array}{l}\text { Não apresenta } \\
\text { representações gráficas } \\
\text { e/ou cartográficas no } \\
\text { estudo locacional. }\end{array}$ \\
\hline 2.1 & $\begin{array}{l}\text { Avalia distâncias das infraestruturas } \\
\text { em cada alternativa, justificando a } \\
\text { influência/dependência em relação a } \\
\text { essas e detalhando a relevância } \\
\text { desse critério para a seleção da } \\
\text { alternativa. }\end{array}$ & $\begin{array}{l}\text { Avalia distâncias das infraestruturas de cada alternativa, } \\
\text { porém não detalha a relevância desse critério para a } \\
\text { seleção da alternativa. }\end{array}$ & $\begin{array}{l}\text { Considera a proximidade das } \\
\text { infraestruturas sem detalhar dados ou } \\
\text { justificar a relevância desse critério. } \\
\text { Avalia apenas para a alternativa } \\
\text { selecionada. }\end{array}$ & $\begin{array}{l}\text { Não menciona outras } \\
\text { infraestruturas ou não } \\
\text { avalia as distâncias dentro } \\
\text { do estudos de alternativas } \\
\text { locacionais. }\end{array}$ \\
\hline 2.2 & $\begin{array}{l}\text { Avalia o uso e ocupação da área } \\
\text { para todas alternativas com a } \\
\text { mesma profundidade, apresentando } \\
\text { dados e justificando a relevância } \\
\text { desse critério para a análise de } \\
\text { alternativas. }\end{array}$ & $\begin{array}{l}\text { Avalia o uso e ocupação da área para todas } \\
\text { alternativas, apresentando dados comparáveis entre as } \\
\text { opções. Não justifica diretamente a relevância desse } \\
\text { critério para a análise de alternativas. }\end{array}$ & $\begin{array}{l}\text { Menciona o uso e ocupação da área, } \\
\text { porém não apresenta dados ou avalia } \\
\text { apenas para a alternativa selecionada. }\end{array}$ & $\begin{array}{l}\text { Não avalia o uso e } \\
\text { ocupação da área dentro do } \\
\text { estudo de alternativas. }\end{array}$ \\
\hline 2.3 & $\begin{array}{l}\text { Analisa diretrizes de uso e ocupação } \\
\text { da área de acordo com os planos } \\
\text { locais e regionais para todas as } \\
\text { alternativas, explicitando as } \\
\text { consequências e a relevância } \\
\text { dessas diretrizes para a análise e } \\
\text { para a escolha das alternativas. }\end{array}$ & $\begin{array}{l}\text { Analisa diretrizes de uso e ocupação da área de acordo } \\
\text { com os planos locais e regionais para todas as } \\
\text { alternativas, porém não explicita as consequências e a } \\
\text { relevância dessas diretrizes para a análise e escolha } \\
\text { das alternativas. }\end{array}$ & $\begin{array}{l}\text { Menciona alguns planos e diretrizes } \\
\text { locais e regionais, porém não os } \\
\text { detalha e não explicita a influência } \\
\text { dessas diretrizes na análise e escolha } \\
\text { de alternativas. Avalia em detalhes, } \\
\text { porém somente para a alternativa } \\
\text { selecionada. }\end{array}$ & $\begin{array}{l}\text { Não menciona planos e } \\
\text { diretrizes locais e regionais } \\
\text { dentro do estudo de } \\
\text { alternativas. }\end{array}$ \\
\hline
\end{tabular}


Identifica e analisa todos os empreendimentos relevantes para

4 cada alternativa considerando os

principais impactos e sinergias com o mesmo detalhamento.

Determina critérios específicos para a análise de alternativas de acordo

2.5 com a tipologia, considerando esses critérios em todas as alternativas e justificando a relevância de tais critérios para a seleção.

Explicita e justifica todos os critérios

26 de análise de maneira aprofundada, apresentando dados para todos os critérios e para todas as alternativas. Apresenta os mesmos critérios de análise, avaliando-os com a mesma profundidade para todas as

3.1 alternativas, permitindo a

comparação direta entre as

alternativas e justificando

necessidade de possíveis

divergências nas análises.

Compara os indicadores de todos os

critérios entre todas as alternativas

3.2 com o mesmo detalhamento,

explicitando e descrevendo a

metodologia de comparação.

Explicita a metodologia de

3 ponderação dos critérios

considerados, justificando cada atribuição.

Apresenta uma justificativa de

escolha da alternativa priorizada

baseada na análise comparativa

3.4 direta dos critérios de maneira clara

e objetiva, sendo possíve

compreender a comparação e o

processo de seleção.
Identifica e analisa os principais tipos de

empreendimentos em cada localidade considerando os principais impactos e sinergias com nível de

detalhamento semelhante.

\section{Determina critérios específicos para a análise de}

alternativas de acordo com a tipologia, considerando

esses critérios em todas as alternativas. Não justifica a

relevância desses critérios para análise e seleção.

Explicita os critérios de análise, apresentando dados

para todos os critérios e para todas as alternativas. Não apresenta justificativa para cada critério.

Apresenta critérios de análise comparáveis entre as

alternativas, avaliando-os com detalhamento

semelhante e permitindo a comparação direta entre as

alternativas. Não justifica possíveis divergências nas

análises.

Compara os indicadores de todos os critérios entre todas as alternativas com o mesmo detalhamento, não

explicita ou descreve diretamente a metodologia de comparação.

Explicita a ponderação dos critérios considerados, porém não cada atribuição de valor ou peso.

Apresenta uma justificativa de escolha da alternativa

priorizada baseada na análise comparativa dos critérios, porém não sendo totalmente claro o processo de seleção.
Menciona outros empreendimentos, porém focando em apenas algumas

de análise. Menciona, porém não

apresenta dados sobre os outros

empreendimentos.

Apresenta critérios específicos para a

tipologia, porém não os analisa para

todas as alternativas. Menciona

critérios específicos, porém não

apresenta dados referentes a esses

critérios.

Explicita os critérios de análise, porém

não apresenta dados para todos os

critérios ou para todas as alternativas.

Não os justifica.

Apresenta critérios semelhantes na

análise das alternativas, porém que

não permitem ou dificultam a

comparação direta entre as

alternativas. Não justifica análises

diferenciadas.

Compara alguns critérios ou entre algumas alternativas. Apresenta apenas o resultado da comparação, sem explicitá-la ou detalhá-la. Não explicita ou descreve a metodologia de comparação de maneira adequada.

Não explicita a ponderação de cada

critério, porém explicita todos os critérios com dados utilizados para a seleção.

Apresenta justificativa de escolha,

porém não é baseada na análise

comparativa direta dos critérios.
Não analisa ou menciona outros empreendimentos dentro do estudo de alternativas.

\section{Não apresenta critérios}

específicos de acordo com

a tipologia e não justifica a

ausência desses critérios.

Não explicita nem justifica os critérios de análise.

Não apresenta critérios de

análise. Os critérios não

possibilitam qualquer

comparação das

alternativas. Não apresenta alternativas.

\section{Não compara os}

indicadores dos critérios

entre as alternativas.

Não explicita a ponderação

ou dados de todos os

critérios considerados.

Não apresenta justificativa

de escolha no estudo das

alternativas locacionais. 
Explicita e justifica as escolhas de escalas temporais de acordo com a

3.5 tipologia e localidade, analisando-as em detalhe para todas as alternativas.

Explicita e justifica as escolhas de

3.6 tipologia e localidad com o mesmo detalhamento para todas as alternativas

Reconhece limitações e incertezas

1 as apresenta no texto de maneira direta, justificando-as de maneira adequada.

Cita os estudos, as fontes de dados e a metodologia utilizada para obtenção das informações

4.2 apresentadas no estudo das alternativas locacionais.

Descrição ou menção de equipe técnica para todos estudos

4.3 apresentados nas alternativas de localização.

Estudos de alternativa locacional estão de acordo e contemplam todas

4 as diretrizes indicadas no TR de maneira adequada.

Apresenta resumo da descrição, comparação, metodologias e justificativas de maneira clara acessível. Não omite informações

4.5 relevantes do EIA. Apresenta as mesmas informações do EIA de maneira organizada, mesmo que o estudo de alternativas do EIA esteja inadequado.
Explicita e justifica as escolhas de escalas temporais de acordo com a tipologia e localidade, analisando-a de maneira geral para todas as alternativas.

Explicita as escolhas de escalas espaciais de acordo com a tipologia e localidade, analisando-as com o mesmo detalhamento para as alternativas. Não as justifica de maneira direta.

Apresenta as limitações e incertezas de maneira indireta, justificando-as de maneira adequada.

Apresenta os dados e informações de maneira direta mencionando os estudos realizados para sua obtenção ou fontes de maneira geral. Não menciona metodologia utilizada.

Identifica a maioria dos estudos realizados, porém a equipe técnica é descrita em outro capítulo. Identifica equipe técnica no estudo de alternativas apenas para alguns estudos.

Estudos de alternativa locacional estão de acordo e contemplam a maioria das diretrizes indicadas no TR, podendo conter diferentes níveis de aprofundamento que não prejudicam a análise.

Apresenta comparação resumida das alternativas de maneira clara e objetiva, porém foca na selecionada. Não omite informações relevantes do EIA.
Menciona escalas temporais de maneira indireta e não as justifica com base na tipologia e na localidade ou não a analisa.

Menciona as escalas espaciais utilizadas, porém não as justifica com base na tipologia e na localidade ou não as utiliza de maneira semelhante para todas as alternativas.

Apresenta as limitações e incertezas de maneira indireta e não as justifica.

Não apresenta fonte ou menciona os estudos realizados para obtenção de informações para a análise de alternativas locacionais, porém apresenta os dados gerais obtidos. Apresenta estudos e dados apenas para alguns fatores. Apresenta fontes, porém não explicita dados.

Identifica apenas alguns estudos realizados, porém a equipe técnica é descrita em outro capítulo. abordam algumas das diretrizes indicadas no TR com diferentes níveis de aprofundamento Não abordam diretrizes relevantes indicadas no TR.

Omite informações relevantes presente do EIA. Apresenta o estudo de alternativas apenas como justificativa para a seleção, não descreve alternativas não selecionadas.
Não explicita ou justifica as escalas temporais utilizadas dentro dos estudos das alternativas locacionais

Não explicita ou justifica as escalas espaciais utilizadas dentro dos estudos das alternativas locacionais.

Não reconhece ou

apresenta incertezas e limitações e não justifica.

Não apresenta os dados e fontes de maneira direta.

Sem descrição de estudos, dados ou equipe técnica da análise de alternativas ou apenas com descrição de equipe em outro capítulo. Estudos de alterativa locacional abordam poucas diretrizes do TR com perdas significativas do conteúdo que não permitem a análise de alternativas.

Não apresenta discussão de alternativas no RIMA. 
Apresenta e detalha o cenário de não-execução, apresentando o

4.6 cenário geral futuro para todas as variáveis consideradas no estudo.

Apresenta diretrizes claras sobre como as alternativas devem ser selecionados para estudo, propondo

5.1 instrumentos de auxílio que devem guiar essa seleção e garantir a razoabilidade das alternativas a serem avaliadas.

Explicita a necessidade das etapas de descrição, comparação e

justificativa de escolha com base na

5.2 comparação, definindo ainda

diretrizes específicas para esse

processo considerando a tipologia e

as especificidades do

empreendimento.

Apresenta diretrizes claras sobre

componentes técnicos minimamente

esperados no estudo de alternativas,

5.3 considerando a tipologia do

empreendimento e descreve o nível

razoável de detalhamento esperado

no estudo locacional.
Apresenta e detalha o cenário de não-execução, abordando-o de maneira generalizada, porém

considerando as principais variáveis analisadas no

estudo, utilizando a não-execução como embasamento para a justificativa de execução.

Menciona o processo de seleção de alternativas

propondo garantir a razoabilidade das opções a serem estudadas, porém deixa em aberto os instrumentos necessários para essa seleção, exigindo um processo claro e coerente na seleção de alternativas a serem avaliadas.

Explicita a necessidade das etapas de descrição, comparação e justificativa de escolha com base na comparação, definindo apenas diretrizes gerais para essas etapas do estudo.

Apresenta algumas diretrizes claras sobre componentes técnicos minimamente esperados no estudo de

alternativas, porém de maneira mais generalizada, sem relacionar a tipologia. Não especifica de maneira detalhada o nível de aprofundamento necessário, embora exija que os estudos garantam uma compreensão adequada da análise.
Menciona o cenário porém não o detalha para as principais variáveis, apresentando apenas como

embasamento para a justificativa de execução.

Menciona o processo de seleção de alternativas minimamente razoáveis para análise, porém não apresenta diretrizes específicas para essa etapa.

Menciona a necessidade de descrição, comparação e justificativa de escolha de maneira superficial ou incompleta, não detalhando diretrizes básicas.

Menciona apenas algumas dessas

necessidades de modo desconexo,

sem caracterizar o processo de estudo

de alternativas como um todo.

Menciona poucos componentes

técnicos a serem avaliados, porém

não os detalha e não apresenta

diretrizes sobre o nivel de

detalhamento esperado.
Hipótese de não realização

mpreendimento não

localizada no EIA.

Não menciona ou apresenta

qualquer diretriz para o

processo de seleção de

alternativas a serem

avaliadas no estudo.

Não menciona ou apresenta qualquer diretriz

relacionada a descrição,

comparação e justificativa

de seleção.

Não menciona ou apresenta

qualquer diretriz

relacionada a componentes

técnicos exigidos ou nível

de detalhamento esperado. 


\section{APÊNDICE C - FICHA DE ANÁLISE}

Ficha no

Número processo:

Título do EIA

Tipo do empreendimento

Ampliação?

RIMA?

TR?

Obs.:

\section{Código CETESB:}

Ano:

1.Análise descritiva 
2.Análise qualitativa

\begin{tabular}{|c|c|c|c|}
\hline \multicolumn{2}{|c|}{ CATEGORIA } & CONCEITO & COMENTÁRIO \\
\hline \multirow{3}{*}{$\begin{array}{l}\text { Apresentação } \\
\text { e descrição }\end{array}$} & 1.1 & & \\
\hline & 1.2 & & \\
\hline & 1.3 & & \\
\hline \multirow{6}{*}{$\begin{array}{c}\text { Critérios } \\
\text { considerados }\end{array}$} & 2.1 & & \\
\hline & 2.2 & & \\
\hline & 2.3 & & \\
\hline & 2.4 & & \\
\hline & 2.5 & & \\
\hline & 2.6 & & \\
\hline \multirow{3}{*}{$\begin{array}{c}\text { Comparação e } \\
\text { Análise }\end{array}$} & 3.1 & & \\
\hline & 3.2 & & \\
\hline & 3.3 & & \\
\hline
\end{tabular}




\begin{tabular}{|c|c|}
\hline & 3.4 \\
\hline & 3.5 \\
\hline & 3.6 \\
\hline \multirow{6}{*}{ Consistência } & 4.1 \\
\hline & 4.2 \\
\hline & 4.3 \\
\hline & 4.4 \\
\hline & 4.5 \\
\hline & 4.6 \\
\hline \multirow{3}{*}{$\begin{array}{c}\text { Detalhamento } \\
\text { do escopo }\end{array}$} & 5.1 \\
\hline & 5.2 \\
\hline & 5.3 \\
\hline
\end{tabular}

OBSERVAÇÕES: 
APÊNDICE D - DADOS GERAIS DA ANÁLISE DESCRITIVA

\begin{tabular}{|c|c|c|c|c|c|c|c|c|c|}
\hline & Organização & $\begin{array}{l}\text { № } \\
\text { alt. }\end{array}$ & Representação visual & № crit. & Critérios & $\begin{array}{l}\text { Ponderação/ } \\
\text { Classificação }\end{array}$ & Organização não execução & Setor & $\begin{array}{c}\text { Localização } \\
\text { de } \\
\text { estruturas }\end{array}$ \\
\hline 1 & $\begin{array}{l}\text { Cap. próprio de } \\
\text { estudo de } \\
\text { alternativas }\end{array}$ & 0 & Mapa local selecionado & 3 & $\begin{array}{l}\text { Orientação da vista em relação ao vento, liberação das zonas } \\
\text { de proteção, proximidade da cidade de São Paulo }\end{array}$ & Não há & $\begin{array}{l}\text { Tópico do cap. de estudo de } \\
\text { alternativas }\end{array}$ & A & Não \\
\hline 2 & $\begin{array}{l}\text { Cap. próprio de } \\
\text { estudo de } \\
\text { alternativas }\end{array}$ & 12 & Mapas sem sobreposição & 3 & $\begin{array}{l}\text { Interferência em área de preservação permanente, } \\
\text { interferência em áreas urbanas, interferência em cursos d'água }\end{array}$ & Não há & $\begin{array}{l}\text { Tópico do cap. de prognóstico } \\
\text { ambiental }\end{array}$ & A & Sim \\
\hline 3 & $\begin{array}{l}\text { Cap. de justificativa } \\
\text { e alternativas }\end{array}$ & 5 & Mapas sem sobreposição & 6 & $\begin{array}{l}\text { Custo da implantação, flexibilidade para atracação, } \\
\text { compatibilidade com operações, atendimento a futuras } \\
\text { demandas, otimização do espaço, minimização dos impactos } \\
\text { ambientais. }\end{array}$ & Não há & $\begin{array}{l}\text { Tópico dentro do cap. de } \\
\text { justificativas e alternativas }\end{array}$ & $\mathrm{P}$ & Sim \\
\hline 4 & $\begin{array}{l}\text { Cap. próprio de } \\
\text { estudo de } \\
\text { alternativas }\end{array}$ & 3 & Mapas com sobreposição & 7 & $\begin{array}{l}\text { Extensão do empreendimento, interferência em UCs e áreas } \\
\text { tombadas, intercepção de pontos de relevante interesse, } \\
\text { intervenção em APPs, interferência em áreas construídas, } \\
\text { interferência no trânsito de embarcações, interferência no } \\
\text { aspecto paisagístico }\end{array}$ & Atribuição de pontos & $\begin{array}{l}\text { Tópico do cap. de estudo de } \\
\text { alternativas }\end{array}$ & $\mathrm{P}$ & Sim \\
\hline 5 & $\begin{array}{l}\text { Cap. próprio de } \\
\text { estudo de } \\
\text { alternativas }\end{array}$ & 3 & Mapas com sobreposição & 5 & $\begin{array}{l}\text { Porção em área urbana, extensão, porcentagem da classe de } \\
\text { uso do solo, declividade, uso de faixas existentes }\end{array}$ & Não há & $\begin{array}{l}\text { Tópico do cap. de estudo de } \\
\text { alternativas }\end{array}$ & D & Não \\
\hline 6 & $\begin{array}{l}\text { Cap. próprio de } \\
\text { estudo de } \\
\text { alternativas }\end{array}$ & 2 & Mapas com sobreposição & 6 & $\begin{array}{l}\text { Cruzamento de cursos d'água, intervenção em unidades de } \\
\text { conservação, intervenção em faixa de proteção de UC, } \\
\text { intervenção em manancial de captação para abastecimento } \\
\text { urbano, intervenção em ocupação urbana, ocupação em áreas } \\
\text { de pastagem }\end{array}$ & Não há & $\begin{array}{l}\text { Tópico do cap. de estudo de } \\
\text { alternativas }\end{array}$ & TL & Não \\
\hline 7 & $\begin{array}{l}\text { Tópico do cap. } \\
\text { Informações sobre } \\
\text { o empreendimento } \\
\end{array}$ & 0 & Mapa local selecionado & 0 & 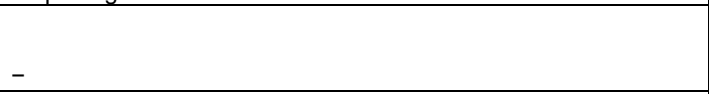 & Não há & Não identificado & TL & Não \\
\hline 8 & $\begin{array}{l}\text { Cap. próprio de } \\
\text { estudo de } \\
\text { alternativas } \\
\end{array}$ & 2 & Mapas com sobreposição & 9 & $\begin{array}{l}\text { Viabilidade de adequação dos padrões geométricos, porte e } \\
\text { intervenção da terraplanagem, restrição a travessias de corpos } \\
\text { d'água, cobertura vegetal remanescente, interferência em } \\
\text { moradias, desapropriações, interferência em redes de } \\
\text { infraestrutura, alinhamento vertical e horizontal, aspectos } \\
\text { construtivos. }\end{array}$ & Não há & $\begin{array}{l}\text { Indiretamente no cap. } \\
\text { Justificativa do empreendimento }\end{array}$ & TL & Sim \\
\hline 9 & $\begin{array}{l}\text { Cap. próprio de } \\
\text { estudo de } \\
\text { alternativas }\end{array}$ & 4 & Mapas com sobreposição & 4 & $\begin{array}{l}\text { Cobertura vegetal, travessia de corpos d'água, área } \\
\text { urbanizada, unidades de conservação }\end{array}$ & Não há & $\begin{array}{l}\text { Indiretamente no cap. do estudo } \\
\text { de alternativas empreendimento }\end{array}$ & TL & Não \\
\hline 10 & $\begin{array}{l}\text { Tópico do cap. de } \\
\text { introdução }\end{array}$ & 3 & Mapas sem sobreposição & 3 & $\begin{array}{l}\text { Potencial hidrelétrico, impactos no meio ambiente, custos da } \\
\text { geração de energia }\end{array}$ & Não há & $\begin{array}{l}\text { Tópico do cap. de prognóstico } \\
\text { ambiental }\end{array}$ & E & Não \\
\hline 11 & $\begin{array}{l}\text { Cap. próprio de } \\
\text { estudo de } \\
\text { alternativas }\end{array}$ & 4 & Mapas com sobreposição & 8 & $\begin{array}{l}\text { Supressão da vegetação, interferência em áreas legalmente } \\
\text { protegidas, interferencia em áreas prioritárias para } \\
\text { conservação da biodiversidade, interferência em cursos } \\
\text { d'água, interferência no patrimônio arqueológico, interferência } \\
\text { em áreas urbanas e processos produtivos, necessidade de } \\
\text { abertura de vias de acesso, aspectos construtivos }\end{array}$ & Atribuição de pontos & $\begin{array}{l}\text { Tópico do cap. de estudo de } \\
\text { alternativas }\end{array}$ & LT & Não \\
\hline
\end{tabular}




\begin{tabular}{|c|c|c|c|c|c|c|c|c|c|}
\hline 12 & \begin{tabular}{|l|} 
Cap. próprio de \\
estudo de \\
alternativas
\end{tabular} & 3 & Mapas sem sobreposição & 3 & $\begin{array}{l}\text { Menor área de supressão, respeito a drenagem, menor } \\
\text { impacto na paisagem }\end{array}$ & Não há & Não identificado & u & Sim \\
\hline 13 & \begin{tabular}{|l|} 
Tópico do cap. de \\
informações gerais \\
do empreendimento \\
\end{tabular} & 0 & Mapa local selecionado & 5 & $\begin{array}{l}\text { Extensão, distância da infraestrutura, possibilidade de } \\
\text { interligação com a rede pública de esgoto, interferência na } \\
\text { vegetação, declividade }\end{array}$ & Não há & $\begin{array}{l}\text { Tópico do cap. de estudo de } \\
\text { alternativas }\end{array}$ & u & Não \\
\hline 14 & $\begin{array}{l}\text { Cap. próprio de } \\
\text { estudo de } \\
\text { alternativas } \\
\end{array}$ & 3 & Mapas sem sobreposição & 9 & $\begin{array}{l}\text { Acessibilidade, características do terreno, cobertura vegetal, } \\
\text { presença de UCs, áreas prioritárias para conectividade } \\
\text { ambiental, APPs, processos minerários, legislação ambiental } \\
\text { restritiva do uso do solo, legislação relativa ao parcelamento do } \\
\text { solo }\end{array}$ & Não há & $\begin{array}{l}\text { Tópico do cap. de estudo de } \\
\text { alternativas }\end{array}$ & u & Sim \\
\hline 15 & $\begin{array}{l}\text { Tópico do cap. de } \\
\text { informações gerais } \\
\text { do empreendimento }\end{array}$ & 3 & Mapas sem sobreposição & 4 & $\begin{array}{l}\text { Maior diversidade de tipologias para a demanda de moradia, } \\
\text { melhor aproveitamento da gleba, relação do empreendimento } \\
\text { com outros da região já implantados, menor influência nos } \\
\text { componentes ambientais }\end{array}$ & Não há & $\begin{array}{l}\text { Tópico do cap. de informações } \\
\text { gerais do empreendimento }\end{array}$ & u & Sim \\
\hline 16 & $\begin{array}{l}\text { Cap. próprio de } \\
\text { estudo de } \\
\text { alternativas } \\
\end{array}$ & 2 & Mapas sem sobreposição & 8 & $\begin{array}{l}\text { Ocupação da gleba, total de vegetação nativa a ser suprimida, } \\
\text { total de vegetação em estágio inicial de regeneração, total de } \\
\text { vegetação em estágio avançado de regeneração, porcentagem } \\
\text { de área preservada, conectividade da paisagem, viabilidade } \\
\text { econômica }\end{array}$ & Não há & Não identificado & $u$ & Sim \\
\hline 17 & $\begin{array}{l}\text { Tópico do cap. de } \\
\text { justificativa do } \\
\text { empreendimento }\end{array}$ & 0 & Não há & 0 & - & Não há & $\begin{array}{l}\text { Indiretamente no cap. de } \\
\text { justificativa do empreendimento }\end{array}$ & $\mathrm{u}$ & Não \\
\hline 18 & Não identificado & 0 & Não há & 0 & - & Não há & Não identificado & $u$ & Não \\
\hline 19 & \begin{tabular}{|l|} 
Tópico do cap. de \\
características do \\
empreendimento
\end{tabular} & 0 & Não há & 4 & $\begin{array}{l}\text { Acesso, áreas verdes, zoneamento municipal, infraestrutura } \\
\text { urbana }\end{array}$ & Não há & Não identificado & $u$ & Não \\
\hline 20 & $\begin{array}{l}\text { Tópico do cap. de } \\
\text { características do } \\
\text { empreendimento } \\
\end{array}$ & 0 & Não há & 4 & $\begin{array}{l}\text { Infraestrutura urbana, zoneamento municipal, áreas verdes, } \\
\text { acessos }\end{array}$ & Não há & Não identificado & u & Não \\
\hline 21 & $\begin{array}{l}\text { Tópico do cap. de } \\
\text { dados gerais do } \\
\text { empreendimento } \\
\end{array}$ & 3 & Mapas sem sobreposição & 3 & $\begin{array}{l}\text { Atender critérios do projeto, melhor aproveitamento da gleba, } \\
\text { preservação de componentes ambientais }\end{array}$ & Não há & $\begin{array}{l}\text { Indiretamente no cap. de dados } \\
\text { do empreendimento }\end{array}$ & u & Sim \\
\hline 22 & $\begin{array}{l}\text { Cap. próprio de } \\
\text { estudo de } \\
\text { alternativas } \\
\end{array}$ & 3 & Mapas com sobreposição & 5 & $\begin{array}{l}\text { Via já existente, intervenção na via, fragmentos florestais } \\
\text { nativos, áreas de proteção, presença de residências }\end{array}$ & Atribuição de pontos & Não identificado & M & Sim \\
\hline 23 & $\begin{array}{l}\text { Cap. próprio de } \\
\text { estudo de } \\
\text { alternativas } \\
\end{array}$ & 0 & Não há & 0 & e & Não há & $\begin{array}{l}\text { Tópico do cap. de prognóstico } \\
\text { ambiental }\end{array}$ & M & Não \\
\hline 24 & $\begin{array}{l}\text { Cap. próprio de } \\
\text { estudo de } \\
\text { alternativas }\end{array}$ & 0 & Não há & 4 & $\begin{array}{l}\text { Futuras áreas de lavras, distância de deslocamento, melhor } \\
\text { aproveitamento do espaço, vantagens ambientais }\end{array}$ & Não há & $\begin{array}{l}\text { Tópico do cap. de estudo de } \\
\text { alternativas }\end{array}$ & M & Não \\
\hline 25 & $\begin{array}{l}\text { Cap. de justificativa } \\
\text { e alternativas }\end{array}$ & 6 & Mapas com sobreposição & 1 & Distância de transporte & Não há & $\begin{array}{l}\text { Indiretamente no cap. } \\
\text { Justificativa do empreendimento }\end{array}$ & M & Sim \\
\hline 26 & \begin{tabular}{|l|} 
Cap. próprio de \\
estudo de \\
alternativas
\end{tabular} & 9 & Mapa local selecionado & 6 & $\begin{array}{l}\text { Distância de transporte, requerimento no DNPM, } \\
\text { reflorestamento, extensão, entorno }\end{array}$ & Atribuição de pontos & Não identificado & M & Sim \\
\hline
\end{tabular}




\begin{tabular}{|c|c|c|c|c|c|c|c|c|c|}
\hline 27 & $\begin{array}{l}\text { Cap. próprio de } \\
\text { estudo de } \\
\text { alternativas + } \\
\text { Anexo }\end{array}$ & 29 & Mapas com sobreposição & 15 & $\begin{array}{l}\text { Área de pastagem, rede hidrográfica, vegetação exótica, } \\
\text { Intervenção em propriedades em solo de terceiro, Intervenção } \\
\text { em vias públicas, vegetação em estágio inicial de regeneração, } \\
\text { emissão atmosférica, títulos minerários de terceiros, margem } \\
\text { de canais de drenagem, área de fauna vulnerável, } \\
\text { assentamento humano, vegetação em estágio médio de } \\
\text { regeneração, área de flora ameaçada, área de fauna } \\
\text { ameaçada ou com perigo de extinção, vegetação primária ou } \\
\text { em estágio de regeneração avançado }\end{array}$ & Atribuição de pontos & $\begin{array}{l}\text { Tópico do cap. De avaliação de } \\
\text { impactos ambientais }\end{array}$ & M & Sim \\
\hline 28 & $\begin{array}{l}\text { Cap. próprio de } \\
\text { estudo de } \\
\text { alternativas }\end{array}$ & 4 & Mapas sem sobreposição & 8 & $\begin{array}{l}\text { Área de intervenção afetada, supressão da vegetação, } \\
\text { travessia e canalização em cursos d'água, intervenção em } \\
\text { APP, interferência em UCs, interferência em áreas de } \\
\text { ocupação antrópica, extensão da adutora, túnel e canal, custo } \\
\text { e prazo }\end{array}$ & Escala de impacto & $\begin{array}{l}\text { Tópico do cap. de estudo de } \\
\text { alternativas }\end{array}$ & $\mathrm{H}$ & Não \\
\hline 29 & $\begin{array}{l}\text { Cap. próprio de } \\
\text { estudo de } \\
\text { alternativas }\end{array}$ & 21 & Mapas com sobreposição & 18 & $\begin{array}{l}\text { Formação geológica, solo, relevo, águas superficiais, áreas de } \\
\text { vegetação, áreas urbanas, proximidade de aeroportos, } \\
\text { unidades de conservação, presença de comunidades, } \\
\text { aspectos geotécnicos, infraestrutura, estrutura fundiária, } \\
\text { distância do centro gerador, posicionamento em relação aos } \\
\text { ventos, diretrizes e restrição locais, condições de acesso, } \\
\text { existência de habitações próximas, potencial para impacto } \\
\text { visual. }\end{array}$ & $\begin{array}{l}\text { Escala de aptidão e } \\
\text { avaliação } \\
\text { positiva/negativa }\end{array}$ & $\begin{array}{l}\text { Tópico do cap. de estudo de } \\
\text { alternativas }\end{array}$ & $\mathrm{R}$ & Não \\
\hline 30 & $\begin{array}{l}\text { Tópico do cap. de } \\
\text { justificativa do } \\
\text { empreendimento }\end{array}$ & 8 & Mapas com sobreposição & 8 & $\begin{array}{l}\text { Condições topográficas, geológicas e hidrológicas, vida útil do } \\
\text { projeto, obras de adequação da área, densidade populacional } \\
\text { da região, custos de desapropriação, distância do centro } \\
\text { gerador, acessibilidade viária, infraestrutura }\end{array}$ & $\begin{array}{l}\text { Escala de } \\
\text { adequabilidade }\end{array}$ & $\begin{array}{l}\text { Tópico do cap. de justificativa do } \\
\text { empreendimento }\end{array}$ & $\mathrm{R}$ & Não \\
\hline 31 & $\begin{array}{l}\text { Cap. próprio de } \\
\text { estudo de } \\
\text { alternativas }\end{array}$ & 5 & Mapas com sobreposição & 7 & $\begin{array}{l}\text { Distância do centro gerador, vizinhança, atendimento ao } \\
\text { zoneamento, tamanho da área, preço para aquisição, } \\
\text { condições de acesso, interferências naturais }\end{array}$ & Não há & $\begin{array}{l}\text { Tópico do cap. de estudo de } \\
\text { alternativas }\end{array}$ & $\mathrm{R}$ & Não \\
\hline 32 & $\begin{array}{l}\text { Cap. próprio de } \\
\text { estudo de } \\
\text { alternativas }\end{array}$ & 6 & Mapas com sobreposição & 22 & $\begin{array}{l}\text { Tamanho da área, distância do centro de geração, zoneamento } \\
\text { ambiental, acessos, topografia, declividade, forma da encosta, } \\
\text { erosão, planícies de inundacãa, densidade de drenagem, } \\
\text { disponibilidade de energia elétrica, distância de cursos d'água, } \\
\text { uso e ocupação do solo, possibilidade de expansão, densidade } \\
\text { populacional da área, densidade populacional do núcleo, valor } \\
\text { da terra para aquisição, impacto no sistema viário, geração de } \\
\text { emprego e renda, impacto no comercio e serviços, impacto na } \\
\text { fauna, impacto na flora }\end{array}$ & $\begin{array}{l}\text { Escala de } \\
\text { adequabilidade }\end{array}$ & $\begin{array}{l}\text { Tópico do cap. de estudo de } \\
\text { alternativas }\end{array}$ & $\mathrm{R}$ & Não \\
\hline 33 & $\begin{array}{l}\text { Tópico do cap. de } \\
\text { justificativa } \\
\text { ambiental }\end{array}$ & 13 & Mapas com sobreposição & 9 & $\begin{array}{l}\text { Acessibilidade regional, acessibilidade local, vizinhança, } \\
\text { ocupações, impacto na paisagem, impacto na vegetação, } \\
\text { topografia, geologia, hidrologia }\end{array}$ & $\begin{array}{l}\text { Atribuição de pontos, } \\
\text { escala de } \\
\text { importância dos } \\
\text { critérios }\end{array}$ & $\begin{array}{l}\text { Indiretamente no cap. justificativa } \\
\text { ambiental }\end{array}$ & $\mathrm{R}$ & Não \\
\hline 34 & $\begin{array}{l}\text { Cap. próprio de } \\
\text { estudo de } \\
\text { alternativas }\end{array}$ & 4 & Não há & 3 & Zoneamento municipal, infraestrutura, vegetação nativa & Não há & $\begin{array}{l}\text { Tópico do cap. de estudo de } \\
\text { alternativas }\end{array}$ & $\mathrm{R}$ & Não \\
\hline 35 & $\begin{array}{l}\text { Cap. próprio de } \\
\text { estudo de } \\
\text { alternativas }\end{array}$ & 6 & Mapas com sobreposição & 16 & $\begin{array}{l}\text { Uso e ocupação do solo, distância do núcleo populacional, } \\
\text { valor da terra para aquisição, impacto no sistema local viário, } \\
\text { geração de emprego e renda, impacto no comércio e serviços, } \\
\text { tamanho da área, distância do centro de geração, zoneamento } \\
\text { ambiental, acessos, distância de aeroportos, disponibilidade de } \\
\text { energia elétrica, distância de cursos d'água, impactos na } \\
\text { fauna, impactos na flora }\end{array}$ & $\begin{array}{l}\text { Escala de } \\
\text { adequabilidade }\end{array}$ & $\begin{array}{l}\text { Tópico do cap. de estudo de } \\
\text { alternativas }\end{array}$ & $\mathrm{R}$ & Não \\
\hline
\end{tabular}




\begin{tabular}{|c|c|c|c|c|c|c|c|c|c|}
\hline 36 & \begin{tabular}{|l|} 
Cap. próprio de \\
estudo de \\
alternativas \\
\end{tabular} & 3 & Mapas com sobreposição & 0 & - & Não há & $\begin{array}{l}\text { Tópico do cap. de estudo de } \\
\text { alternativas }\end{array}$ & $\mathrm{R}$ & Não \\
\hline 37 & \begin{tabular}{|l|} 
Cap. próprio de \\
estudo de \\
alternativas
\end{tabular} & 0 & Não há & 0 & - & Não há & $\begin{array}{l}\text { Tópico do cap. de estudo de } \\
\text { alternativas }\end{array}$ & 1 & Não \\
\hline 38 & $\begin{array}{l}\text { Tópico do cap. de } \\
\text { justificativa do } \\
\text { empreendimento } \\
\end{array}$ & 2 & Não há & & - & Não há & $\begin{array}{l}\text { Indiretamente no cap. } \\
\text { Justificativa do empreendimento }\end{array}$ & 1 & Não \\
\hline 39 & $\begin{array}{l}\text { Tópico do cap. de } \\
\text { justificativa do } \\
\text { empreendimento } \\
\end{array}$ & 0 & \begin{tabular}{|l|} 
Mapa local selecionado, \\
com sobreposição do \\
zoneamento agroambiental
\end{tabular} & 3 & $\begin{array}{l}\text { Disponibilidade de terras, zoneamento agroambiental, apoio de } \\
\text { governos locais }\end{array}$ & Não há & $\begin{array}{l}\text { Tópico do cap. de justificativa do } \\
\text { empreendimento }\end{array}$ & $\mathrm{Al}$ & Não \\
\hline 40 & $\begin{array}{l}\text { Tópico do cap. de } \\
\text { justificativa do } \\
\text { empreendimento }\end{array}$ & 0 & Não há & 0 & 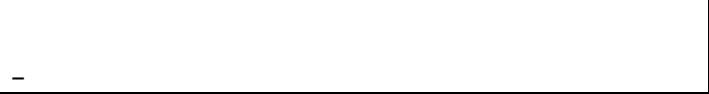 & Não há & Não identificado & $\mathrm{Al}$ & Não \\
\hline 41 & $\begin{array}{l}\text { Tópico do cap. de } \\
\text { justificativa do } \\
\text { empreendimento } \\
\end{array}$ & 0 & $\begin{array}{l}\text { Mapa local selecionado, } \\
\text { com sobreposição do } \\
\text { zoneamento agroambiental } \\
\end{array}$ & 3 & $\begin{array}{l}\text { Disponibilidade de terras, zoneamento agroambiental, apoio de } \\
\text { governos locais }\end{array}$ & Não há & $\begin{array}{l}\text { Tópico do cap. de justificativa do } \\
\text { empreendimento }\end{array}$ & $\mathrm{Al}$ & Não \\
\hline 42 & $\begin{array}{l}\text { Tópico do cap. de } \\
\text { justificativa do } \\
\text { empreendimento }\end{array}$ & 0 & Não há & 6 & $\begin{array}{l}\text { Uso e ocupação do solo, qualidade do solo, clima, topografia, } \\
\text { acesso viário, extensão da área }\end{array}$ & Não há & Não identificado & $\mathrm{Al}$ & Não \\
\hline 43 & $\begin{array}{l}\text { Tópico do cap. de } \\
\text { justificativa do } \\
\text { empreendimento } \\
\end{array}$ & 0 & Não há & 0 & (1) & Não há & $\begin{array}{l}\text { Tópico do cap. de justificativa do } \\
\text { empreendimento }\end{array}$ & $\mathrm{Al}$ & Não \\
\hline 44 & $\begin{array}{l}\text { Tópico do cap. de } \\
\text { justificativa do } \\
\text { empreendimento } \\
\end{array}$ & 0 & Não há & 0 & - & Não há & $\begin{array}{l}\text { Tópico do cap. de descrição do } \\
\text { projeto }\end{array}$ & $\mathrm{Al}$ & Não \\
\hline 45 & $\begin{array}{l}\text { Tópico do cap. de } \\
\text { justificativa do } \\
\text { empreendimento } \\
\end{array}$ & 0 & Não há & 0 & - & Não há & Não identificado & $\mathrm{Al}$ & Não \\
\hline 46 & $\begin{array}{l}\text { Tópico do cap. de } \\
\text { justificativa do } \\
\text { empreendimento }\end{array}$ & 0 & Não há & 2 & $\begin{array}{l}\text { Disponibilidade de terras e proximidade dos sistemas } \\
\text { rodoviários }\end{array}$ & Não há & Não identificado & $\mathrm{Al}$ & Não \\
\hline 47 & $\begin{array}{l}\text { Tópico do cap. de } \\
\text { justificativa do } \\
\text { empreendimento }\end{array}$ & 0 & Não há & 0 & 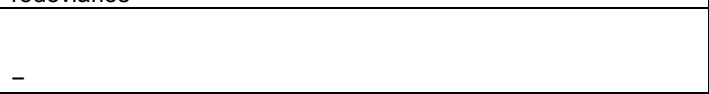 & Não há & $\begin{array}{l}\text { Indiretamente no cap. } \\
\text { Justificativa do empreendimento }\end{array}$ & $\mathrm{Al}$ & Não \\
\hline 48 & $\begin{array}{l}\text { Tópico do cap. de } \\
\text { justificativa do } \\
\text { empreendimento }\end{array}$ & 0 & Não há & 0 & - & Não há & $\begin{array}{l}\text { Indiretamente no cap. } \\
\text { Justificativa do empreendimento }\end{array}$ & $\mathrm{Al}$ & Não \\
\hline 49 & $\begin{array}{l}\text { Tópico do cap. de } \\
\text { justificativa do } \\
\text { empreendimento } \\
\end{array}$ & 0 & $\begin{array}{l}\text { Mapa local selecionado, } \\
\text { com sobreposição do } \\
\text { zoneamento agroambiental }\end{array}$ & 0 & - & Não há & $\begin{array}{l}\text { Indiretamente no cap. } \\
\text { Justificativa do empreendimento }\end{array}$ & $\mathrm{Al}$ & Não \\
\hline 50 & $\begin{array}{l}\text { Tópico do cap. de } \\
\text { justificativa do } \\
\text { empreendimento } \\
\end{array}$ & 0 & $\begin{array}{l}\text { Mapa local selecionado, } \\
\text { com sobreposição do } \\
\text { zoneamento agroambiental } \\
\end{array}$ & 3 & $\begin{array}{l}\text { Disponibilidade de terras, zoneamento agroambiental, apoio de } \\
\text { governos locais }\end{array}$ & Não há & $\begin{array}{l}\text { Tópico do cap. de justificativa do } \\
\text { empreendimento }\end{array}$ & $\mathrm{Al}$ & Não \\
\hline 51 & Não identificado & 0 & Não há & 0 & - & Não há & Não identificado & $\mathrm{Al}$ & Não \\
\hline 52 & $\begin{array}{l}\text { Tópico do cap. de } \\
\text { justificativa do } \\
\text { empreendimento }\end{array}$ & 0 & $\begin{array}{l}\text { Mapa local selecionado, } \\
\text { com sobreposição do } \\
\text { zoneamento agroambiental }\end{array}$ & 3 & $\begin{array}{l}\text { Disponibilidade de terras, zoneamento agroambiental, apoio de } \\
\text { governos locais }\end{array}$ & Não há & $\begin{array}{l}\text { Tópico do cap. de justificativa do } \\
\text { empreendimento }\end{array}$ & $\mathrm{Al}$ & Não \\
\hline
\end{tabular}




\section{APÊNDICE E - DADOS GERAIS DA ANÁLISE QUALITATIVA}

\begin{tabular}{|c|c|c|c|c|c|c|c|c|c|c|c|c|c|c|c|c|c|c|c|c|c|c|c|c|}
\hline \multirow{2}{*}{ EIA } & \multicolumn{3}{|c|}{$\begin{array}{c}\text { Apresentação } \\
\text { e descrição }\end{array}$} & \multicolumn{6}{|c|}{ Critérios considerados } & \multicolumn{6}{|c|}{ Comparação e análise } & \multicolumn{6}{|c|}{ Consistência } & \multicolumn{3}{|c|}{ Análise do TR } \\
\hline & 1.1 & 1.2 & 1.3 & 2.1 & 2.2 & 2.3 & 2.4 & 2.5 & 2.6 & 3.1 & 3.2 & 3.3 & 3.4 & 3.5 & 3.6 & 4.1 & 4.2 & 4.3 & 4.4 & 4.5 & 4.6 & 5.1 & 5.2 & 5.3 \\
\hline 1 & $\mathrm{C}$ & $\mathrm{D}$ & C & $\mathrm{C}$ & $\mathrm{D}$ & $\mathrm{D}$ & $\mathrm{C}$ & $\mathrm{C}$ & $\mathrm{C}$ & $\mathrm{D}$ & $\mathrm{D}$ & $\mathrm{D}$ & $\mathrm{C}$ & $\mathrm{C}$ & C & $\mathrm{D}$ & $\mathrm{D}$ & $\mathrm{D}$ & $\mathrm{D}$ & $\mathrm{B}$ & C & $\mathrm{D}$ & $\mathrm{B}$ & $A$ \\
\hline 2 & $\mathrm{C}$ & $\bar{B}$ & $B$ & $\mathrm{C}$ & $B$ & $\mathrm{C}$ & $\mathrm{C}$ & $\mathrm{C}$ & $\mathrm{C}$ & C & $\mathrm{C}$ & $\mathrm{D}$ & $\mathrm{B}$ & $\mathrm{C}$ & B & D & C & $\bar{D}$ & $\mathrm{C}$ & $B$ & $\mathrm{~B}$ & $A$ & $\mathrm{C}$ & C \\
\hline 3 & $\mathrm{D}$ & $\bar{B}$ & $B$ & C & $\mathrm{C}$ & $\mathrm{C}$ & $\mathrm{C}$ & C & $\mathrm{C}$ & C & $\mathrm{C}$ & $\bar{D}$ & $\mathrm{C}$ & C & $\mathrm{C}$ & D & D & C & - & $B$ & $\mathrm{C}$ & - & - & - \\
\hline 4 & $\overline{\mathrm{D}}$ & $\bar{A}$ & $A$ & B & $A$ & B & $\mathrm{C}$ & $A$ & $A$ & $A$ & $A$ & B & $A$ & D & $\mathrm{C}$ & D & C & $\mathrm{C}$ & C & $\mathrm{C}$ & $\mathrm{C}$ & $D$ & B & B \\
\hline 5 & $A$ & A & $A$ & B & $A$ & $\mathrm{C}$ & $B$ & $A$ & $A$ & $A$ & A & $\mathrm{C}$ & B & $B$ & B & C & $A$ & B & $A$ & $\mathrm{C}$ & $\mathrm{C}$ & $\mathrm{D}$ & B & $\mathrm{C}$ \\
\hline 6 & C & B & $A$ & $B$ & $B$ & C & $\mathrm{C}$ & $B$ & B & B & C & D & $B$ & $\mathrm{C}$ & $B$ & D & C & D & - & C & C & - & - & - \\
\hline 7 & $\mathrm{C}$ & $\mathrm{D}$ & $\mathrm{C}$ & $\mathrm{C}$ & $\mathrm{C}$ & $\mathrm{C}$ & $\mathrm{C}$ & $D$ & $\mathrm{D}$ & $D$ & $\mathrm{D}$ & $\bar{D}$ & $\mathrm{C}$ & $\mathrm{D}$ & $\mathrm{C}$ & $\mathrm{D}$ & $\mathrm{D}$ & $\bar{D}$ & - & $B$ & D & - & - & - \\
\hline 8 & $\mathrm{C}$ & $\bar{A}$ & $A$ & $B$ & $B$ & $\mathrm{C}$ & $\mathrm{C}$ & $B$ & B & $A$ & $\mathrm{~A}$ & $\mathrm{C}$ & $B$ & $\mathrm{C}$ & $B$ & $\mathrm{D}$ & $\mathrm{C}$ & $\mathrm{C}$ & $A$ & $B$ & C & $\mathrm{D}$ & $\mathrm{D}$ & C \\
\hline 9 & $\mathrm{C}$ & $\mathrm{C}$ & $A$ & $B$ & $A$ & $\mathrm{C}$ & $\mathrm{C}$ & $\mathrm{D}$ & $B$ & $A$ & $A$ & $\mathrm{C}$ & $B$ & $\mathrm{D}$ & $A$ & $\mathrm{D}$ & $\mathrm{C}$ & B & B & $\mathrm{C}$ & $\mathrm{C}$ & $\bar{D}$ & $\mathrm{C}$ & $\mathrm{D}$ \\
\hline 10 & A & A & $A$ & $\mathrm{D}$ & $\mathrm{C}$ & $\mathrm{C}$ & $D$ & $\mathrm{C}$ & $\mathrm{C}$ & $B$ & $\mathrm{C}$ & $\mathrm{C}$ & $B$ & $\mathrm{D}$ & C & $\mathrm{C}$ & $B$ & $\mathrm{~B}$ & $B$ & $\mathrm{C}$ & $B$ & $\bar{D}$ & $\mathrm{C}$ & $\mathrm{C}$ \\
\hline 11 & B & A & $\mathrm{A}$ & B & $\mathrm{A}$ & B & B & A & $A$ & $A$ & $\mathrm{~A}$ & $\mathrm{~A}$ & $A$ & $\mathrm{C}$ & $A$ & $B$ & $\mathrm{~A}$ & $\mathrm{~A}$ & $B$ & $A$ & $B$ & $\frac{L}{D}$ & $B$ & $B$ \\
\hline 12 & $\mathrm{C}$ & B & B & $\mathrm{C}$ & B & B & $\mathrm{C}$ & C & C & B & $\mathrm{C}$ & D & D & $\mathrm{D}$ & D & $\mathrm{D}$ & D & D & - & $B$ & $\mathrm{D}$ & - & - & - \\
\hline 13 & $\mathrm{C}$ & $\bar{D}$ & $\mathrm{C}$ & $\mathrm{C}$ & $\bar{C}$ & $\mathrm{C}$ & $\mathrm{C}$ & $\mathrm{C}$ & $\mathrm{C}$ & D & D & D & $\mathrm{C}$ & D & $\mathrm{C}$ & D & D & $\bar{D}$ & $A$ & $B$ & $\bar{B}$ & $\mathrm{D}$ & $\mathrm{D}$ & $\mathrm{D}$ \\
\hline 14 & $\mathrm{D}$ & $\mathrm{C}$ & $\mathrm{C}$ & $\mathrm{C}$ & $\mathrm{C}$ & $B$ & $\mathrm{C}$ & $\mathrm{C}$ & $\mathrm{D}$ & $\mathrm{C}$ & $\mathrm{D}$ & $\mathrm{D}$ & $\mathrm{C}$ & $\mathrm{C}$ & $\mathrm{D}$ & $\mathrm{D}$ & $\mathrm{D}$ & $\mathrm{D}$ & D & $\mathrm{D}$ & $\mathrm{C}$ & $\mathrm{D}$ & B & C \\
\hline 15 & $\bar{D}$ & B & B & $\mathrm{C}$ & $\mathrm{C}$ & B & $\mathrm{C}$ & $\mathrm{C}$ & C & $\mathrm{C}$ & $\mathrm{C}$ & D & C & $\mathrm{D}$ & C & D & D & $\mathrm{D}$ & - & C & C & - & - & - \\
\hline 16 & $\mathrm{D}$ & $A$ & $B$ & C & $A$ & $B$ & $\mathrm{D}$ & $B$ & $B$ & $B$ & $B$ & $\mathrm{D}$ & $\mathrm{C}$ & $\bar{D}$ & $\mathrm{C}$ & $\mathrm{D}$ & $\mathrm{D}$ & $B$ & $B$ & $B$ & $D$ & $\mathrm{D}$ & $\mathrm{C}$ & $\mathrm{C}$ \\
\hline 17 & $\overline{\mathrm{D}}$ & $\mathrm{D}$ & $\mathrm{D}$ & C & $\mathrm{D}$ & $\mathrm{D}$ & C & D & $\bar{D}$ & $\mathrm{D}$ & $\bar{D}$ & D & D & $\bar{D}$ & C & D & D & $\mathrm{D}$ & - & $\mathrm{C}$ & C & - & - & - \\
\hline 18 & $\overline{\mathrm{D}}$ & $\bar{D}$ & D & C & D & D & D & D & D & D & D & C & D & $\bar{D}$ & D & D & D & C & $\mathrm{D}$ & D & C & D & C & $\mathrm{D}$ \\
\hline 19 & $\bar{D}$ & $\bar{D}$ & $D$ & C & D & $\mathrm{C}$ & C & D & C & D & D & D & C & $\bar{D}$ & D & D & D & D & - & D & $D$ & - & - & - \\
\hline 20 & $\overline{\mathrm{D}}$ & $\overline{\mathrm{D}}$ & $D$ & $\mathrm{C}$ & $\mathrm{C}$ & $\mathrm{C}$ & $\mathrm{C}$ & $\mathrm{C}$ & $\mathrm{C}$ & D & $\bar{D}$ & $\overline{\mathrm{D}}$ & $\mathrm{C}$ & $\overline{\mathrm{D}}$ & $\overline{\mathrm{D}}$ & D & $\mathrm{C}$ & C & - & $\bar{B}$ & D & - & - & - \\
\hline 21 & D & B & B & C & C & B & D & C & $\mathrm{C}$ & C & $\bar{D}$ & D & C & $\mathrm{D}$ & C & D & C & B & $A$ & $\overline{\mathrm{D}}$ & C & $\mathrm{D}$ & C & $\mathrm{D}$ \\
\hline 22 & $\mathrm{C}$ & B & $B$ & $\mathrm{C}$ & $\mathrm{C}$ & $\mathrm{C}$ & $\bar{C}$ & C & $\mathrm{C}$ & $B$ & $\mathrm{C}$ & $B$ & $B$ & $\bar{C}$ & $\mathrm{C}$ & D & $\mathrm{C}$ & $\bar{D}$ & - & $A$ & D & - & - & - \\
\hline 23 & $\mathrm{D}$ & $\mathrm{D}$ & $\mathrm{D}$ & D & $\mathrm{D}$ & $\mathrm{D}$ & $\mathrm{D}$ & $\mathrm{D}$ & $\mathrm{D}$ & D & D & $\mathrm{D}$ & D & $\mathrm{C}$ & $\mathrm{D}$ & D & $\mathrm{D}$ & $\mathrm{C}$ & - & B & $B$ & - & - & - \\
\hline 24 & $\bar{D}$ & $\bar{D}$ & D & C & $\bar{D}$ & D & $\bar{D}$ & C & C & C & D & D & D & $\mathrm{D}$ & $\mathrm{D}$ & D & D & D & - & $B$ & $B$ & - & - & - \\
\hline 25 & $\mathrm{C}$ & C & $B$ & A & C & $\mathrm{D}$ & C & C & C & D & C & D & C & $\mathrm{D}$ & C & D & C & C & $A$ & $B$ & $\mathrm{C}$ & D & $\mathrm{C}$ & $B$ \\
\hline 26 & $\mathrm{C}$ & $\mathrm{D}$ & D & C & $\mathrm{C}$ & $\mathrm{C}$ & C & $B$ & $A$ & C & $\mathrm{C}$ & C & C & $\bar{D}$ & $\mathrm{C}$ & D & $\mathrm{C}$ & $\mathrm{C}$ & C & $B$ & $D$ & $\bar{B}$ & B & $\mathrm{C}$ \\
\hline 27 & B & $\bar{A}$ & $A$ & $A$ & B & B & $A$ & $A$ & A & $A$ & $A$ & $A$ & $A$ & B & B & C & B & $A$ & B & C & C & $\bar{C}$ & B & C \\
\hline 28 & $\bar{C}$ & B & $A$ & B & $A$ & $B$ & C & B & B & $A$ & B & B & B & $\mathrm{C}$ & B & D & $\mathrm{C}$ & C & - & B & C & - & - & - \\
\hline 29 & $A$ & $\bar{A}$ & $A$ & $A$ & A & $A$ & $A$ & $A$ & $A$ & $A$ & $B$ & $A$ & B & B & $A$ & $A$ & $A$ & $B$ & - & $A$ & $B$ & - & - & - \\
\hline 30 & C & $\mathrm{D}$ & $A$ & C & C & B & C & C & C & C & $\mathrm{D}$ & B & $\mathrm{C}$ & $\mathrm{C}$ & C & D & C & $B$ & $B$ & B & $\mathrm{C}$ & $\mathrm{D}$ & C & B \\
\hline 31 & $B$ & B & C & $\mathrm{C}$ & $B$ & $A$ & $\mathrm{D}$ & $\mathrm{C}$ & $\mathrm{C}$ & $\mathrm{C}$ & D & $\mathrm{D}$ & $\mathrm{C}$ & $\mathrm{D}$ & $B$ & D & $\mathrm{C}$ & $B$ & $\mathrm{C}$ & $\mathrm{C}$ & $\mathrm{C}$ & $\bar{D}$ & $\mathrm{C}$ & $\mathrm{C}$ \\
\hline 32 & $B$ & $\mathrm{~A}$ & $A$ & $A$ & $A$ & C & $B$ & $A$ & $B$ & $A$ & $A$ & $A$ & $A$ & $\bar{D}$ & $A$ & $\mathrm{D}$ & $\mathrm{C}$ & $\mathrm{C}$ & $B$ & $A$ & $B$ & $\bar{D}$ & $B$ & $\mathrm{C}$ \\
\hline 33 & $B$ & D & B & B & B & $\mathrm{C}$ & $\mathrm{C}$ & B & B & B & $\mathrm{C}$ & B & B & $\bar{D}$ & A & D & $\mathrm{C}$ & B & - & $\mathrm{C}$ & $\mathrm{C}$ & - & - & - \\
\hline 34 & $\mathrm{C}$ & $\bar{D}$ & $\mathrm{D}$ & $\mathrm{C}$ & $\mathrm{D}$ & $\mathrm{C}$ & $\mathrm{D}$ & $\mathrm{D}$ & $\mathrm{C}$ & $\mathrm{D}$ & $\mathrm{D}$ & $\mathrm{D}$ & $\mathrm{C}$ & $\bar{D}$ & D & $\mathrm{D}$ & $\mathrm{D}$ & $\mathrm{D}$ & $\mathrm{D}$ & $\mathrm{D}$ & $\mathrm{C}$ & D & $\mathrm{C}$ & D \\
\hline 35 & $\mathrm{C}$ & $\mathrm{A}$ & $A$ & $B$ & $A$ & $B$ & $B$ & $B$ & $B$ & $A$ & $A$ & $A$ & $A$ & $\frac{L}{D}$ & $B$ & $D$ & $\mathrm{C}$ & $\mathrm{C}$ & $B$ & $A$ & $B$ & $\frac{L}{D}$ & $\mathrm{C}$ & $\mathrm{C}$ \\
\hline
\end{tabular}




\begin{tabular}{|c|c|c|c|c|c|c|c|c|c|c|c|c|c|c|c|c|c|c|c|c|c|c|c|c|}
\hline 36 & C & C & B & C & C & C & D & D & D & D & D & D & C & D & C & D & D & D & C & D & C & D & C & D \\
\hline 37 & D & D & D & D & D & $\mathrm{D}$ & D & D & D & D & D & D & D & D & D & D & D & D & A & A & C & D & C & D \\
\hline 38 & D & D & D & $D$ & C & $D$ & D & D & C & $D$ & D & D & $D$ & D & $D$ & D & $D$ & C & - & B & C & - & - & - \\
\hline 39 & $\mathrm{D}$ & D & C & D & C & C & C & C & C & D & D & D & C & D & C & D & C & $\mathrm{D}$ & - & C & C & - & - & - \\
\hline 40 & $\mathrm{D}$ & D & $\mathrm{D}$ & C & C & $\mathrm{D}$ & C & D & $\mathrm{D}$ & $\mathrm{D}$ & D & $\mathrm{D}$ & C & $\mathrm{D}$ & $\mathrm{D}$ & $\mathrm{D}$ & C & $\mathrm{D}$ & C & $B$ & D & D & C & C \\
\hline 41 & $\mathrm{D}$ & D & C & D & C & C & C & C & C & D & D & D & D & D & C & D & C & D & C & A & C & C & C & C \\
\hline 42 & C & D & D & C & $\mathrm{C}$ & $\mathrm{C}$ & $\mathrm{D}$ & $\mathrm{C}$ & $\mathrm{C}$ & D & D & D & $\mathrm{C}$ & D & $\mathrm{C}$ & D & $\mathrm{C}$ & $\mathrm{C}$ & A & $D$ & D & D & $\mathrm{C}$ & $\mathrm{C}$ \\
\hline 43 & $\mathrm{D}$ & D & $\mathrm{D}$ & $D$ & $\mathrm{D}$ & $\mathrm{D}$ & $\mathrm{C}$ & $\mathrm{D}$ & $\mathrm{D}$ & D & D & D & C & D & $D$ & D & $\mathrm{D}$ & $\mathrm{D}$ & - & B & C & - & - & - \\
\hline 44 & D & D & D & C & C & C & C & D & D & D & D & D & $\mathrm{C}$ & D & D & D & D & D & B & B & C & D & C & C \\
\hline 45 & C & D & D & $\mathrm{C}$ & $\mathrm{C}$ & $\mathrm{C}$ & $\mathrm{D}$ & D & D & D & D & D & $\mathrm{C}$ & D & C & D & D & C & $\mathrm{A}$ & $\mathrm{C}$ & $\mathrm{D}$ & D & $\mathrm{C}$ & C \\
\hline 46 & $\bar{D}$ & D & $\mathrm{D}$ & $\mathrm{C}$ & $\mathrm{C}$ & $\mathrm{D}$ & C & D & C & D & D & D & $\mathrm{C}$ & D & $\mathrm{D}$ & D & D & $\mathrm{D}$ & $\mathrm{C}$ & $\mathrm{C}$ & D & D & $\mathrm{C}$ & C \\
\hline 47 & $\mathrm{D}$ & D & D & D & $\mathrm{D}$ & $\mathrm{D}$ & $\mathrm{D}$ & D & $D$ & D & D & D & D & D & D & D & D & D & $\mathrm{C}$ & A & $\mathrm{C}$ & D & $\mathrm{C}$ & $\mathrm{C}$ \\
\hline 48 & D & D & $\mathrm{D}$ & D & D & C & C & D & D & D & D & D & C & D & D & D & D & D & $B$ & $B$ & $\mathrm{C}$ & D & $\mathrm{C}$ & $\mathrm{C}$ \\
\hline 49 & $\mathrm{D}$ & D & C & C & C & $\mathrm{C}$ & $\mathrm{C}$ & $\mathrm{D}$ & $\mathrm{D}$ & $\mathrm{D}$ & D & D & C & D & C & D & $\mathrm{D}$ & $\mathrm{D}$ & $\bar{A}$ & $\bar{A}$ & $\mathrm{C}$ & D & $\mathrm{C}$ & $\mathrm{C}$ \\
\hline 50 & D & D & $\mathrm{C}$ & D & C & C & $\mathrm{C}$ & $\mathrm{D}$ & $\mathrm{D}$ & $\mathrm{D}$ & D & $D$ & C & D & C & $\mathrm{D}$ & C & $\bar{D}$ & A & C & C & D & C & D \\
\hline 51 & D & D & D & D & D & $\mathrm{D}$ & D & D & D & D & D & D & $\mathrm{C}$ & D & D & D & D & D & - & $\mathrm{C}$ & D & - & - & - \\
\hline 52 & D & D & C & C & $\mathrm{C}$ & $\mathrm{C}$ & C & C & $\mathrm{C}$ & D & D & D & C & D & $\mathrm{C}$ & D & C & D & - & $\mathrm{C}$ & C & - & - & - \\
\hline
\end{tabular}

